Illinois State University

ISU ReD: Research and eData

Theses and Dissertations

5-26-2016

\title{
An Intervention Study Aimed At Enhancing Seventh-Grade Students' Development Of The Concept Of A Variable
}

Sinan Kanbir

Illinois State University, sinankanbir@gmail.com

Follow this and additional works at: https://ir.library.illinoisstate.edu/etd

Part of the Elementary and Middle and Secondary Education Administration Commons, Junior High, Intermediate, Middle School Education and Teaching Commons, and the Science and Mathematics Education Commons

\section{Recommended Citation}

Kanbir, Sinan, "An Intervention Study Aimed At Enhancing Seventh-Grade Students' Development Of The Concept Of A Variable" (2016). Theses and Dissertations. 575.

https://ir.library.illinoisstate.edu/etd/575

This Dissertation is brought to you for free and open access by ISU ReD: Research and eData. It has been accepted for inclusion in Theses and Dissertations by an authorized administrator of ISU ReD: Research and eData. For more information, please contact ISUReD@ilstu.edu. 


\title{
AN INTERVENTION STUDY AIMED AT ENHANCING SEVENTH-GRADE STUDENTS' DEVELOPMENT OF THE CONCEPT \\ OF A VARIABLE
}

\author{
Sinan Kanbir
}

\section{Pages}

Thirty-two seventh-grade students attending a public middle school in a rural district in a midwestern state of the United States of America participated in a mixedmethod intervention study aimed at enhancing student understandings of the algebraic concept of a variable, especially in relation to structure and modeling. Participating students were randomly allocated to two class groups, with one class initially being taught by Mr. X and the other by Mr. Y, who had both participated in professional development sessions led by two senior mathematics educators. Mr. X initially led one of the class groups in seven sessions on algebraic structure and Mr. Y led the other class group in seven sessions on modeling using algebra. Then, halfway through the intervention, the class groups swapped, with the teachers repeating the workshops with their new classes. Pre-teaching, mid-intervention, post-teaching, and retention assessment of learning occurred over a period of 24 weeks, with data gathered from pencil-and-paper tests and from 56 one-to-one interviews at various stages of the study. The theoretical bases for the study derived from the writings of two main scholars-first, the 
semiotic theory of Charles Sanders Peirce; and second the theory of apperception put forward by Johann Friedrich Herbart. Six research questions were identified, and answered after all data had been collected and analyzed. Most of the participating students showed large gains in their understandings of algebraic structure and modeling, effect sizes of the intervention were large, and concept images of a variable were substantially modified.

KEYWORDS: Algebra education, Charles Sanders Peirce, Common core algebra, Concept image, Johann Friedrich Herbart, Modeling in middle-school mathematics 


\title{
AN INTERVENTION STUDY AIMED AT ENHANCING SEVENTH-GRADE STUDENTS' DEVELOPMENT OF THE CONCEPT \\ OF A VARIABLE
}

\author{
SINAN KANBIR
}

A Dissertation Submitted in Partial

Fulfillment of the Requirements for the Degree of

DOCTOR OF PHILOSOPHY

Department of Mathematics

ILLINOIS STATE UNIVERSITY

2016 
(C) 2016 Sinan Kanbir 


\section{AN INTERVENTION STUDY AIMED AT ENHANCING SEVENTH-GRADE STUDENTS' DEVELOPMENT OF THE CONCEPT \\ OF A VARIABLE}

SINAN KANBIR

COMMITTEE MEMBERS:

McKenzie A. Clements, Co-Chair

Nerida F. Ellerton, Co-Chair

David Barker

John K. Rugutt 


\section{ACKNOWLEDGMENTS}

There are many people who have helped me complete this dissertation in a timely way. I would like to thank my parents, and my brothers and sisters who have always supported me, throughout my studies.

I have been very fortunate to be able to have had helpful and knowledgable committee members. First of all, I would like to express my gratitude to my co-chairs, Dr. Ken Clements and Dr. Nerida Ellerton. I started my mathematics education research journey with them and have valued their astute guidance and encouragement. They have been with me throughout my journey. I want them to know how grateful I am for the interest, time, expertise, and genuine friendship which they have offered, at all times. Despite their busy schedules, they were always there for me when I needed them most. Dr. David Barker contributed much with his great knowledge of the topic under consideration, and Dr. John Rugutt was of great assistance on statistical and design issues.

Of course, the research described in this dissertation would not have been possible if I had not been able to find a school where the teaching intervention and data collection could happen. It is a pity that I am not free to name the school, its Principal, the two participating teachers, and the 32 participating seventh-grade students on this page, for they were absolutely wonderful throughout the study. There was no time that I felt that I was receiving less than 100 percent cooperation from them.

I would also like to thank the Department of Mathematics at Illinois State University for everything I have learned during my time as a doctoral student in mathematics 
education at the University. I look forward to being able to develop many of the skills that I have learned in future years.

S. K. 


\section{CONTENTS}

\section{Page}

ACKNOWLEDGMENTS $\quad$ i

CONTENTS

TABLES viii

FIGURES $\quad$ X

\section{CHAPTER}

I. IDENTIFYING THE PROBLEM, AND PLANNING FOR THE INVESTIGATION 1

Approaches to Introducing Algebra: Structure and Modeling 2

Overview of the Current Study 3

The Concepts of Algebraic Structure, and Modeling, as Presented

in the Common Core State Standards for Mathematics 5

Structural Thinking in Algebra, Across the Grades 5

Algebraic Structure as it Appears in the Common Core State Standards for Mathematics

The Associative Properties for Addition and Multiplication, and the Distributive Property, in Common Core Mathematics

Modeling Across the Grades in CCSSM Algebra 13

Summary of Research on Learning and Teaching Algebra 18

Structural and Functional Approaches as Presented in the

Mathematics Textbook Used by Participating Students

Textbook Treatment of the Associative Property for Addition

Textbook Treatment of the Associative Property for Multiplication

Textbook Treatment of the Distributive Property 
Textbook Treatment of Modeling and Related Problem Solving

The Problem as it Appeared to be at the Beginning of the Study 24

II. LITERATURE REVIEW 29

The Design Research Foundation for the Study 32

Theoretical Bases for the Study $\quad 35$

Signifiers, Objects and Interpretants—and Charles Sanders Peirce $\quad 37$

Semiotic Aspects of Structural Properties for Rational Numbers 39

Semiotic Aspects of the Functional-Thinking Approach to Early Algebra 51

Radford's Comments on "Objectification" for MiddleSchool Algebra 55

Some Scholars' Preference for the Functional-Thinking Approach

Signs, Symbols, Representations, Cognitive Structures and Individual Learners

Literature Which Helped Frame the Design of the Teaching Intervention

Research Questions

III. RESEARCH DESIGN AND METHODOLOGY 75

Design Research $\quad 75$

Setting up the Intervention $\quad 78$

Two Pilot Studies $\quad 78$

Preparing for the Current Study 83

Defining Desirable Learning Outcomes 85

Professional Development in a Theoretical Context 86

The Research Team for the Current Study 86

Model Lessons $\quad 87$

$\begin{array}{lr}\text { Intervention Setting and Theoretical Base } & 89\end{array}$

The Teaching Approach $\quad 89$

$\begin{array}{ll}\text { Procedures } & 91\end{array}$ 
Instrumentation

The Main Test Instrument: The Algebra Test 95

The Interview Protocol

Research Hypotheses, and Issues Related to the Quantitative Analyses

Comparisons of Scores on Tests Administered at the Same Time

Comparisons Between Gain Scores at Different Times

Effect Sizes

Post-Hoc Statistical Analyses

Issues Related to the Qualitative Analyses

Semiotic Aspects of the Qualitative Analyses

Concluding Comments

IV. QUANTITATIVE ANALYSES OF DATA

Overview of Quantitative Data

Pre-Teaching Group Differences with Respect to Structure

Pre-Teaching Group Differences with Respect to Modeling

Mid-Intervention Group Differences with Respect to Structure

Mid-Intervention Group Differences with Respect to Modeling

Post-Teaching Group Differences with Respect to Structure

Post-Teaching Group Differences with Respect to Modeling

Retention Group Differences with Respect to Structure

Retention Group Differences with Respect to Modeling

Comparisons Between Mean Gain Scores at Different Times

First Mean-Gain Comparison (Structure, Mid-Intervention Versus Pre-Teaching) 
Second Mean-Gain Comparison (Modeling, Mid-Intervention Versus Pre-Teaching)

Third Mean-Gain Comparison (Structure, Post-Teaching Versus Pre-Teaching)

Fourth Mean-Gain Comparison (Modeling, Post-Teaching Versus Pre-Teaching)

Fifth Mean-Gain Comparison (Structure, Retention Versus Pre-Teaching)

Sixth Mean-Gain Comparison (Modeling, Retention Versus Pre-Teaching)

Seventh Mean-Gain Comparison (Structure, Retention Versus Post-Teaching)

Eighth Mean-Gain Comparison (Modeling, Retention Versus Post-Teaching)

Calculation of Effect Sizes

Summary and Concluding Comments on the Quantitative Analyses

Introduction: Intended and Attained Common Core Curricula

Peirce's Triadic Semiotic Position and Herbart's Theory of Apperception

Analyses of Qualitative Data Generated by the "Structure"

Intervention

Analyzing Samples of Interview Data Relating to "Structure"

Analyses of Qualitative Data Generated by the Modeling Intervention

Interview Data: Student Responses to Modeling Tasks

Cognitive Growth in Modeling Related to the Subscript Notation for a Sequence

Cognitive Growth in Modeling Related to Generalizing for the $n$th Term

Analyses of Student Responses to Six Interview Questions 
Answer to Research Question 1

Answer to Research Question 2 205

Answer to Research Question 3 209

Answer to Research Question 4 212

Answer to Research Question 5 215

Changing Attitudes: "I was Really Good at All that Stuff” 216

Answer to Research Question 6 219

Limitations of the Study 221

Possibilities for Future Related Research 223

Final Comments on the Workshop "Lessons" 225

Comments on the Study by the Two Participating Teachers 227

A Call to Action 229

$\begin{array}{ll}\text { REFERENCES } & 230\end{array}$

APPENDIX A: Protocol for Algebra Interviews with Seventh-Graders 244

APPENDIX B: Algebra Test (Three Parallel Versions are Reproduced) 247

APPENDIX C: "Questionnaire” Completed by Seventh-Grade Students at School $\mathrm{W}$ at the Beginning of the Algebra Workshops on "Structure" 258

APPENDIX D: Statement of Instructional Aims for the Structure Workshops with the Seventh-Grade Students at School W

APPENDIX E: Detailed Lesson Plans for Four Workshops on "Structure" for Seventh-Grade Students at School W, Including Homework Challenges for Each Workshop

APPENDIX F: Detailed Plans for Group Tasks in the Modeling Workshops:

Finding Recursive and Explicit Rules for Patterns

APPENDIX G: Classroom Observation Schedule

APPENDIX H: Pre-Teaching to Post-Teaching "Growth" with Respect to the Five Basic Cognitive Structure Components

APPENDIX I: Generalization Categories (After Radford, 2006) 


\section{TABLES}

Table

Page

1. A Table of Values from Charles et al. (2004), p. 481

2. Receptive and Expressive Modes of Communication (Del Campo \& Clements, 1987, p. 12)

3. Pre-Teaching Algebra Test Mean Scores, Standard Deviations (SD), and Difference of SDs

4. Summary of the Research Design and Timing in the Planned

Research Program

5. Subscript Notations for Describing Class Means at Various Points in the Study

6. Group 1 Students' Pre-Teaching, Mid-Intervention, Post-Teaching, and Retention Scores for the Structure and Modeling Questions (Out of 10 in Each Case)

7. Group 2 Students' Pre-Teaching, Mid-Intervention, Post-Teaching, and Retention Scores for the Structure and Modeling Questions (Out of 10 In Each Case)

8. Effect Sizes for Four Intervention Workshops

9. Evidences for Qualities of Components of Students' Concept Images with Respect to the Associative and Distributive Properties

10. Summary of Data from 28 Interviewees in Relation to Concept Images for the Associative Property for Addition

11. Summary of Data from 28 Interviewees in Relation to Concept Images for the Associative Property for Multiplication

12. Summary of Data from 28 Interviewees in Relation to Concept Images for the Distributive Property for Multiplication Over Addition 
13. Evidences for Qualities of Components of Students' Concept Images with Respect to Modeling Relationships

14. Summary of Data from 28 Interviewees in Relation to the Use of the Subscript Notation in Modeling Tasks (Associated with Linear Sequences)

15. Summary of Data from 28 Interviewees in Relation to Generalizing for the $n$th Case

16. Examples of Students' Generalizations on Various Written Test Items

17. Effect Sizes for Intervention Workshops, Pre-Teaching to MidIntervention

18. Effect Sizes for Four Intervention Workshop Periods 


\section{FIGURES}

Figure $\quad$ Page

1. Table associated with "Visiting Old Houses" task 52

2. A Sequence of Figures Inviting a Generalization of a Relationship Between the Number of a Figure and the Corresponding Number of Matchsticks

3. Summary of the Design and Time Intervals for the Study

4. Two Structure Questions (Pre-Teaching Version of the Algebra Test) 97

5. A Modeling Question (Pre-Teaching Version of the Algebra Test) 98

6. Bar Graphs, Showing Mean Scores of the Two Groups at Different Stages, on the Structure and Modeling Subtests

7. Group 1 and Group 2 Students' Pre-, Mid-, Post-Teaching, and Retention Mean Scores on the Structure Subtest (Maximum Possible Score was 10)

8. Group 1 and Group 2 Students' Pre-, Mid-, Post-Teaching, and Retention Mean Scores on the Modeling Subtest (Maximum Possible Score was 10)

9. A Student's Vague (Pre-Teaching) "Understanding" of the Distributive Property

10. Student 2.6's Written Pre- and Post-Teaching Interview Responses To the Request Regarding the "Distributive Property"

11. Student 2.6's Written Pre- and Post-Teaching Interview Responses to a Question Concerned with the Associative Property for Multiplication

12. A Student Demonstrating a Correct Expressive Understanding of a Property, Without Knowing its Name 
13. Student 1.1 Indicated that Although She Really Liked the "Crossingthe-River" Modeling Task, the Associative Properties Sometimes Confused Her

14. Learning to Comprehend Subscript Notation for Linear Sequences

15. Evidence for Having Learned to Comprehend Subscript Notation

16. Student 1.13's Post-Teaching Interview Response to the Table-ofValues" Task

17. Student Generalizations in the Pre- and Post-Teaching Interviews

18. Seventh-Grade Students' Cognitive Growth on Two Different Tasks Inviting Students to State the Rule for the $n$th Term

19. Comparison of Pre-Teaching and Mid-Intervention Structure Means, Group 1 and Group 2

20. Comparison of Pre-Teaching and Mid-Intervention Modeling Means, Group 1 and Group 2

21. Bar Graphs, Showing Mean Scores of the Two Groups at Pre-Teaching and Post-Teaching Stages, on the Structure and Modeling Subtests

22. Bar Graphs, Showing Mean Scores of the Two Groups at Post-Teaching and Retention Stages, on the Structure and Modeling Subtests 


\section{CHAPTER I}

\section{IDENTIFYING THE PROBLEM, AND PLANNING FOR THE INVESTIGATION}

Before planning the investigation which is described in this dissertation (which, hereafter, will usually be referred to as the "current study," or the "present study," or the "main study"), I conducted two pilot studies with seventh- and eighth-grade students at a school in a rural city in a midwestern state of the United States of America (Kanbir, 2014, 2016). In both of those pilot studies I investigated the students' knowledge and understandings of algebra content which, according to the school's syllabus documents, the students might have been expected to know.

Both of the pilot studies included interview components, and during interviews that I conducted with the students I came to realize that they knew less school algebra than might have been expected. Hardly any of the interviewees knew the meanings of common signs used in elementary algebra texts, and most of them did not know what expressions like "the associative property for multiplication" or "the distributive property" meant. They struggled to identify and to describe explicit rules which might apply to even relatively simple numerical patterns such as $1,4,7,10,13, \ldots$-although they usually noticed that such a sequence was "going up by three" (or words to that effect). 
My analyses of pilot-study data prompted me to carry out the present study — but at a different school from the one where the pilot studies took place. I wanted to know whether the lack of knowledge of elementary algebra among seventh-grade students in the pilot-study school would also be found among seventh-graders in another school.

\section{Approaches to Introducing Algebra: Structure and Modeling}

Researchers (e.g., Cai \& Knuth, 2011; Kieran, 2006, 2007) have drawn attention to the following three forms of algebraic reasoning:

1. The recognition, formalization, and use of structures within sets of numbers. This can involve reasoning about operations and structural properties with respect to sets of numbers-like, for example, reflecting on whether the associative or commutative properties hold for different operations when they are applied to different sets of numbers.

2. Generalizing numerical and visual patterns to describe relationships between variables. This form involves exploring and expressing regularities in, for example, growth patterns concerned with the sum of odd natural numbers.

3. Modeling real-life situations by developing appropriate equations and inequalities.

In the transition from arithmetic to algebra, students are introduced to a powerful new language for expressing numerical structures, for representing patterns, and for modeling real-to-life situations. According to the common-core mathematics curriculum (CCSSM, 2010), students should be introduced to formal symbolic algebra in the sixth 
grade, and in grades 7 through 10 they should use this symbolism when exploring major school algebra concepts. The present study examined what might realistically be part of the implemented curriculum at the seventh-grade level. Analyses of data presented in forthcoming chapters, and especially in Chapters 4 and 5, will provide commentary on what proved to be successful, and what did not, with a cohort of students at one school. More follow-up research will obviously be needed.

\section{Overview of the Current Study}

This dissertation describes an investigation into the developing knowledge and understandings of key elementary algebraic concepts of 32 seventh-grade students at a rural public middle school in a midwestern state of the United States of America (hereafter that school will be referred to as "School W"). In particular, a teaching intervention is described in which most of the seventh-grade students at School W participated in a series of workshops in which they explored elementary algebraic structures, and applied algebraic concepts in real-world modeling contexts.

In particular, the participating students' growth in their knowledge, understanding and use of algebraic concepts associated with the terms "associative property of addition," "associative property of multiplication," "distributive property," "recursive rule," and "explicit rule," was investigated. Two teachers from School W also participated in the study — and henceforth these teachers will be referred to as "Mr. X" and "Mr. Y." Both are well-qualified and experienced middle-school mathematics teachers. Further details relating to the design of the study will be given in Chapter 3 of this dissertation.

Among other things, the current study was designed to investigate: 
- The seventh-grade students' knowledge and understanding of structural properties of the set of rational numbers, especially the associative properties (for addition and multiplication), and the distributive property for multiplication over addition for real numbers), before they were reminded of those properties in their seventh-grade classes.

- The extent to which, at the pre-teaching stage (that is to say, before participating in the intervention workshops), the seventh-grade students could apply the above-mentioned structural properties of rational numbers when making calculations.

- The extent to which the students were able, at the pre-teaching stage, to use recursive and explicit algebraic language and concepts to describe patterns associated with linear sequences.

- The extent to which the students learned, during the intervention, to use elementary ideas concerned with the concept of a variable so that they were enabled to identify and formulate patterns which model relationships between variables, and to apply elementary mathematics to solve relevant visual and non-visual problems.

In later chapters of this dissertation details of the design, implementation, and results of the intervention will be provided. It will be sufficient here to state, though, that in the current study Mr. X and Mr. Y led workshops in which structural and modeling approaches were introduced and consolidated, with almost all the seventh-grade students at School W being active participants in those workshops. 


\section{The Concepts of Algebraic Structure, and Modeling, as Presented in the Common Core State Standards for Mathematics}

The mathematics component of the common core curriculum (National Governors Association Center for Best Practices and the Council of Chief State School Officers, 2010 - hereafter cited as CCSSM, 2010) emphasizes the importance of developing algebraic reasoning in the elementary and middle grades. CCSSM (2010) defines proficiency standards in two areas: mathematical content and mathematical practice. The content standards are organized by grade (until eighth-grade) and comprise a list of facts, skills, symbols, procedures, and so on, which students will be expected to know, understand and apply.

CCSSM (2010) also describes eight "standards for mathematical practice" (hereafter "SMP”). These focus on problem solving, reasoning, constructing argument, modeling, using tools, attending to precision, looking for structure, and expressing regularity in repeated reasoning. The practice standards emphasize the need for students to develop deep understandings of the relevant concepts and procedures. Gavin and Sheffield (2015) suggested that the SMP ask teachers to teach in ways which will enable their students to develop their thinking in ways like mathematicians think.

\section{Structural Thinking in Algebra, Across the Grades}

Those who prepared the K-8 Common Core standards for mathematics regarded the "field properties" for rational and real numbers as so important that they listed them in what they called a "glossary" (CCSSM, 2010, Table 3). However, CCSSM does not provide specific details on how these properties should be taught or on what it means to 
understand them. For example, the distributive property of multiplication over addition becomes a powerful algebraic tool when we consider an expression like " $8 x+4 x$." By the distributive property, $8 x+4 x$ equals $(8+4) x$ or $12 x$. Indeed, it is the distributive property which is behind (or justifies) the popular language, used in many school algebra texts, that although one can add or subtract "like terms," one should not attempt to simplify the addition or subtraction of "unlike terms." Hence, $8 x+5 x$ equals $13 x$, but $8 x+5$ cannot be further simplified. And, one should not say that $8 x+4 x^{2}$ always equals $12 x^{2}$. The same distributive property, but thought of in the "reverse direction," can be called upon to justify statements like $5(2 x-1)=10 x-5$.

This study specifically examined the extent to which seventh-grade students learned to notice, to state, and to apply the distributive property and the associative properties of addition and multiplication for real numbers. Because the students had not yet studied irrational numbers — other than to become aware of pi $(\pi)$ and square roots - the emphasis would be on the distributive property and the associative properties of addition and multiplication for rational numbers.

Before outlining introductory algebra topics (many of which are introduced in its notes for sixth and seventh grades), CCSSM (2010) formalized, for grades K-5, the subdomain of "Operation and Algebraic Thinking" within its "Number Strands." The interconnection between numbers (arithmetic) and symbols (algebra) is an important feature of CCSSM, with elementary and middle-school teachers being urged to encourage their students to pay special attention to the meaning of the" equals sign," and to terms such as "variable" and "graph." 


\section{Algebraic Structure as it Appears in the Common Core State Standards for Mathematics}

Table 3 in the "mathematics glossary" of the K- 8 Common Core State Standards listed nine "properties of operations." There are the associative and commutative properties for addition and multiplication, the additive identity property of 0 , existence of additive inverses, the multiplicative identity property of 1 , existence of multiplicative inverses, and the distributive property of multiplication over addition. These properties are formally stated in terms of "arbitrary numbers" $a, b$, and $c$.

An important aspect of any curricular planning aimed at assisting children to become familiar with structural properties with respect to numbers is the fact that the properties are often summarized using algebraic notations. Thus, for example, the associative property for addition often appears as " $(a+b)+c=a+(b+c)$." What is not emphasized in CCSSM, or in associated textbooks, is that in such a statement, $a, b$, and $c$ are being used as variables in the sense that $(a+b)+c$ will equal $a+(b+c)$ no matter which numerical values one gives to $a, b$, and $c$-provided, of course, if $a$ is given a particular value in $(a+b)+c$ then $a$ must be given the exact same value in $a+(b+c)$, etc. For a mature mathematician, or for an inexperienced but otherwise well-qualified middle-school mathematics teacher, the meaning of that proviso will be obvious, but for a seventh-grade student a correct interpretation of the complex sign "for arbitrary real numbers, $a, b, c,(a+b)+c$ will always equal $a+(b+c)$ " is anything but obvious.

Part of the problem, from an educational perspective, lies in the meaning many children give to the word "arbitrary" in the statement "For arbitrary numbers $a, b, c$ in a given number system, $(a+b)+c=a+(b+c)$." A seventh-grade child might think: "I'll 
let $a=7, b=2$, and $c=4$ on the left side, and $a=5, b=3$, and $c=10$ on the right side. ... But ... that wouldn't make a true statement. The rule's wrong!"

After examining the CCSSM (2010) curriculum, the researcher decided that it would not be wise to attempt to teach the Grade 7 students who participated in the current study all of the field properties during the course of the investigation. An understanding of the mathematical poignancy of those properties is something to be built up carefully over years, and in this study it was decided to pay special attention to just three of the properties - namely, the associative property for addition, the associative property for multiplication, and the distributive property (by which multiplication is distributed over addition or subtraction). The wisdom of the decision to limit the scope of the investigation in that way should become apparent in the light of the following examination of what the CCSSM curriculum requires in relation to those three chosen properties.

\section{The Associative Properties for Addition and Multiplication, and the Distributive Property, in Common Core Mathematics}

Grade 1. The associative property is first specifically mentioned in first-grade CCSSM mathematics content, when the following terminology is used:

Grade 1, CCSS.Math.Content.1.OA.B.3

Apply properties of operations as strategies to add and subtract. Examples: If $8+3$ $=11$ is known, then $3+8=11$ is also known (commutative property of addition).

To find $2+6+4$, the second two numbers can be added to make a ten, so $2+6+4$ $=2+10=12$ (associative property of addition). (CCSSM, 2010, p. 15) 
The form of words used suggests that first-grade teachers might be expected to help their students realize that in order to calculate $2+6+4$ it might be better to add the 6 and the 4 first, rather than add the 2 and the 6 first, because $6+4$ equals 10 , and young learners get to know about properties of 10 early. But young children are being taught to read printed text from left to right, and therefore it is unlikely that many of them would think of adding the 6 and the 4 first. Whether it would be wise to expect first-graders to carry out such an analysis needs to be determined by research.

Grade 3. In the "glossary" (labeled "Table 3"), the CCSSM curriculum refers to the "associative property of multiplication," and to the "distributive property of multiplications over additions," and in a statement on "Operations and Algebraic Thinking" in the section for Grade 3, the common core curriculum document states: Apply properties of operations as strategies to multiply and divide. Examples: If 6 $\times 4=24$ is known, then $4 \times 6=24$ is also known (commutative property of multiplication). $3 \times 5 \times 2$ can be found by $3 \times 5=15$, then $15 \times 2=30$, or by $5 \times 2$ $=10$, then $3 \times 10=30$ (associative property of multiplication). Knowing that $8 \times 5$ $=40$ and $8 \times 2=16$, one can find $8 \times 7$ as $8 \times(5+2)=(8 \times 5)+(8 \times 2)=40+16$ $=56$ (distributive property). (CCSSM, 2010, p. 23)

In the Grade 3 measurement section for CCSSM one finds the intriguing expectation: "Use tiling to show in a concrete case that the area of a rectangle with whole-number side lengths $a$ and $b+c$ is the sum of $a \times b$ and $a \times c$. Use area models to represent the distributive property in mathematical reasoning" (CCSSM, 2010, p. 25).

Grade 4. In the fourth grade, CCSSM asks for letters to be used to represent unknown quantities. The specific statement in the CCSSM document is: "Solve two-step 
word problems using the four operations. Represent these problems using equations with a letter standing for the unknown quantity" (CCSSM, 2010, p. 23). In CCSSM's section on fourth-grade “Operations \& Algebraic Thinking," teachers are advised to help students to use drawings, equations and letter symbols when representing problems. Also, students should learn to justify standard short multiplication and long multiplication algorithms by referring to distributive and associative properties and to illuminate the sense of these algorithms by using equations, rectangular arrays, and/or area models.

Grade 5. The section on "Operations \& Algebraic Thinking" states that students are to "write and interpret numerical expressions" without necessarily evaluating them. According to CCSSM, students might profitably express the calculation "add 8 and 7, then multiply by 2 " as " $2 \times(8+7)$," and be asked to "recognize that $3 \times(18932+921)$ is three times as large as $18932+921$, without having to calculate the indicated sum or product" (p. 35). So, clearly, it is expected that the distributive property be used, and understood, by the end of fifth grade.

In the Measurement section of CCSSM's Grade 5 curriculum, students are expected to learn to find the volume of a right rectangular prism with whole-number side lengths by packing it with unit cubes, and then to show that the volume is the same as would be found by multiplying the edge lengths, or equivalently by multiplying the height by the area of the base. Finally, and most pertinent to thinking about structure, the students should learn to "represent threefold whole-number products as volumes, e.g., to represent the associative property of multiplication" (CCSSM, 2010, p. 37). 
Grade 6. In the sixth grade, students are expected to make noticeable advances in algebra. Thus, for example, they should learn to describe $2(8+7)$ as a product of two factors and view $(8+7)$ as both a single entity and as a sum of two terms. They should also be able to apply the distributive property to expressions such as $3(2+x)$, to produce the equivalent expression $6+3 x$ and, in the reverse direction, for expressions such as $24 x+18 y$, to produce the equivalent expression $6(4 x+3 y)$. They should also learn to apply properties of operations to $y+y+y$ to produce the equivalent expression $3 y$.

Details in the last paragraph make clear the CCSSM expectation that by the end of the sixth grade, students should be able to use the distributive property for both "expanding parentheses" and for factoring (using the "common factor"). Furthermore, the apparently simple $y+y+y=3 y$ is really to be justified from the distributive property (because in " $y+y+y$ " the $y$ is common and, therefore, by the distributive property $y+y+y=y(1+1+1)=y \times 3$ or $3 y$, if one assumes the commutative property for multiplication, and knows that $3 y$ is a shorthand for $3 \times y$ ).

Grade 7. By this stage, students will be expected "to apply properties of operations as strategies to add, subtract, factor, and expand linear expressions with rational coefficients" (p. 49); and, hence, the distributive property is to be used to justify assertions such as "one can add and subtract like terms, but not unlike terms." For example, $3(2 x-1 / 3)+5 x+7$ can be written as $6 x-1+5 x+7$ (having applied the distributive property and a multiplicative inverse property), which can be written as $11 x$ +6 (having applied commutative, associative, and distributive properties). But, $11 x+6$ must not be written as $17 x$ because there is no common factor. 
Also, the Grade 7 CCSSM section on "Expressions \& Equations" states that "students are to learn to use properties of operations to generate equivalent expressions," and are to "understand that rewriting an expression in different forms in a problem context can shed light on the problem and on how the quantities in it are related." The following example of this is given: " $a+0.05 a=1.05 a$ " means that "increase by $5 \%$ " is the same as "multiply by $1.05 . "$

Part of the current study will be concerned with the extent to which the participating seventh-grade students' developing knowledge and understanding of the associative and distributive properties for real numbers helped them not only to formalize the concept of a variable, but also to develop a better understanding of what is traditionally regarded as elementary algebra.

The existing algebra-education literature has not paid much attention to how structural aspects of the set of real numbers involve the concept of a variable. But, for example, the distributive property asserts that if $a, b$, and $c$ represent any real numbers then $a \times(b+c)$ will equal $(a \times b)+(a \times c)$. One can vary the values of $a, b$, and $c$ as much as one likes, but if $a, b, c$ represent real numbers then this relationship will always be true. Similarly, $a+(b+c)$ will equal $(a+b)+c$ and $a \times(b \times c)$ will equal $(a \times b) \times c$. However, $a-(b-c)$ will not usually be equal to $(a-b)-c$; and it will not generally be true that $a \div(b \div c)$ equals $(a \div b) \div c$. Such reasoning draws attention to links between structural number properties and the concept of variable.

There is evidence that despite CCSSM's (2010) strong emphasis on field properties, and on the distributive property in particular, some recent researchers have preferred to train teachers to engage school students in a "separate-multiply-add" (SMA) 
"strategy" for multidigit multiplication. In a 38-page paper, Whitacre and Nickerson (2016) stated, in a footnote, that it was "important to note the distinction between strategies and properties," and that "SMA is distinct from the distributive property" (Whitacre \& Nickerson, 2016, p. 283). That was the only time the term "distributive property" was mentioned in the paper.

In the current study there was a series of workshops dedicated to algebraic structure which were expected to occupy three weeks with the seventh-graders. The aim for those workshops was to involve all of the students actively and expressively in the learning process so that they would achieve an understanding not only of the "variables" aspect of statements such as $(a+b)+c=a+(b+c),(a \times b) \times c=a \times(b \times c)$, and $a \times(b+c)=a \times b+a \times c$, but also of how those properties are vitally important in the development of standard ways of operating in elementary algebra (for solving equations and inequalities, and creating equivalent algebraic expressions). They also provided justification for "clever" ways of doing "mental arithmetic" calculations (such as finding the value, mentally, of $803+798$, or finding the value of $25 \times(4 \times 19)$, or finding the cost of 11 pens at $\$ 1.05$ each). The workshop notes for the structure workshop are reproduced as Appendix E to this dissertation.

\section{Modeling Across the Grades in CCSSM Algebra}

Three seventh-grade classes participated in the second pilot study—one of the classes had lessons which focused on visual-modeling tasks, another had lessons in which students solved non-visual, modeling problems, and the third had lessons on structural aspects of rational numbers (Kanbir, 2016). In the current study the "structural" aspect was retained but because of the limitations of time, in particular, but 
also because of some of the pilot-study findings and of the implications of careful examination of the elementary algebra requirements in the CCSSM curriculum, it was decided there would be only one modeling component for the main study, and that that component would incorporate both visual and non-visual aspects.

Another decision, made before the current study commenced, was that the patterns to be investigated by the seventh-graders would mainly be in the form of linear sequences in which there would be identifiable first, second, third, etc., terms. One of the challenges of the workshops on modeling was to get the students to the stage where they could understand the idea of an $n t h$ term in a sequence, where $n$ could represent an unspecified natural number (and, sometimes, zero as well).

It was thought that the current study would generate findings which would contribute to the literature concerning the growth of middle-school students' abilities to generalize. Terms such as "recursive rule" and "explicit rule" would be employed in the modeling workshops, and the subscript sequence notation, $t_{n}$, would also be introduced and used. It was a matter of some interest to the researcher whether the Grade 7 students would learn to cope with the subscript notation (which is commonly employed by mathematicians in the specification of sequences, and is expected of Algebra 1 students in middle schools and in high schools).

Grade 3. In the "Operations \& Algebraic Thinking” section of the CCSSM curriculum it is stated that students should learn to "solve problems involving the four operations, and identify and explain patterns in arithmetic" (CCSSM, 2010, p. 23). Notice the specific use of the term "patterns" in that statement. Furthermore, Grade 3 
students were expected to learn to use letters to represent unknown quantities when attempting to solve two-step word problems.

Grade 4. The following statement in a section in the CCSSM (2010) curriculum on "Generate and analyze patterns" makes it clear that fourth-grade students were to be expected to learn to describe patterns both explicitly and recursively:

Generate a number or shape pattern that follows a given rule. Identify apparent features of the pattern that were not explicit in the rule itself. For example, given the rule "Add 3" and the starting number 1, generate terms in the resulting sequence and observe that the terms appear to alternate between odd and even numbers. Explain informally why the numbers will continue to alternate in this way. (p. 29)

Grade 5. Fifth-grade students are to "analyze patterns and relationships." They are to generate numerical patterns from two given rules, to identify apparent relationships between corresponding terms, to form ordered pairs consisting of corresponding terms from the two patterns, and graph the ordered pairs on a coordinate plane. For example, they might be given the rule "Add 3" and the starting number 0 , or given the rule "Add 6 " and the starting number 0 , and asked to generate terms in the resulting sequences, and observe that the terms in one sequence are twice the corresponding terms in the other sequence. They could be asked to explain informally why this was the case (CCSSM, 2010, p. 35).

Grade 6. The terms "dependent variable" and "independent variable" are to be introduced to sixth-graders, who should learn to use them to represent and analyze quantitative relationships between variables (CCSSM, 2010). Students are to "use 
variables to represent two quantities in a real-world problem that change in relationship to one another; write an equation to express one quantity, thought of as the dependent variable, in terms of the other quantity, thought of as the independent variable" (p. 44). They are to be invited to investigate relationships between dependent and independent variables using graphs and tables, and to relate these to the equation. For example, in a problem involving motion at constant speed, they will be expected to list and graph ordered pairs of distances and times, and to write the equation $d=65 t$ to represent the relationship between distance and time.

An interesting reflection on the information in the last paragraph is that whereas in Grade 5 the domain for the variable was to be the set of counting numbers (with, perhaps, zero as well), in Grade 6 the domain for the variable could be subsets of the set of real numbers (corresponding, for example, to measures of time and distance). By the end of Grade 6, students will be expected to be able to translate between real-life modeling and algebraic expressions. They should also be expected to create algebraic expressions which summarize a pattern.

Grade 7. By the end of Grade 7, students will be expected to model situations involving linear equations and inequalities. They should have learned to solve word problems leading to inequalities of the form $p x+q>r$ or $p x+q<r$, where $p, q$, and $r$ represent specific rational numbers. Ideas developed from modeling will appear frequently in problems — for example: “As a salesperson, you are paid $\$ 50$ per week plus $\$ 3$ per sale. This week you want your pay to be at least $\$ 100$. Write an inequality for the number of sales you need to make, and describe the solutions" (CCSSM, 2010, p. 49). 
Notice that in that particular example, the independent variable would be a natural number, or zero.

Whereas the common-core mathematics curriculum specifically asks for fifth- and sixth-grade students to become acquainted with the concepts of explicit and recursive rules for sequences, the issue whether students should be expected to learn the subscript notation for sequences is not addressed. However, algebra students in the ninth grade will be expected to have learned the notation (CCSSM, 2010).

Over the past few decades, arguments supporting the idea that modeling activities should be more important at all grade levels in school algebra than has traditionally been the case, have become commonplace in the algebra education literature. However, as Kieran (2007) pointed out, the meaning of the term "modeling" has not always been made clear. It has been interpreted as applying to a broad range of situations (e.g., with respect to word problems, physical situations, numerical and visual patterns, etc.) - the commonality in all of these, though, is that students are invited to capture and generalize regularities by using the mathematical language of formulas.

The seventh-grade participants in the current study were introduced to the subscript notation for sequences, and it was a matter of interest whether they would be able to cope with that notation. Two issues could be identified: first, could they interpret statements in which someone else used the notation; and second, could they themselves become fluent in using the notation to describe sequences?

Mathematicians typically regard a functional relationship in which the domain is the set of natural numbers (with, perhaps, zero also included) as a special type of function - which is called a sequence. Part of the current study was concerned with the 
seventh-graders' investigations of sequence-like functional relationships, and although developments in the students' "functional thinking" were studied, the emphasis was on sequences only, and therefore the type of function was restricted. From that perspective, it could be argued that a restricted, and therefore perhaps misleading, sense of a functional relationships might have been portrayed to, and acquired by, the student participants.

The other main content area with which the seventh-grade participants in the current study grappled involved algebraic properties for which the variables were not restricted to being natural numbers. In a statement like "if $a, b, c$ denote any real numbers then $a+(b+c)$ is equal to $(a+b)+c$," for example, the $a, b, c$, are signs that can represent any real numbers. In the workshops on the associative and distributive properties in the current study, the types of numbers which $a, b, c$ could represent were deliberately varied. In some tasks they represented natural numbers; in other tasks they represented integers which could include negative numbers or zero; and in other tasks they represented common fractions. From that perspective, the structure component of the current study presented a different view of school algebra from the component which concentrated on students dealing with sequences, in which the domain comprised the set of natural numbers, perhaps with zero.

\section{Summary of Research on Learning and Teaching Algebra}

Cai and Knuth (2011) drew attention to two dominant perspectives in algebra education research. The first related to a perceived need to develop students' algebraic thinking so that the students will be able to make strong connections between arithmetic and algebra. The second related to the importance of supporting teachers' efforts to 
foster the development of students' algebraic thinking. The current study was concerned to investigate both of those perspectives.

In the next section, I will present content and some samples of text regarding how two approaches were placed in the textbook which the seventh-grade students at School W have been using.

\section{Structural and Functional Approaches as Presented in the Mathematics Textbook Used by Participating Students}

For some years, now, seventh-grade classes at School W have been using a textbook, authored by Charles, Branch-Boyd, Illingworth, Mills and Reeves (2004). The book is titled Mathematics Course 2, and was published by Pearson Prentice Hall. The School has class sets of that textbook.

Charles et al. (2004) defined a variable as "a symbol that represents one or more numbers" (p. 71). Immediately after that definition was given, an "algebraic expression" was defined as "a mathematical phrase with at least one variable" (p. 71). Three examples of variables $(g, z$, and $x)$ were given, and three examples of algebraic

expressions $\left(13-g, \frac{z}{2}\right.$, and $\left.3 x+8\right)$ were also given. Readers were informed that the "value of an algebraic expression varies or changes, depending on the value of the variable" (p. 71). Later in the book, an equation was defined as "a mathematical sentence with an equal sign" (p. 122), and a solution was defined as "a value for a variable that makes an equation true" (p. 122). An inequality was "a mathematical sentence which contains $<,>, \leq, \geq$, or $\neq$ "' (p. 123), and a solution to an inequality was "any number that makes the inequality true" (p. 123). That definition was, perhaps, 
unfortunate for it could make a reader believe, for example, that 5 was the solution to the inequality $2 x+1>10$.

The introduction to algebra given in Charles et al. (2004) is standard, and similar to introductions found in many textbooks used in middle schools during the past 50 years. Among other things, the proposed study investigated how well the 32 participating students understood the concept of a variable as it is assumed in the treatment of the associative property for addition of real numbers, the associative property for multiplication of real numbers, the distributive property, and in situations and contexts involving modeling from numerical and visual patterns.

\section{Textbook Treatment of the Associative Property for Addition}

The first mention of the associative property for addition of real numbers in Charles et al. (2004) was on page 12, where the property was described by the statement "changing the grouping of the addends does not change the sum." Then, examples from arithmetic and algebra were given:

Arithmetic. $(2.5+6)+4=2.5+(6+4)$

Algebra. $(a+b)+c=a+(b+c)$

A model example was then given under a heading "Why It Works":

$$
\begin{aligned}
0.7+12.5+1.3 & =0.7+1.3+12.5(\text { commutative property) } \\
& =(0.7+1.3)+12.5 \text { (associative property) } \\
& =2+12.5
\end{aligned}
$$




$$
=14.5(\mathrm{p} .13)
$$

Then, exercises in which the associative property for addition could be used were given (pp. 13-15). The fact that an associative property for subtraction of real numbers does not hold was not mentioned.

\section{Textbook Treatment of the Associative Property for Multiplication}

The associative property for multiplication of real numbers was first mentioned in Charles et al. (2004) on page 18, where the property was summarized by the statement "changing the order of the factors does not change the product." Then, examples from arithmetic and algebra were given:

Arithmetic. $(3 \cdot 2) \cdot 5=3 \cdot(2 \cdot 5)$

Algebra. $(a \cdot b) \cdot c=a \cdot(b \cdot c)$

A model example was then given under a heading "Why It Works":

$0.25 \cdot 3.58 \cdot 4=0.25 \cdot 4 \cdot 3.58$ (commutative property of multiplication)

$=(0.25 \cdot 4) \cdot 3.58($ associative property of multiplication $)$

$=1 \cdot 3.58$

$=3.58($ p. 18) 
Then, exercises in which the associative property for multiplication could be used were given (pp. 19-22). The fact that an associative property for division of real numbers does not hold was not mentioned.

\section{Textbook Treatment of the Distributive Property}

The distributive property for multiplication over addition of real numbers was first mentioned in Charles et al. (2004) on page 51, where the property was summarized. Then, examples from arithmetic and algebra were given:

Arithmetic. $9(4+5)=9(4)+9(5)$ and $5(8-2)=5(8)-5(2)$

Algebra. $a(b+c)=a(b)+a(c)$ and $a(b-c)=a(b)-a(c)$

A model example was then given under a heading "Mental Math."

The distributive property was then used to find 6(53), which was said to equal $6(50)+6(3)$, or $300+18$, or 318 . Then the reader was asked whether $6(50+3)$ must equal $(50+3) 6$. Overall, there was surprisingly little attention given to the distributive property in the book, and in most of the cases which were mentioned the context was numerical rather than specifically algebraic.

\section{Textbook Treatment of Modeling and Related Problem Solving}

On pages 72 and 73 of the textbook, attention was given to writing algebraic expressions corresponding to real-world situations. The theme was introduced by the statement: 
You can use algebraic expressions to describe data. Suppose your heart beats 72 times in one minute. You can write an expression for the number of beats in any number of minutes.

Let $m$ represent the number of minutes. $\rightarrow 72 m$ the algebraic expression represents the number of heartbeats in $m$ minutes. (Charles et al., 2004, p. 72)

Then an example was given, with the temperature being increased from $t$ degrees to 5 degrees more than that. It was stated that the new temperature could be summarized by $t$ +5 . Then followed several pages of practice exercises in which algebraic expressions were to be found for given expressions such as "four shirts more than $s$ shirts" (p. 73).

Chapter 9 of the textbook was entitled "Patterns and Rules," and had sections on "Patterns and Graphs," "Number Sequences," "Patterns and Tables," and "Using Tables, Rules and Graphs." Although terms like "arithmetic sequence," "function," "geometric sequence," and "conjecture" were often used, the emphasis was on informal rather than formal mathematics, and only occasionally was attention given to making generalizations. There were many tables of values in the chapter, and perhaps the most interesting, from a pedagogical perspective, was the following (see Table 1), which appeared on page 481:

Table 1

A Table of Values from Charles et al. (2004), p. 481

\begin{tabular}{lllllll}
\hline Number & 1 & 2 & 3 & 4 & $\ldots$ & $n$ \\
\hline & $\times 8$ & $\times 8$ & $\times 8$ & $\times 8$ & $\times$ & $\times 8$ \\
& & & & & 8 & \\
\hline Value of & 8 & 16 & 24 & 32 & $\ldots$ & $?$ \\
Sequence & & & & & & \\
\hline
\end{tabular}


This is the only table in Charles et al. (2004) which included the symbol ... (a notation which is intended to invite readers to make a cognitive leap from specific cases to the general case). No explanation of the meaning of ... was given, and it is a matter of interest whether seventh-grade students would be aware of what was required of them. In the two pilot studies conducted by the researcher (Kanbir, 2014, 2016), it was found that seventh- and eighth-grade students at a school different from School W were not aware of this convention, and in Table 1 would have been inclined to place " 48 " under $n$, rather than " $8 n$. ."

On reading the treatment of modeling in Charles et al. (2004), the writer must confess to having been surprised that there were so very few examples of sequences in which students were invited to formulate the explicit rule for the $n$th term.

\section{The Problem as it Appeared to be at the Beginning of the Study}

Having participated in the two pilot studies I began to wonder whether the expectations set out for middle-school algebra in the common-core mathematics curriculum (CCSSM, 2010) were unduly optimistic. When conducting interviews with seventh- and eighth-grade students at a well-organized, outcomes-oriented, middle school, and while analyzing pencil-and-paper test data, as well as interview data, for the

pilot studies, I gained the impression that most of the students knew very little about the associative properties for addition and multiplication, or about the distributive property. They did not know the meanings of the formal language "associative property for addition," "associative property for multiplication," and "distributive property for multiplication over addition." More seriously, perhaps, they did not seem to have an intuitive understanding of how these properties might be useful for simplifying 
calculations like "17 times 11 " or " $172 \times 5 \times 1 / 5$ " or "502 + 499." Likewise, other than being able to identify recursive rules, like "add 3," for simple pattern tasks, the students seemed to struggle to identify and describe patterns or to engage profitably in modeling tasks.

At first, I wondered whether the data generated in the pilot studies pointed to something unique about the school at which I had conducted those studies. But, on reflection, I recognized that that school seemed to be very well organized, the teacher who was teaching the pilot-study mathematics classes was qualified, enthusiastic, and dedicated, and the students were cooperative and well behaved. I conjectured that the pilot-study school had not given much attention to early algebra or to patterns in its $\mathrm{K}-6$ mathematics program, but inquiries indicated that that was not the case. This led me to suspect that a statement by the University of California mathematician, Hung-Hsi Wu (2007), that "by the sixth grade most students already know about the associative and commutative laws of addition and multiplication," might be seriously wrong. My suspicions hardened into belief when I read a paper by Ding, Li and Capraro (2013) which reported data indicating that preservice elementary school mathematics teachers within the United States of America did not know the difference between the associative and commutative properties of multiplication.

Thus, I felt I needed to check if the situation regarding middle-school algebra which I found in the pilot-study school was not atypical. That prompted me to conduct the current study in a middle school other than the pilot school. My doctoral supervisors, who will be denoted by "Prof. E" and "Prof. F" in this dissertation, thought that they 
knew of an appropriate school — and thus it came to be that I approached the Principal and middle-school mathematics teachers at School W.

Prof. E and Prof. F had supervised previous doctoral research involving students and teachers at School W, and knew it well. They assured me that it had high mathematics standards and that in previous years they had examined data which suggested that middle-school students from School W tended to perform slightly above the average on pencil-and-paper tests of middle-school mathematics. They also stated that in the past the school had been very willing to participate actively in mathematics education research projects that it deemed to be well designed and consistent with its curriculum. After talking with the Principal and with middle-school teachers at School W, it was agreed that the current study would be based there-provided, of course, the necessary assents and consents from students and parents could be obtained.

Contemporary thinking about middle-school algebra has tended to emphasize the importance of "functional thinking." Amy Ellis (2011) is among many recent researchers to have referred to "the value of organizing algebra around a functions approach" (p. 218). However, Ellis (2011) stated that endeavors to implement an agenda based on that approach had "proved difficult" (p. 218) and that "students emerge from middle school and high school algebra classes with a weak understanding of function" (p. 219). Despite acknowledging past failures with the functional approach, Ellis nevertheless called for middle-school students to be introduced to functional relationships through "meaningful situations" (p. 235). Furthermore, Miriam Lüken (2012) argued that although patterning competences and algebraic thinking have been 
described on a theoretical basis, the sense and practicality of expecting elementary and middle-school children to deal with these have not yet been shown empirically.

Rivera (2003) recognized that unless students receive more support in the development of their structural thinking with respect to patterning activities-in order to develop their "functional thinking"- they may not become proficient with their symbolic algebraic thinking.

From another perspective, Kieran (2007) argued that although field and order properties of real number were always an implicit part of symbol manipulations, they were rarely the theme of algebra education research. She maintained that future research needed to be carried out concerning the interactions with and the distinctions between the function approach which emphasized modeling and an equation approach which emphasized algebraic structures. This argument supported Blanton, Stephens, Knuth, Gardiner, Isler, and Kim's (2015) arguments in favor of a multilayered approach to algebra instruction. Blanton et al. (2015) argued that such an approach could have significant effects on students' ability to generalize, represent, justify, and reason with mathematical structures.

In the current study, middle-school students at School W were engaged in tasks involving functional relationships. However, the truth of the often-repeated assertion that in early algebra and in middle-school algebra a functional-thinking approach is likely to be more beneficial for learners than a structure approach, was not taken for granted. All of the participating students were involved in workshops in which both the functional thinking (modeling) approach and the structure approach were featured, and 
the effects of each approach, as well as a combination of the two approaches, on student knowledge, understandings, and attitudes, were studied.

Having identified the problem for the research study, the question arose how I should frame it, theoretically. Almost all the seventh-grade students in the pilot studies had not recognized the meanings or implications of important signs often used in middle-school algebra. They did not use, or know the meanings, of terminology that the common-core curriculum suggested they should have known. Their thinking with respect to structure was dominated by a perceived need to apply the "Please Excuse My Dear Aunt Sally" (PEMDAS) mnemonic, and their approaches to modeling were hampered by a lack of knowledge of symbolic conventions that subtly apply in tasks involving tables of values.

I chose the major semiotic theory presented by Charles Sanders Peirce as part of the theoretical base for the current study. Peirce emphasized the triadic "signifier, interpretant, signified" relationship, and I had found, in the pilot studies, that signifiers for algebra were not being linked, by the students, to the appropriate, curriculum-related, “signifieds.” In order to complement Peirce's theoretical position, I chose Johann Friedrich Herbart's theory of apperception-which emphasized the need to take account of what was already "in the minds" of learners during mathematics lessons.

More will be said about Peirce's and Herbart's theoretical positions in Chapter 2, which will conclude with a statement of the six research questions which were addressed in the current study. 


\section{CHAPTER II}

\section{LITERATURE REVIEW}

In the first chapter I drew attention to some of the problems faced by middleschool teachers, textbook authors, and curriculum designers in regard to middleschool algebra. One of the problems was that although the National Governors Association Center for Best Practices and the Council of Chief State School Officers' Common Core State Standards for Mathematics (CCSSM, 2010) has clearly recommended that elementary and middle-school mathematics curricula should have a strong early-algebra component, it has not been made clear exactly what the term "early algebra" means. Certainly, though, two main strands of thought with respect to middle-school algebra have been identified - these are to be associated with (a) the structure of rational numbers and (b) a functional-thinking approach by which learners are engaged in patterning and modeling activities which link independent and dependent variables (Cañadas, Brizuela, \& Blanton, 2016; Kieran, 2011; Taylor-Cox, 2003). In the remainder of this chapter these will be called the "structure" approach and the "modeling" or "functional-thinking" approach.

The research literature has not established whether the two main approaches to middle-school algebra require the learning and application of the same kind of skills, concepts, and principles. Although desirable teaching methods have often been discussed for the functional-thinking approach, that has not been the case with the 
structure approach. And, the question of how much classroom time in middle schools should be dedicated to each has not been resolved. Should both approaches receive the same amount of attention in classrooms, or should one of the two be given more time, and priority, over the other? The research literature has not established how the two forms should be combined in order that students will be best prepared for applications in real-life situations and for the study of higher mathematics and science.

Advocates of the structure approach emphasize the need to assist middle-school students to learn to identify and use key structural properties which carry the names “closure," “associative," “commutative," "identity," "inverse,” and “distributive." These properties are much emphasized throughout the recommended common-core mathematics curriculum — indeed, the common-core curriculum includes a glossary summarizing them (CCSSM, 2010). Although these structural properties were obviously regarded as extremely important by those who developed the CCSSM curriculum statement, and that view is shared by many mathematicians (see, e.g., $\mathrm{Wu}$, 2001), the common-core curriculum has framed the structural properties in very formal language and it is not clear whether, in that form, they can be learned by middle-school students in mathematically acceptable ways.

For instance, in the CCSSM curriculum the distributive property is specifically mentioned for seventh-grade algebra, and the identity $0.05 a+a=1.05 a$ is given as an illustration of the property. The implication seems to be that students will recognize that the distributive property enables $0.05 a+a$ to be written as $a \times(0.05+1)$, which can be written as $a \times 1.05$; then, by the commutative property for multiplication (and 
a knowledge of some of the conventions of the syntax of elementary algebra), that could be written as $1.05 a$. Many middle-school teachers would say that such an approach is extremely bookish, and will not be appreciated or understood by students. The research literature for middle-school mathematics (e.g., Cai \& Knuth, 2011) does not provide detailed evidence on what middle-school students might reasonably be expected to learn about the key structural properties of the set of rational numbers, and hardly any attention is given to describing methods for engaging students actively and profitably in learning about them.

In recent years, considerable attention has been given in the algebra-education research literature to the functional-thinking approach. In 2015, for example, lengthy papers appeared in separate issues of the Journal for Research in Mathematics Education in which some authors pushed, unambiguously, for the importance of that approach in elementary and middle schools (Blanton, Brizuela, Gardiner, Sawrey \& Newman-Owens, 2015; Blanton, Stephens, Knuth, Gardiner, Isler \& Kim, 2015). But other commentators (e.g., Kieran, 2011) have stopped short of recommending that the functional-thinking approach should receive greater emphasis than the structure approach.

It was the controversy relating to whether middle-schools should attempt to balance the amount of classroom time given to the two approaches and, if so, whether it is possible to link the approaches conceptually, which was at the heart of the research described in this dissertation. I decided to study how well seventh-grade students in a highly-regarded, medium-sized public school in a rural area in a midwestern state within the United States of America-in Chapter 1 the school was 
called "School W"-had learned both the structure and functional-thinking approaches during their elementary and early middle-school years. I also decided to study whether it would be possible, in a modest amount of evenly-distributed classroom time, to improve significantly the middle-school students' knowledge and application with respect to both the main approaches to elementary and middle-school algebra.

\section{The Design Research Foundation for the Study}

Planning for the investigation described in this dissertation was strongly influenced by the design research literature (see, e.g., Brown, 1992; Clements, 2011; Kelly \& Lesh, 2000; Kelly, Lesh \& Baek, 2008). The extent of that influence will now be briefly summarized and discussed.

The early-algebra issues outlined above were recognized by the two main teachers of middle-school mathematics at School W (in Chapter 1 these teachers were called "Mr. X" and "Mr. Y"). Agreement was reached that a research team should be formed comprising Mr. X, Mr. Y, myself, and two members of my doctoral advisory team - "Prof. E" and "Prof. F." With the agreement of the Principal of School W, and with relevant ethics approval having been obtained, it was decided that the team members would design an early-algebra intervention program which would include:

1. The collection and analysis of initial, pre-intervention pencil-and-paper test data, and also interview data.

2. Some initial pre-intervention teaching and observation of eighth-grade algebra classes at School W. This would involve all five members of the research team. 
3. A teaching intervention involving seventh-grade classes at School W. The teachers of the seventh-grade students would be Mr. X and Mr. Y.

4. The collection and analysis of middle- and post-intervention data, including middle- and post-intervention pencil-and-paper test data and postintervention interview data.

5. The collection and analysis of pencil-and-paper retention test data.

In the planning process, careful attention was given to each of the following three design elements:

1. What were the dimensions of the task?

- What was the aim of the intervention program?

- What did we plan to do in order to achieve that aim?

- What were the most likely threats that would prevent us from achieving our aim, and what did we need to do to prevent those threats from becoming a reality?

2. Who would be the key players in the intervention program?

- With the permission of the Principal of School W, it was agreed that a research and teaching team of five persons would be involved, and the students in the main part of the study would be all those seventh-grade students at School W who gave their assent to participate and whose parents gave their consent for their children to be involved.

- Preliminary meetings involving all five team members took place, and at those meetings shared responsibilities for important components of the 
intervention program were agreed upon. More details will be provided in Chapter 3 of this dissertation.

3. How should the program be implemented, evaluated and reported?

- It was agreed at the preliminary meetings that Prof. E, Prof. F, and I should model the proposed forms of the lessons for seventh-graders to classes of eighth-grade students at School W, and that Mr. X and Mr. Y would be present and observe all the eighth-grade classes taken by Prof. E and Prof. F and me. Then, with the seventh-grade classes, Mr. X and Mr. Y would attempt to follow the approaches and materials prepared by Prof. E, Prof. F and me-with the proviso that Mr. X and Mr. Y should feel free, at any time, to depart from the teaching approaches that they had observed in the model lessons, and from the materials used in those lessons, when and if either or both of them felt the need to do so. More details of the teaching intervention will be provided in Chapter 3.

- It was also agreed that Prof. E, Prof. F and I should develop the materials and artifacts to be used in the seventh- and eighth-grade lessons, and also prepare pre- and post-intervention interview protocols and pencil-and-paper tests.

- With the assistance of Prof. E and Prof. F, I would analyze all relevant data arising from the study.

- It was also agreed that I would prepare a doctoral dissertation based on the investigation and that, in addition, I would prepare two "teaching" papers - one that would be co-authored with Mr. X and the other with 
Mr. Y - with the intention of submitting the papers to NCTM's

Mathematics Teaching in the Middle School. With Prof. E and Prof. F, I would also prepare a research paper for submission to a mathematics education research journal.

Design research approaches to education research and development have emerged from considerations of planning and design methods used by teams of architects and engineers who were preparing to carry out major design projects. If, for example, architects and engineers faced the challenge of designing and building a bridge which would span a large gap over a deep ravine whose sides were at very different heights, then careful collaboration between experts would obviously be called for, because the consequences of poor design or poor construction could be great. And, of course, all relevant theories for designing and building would need to be carefully taken into account. In that sense, design research should not be regarded as involving theory-free activity, even though the theories would be chosen to fit the problem, and not the reverse.

Similarly, in the education investigation described in this dissertation, careful consideration was given, by members of the research team, to the selection of the most appropriate theories and to how those theories should be taken into account at the planning, intervention, and evaluation phases of the study. The theoretical bases for the study will now be outlined.

\section{Theoretical Bases for the Study}

The research team decided that the planning and implementation of the study, and the interpretation of data generated by the investigation, should be informed by 
the work of several scholars who had put forward theories that team members deemed to be especially relevant to the study. We paid particular attention to the ideas of those who had attempted to (a) link semiotic theories to middle-school mathematics curricula and practices in school mathematics; (b) identify the importance of students' cognitive structures with respect to curricular themes in school mathematics; and (c) to identify how those structures might be affected by instruction and patterns of classroom communication.

When making decisions on how the study should be framed theoretically we did not assume that the positions of modern scholars should be preferred to those of earlier scholars. Indeed, three of the most important influences on our thinking came from the early, but classic, works of:

- Johann Friedrich Herbart (1776-1841), a German philosopher and educator whose main writings on education first appeared about 200 years ago;

- Charles Sanders Peirce (1839-1914), a U.S. philosopher and logician and the son of a famous Harvard University mathematician, Benjamin Peirce. Charles Sanders Peirce is often regarded as the father of pragmatism, and his semiotic theory provided an account of signification, representation, reference, and meaning that, the research team believed, is important for understanding students' thinking about mathematics; and

- Ferdinand de Saussure (1857-1913), a Swiss linguist and philosopher who is regarded as a pioneer in the field of semiotics, especially with respect to "structuralism." De Saussure emphasized that in language each unit acquires meaning in conjunction with other units, and in this dissertation that idea 
will be applied to the algebra learning of the participating seventh-grade students.

Herbart, Peirce and de Saussure were not the only theorists whose writings had an impact on our thinking - that will become clear as this chapter progresses.

This study did not aim specifically to apply Herbart's, Peirce's, or de Saussure's ideas in defining the investigation, or in interpreting data arising from it. The ideas of other theorists would be taken into account—-thus, for example, Luis Radford's (2006) distinctions between various types of generalizations (factual, arithmetic, algebraic, contextual, and symbolic generalizations) were noted. It would be an exaggeration, though, to say that Radford's writings, or those of any other modern theorist, on semiotics, were taken more seriously than Peirce's or de Saussure's.

From the outset, then, I did not seek to frame the investigation around any particular theory, or theorist. Rather, I decided to investigate several important issues associated with algebra education involving seventh-grade students and their teachers. Having made that decision, I then conducted a pilot study with seventh-grade students (Kanbir, 2016), and observations and results from that pilot study prompted me to define, extend and ultimately to refine the theoretical base for the current study. The new expanded group of influential theories helped me prepare the research questions for the current study, and these research questions are listed at the end of this chapter.

\section{Signifiers, Objects and Interpretants—and Charles Sanders Peirce}

The first set of theoretical ideas that I linked to the study were those in the literatures related to "semiotics." During the course of conducting interviews and 
observing classes for the second pilot study it became apparent to me that most of the seventh-grade students who participated in that study had not learned to interpret the symbols of early algebra, and often they were not aware of conventions used in texts seeking to convey information and ideas related to algebra. This led me to focus part of my search within the literature on writers who had concentrated on learners' understandings of signs, symbols and representations — and, of course, this decision brought me to the main literatures in the field of "semiotics." However, it did not take long for me to realize that writers in that field often express simple, but important, ideas in what seemed to me to be unnecessarily sophisticated and dense language. In this literature review I will try to use as simple and direct language as possible.

Both Peirce $(1992,1998)$ and de Saussure (1959) developed theories in which they emphasized the importance of signs, and the ways those signs influenced the thinking and cognitive development of people (Presmeg, 2014). They showed how signs might be regarded as "signifiers" which communicate features of objects (or "signifieds") to people ("referents"). Thus, for example, the word "parallel" is a sign which communicates something definite to adults who know the English language; adults also know that although "parallel" means something different from "parallelogram," the concepts represented by the two words, or signs, are, somehow, related. However, for a 10-year-old child growing up in a non-English-speaking family, the "meanings" of the words "parallel" and "parallelogram" might not yet be differentiated. In other words, biological, conceptual, social, and linguistic development can influence the meanings that learners attribute to signs. 
For Peirce a sign relation defines three roles encompassing: (a) a sign, (b) the sign's subject matter, called its object, and (c) the sign's meaning or effect called its interpretant (a further sign, for example a translation). A sign relation is an irreducible triadic relation-irreducible in the sense that the full meaning of the sign relation will not be obtained by considering only two of the three roles (Peirce, 1998). By contrast, for de Saussure (1959), the sign relation is dyadic, consisting only the sign (or signifier) and its meaning (the signified). De Saussure saw this relation as arbitrary, motivated mainly by social convention or by instruction.

With de Saussure's model a signifier, for example the word "tree," stands for something which is "signified," which in this case relates to the abstract concept of "a tree." Thus a sign can direct someone's thinking toward an abstract object. Charles Sanders Peirce went beyond this dyadic model by adding an object representamen, which would stand for the object other than the sign and an interpretant, the assigned meaning. According to Peirce, 'a sign is a third mediating between the mind addressed and the object represented" (Peirce, 1992, p. 281). Some other triads—such as firstness, secondness, and thirdness, and icon, index, and symbol—were offered by Peirce in relation to this process of objectification. In the current study Peirce's triadic semiotic theory was regarded as central, the view being taken that there were three major curriculum aspects, intended, implemented, and attained (Westbury, 1980).

\section{Semiotic Aspects of Structural Properties for Rational Numbers}

What might Peirce's and de Saussure's ideas have to do with seventh-graders as they attempt to learn algebra? We answer that question by considering a task which was used in the study which will be described in this dissertation. Twenty-eight of the 
32 participating seventh-grade students were asked to engage with the task on two occasions - when they were individually interviewed for the study before the main teaching intervention and when, after they had participated in workshops on seventhgrade algebra, they were re-interviewed.

During the interviews each interviewee was shown a typed pencil-and-paper version of the following task:

Without using a calculator, find the value of $4 \times\left(\frac{1}{4} \times 128\right)$.

This stimulus involved many symbols. Each interviewee was asked to read the problem, and although the 28 interviewees involved in the study had no trouble doing that, they tended to read the sign $4 \times\left(\frac{1}{4} \times 128\right)$ in different ways-like, for example, "four times, open parentheses, one-fourth times one hundred twenty-eight, close parentheses," and "four multiplied by a quarter times one twenty-eight."

What was especially interesting is that before participating in any of the lessons on algebra all 28 interviewees interpreted the signs incorporated in the task as signifying an instruction first to multiply one-fourth by 128 and then to multiply the answer obtained by four. No interviewee at the pre-teaching stage associated the 4 with the $\frac{1}{4}$. The students' thinking tended to be dominated by the mnemonic PEMDAS ("Please Excuse my Dear Aunty Sally") which they had learned to use as a guide for the order of operations to be performed in complex calculations. In PEMDAS, the "P" is meant to indicate that what is "inside" the "parentheses" needs to be dealt with first; and, therefore, at the pre-intervention stage all 28 interviewees 
believed that they were expected to find the value of $\frac{1}{4} \times 128$ before they did anything else. Furthermore, many of the students had come to believe that to find the value of $\frac{1}{4} \times 128$, the first thing they needed to do was to write the 128 as $\frac{128}{1}$, and that is what they tried to do in their minds.

After the students had participated in the teaching intervention provided in this study, the words in the problem tended to signify to the students something quite different from what they had signified before the intervention. In the "post-teaching" interviews, a majority of the students tended, first of all, to link the 4 and the $1 / 4$, and to say that since 4 times $1 / 4$ equals 1 , the answer is 1 times 128 , which is 128 . When asked why they could multiply 4 by $1 / 4$ before doing anything else, some would say that they had used the associative property for multiplication. Yet, before the teaching intervention none of the students used the property, or knew the meaning of, the expression "associative property for multiplication."

The symbols used to define the task "Without using a calculator, find the value of $4 \times\left(\frac{1}{4} \times 128\right)$ " were not just any, randomly-ordered and randomly-chosen symbols. Clearly, they originated from a "mathematical mind" and were designed to invite application of a mathematical property known as the associative property for multiplication. Inherent within the symbols was an educational idea-if you have well-formed mathematical knowledge then you will link, mentally, the 4 with the $1 / 4$, and realize that the answer is the product of 1 and 128 , which is simply 128 . The interesting issue, from a mathematics education perspective, is that according to the common-core curriculum (CCSSM, 2010), seventh-grade students should be expected 
to notice that the 4 and $1 / 4$ should be linked, so that the answer 128 would be fairly easily obtained, mentally. The associative property for addition is specifically mentioned in the first grade statements of CCSSM (2010), and there is much reference to associative properties for addition and multiplication throughout the elementary and middle-school CCSSM content descriptions. In other, words, using the language of Peirce (1998), Otte (1998, 2011), and de Saussure (1959), the words "find the value of $4 \times\left(\frac{1}{4} \times 128\right)$ " form a composite sign that a seventh-grade teacher might have expected would have signified to students the need to take the $\frac{1}{4}$ out of the parentheses and link it with the 4 , with the object of simplifying the carrying out of the task.

Most fifth- and sixth-grade students across the United States are taught the "Please Excuse My Dear Aunt Sally" (PEMDAS) mnemonic, which is well known among U.S. middle-school teachers. Jeon (2012), however, has provided evidence that although preservice teachers tend to know the mnemonic, they do not know why it works, and many are not aware of additional caveats which need to be linked to it.

One such caveat is that if a calculation involves a combination of multiplications and divisions (and no other operations) then PEMDAS does not apply — but the operations should be carried out in the order in which they are listed, from left to right. For example, consider the sign $36 \div 4 \times 9$. If a student followed PEMDAS then the multiplication would come first, and the answer would be 1 . But the additional caveat requires that the division be carried out first, so the correct answer is 81 . How can fifth- or sixth-graders be expected to cope with a mnemonic 
with "extras" like that? Of course, there is a similar caveat for calculations involving addition and subtraction only-for example, $9-4+5$ equals 10 , and not 0 .

Such is the power of the PEMDAS mnemonic that if children in grades 5, 6, or 7 are asked to find the value of $97 \times 9+3 \times 9$ they are likely to carry out the multiplications first and then the addition. If the calculations are done accurately then a correct answer will be obtained, but students using that method have not attended to the structure inherent in the calculation.

Without number structure sense and with rigid memorization of the order of operations demanded by PEMDAS, students can not only get wrong answers for calculations, but also fail to learn important structural principles. Yet, a common-core progression document (Common Core Standards Writing Team, 2011) for "K, Counting and Cardinality; K-5 Operations and Algebraic Thinking” has specifically stated that Grade 6 students should be able to "discuss their reasoning more explicitly by focusing on the structures of expressions and using the properties of operations explicitly" (p. 35).

The Common Core Writing Team (2011) made it clear that they expect middleschool students to get to know the structural properties of rational numbers. Its team members also drew attention to the importance of parentheses when they wrote:

Parentheses are important in expressing the associative and especially the distributive properties. These properties are at the heart of Grades 3 to 5 because they are used in the Level 3 multiplication and division strategies, in multi-digit and decimal multiplication and division, and in all operations with fractions. (p. 27) 
The Writing Team (2011) went on to say:

Understanding and using the associative and distributive properties ... requires students to know two conventions for reading an expression that has more than one operation:

1. Do the operation inside the parentheses before an operation outside the parentheses (the parentheses can be thought of as hands curved around the symbols and grouping them).

2. If a multiplication or division is written next to an addition or subtraction, imagine parentheses around the multiplication or division (it is done before these operations). At Grades 3 through 5, parentheses can usually be used for such cases so that fluency with this rule can wait until Grade 6. (p. 27)

Although the Writing Team clearly recognized and attempted to address issues which were similar to those we have raised, it fell short of demonstrating a genuine understanding of the considerable semiotic difficulties involved. That is unfortunate because there is a danger that students whose teachers focus on the PEMDAS orderof-operations convention may fail to develop the kinds of structural thinking which was expected by those who developed the curriculum.

To reiterate, there is a likelihood that, for many seventh-graders, the sign “4 $\times\left(\frac{1}{4} \times 128\right)$ " will not be recognized as anything to do with a structural property of rational numbers. Rather, it will signify a quite different mathematical principle - that related to the mnemonic PEMDAS, by which the order in which a composite calculation is be carried out, is dictated by the words Parentheses, Exponent, 
Multiplication, Division, Addition, Subtraction, whose first letters can be combined to form PEMDAS. Since there are parentheses in the sign " $4 \times\left(\frac{1}{4} \times 128\right)$," the popularity of the mnemonic explains why seventh-graders might decide that they are expected to carry out the calculation within the parentheses first. In other words, they will attempt to find $1 / 4$ of 128 mentally, while holding the first 4 aside (mentally) for the moment. Then, if they succeed in reducing $\frac{1}{4} \times 128$ to 32 (which should not be taken for granted because calculations with fractions, even apparently simple ones, are notoriously difficult for many middle-school students), then there is still the task of remembering the stored " 4 " and the fact that this has to be multiplied by 32 . Then there is the mental task of carrying out that multiplication and obtaining 128. For most seventh-graders the cognitive load associated with this method is overwhelming.

The above discussion suggests that signs used in middle-school mathematics may signify different mathematical objects to different students. For many seventhgraders, the sign $4 \times\left(\frac{1}{4} \times 128\right)$ signifies a series of calculations for which the first calculation has to be $\frac{1}{4} \times 128$; but for some students, and hopefully for the teacher, the same sign signifies the need to apply a mathematical property by which the first mental decision is to associate the 4 and $\frac{1}{4}$. Of interest is whether instruction aimed at getting seventh-grade students to decide to proceed by the second route (that is to say, to link the 4 and $\frac{1}{4}$, first) will have the desired effect for most students. 


\section{What is an algebraic task for elementary and middle-school students?}

Some mathematics educators distinguish sharply between what they call "arithmetic" and "algebra." Luis Radford (2011), for example, has stated that "to make algebraic thinking appear, and to make it accessible to the students, some pedagogical conditions need to be created" (pp. 308-309). According to Radford (2011), "what characterizes thinking as 'algebraic' is that it deals with indeterminate quantities conceived of in analytic ways" (p. 310, original emphases). "In other words," Radford added, "you consider the indeterminate quantities (e.g., unknowns or variables) as if they were known and carry out calculations with them as you do with known numbers" (p. 310). Such a viewpoint seems to be quite traditional, despite Radford's subsequent attempt to argue that one does not really need to introduce a letter (or some other symbol) to be in the realm of algebra. Like many mathematics educators (e.g., Blanton \& Kaput, 2011; Cai, Moyer, Wang \& Nie, 2011), Radford tends to see algebra with elementary and middle-school students as being most beneficial, educationally, if it is placed in the context of sequences or modeling tasks in which the aim is to help students make decisions based on perceived patterns between varying quantities.

That said, Kaput (2008) argued for a wider view of algebra when he described algebraic thinking as having either or both of two ingredients:

1. Making and expressing generalizations in increasingly formal and conventional symbol systems; and

2. Reasoning with symbolic forms, including the syntactically-guided manipulations of these symbols. 
From this, Kaput (2008) called for school algebra curricula which, among other things, were based on the premise that algebra is the study of (a) structures and systems abstracted from computations and relations, and (b) functions, relations and joint variation. In the investigation described in this dissertation both of those aspects were inherent in the assessment instruments which were developed and used in the teaching interventions which were devised and used with seventh-grade students.

Researchers have argued that there are traditional, alphanumerical and nontraditional (non-symbolic/numerical) forms of algebraic thinking (see, e.g., Britt \& Irwin, 2011; Radford, 2011, 2015). In his recent research on algebraic thinking, Radford (2011, 2015) has mostly focused on non-symbolic algebraic thinking and its progressive transition to symbolic thinking. He has maintained that if a student generates a formula merely by guessing and checking, then that kind of naïve inductive thinking would not correspond to algebraic thinking (Radford, 2006, 2015).

In their work for the New Zealand Numeracy Project, Britt and Irwin (2011) argued along different lines from Radford. According to Britt and Irwin, students' awareness of numbers and operations structure can illustrate their algebraic thinking, even though pro-numerals are not involved. Borrowing the term "quasi-variable" from Fujii and Stephens (2001), they argued that often students' explanations of their thinking revealed that they were treating the numbers as if they were variablesprovided they were being used in signs which pointed toward particular structures, the numbers might be regarded as "quasi-variables" (Britt \& Irwin, 2011, p. 138).

Some readers might complain that although the investigation described in this dissertation is supposed to be concerned with algebra education, a task such as 
"Without using a calculator, find the value of $4 \times\left(\frac{1}{4} \times 128\right)$ " is in the domain of arithmetic and not of algebra. If one accepts the first of Kaput's (2008) ingredients, listed above, then that complaint is invalid. It can be argued that it is not necessary for a written mathematical task to involve manipulation of pronumerals to be an algebraic task. Recognizing that $4 \times\left(\frac{1}{4} \times 128\right)$ has the same value as $\left(4 \times \frac{1}{4}\right) \times 128$ demands knowledge of the essence (if not the formal name) of the associative property for multiplication of rational numbers (Sriraman \& Lee, 2011). There are various kinds and degrees of algebraic knowledge and, like Britt and Irwin (2011), Fried (2008), Fujii and Stephens (2001), Hewitt (1998), and de Saussure (1974), I do not believe that algebraic thinking can occur only in contexts in which pronumerals (e.g., $x, y, a, b$, etc.) are being employed.

The fact that $4 \times\left(\frac{1}{4} \times 128\right)$ is equal to $\left(4 \times \frac{1}{4}\right) \times 128$ can be regarded as something which follows from the associative property for multiplication of rational numbers; it is also the case that many seventh-grade students who can carry out an associative transformation may not be able to state, verbally, that the property that they have used is called the "associative property for multiplication."

In the study described in this dissertation an attempt will be made to see whether seventh-grade students, before participating in lessons emphasizing associative and distributive properties of rational numbers, have already learned to make associative and distributive transformations, with addition and multiplication (and subtraction with the distributive property). A second focus of the study will be to examine the extent to which seventh-grade students will improve their ability to 
recognize and make associative and distributive transformations as a result of participating in lessons aimed at helping them to do that. A third focus will be to ascertain whether some of the students will learn the formal names of the associative and distributive properties of rational numbers confidently and accurately.

Attention will be given, therefore, to whether, and when, the participating seventh-grade students could generalize sufficiently to able to recognize, almost instantly, that, for example: $9 \times\left(\frac{1}{9} \times 280\right)$ equals $1 \times 280$; that $(29 \times 15) \times \frac{1}{15}$ equals $29 \times 1$; and that similar transformations can occur with addition (e.g., $288+(12+$ $453)$ is equal to $(288+12)+453)$. Students who carry out such mathematically astute transformations without being prompted to do so by another person have learned to generalize, even though their generalizations may not involve pronumerals. In this dissertation this kind of generalizing from arithmetic will be regarded as a form of algebraic thinking. Although relatively few seventh-graders would be expected to be able to give, from memory, a formal verbal statement of, for example, the associative property for rational numbers - "for all rational numbers, $a, b$, and $c$, the value of $a \times(b \times c)$ is equal to the value of $(a \times b) \times c$, "- - decision by a student to transform $4 \times\left(\frac{1}{4} \times 128\right)$ to $\left(4 \times \frac{1}{4}\right) \times 128$ would represent a kind of thinking which, according to the CCSSM curriculum, might reasonably be classified as exhibiting "algebraic thinking."

Signs do not signify the same thing to everyone. It is obviously wrong to think that a sign will signify the same object to all persons. From that perspective although an intended curriculum statement, such as that provided by CCSSM (2010), 
might provide signposts which are intended to guide teachers and school authorities toward key ideas for school mathematics, readers of that curriculum statement may interpret signs in different ways. An indication that those who developed the CCSSM mathematics curriculum greatly valued structural aspects of school algebra was that they included a list of the so-called field properties for real numbers (the associative properties for addition and multiplication and the distributive property, are three such properties) in an appendix (or "glossary"). But they never made it entirely clear exactly when students should be able to recognize and apply the different properties, and when they should be able to state them, formally. Furthermore, published research has not provided much guidance on such issues, either.

We do not know if it is reasonable, for example, to expect seventh-graders to recognize, instantly, that $4 \times\left(\frac{1}{4} \times 128\right)$ is equal to $\left(4 \times \frac{1}{4}\right) \times 128$ or $1 \times 128$ or 128 . Nor do we know the proportion of seventh-grade students across the United States of America who would do that without prompting, or the proportion of seventh-graders who would recognize that the sign "Without using a calculator, find the value of $4 \times\left(\frac{1}{4} \times 128\right)$ " was inviting the application of the associative property for multiplication of rational numbers. Furthermore, we do not know the proportion of such students who can state, verbally and formally, the associative property for multiplication of rational numbers.

Similar statements to those made in the last paragraph are true for all the field properties for rational numbers. Although the authors of the common-core curriculum have recognized that the field properties are important in elementary and middle- 
school mathematics, they have not made clear the sequences in which such properties might reasonably be expected to be acquired by schoolchildren-and at which levels of formalism. From that perspective, the research described in this dissertation will break ground that has become hardened as a result of neglect over the years. The research will concentrate on seventh-graders' knowledge and understandings of the associative properties for addition and multiplication, and the distributive property for

multiplication over addition (and subtraction)—but, obviously, much more research is needed, involving various educational aspects of all the field properties.

The writer intends to adopt some of the language used by semiotic theorists such as Peirce (1992, 1998), de Saussure (1959), and Radford (2006). However, not all of the often highly complex, linguistic distinctions and terminologies introduced and advocated by those theorists have been regarded as relevant to the study.

\section{Semiotic Aspects of the Functional-Thinking Approach to Early Algebra}

In the study described in this dissertation all of the seventh-grade students participated in two separate interventions — one involved the structural approach to middle-school algebra and the other the functional-thinking or modeling approach. In this section, semiotic aspects of the modeling approach will be discussed.

We do not know whether most adults are able to give appropriate meanings to the signs, symbols, and conventions used in "tables of values" like the one shown in Figure 1. However, many algebra educators believe that before elementary and middle-school children can learn to think algebraically they will need to learn to interpret, and even to create, such tables. Thus, it is important to consider tasks like "Visiting Old Houses," which we now consider from a semiotic perspective. 
The "Visiting Old Houses" task. Seventh-grade students were asked to imagine that they went on a tour of old houses. They were told that it cost $\$ 5$ to register for the tour, and then $\$ 2$ extra for every old house visited - see the table in Figure 1.

\begin{tabular}{l|l|l|l|l|l|l|l}
\hline Number of Old Houses Visited & 0 & 1 & 2 & 3 & 4 & $\ldots$ & $n$ \\
\hline Total Cost (dollars) & $\$ 5$ & $\$ 7$ & $\$ 9$ & $\$ 11$ & $?$ & $\ldots$ & $? ?$ \\
\hline
\end{tabular}

Figure 1. Table associated with "Visiting Old Houses" task.

The students were then asked two questions:

1. What number should we place under the 4 in the table?

2. What do you think we should we put under the $n$ ?

The first and most obvious aspect of the composite sign represented by the table in Figure 1 is its horizontal form. In the study described in this dissertation the assumption that seventh-grade students would realize that the numerals in the "cells" to the right of the words "Number of Old Houses Visited" need to be related to the numerals in the cells immediately below the upper-level cells was investigated. Would the seventh-graders realize that there is a relationship between the numerical symbols in the upper cells, and the symbols representing the costs (in dollars) in the corresponding lower cells? That might be especially difficult for a child whose teacher had preferred to use tables of values which are presented in vertical rather than horizontal form. In such a case there could be confusion between the signifier and the signified.

In the top and bottom rows of the table in Figure 1 there are two cells which have three dots (...) and, by convention, these dots are intended to convey the idea 
that there is a "leap" toward generality. Thus, it is expected that the question mark beneath the " 4 " could be replaced by the symbol " $\$ 13$," and the pair of question marks beneath the " $n$ " by something like $\$(5+2 n)$. It was also hoped that students would be able to offer a reason (beyond guessing and checking) for why that should be the case.

At first, many of the seventh-graders did not know the convention represented by the three dots, and thought that the $n$ (in the last upper cell) represented 6 ("because $4+1+1$ equals 6"). In a similar way, they thought that the symbol "??" represented $\$ 17$ (“because $11+2+2+2$ equals 17 ”).

There are educationally significant assumptions that are built into numerical relationships represented in tabular form. Even if the conventions are known, the question whether seventh-graders are ready to make the cognitive leap needed to go from particular values associated with a recursive recognition of the sequence pattern to an explicit, generalized representation, like $\$(5+2 n)$, or $\$(2 n+5)$ in Figure 1 , is something which demands much relevant educational research. Is it reasonable to expect most seventh-graders to be able to make that leap? What kind of teaching will assist students to learn to make such leaps?

It should also be emphasized that the composite sign that makes up a table of values like that in Figure 1 comprises not just any, randomly-ordered and randomlychosen symbols. Clearly, Figure 1 originated from a "mathematical mind," and was designed to invite someone to make a generalization. No clue was given how the task was to be completed, except that a real-life scenario was well defined. This was an educational task, and those who developed it — Prof. E, Prof. F, and myself — were 
interested in finding out if seventh-grade students knew the meanings of the signifiers that defined the composite sign, and ultimately whether they could identify the mathematical object that was in the minds of the persons who developed the task.

There is also an issue about developing appropriate notations to represent correspondences between variables. If the cost for visiting $n$ old houses is denoted by $\$ C_{n}$, would it possible for most seventh-graders to learn to comprehend and write $C_{n}$ $=2 n+5$ ? Which is a better notation, from a curriculum perspective- the function notation $C(n)$, or the sequence notation, $C_{n}$ ? Or, would it be better merely to write something like $C=2 n+5$ ? And, do the answers to those questions depend on the ages or grade levels of students?

For this study it was decided that there would be an emphasis on helping seventh-graders to use the subscript (sequence) notation. Could seventh-graders learn to give appropriate meanings to the subscript notation, and could they be expected to develop the explicit equation $C_{n}=2 n+5$ ? Would it be reasonable to expect seventhgraders to develop and comprehend this subscript notation to such an extent that they could describe the relationship between the number of old houses visited and the cost recursively in the form $C_{n+1}=C_{n}+2$, with $C_{1}=7$ ? As far as this writer is aware, despite the large amount of research reported on young children's development of socalled "functional thinking," and despite recursive and explicit relationships being present in CCSSM algebra specifications, researchers have not provided answers to such fundamental curriculum questions. The study described in this dissertation will begin to provide answers, but much more research will be needed. 


\section{Radford's Comments on “Objectification” for Middle-School Algebra}

Luis Radford's (2003, 2004, 2006, 2011) discussions of semiotic means of objectification have been part of his attempt to provide a theoretical base with respect to how early-algebra students give meanings to symbolic algebraic expressions as they proceed from arithmetic operations to algebraic abstractions in tasks of the pattern and modeling variety. According to Radford (2003), the process of objectification takes place through three successive generalization processes which

finally produce what he calls "symbolic mathematical objects." Radford (2006) called his three processes "factual generalization" (p. 9), "contextual generalization" (p. 12), and "symbolic generalization" (p. 13). Of those three processes, he regarded the first two as pre-symbolic generalizations, and the third as true generalization. We now look at the meanings Radford attached to these three processes.

Factual generalization. With factual generalization, students do not go beyond particular figures, but realize that there are some commonalities between consecutive figures. Radford (2006) called a generalization of this kind an "arithmetic generalization" (p. 9). For example, in the pattern shown in Figure 2, a factual generalization would allow the students to find the number of matchsticks in any particular figure (e.g., Figure 10, or Figure 25, etc.) without counting the matchsticks one after the other. 


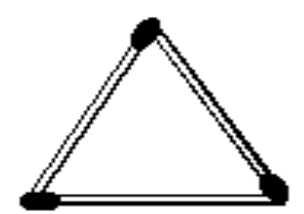

Figure 1

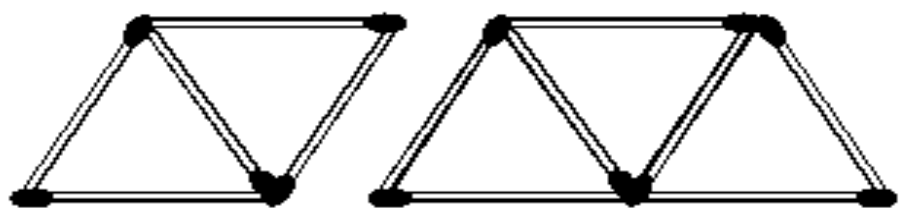

Figure 2

Figure 3

Figure 2. A sequence of figures inviting a generalization of a relationship between the number of a figure and the corresponding number of matchsticks.

Although these types of actions are abstracted in the form of a numerical scheme, Radford (2003) does not regard them as being in the realm of algebra. A process of generalization has begun, but thinking is still "in the realm of arithmetic" (Radford, 2006, p. 10), and a mathematical object has not been recognized and described. Thus, for the number of matches in Figure 10 say, a student might say, erroneously: "There will be 10 triangles, and since there are 3 matches for each triangle, there will be 30 matches altogether." Factual generalization will not always allow a student to explain accurately how to find the number of matchsticks in any figure or to find a formula for calculating the number of matchsticks in Figure $n$ (where $n$ is some unspecified natural number, or depending on the sequence, zero).

Contextual generalization. According to Radford (2006), contextual generalization occurs when symbols are given more concentrated meanings and there is a tendency to use fewer signs (words). For example, with respect to Figure 2, a student might say: "If you multiply the number of the figure by 2 and then add 1 you'll get the number of matches." Such a description includes a mixture of mathematical symbols and natural language. According to Radford (2006), with contextual generalization a sequence is identified verbally and relationships between a figure and the next figure are identified. 
Symbolic generalization. Radford (2006) maintained that at this third stage, students engage in multi-semiotic activities (i.e., making verbal statements or drawings, developing formulas, etc.), as they attempt to create symbolic generalizations. A student's thinking can shift between recursive thinking and explicit thinking, and it is at this stage that generalizations step into the realm of algebra. Radford (2006), after calling this process of noticing, "objectification," argued that it corresponds to an attempt to identify and describe a mathematical object (pp. 5-8). In its etymological meaning, "objectification becomes related to those actions aimed at bringing or throwing something in front of somebody or at making something apparent” (p. 5). With the matchsticks problem (see Figure 2), students can formalize a commonality and construct a standard algebraic syntax. They manage to write a formula representing the number of matchsticks in a "general" figure—as, for example, $n+(n+1)$ - where $n$ is the number of the figure in the sequence- or as $(n+n)+1$. At this level, learners may not be able to arrive at different symbolic representations, but even if they can, they might not consider the two expressions as equal because they represent two different sets of mental actions.

For Radford (2006), by its very nature a sign such as " $x+x+1$ ” can be counted as algebraic even though it is not expressed in standard form. This sign, Radford maintained, can be treated as general statement because the person who wrote it can see the general through the particular situation. The person has used alphanumerical symbolism and by doing so appears to be able to build an expression like " $n+n+3$," irrespective of whether the person can transform that into " $n \times 2+$ 3, , or " $2 n+3 . "$ 
Post-symbolic generalization. In the study described in this dissertation, each of the instruments, the interview questions, the pencil-and-paper testing, and the teaching intervention called for higher levels of objectification in the context of modeling situations. Two different types of algebraic syntax were used. The first asked students to identify and use a recursive formula in order to generalize; and the second asked them to identify, to notate, and to use an explicit formula. For both types, a subscript notation was required for the specifications. For example, for the matchsticks problem (see Figure 2), students were expected to learn to write an explicit specification with a subscript notation-like, for example, $M_{n}=2 n+1$. For a recursive specification, they were supposed to identify the rule (contextual generalization) and write the formula using signs and symbols with subscripts - for example, a recursive specification might look like " $M_{n+1}=M_{n}+2$, with $M_{1}=3$."

Symbolic generalizations and notations usually are first introduced in formal U.S. education settings in eighth- or ninth-grade algebra classes. The purpose of asking seventh-graders to learn to comprehend and use complex symbolic notations in the study described in this dissertation was to investigate whether the students could cope with them in the course of making algebraic generalizations.

\section{Some Scholars' Preference for the Functional-Thinking Approach}

Luis Radford (2006) is one among many recent scholars to display a strong preference for adopting what they call the "functional-thinking approach" to early algebra education (see also Blanton, Brizuela, et al., 2015; Blanton, Stephens, et al. 2015; Cai et al., 2011; Carraher, Schliemann, \& Schwartz, 2008; Moss \& McNab, 2011). This approach is consistent with the common-core expectation that sixth- 
graders should learn to "use variables to represent two quantities in a real-world problem that change in relationship to one another; write an equation to express one quantity, thought of as the dependent variable, in terms of the other quantity, thought of as the independent variable." Students should learn to "analyze the relationship between the dependent and independent variables using graphs and tables, and relate these to the equation" (CCSSM, 2010).

Although the investigation described in this dissertation included a strong component relating to the functional-thinking approach in early-algebra education, the study did not confine itself to that interpretation of early algebra education. Adopting the ideas of Britt and Irwin (2011), a structure approach to early algebra was also incorporated into the study. With some tasks, algebraic concepts were introduced without variables denoted by letters such as $x$ and $y$ being introduced. The emphasis in this approach was on assisting seventh-grade students to learn to recognize and use (a) the associative properties for the addition and multiplication of rational numbers, and (b) the two aspects ("expanding parentheses" and "factoring") of the distributive property for rational numbers. As stated earlier in this chapter, the structural aspect of early algebra has received much emphasis in the common core curriculum for elementary and middle-school grades (CCSSM, 2010).

This present study attempted to place both the functional thinking and the structure approaches to early algebra under the semiotic umbrellas provided by both Peirce (1998) and de Saussure (1959). It also took advantage of the cognitivestructure literature developed by Johann Friedrich Herbart (1898), David Ausubel (1968), Robert Gagné (see Gagné \& Merrill, 1990; Gagné \& White, 1978) and 
Shlomo Vinner (see, especially, Tall \& Vinner, 1981; Vinner \& Hershkowitz, 1980; Vinner \& Dreyfus, 1989), which emphasized the concept of "apperception" or the "cognitive structure" or the "concept image" construct. We now outline an attempt to link semiotic theory and cognitive structure theory with the two dominant thrusts that can be found in the early-algebra and middle-school algebra literatures.

\section{Signs, Symbols, Representations, Cognitive Structures and Individual Learners}

In one of his many definitions of a sign, Charles Sanders Peirce (1998) distinguished between a sign, the object which is being signified, and an interpretant of the sign. He wrote:

I define a sign as anything which is so determined by something else, called its object, and so determines an effect upon a person, which effect I call its interpretant. (p. 478)

Peirce claimed that signs consist of three inter-related parts - a sign, an object, and an interpretant (Campos, 2010). We can think of the sign as the signifier, for example, a written word or calculation, an oil painting, etc. The object, on the other hand, can be thought of as being whatever is signified—like, for example, the meaning of a written sentence. The interpretant, a distinctive feature of Peirce's account, is best thought of as the understanding that a person has of the sign/object relation.

Peirce's introduction of the concept of an "interpretant" draws attention to the fact that a sign can mean different things to different people who are attempting to interpret its meaning. Thus, for example, on seeing $4 \times(1 / 4 \times 128)$ a seventh-grade student might immediately think "PEMDAS - I've got to do what's in the parentheses first." But, 
another student, on seeing the same sign, might immediately think: "I've got to associate the 4 and $1 / 4$, and when I multiply those I'll get 1, which will then be multiplied by $128 . "$ A third student might think: "OK — the teacher wants to see if I recognize that the associative property for multiplication should be used." Clearly, the second and third ways of thinking are, from a mathematical perspective, preferable to the first, and that judgment introduces an educational aspect to semiotics. In the realm of school mathematics, a curriculum statement carries the expectation that learners will learn to give appropriate meanings to signs, where the word "appropriate" is to be interpreted as meaning "consistent with the goals of the curriculum." Seen from that perspective, a major task of teachers of mathematics is to assist learners to recognize signs, give the signs appropriate meanings, and then do the mathematics demanded by what is signified in the tasks in which the signs are present.

If we regard mathematics education as a sequence of processes by which students learn to recognize signs, process their meanings appropriately, and then respond to tasks, and even create tasks, in which the signs are used, then it becomes important to study how different students process signs (“inputs'). But that raises the question why students process the same sign in different ways. The salient point, of course, is that with respect to any concept it is likely that different students will have different "cognitive structures," and that fact will result in their interpreting the signs in different ways.

A historically influential string of theories, which greatly influenced the writer's planning for the study, derived from the writings on "apperception" by Johann Friedrich Herbart, the eighteenth- and early nineteenth-century German scholar, and from theories related to Herbart's apperception put forward by David Ausubel (in the 1960s), Robert 
Gagné and his co-workers (during the period 1975-1995), and Shlomo Vinner and his coworkers (in the 1980s).

According to Herbart (1898), a good teacher should, when planning lessons, consciously try to take account of existing cognitive understandings and relationships that can be assumed to exist in learners' minds. For Herbart, a learner's apperceptions with respect to a concept has been generated by the pool of antecedent experiences which that learner has had. The implication for school education is that a teacher should become fully acquainted with the mental development of pupils, in order that advantage can be taken of what the pupils already know, and of how they think. A problem arises, of course, from the fact that there are many students present in school classrooms, and a teacher cannot be expected to know how each of the pupils will think with respect to what is about to be taught.

Nevertheless, Herbart maintained, in addition to clarifying expected cognitive outcomes for a lesson, or series of lessons, teachers should reflect on, and build into lesson plans, the relevant knowledge, skills, images, beliefs, and principles that their students have already acquired, so that their readiness to learn what is on the agenda for any particular lesson will be enhanced. In the 1890s and early 1900s that idea was held to be of central importance by Charles De Garmo (1900), at Illinois State Normal University — which became the center of Herbartian studies in North America (Dunkley, 1970). Many years later, some of Herbart's ideas were taken up by David Ausubel (1968) who advocated that teachers should build "advance organizers" into lessons plans, in order to create and synthesize cognitive structures, in the relevant learners' minds, which were sympathetic and meaningful with respect to what was to be learned. Accordingly, 
Ausubel (1968) wrote: "The most important single factor influencing learning is what the learner already knows. Ascertain this and teach him accordingly" (p. vi).

During the course of a mathematics lesson a learner can be confronted with an abundance of signs that are intended to represent, or signify, curriculum-relevant mathematical concepts, skills and principles. Herbart, with his theory of apperception, contended that different learners will interpret the same signs in different ways, depending on how their minds are initially structured with respect to the signs. During the period 1975-1995 Robert Gagné and his co-workers (see, e.g., Gagné \& Merrill, 1990; Gagné \& White; 1978) maintained that a learner's working memory comprises a unique set of components which include:

- Verbal knowledge (e.g., the definition of an equilateral triangle);

- Intellectual skills (e.g., how to "complete the square" with quadratic expressions);

- Imagery (e.g., a visual image of an isosceles triangle);

- Episodes (memories of personal events-e.g., remembering a particular occasion when the learner scored 0 out of a possible 20 on a test on fractions); and

- Attitudes toward aspects of the input.

According to Gagné, a learner's processing of an input will depend critically on the interaction, within the learner's mind, of the input with that learner's uniquely-configured cognitive structure. As a result of the interaction of input with cognitive structure, an idiosyncratic restructuring of the mind can occur. In a class of 20 learners a teacher might expect 20 different restructurings, depending on internal reactions to the sign inputs (see, 
e.g., Mackenzie \& White, 1982). In mathematics education in the 1980s, the related idea of a concept image (Vinner \& Hershkowitz, 1980) was accorded center stage.

Vinner and his coworkers (Tall \& Vinner 1981; Vinner \& Hershkowitz, 1980;

Vinner \& Dreyfus, 1989) contended that idiosyncratic and unique links in an individual learner's cognitive structure determine that learner's concept image with respect to any sign. Furthermore, if a teacher attempts to use the sign to convey a mathematical concept or principle to students then it is likely that that sign will be interpreted in as many ways as there are students in the class. That viewpoint was emphasized in a series of mathematics education research investigations conducted in the 1980s (e.g., Dreyfus \& Eisenberg, 1982; Vinner \& Dreyfus, 1989). In those studies, student thinking within important content areas of school mathematics (e.g., fractions, functions, limits) were analyzed with respect to concept definitions and concept images (Clements, 2014). All of the concept-image researchers used the term "concept image" in a way which was totally consistent with Herbart's (1898) theory of apperception. In the words of Tall and Vinner (1981):

We shall use the term concept image to describe the total cognitive structure that is associated with the concept, which includes all the mental pictures and associated properties and processes. ... As the concept image develops it need not be coherent at all times... We shall call the portion of the concept image which is activated at a particular time the evoked concept image. At different times, seemingly conflicting images may be evoked. Only when conflicting aspects are evoked simultaneously need there be any actual sense of conflict or confusion. (p. 152) 
What might this mean in a seventh-grade mathematics classroom? Consider, for example, the concept image that a seventh-grade student, John say, might evoke when exposed to the sign "Without using a calculator, find the value of $4 \times\left(\frac{1}{4} \times 128\right)$." Imagine that during the initial exposure the following "inner" conversation took place in John's mind: “Oh, it's a calculation, and there are parentheses involved. We had this kind of problem a couple of weeks ago, and I got full marks on the test. I'll have to use PEMDAS — which means that I'll have to work out what's inside the parentheses first. Oh no, it's a multiplication sum involving a fraction. I hate fractions. How will I find 1/4 times 128? When I was in Grades 4 and 5 Mr. Jones and Mrs. Tomlinson taught me to think of $1 / 4$ as being one piece of a circle after it has been divided into four equal pieces. Hmm ... we'll need 128 of those smaller bits. How can I do that? Oh, that's right, I've got to multiply $\frac{1}{4}$ by 128 and if you want to do that the first thing you should do is write the 128 as a fraction. So it'll be $\frac{1}{4}$ times $\frac{128}{1}$. How can I do that? ...”

Notice that in this imaginary inner conversation, John's thinking was initially captured by the sign $(1 / 4 \times 128)$. The mnemonic PEMDAS was not mentioned in the question, but the parentheses prompted John to think about PEMDAS. This was linked to, indeed reinforced by, John having successfully applied PEMDAS on a recent test—which is an example of what Gagné and White (1978) called "episodic" thinking. Then the issue of skills arose in John's mind—how could he find $\frac{1}{4}$ times 128 ? This prompted John to recall another earlier episode in which he had represented $1 / 4$ by a circular region- Gagné and White (1978) would have regarded this as evoking a visual image— - but then John 
struggled with the idea of finding what 128 of the circular regions would be. Within his sequence of thought he had cause to reflect that he "hated fractions."

In the above description of an imagined scenario, the sequence and content of the thinking stimulated by the sign " $4 \times\left(\frac{1}{4} \times 128\right)$ " involved:

- Memory of verbal information (concerning PEMDAS);

- An attempt to recall appropriate skills ("How do I find the value of $1 / 4 \times$ $128 ? ")$;

- Memory of a relevant past episode (getting a perfect score on a test);

- Imagery (evoking a circular region in the mind to represent a fraction);

- Expression of an attitude ("I hate fractions").

Although the above discussion is not based on data generated by an actual student, in the study described in this dissertation similar data were, in fact, generated, and analyses of those data enabled important features of seventh-grade students' concept images, for both elementary algebraic structures and for modeling real-world situations using algebra, to be identified. Furthermore, the design of the study enabled salient features of concept images to be identified for each participating student, both before and after teaching interventions, and with respect to both algebraic structure and functional thinking. One of the aims of the study was to be able to describe effects of the teaching interventions on concept images.

Seen from the vantage point of observing students in a seventh-grade algebra classroom, it is not difficult to reconcile the concept of apperception, and its application to analysis of educational data, with semiotic theories. Marx Wartofsky (1979), a philosopher and historical epistemologist, emphasized that what one 
notices, and what escapes one's attention, depend to a large extent on one's cultural, educational, and episodic backgrounds. In other words, what an individual notices in a particular context depends on the cognitive structure of the working memory that the learner brings to the context. Thus, for example, with regard to the second question in Figure 1, in which the "Visiting Old Houses" task was elaborated, seventh-grade students who had never been exposed to tables in which they were expected to make a cognitive leap to the " $n$th case" obviously wondered what they were being asked to do. They wondered, with strong justification, why there was a "space" in the table. For their mathematics teacher, however, the spaces in the table in Figure 1 were signs which invited the reader to enter a world of generalized mathematical objects. Seen from that perspective, the composite sign in Figure 1 could signify to the seventh-grade students the mathematical object which the teacher would like it to signify only if the intended meaning of the sign had been learned by the students. And, even if that sign had been learned by a student, there was no guarantee that that student would always interpret the sign according to what he or she had learned.

Thus, the issue becomes an educational one. An exactly similar argument can be constructed with respect to the composite sign, discussed earlier: "Without using a calculator, find the value of $4 \times\left(\frac{1}{4} \times 128\right)$." An individual seventh-grade student's cognitive structures must have a large influence on how that student links signs and symbols in early algebra to mathematical objects that are specified in the curriculum. An important role for the teacher is to provide experiences for students which will extend and coordinate their cognitive structures so that they will learn to recognize, 
comprehend, and use standard signs and conventions which underlie knowledge, concepts, skills, and principles which are represented in intended curricula (Herbart, 1898).

\section{Literature Which Helped Frame the Design of the Teaching Intervention}

In preparation for the main study two large pilot studies were carried out (Kanbir, 2014, 2016). The second of those studies involved three classes of seventhgrade students and one teacher-who was the day-to-day mathematics teacher for each of the classes (Kanbir, 2016). The following three important lessons were learned as a result of analyzing data from the pilot study:

1. It should not be assumed that seventh-grade teachers and students are ready to use sixth and seventh-grade CCSSM content standards with respect to algebra.

2. The fact that the student participants in the pilot study were not randomly allocated to groups meant that the three groups differed in their initial knowledge and understandings of algebraic notations and concepts, and this could have had an impact on the students' reactions to the intervention lessons. This realization pointed to the need for random allocation to intervention groups in the current study.

3. The method of professional development for the teacher in the pilot study was one-on-one instruction based on notes that had been especially prepared for the occasion. As it turned out, the volume and the complexity of the material tended to be overwhelming for the teacher. 
I have also come to believe, somewhat counter-intuitively, that the difference between arithmetic and algebra cannot be specified entirely in terms of notations, and that algebraic reasoning is not confined to activities which make use of pronumerals. In the current study, I examined two contexts in which, it seemed to me, algebraic reasoning occurred. In some of the tasks in the first context, algebraic thinking took place without the presence of pronumerals; and in the second context, pronumerals were used to denote variables representing independent and dependent variables. Even though the timing of the intervention was relatively short in comparison with many longitudinal studies — the total data-collection period occupying just 24 weeks - it was interesting to investigate the growth of algebraic thinking toward generalization during that period. In particular, I set out to find evidence on the issue of whether structural thinking supports functional thinking, or vice-versa (or neither).

For the current study, which was not conducted at the same school as the pilot study, it was decided that a "modeling" approach to professional development, along the lines suggested by Joyce and Showers (2002), would be adopted. The two participating teachers (Mr. X and Mr. Y) agreed to observe experienced mathematics educators (Prof. E and Prof. F) teaching Grade 8 students in the same school as the study would be conducted, and they would then model their teaching of their seventh-grade classes on what they had observed.

The teaching method which would adopted by the mathematics educators, when preparing the model lessons, was based on the "Modes of Communication" approach (see Table 2) developed by Del Campo and Clements (1987, 1990), and reported in Ellerton 
and Clements (1991). By this approach two forms of language-receptive and expressive-were distinguished, and the aim was for the model lessons to show how expressive language forms could become central in middle-school algebra classrooms which dealt with the structure and functional-thinking approaches to middle-school algebra (see Table 2). Receptive language involved the "processing of someone else's communication" and expressive language the use of one's "own language" (Ellerton \& Clements, 1991, p. 109).

Table 2

Receptive and Expressive Modes of Communication (Del Campo \& Clements, 1987, p. 12)

\begin{tabular}{ccc}
\hline Language Mode & Receptive Language & Expressive Language \\
\hline Spoken & Listening & Speaking \\
Written & Reading & Writing \\
Pictorial & Interpreting diagrams, & Drawing \\
& pictures & \\
Active & Interpreting others' actions & Performing, Demonstrating, \\
& & Problem Solving \\
Imagined & - & Imagining (Creating), \\
& & Problem Posing \\
\hline
\end{tabular}

An important aim of the study described in this dissertation was for all participating seventh-grade students not only to learn to use appropriate expressive language in the course of developing early-algebra concepts and principles related to the associative properties and the distributive property for rational numbers, and to modeling real-life contexts, but also to want to use that language when it was appropriate to do so. By developing a sense of ownership of their learning, it was 
hoped that the students would move significantly toward the reification of key earlyalgebra ideas (Sfard, 1991).

The main purpose of the model lessons would be to show how beginning algebra students could become engaged in expressive activities which would assist them to learn to interpret and recognize and use the main "signs" of early algebra, especially those relating to "structure" and "modeling," appropriately. Learners would be expected to become actively, meaningfully, and creatively engaged in the construction of appropriate concepts, relationships, and principles, to the point where they would feel some ownership of the mathematics that they were studying. The students would regularly be given the opportunity to discuss ideas and concepts in small groups, to construct answers, to pose problems, and then to report their findings to others in their class. They would be invited to own the mathematics, and it was hoped that they would feel that it was a natural thing that they should attempt to convince others of the sense and value of what they were learning.

With the semiotic view, an ultimate form of algebraic knowledge is to be associated with objectification (Radford, 2008). This process of mathematizing involves various levels of awareness and is manifested by signs such as words, gestures, pictures, graphs and symbols. In the study described in this dissertation, the research team created and implemented algebraic tasks and observed seventh-grade students using variables and quasi-variables in expressive classroom environments. In the process, the students were expected to go through different layers of semiotic awareness (Radford, 2011). 
This view of teaching is consistent with Anna Sfard's (2008) theory of commognition in which explanations, interpretations, definitions, etc., become part of an attending/intending flow with at least three aspects.

1. Learners are to be engaged in observing, interpreting, experiencing and explaining;

2. Teachers point learners towards an object, the acquisition of which might be thought of as the aim of the teaching/learning exercise; and

3. The processes of interpreting, observing, explaining constantly involve constructive mental activity for learners. (Sriraman, 2009)

The workshop environment provided in the current study also passed muster on each of the five dimensions that Alan Schoenfeld (2013) claimed mark the robustness of a classroom learning environment-(a) its mathematical focus, (b) its cognitive demand, (c) the support it provides to the diverse range of students in the class to be actively engaged, (d) its agency (the extent to which it provides opportunity for students to make conjectures, give explanations and arguments, and to develop "voice"), and (e) its use of assessment which challenges students to reason.

Before the current study took place the research team did not assume that all, or even most, of the seventh-grade participants would make great progress with generalizing. The sparse literature on student understandings of the structural properties of real numbers had not convinced the team that students would make much progress in the relatively brief time — three weeks — that would be devoted to structure. So far as the effects of the modeling workshops were concerned, Lannin, Barker and Townsend (2006) reported that some students found it difficult to move from the successful use of recursive 
rules to explicit rules, and that students often preferred to develop, and continue to use, recursive rules. Would that description also apply for students in the current study?

\section{Research Questions}

Having completed the pilot study, having prepared relevant pencil-and-paper materials, and artifacts, and having been part of Prof. E's, Prof. F's and my teaching in which those materials were used with eighth-grade students at School W, I framed the following six questions which, after discussion with other members of the research team, were accepted as the questions to be addressed in the main study:

1. What did the participating Grade 7 students know about each of the associative property for addition, the associative property for multiplication, and the distributive property, before the intervention lessons took place?

2. To what extent were the Grade 7 participating students able to recognize patterns and to model relationships by using variables before the intervention lessons took place?

3. What changes in the knowledge and understanding of participating students with respect to structure and modeling were evident in the middle of the intervention period (when either the structure or the modeling lessons were completed, but not both)?

4. Immediately after both groups had participated in both the structure and modeling workshops, were there statistically significant differences between the two groups' mean gain scores in structural understanding and modeling? Also, what were the Cohen's $d$ effect sizes for the two groups for the first half and for the second half of the intervention? 
5. Immediately after both the structure and modeling workshops were completed, were there educationally noticeable differences between the concept images of the students, with respect to the concept of a variable, in comparison with the concept images that the students had before the intervention began?

6. Twelve weeks after both the structure and modeling lessons were completed were there statistically significant differences between the two groups' mean gain scores with respect to the retention of what had been learned in regard to structural understanding and modeling?

Further discussion of these research questions will occur in later chapters of this dissertation, and in the final chapter summary answers will be given to each of the six questions. 


\section{CHAPTER III \\ RESEARCH DESIGN AND METHODOLOGY}

Planning for the current study was strongly influenced by the design research literature (see, e.g., Brown, 1992; Clements, 2011; Kelly \& Lesh, 2000; Kelly, Lesh \& Baek, 2008). This chapter begins with commentary on the concept of design research, in general, and on its application to the current study. Then, following the commentary on design research, the design of the current study is outlined.

\section{Design Research}

Design research approaches to education research and development have emerged from considerations of planning and design methods used by teams of architects and engineers preparing to carry out major design projects. The research team for the current study had identified a problem which was not in the domain of architecture, or in the field of engineering — but in the realm of mathematics education. The design team set out to choose a theoretical frame which would shed the most light possible on the best form of actions that could be taken in order to illuminate, and ultimately to solve, the problem. The team would not only need to develop and implement an actual intervention program, but also an objective scheme for evaluating the effects of the intervention.

Obviously design research in mathematics education should not be regarded as involving theory-free or culture-free activity. That said, the theory, or theories to be used, should be chosen to fit the problem, and not the reverse. 
The decision to adopt a design-research approach for the current study was not made lightly for, as Cobb, Confrey, diSessa, Lehrer and Schauble (2003) have emphasized, design research has a "highly interventionist nature" (p. 10). According to Stylianides and Stylianides (2013), that there is "a high correlation between classroombased interventions and studies following design experiment methodology should not come as surprise" (p. 336).

The preparation phases for design-research mathematics classroom studies include a range of carefully-designed steps aimed at facilitating the ultimate goal of supporting the learning process and addressing problematic mathematics teaching and learning issues. Teachers should be involved for they have important roles in the production of knowledge relating to teaching and learning. Borko (2004) insisted that the design of interventions should bring researchers and other stakeholders together, through multitiered designs, so that they will be best placed to adapt and refine existing professional-development programs and be able to study the impacts of, and on, individual teachers and student outcomes. As Lesh and Sriraman (2005) have asserted, design research has the potential to develop useful knowledge about mathematics education and to provide support for policy makers and curriculum and instructional designers.

Ann Brown (1992), of the University of California at Berkeley, was one of the pioneers of design research studies in education. Her Theoretical and Methodological Challenges in Creating Complex Interventions in Classroom Settings considered those types of education research studies in which real instructional environments (contexts and materials) are deliberately modified. According to Cobb and Gravemeijer (2008), 
the primary goal is not to demonstrate or assess whether the envisioned learning hypothesis works - rather, they argued, "the purpose is to improve the envisioned trajectory developed while preparing for the experiment by testing and revising conjectures about both the prospective learning process and the specific means of supporting it" (p. 73). With the study described in this dissertation-that is to say, "the current study" - the main goal was not to compare two different approaches to middleschool algebra, which, in Slavin's (2004) terms, would be merely be an " $x$ versus $y$ comparison" (p. 27). Rather, the aim was to improve teachers' and researchers' knowledge about middle-school algebra teaching and learning. In order to do that, relevant quantitative and qualitative data would be gathered, analyzed, and interpreted.

In the current study, members of the research team were not only involved in the selection of the most appropriate theories which would be utilized, but also in deciding how those theories should influence the planning, intervention, and evaluation phases of the study. The theoretical frames chosen for the study were outlined in the previous chapter.

As a researcher, I needed to know the "starting points" of the participating students in order that I would be well-placed to investigate their development of “increasingly sophisticated forms of data-based reasoning" (Cobb \& Gravemeijer, 2008, p. 73). I needed to be in a position to document the shifts in the seventh-grade students' algebraic reasoning, and to do that I knew that I would need multiple data sources (e.g., from interviews, classroom observations, questionnaires, and preteaching, mid-intervention, post-teaching, and retention performance data). In order to achieve all of that, it would be necessary to gather and analyze both quantitative and 
qualitative data. That approach is in line with the position that the development of sound methods for algebra teaching and learning should especially look to the findings of mixed-method research.

\section{Setting up the Intervention}

\section{Two Pilot Studies}

As part of the preparation for the main study I conducted two pilot studies with seventh- and eighth-grade students, and their mathematics teacher, in a middle school in the midwest of the United States of America. The school at which the pilot studies were conducted was not School W, where the current study would be conducted. These pilot studies took place during the fall of 2014 and the spring of 2015.

\section{The first pilot study: Two different approaches to the concept of a variable.}

In the first pilot study, the researcher created two instruments — one made use of visualnumber patterns, and the other of structural properties of rational numbers. Task-based interviews were carried out for the purpose of identifying the ways the participating eighth-grade algebra students tended to think about important algebra concepts and operations — such as a variable, generalization, and algebraic structure. Data were collected from 76 eighth-grade students enrolled in algebra and pre-algebra courses. The main pencil-and-paper research instrument comprised 25 items: 7 were concerned with the concept of a variable, 9 with generalizing from visual-number patterns, and 9 with the structural properties of rational numbers. One of the research questions was to find the Pearson product-moment correlation between scores on the subtests comprising the three types of items. In addition, data from task-based interviews were analyzed for 
the purpose of examining, qualitatively, the ways the students thought about key aspects of elementary algebra.

Analysis of data from the first pilot study revealed that correlations between the scores on the subtests comprising the three types of items were low. That finding suggested that middle-school algebra programs based entirely on numerical or geometrical patterns, or entirely on structural aspects of rational numbers, would be inadequate. Analysis of data from six 30-minute interviews showed that the eighthgrade interviewees rarely viewed or used algebraic expressions as mathematical entities in their own right. Most of the students maintained operational views and had great difficulty generalizing. In modeling contexts, they struggled to develop even apparently simple recursive rules.

As part of the first pilot study, the researcher also created an Algebra Readiness Test (ART) which was intended to measure eighth-grade students' readiness to begin studying secondary-school algebra. The Cronbach alpha reliability index for this $A R T$ instrument was 0.84 . But, $A R T$ was not used in the current study, so did the first pilot study have any influence on the current study? The answer to that question is "Yes."

The first pilot study was useful insofar as it alerted the writer to the fact that some eighth-grade students are not in the least aware of structural properties of rational numbers. Hung-Hsi Wu, a University of California at Berkeley mathematician, may well have overstated his case when, in 2007 , he claimed that "by the sixth grade most students already know about the associative and commutative laws of addition and multiplication" (p. 4). 
The first pilot study also provided the writer with experience in interviewing middle-school students, and during the interviews it became clear to the writer that some eighth-graders did not understand notations for representing sequences — and that without prompting, they might struggle to identify even simple recursive patterns that one might have expected they would be able to identify easily when examining given tables of values. Furthermore, none of the six interviewees - two of whom were regarded as top students - was able to identify explicit rules to describe patterns implicit in given tables of values.

\section{The second pilot study: Three different approaches to developing seventh-} grade students' algebraic reasoning. The second pilot study, which was held at the same school as the first, lasted 10 weeks. The study applied three different intervention approaches with students in three seventh-grade classes at a midwestern middle-school. The seventh-grade mathematics teacher at the school was also an active participant. During the period of research for the second pilot study, each of the classes followed a different approach to algebra - these approaches were termed "visual-number," "modeling," and "structural."

The study explored how instruction incorporating the three different approaches to elementary algebra affected student thinking about algebra. Pre-teaching and postteaching pencil-and-paper data were collected, the instruments being the Algebra Readiness Test (the test instrument developed in the first pilot study), a Visual-Number test, a Modeling test, and a Structure test. Eighteen students (six from each of the three classes) were interviewed on a 1-1 basis, on two occasions, with the interview protocol recommended by Newman being used (see Clements, 1980). The goal of the interviews 
was to ascertain how the students were thinking about task-based, pencil-and-paper algebra tasks and to investigate the students' functional and structural thinking before and after the classroom interventions.

Analyses of data from the second pilot study indicated that whereas the mean gain scores for the modeling and visual-number groups were significantly different from zero, the mean gain score for the structure group increased only slightly. Analysis of data from this pilot study suggested that for each of the three groups there was no statistically significant difference between pre-test and post-test scores for "algebra readiness." Such a statement is made with a degree of caution, however, because this second pilot study did not feature random allocation to groups, and the "modeling" class was regarded, within the school, as having the best seventh-grade algebra students in the school.

Analysis of interview data generated by the second pilot study indicated that as a result of participation in the intervention lessons there were changes in students' concept images of a variable and in their understanding related to the meaning of expressions and equations (Kanbir, 2016).

For the second pilot study, students worked in whole-class environments and the teacher's instruction was mostly direct and not dialogic. The researcher, who observed all the lessons, believes that the students would have learned more if there had been more challenging interactions between the students and the teacher.

Although both pilot studies generated informative data, it became clear that a different teaching approach, and a new approach to professional development, were needed for the current study. My participation in the pilot studies was nevertheless 
important for it enabled me to practice different data-collection and interview techniques. A total of 42 interviews were conducted, and I participated in intensive professional development sessions, observed classrooms, analyzed student artifacts, and took many notes. This allowed me to become more confident in qualitative datacollection techniques. Also, I was able to evaluate, and modify, instruments, and plan lesson sequences, professional development sessions, and the interview protocol for the current study (Kanbir 2016).

One of the most important general findings arising from the pilot studies was that it could not be assumed that seventh-grade students would know much about the structural side of rational numbers or about the concept of a variable. When solving linear equations, the pilot-study students tended to adopt a "find the missing number" approach which, incidentally, was advocated in the common core mathematics curriculum. By such an approach, an equation like $3 x+1=13$ will be interpreted as "what number should I put in the place of $x$." A more productive approach, the research team believed, was to regard the $x$ in $3 x+1=13$ as a variable, and the task of solving the equation was to find the value (or values) of $x$ which will make the equation a true statement (Ellerton \& Clements, 2011).

Another finding from the pilot studies was that there did not seem to be much commonality in the ways students thought about structure tasks and about modeling tasks in which they asked to identify rules for given patterns. In other words, although both came under a "beginning algebra" umbrella, the two types of tasks seemed to require fundamentally different kinds of thinking. Recognition of that state of affairs seemed to be important, because there is only so much time allowed for algebra in 
middle-school mathematics programs. It seemed likely that students following mainly an algebra curriculum which focused on structure would not learn the same things as students who followed a modeling curriculum which focused on patterns and relationships. Would it be possible to achieve a balance whereby students developed their knowledge and understandings for both kinds of algebra? Might there be an approach whereby the two types of algebra would be linked? After much reflection, the research team decided that the concept of variable was equally important within both approaches, and that recognition seemed to provide a key for bringing the two components of middle-school algebra together.

\section{Preparing for the Current Study}

In an attempt to be well placed to understand interactions between classroom practice and student learning in the current study, it was decided that an experimental group design should be used. It is well recognized that randomly assigning students to study groups is a signature characteristic of true experimental intervention studies in education (Campbell \& Stanley, 1963; Gersten, Baker \& Lloyd, 2000), and so it was decided that if School W would agree to it, random allocation of students to experimental groups would be a feature of the study design.

In a typical school setting it is not easily to achieve random allocation to groups for a research study — for that is usually at odds with standard organizational requirements of the school. More than half a century ago, Campbell and Stanley (1963) argued that the education research community was struggling with ways to negotiate a balance between rigorous research design and satisfactory research in school classroom environments. 
The problem identified by Campbell and Stanley has never gone away, and in 2002 the Institute of Education Sciences established the "What Works Clearinghouse" (WWC) with the primary goal of assessing the quality of research. For education research, the WWC made a strong commitment to the randomized trial, which was the only method which met its standards without reservation (Schoenfeld, 2006). Indeed, Grover J. Whitehurst (2003), a former director of the Institute of Education Sciences, maintained that "randomized trials are the only sure method for determining the effectiveness of education programs and practices" (p. 6).

Conducting a high-quality intervention teaching and learning study using an experimental design is a complex matter. Any number of factors other than the intervention could cause changes in outcome measures. Campbell and Stanley (1963) listed some threats to internal validity (e.g., events can happen between the first and second measurement which can affect measurement of the experimental variable). Other threats include maturation, instrumentation, statistical regression, biases, experimental mortality, the Hawthorne effect, and selection-maturation interaction. As Trochim and Land (1982) argued, good research designs should minimize probable alternative explanations for any hypothesized cause-effect relationships. Trochim and Land called these types of methodological challenges "threats," and one of the biggest threats in a random-allocation study is that the groups may have initial (pre-teaching) performance assessment differences.

At the beginning of the current study the 32 seventh-grade students at School W were randomly allocated to two groups, and the research team agreed to adopt Campbell and Stanley's (1963) criterion that the difference between the mean score of 
the two groups on a relevant pre-teaching measurement should not exceed one-half of a standard deviation. Table 3 summarizes pre-teaching algebra data for the current study (maximum possible score was 20). Clearly, Campbell and Stanley's criterion requirement was met.

Table 3

Pre-Teaching Algebra Test Mean Scores, Standard Deviations (SD), and Difference of SDs

\begin{tabular}{lcccc}
\hline Group & $\begin{array}{c}\text { Number of } \\
\text { students } \\
\text { (Overall, } \\
n=32)\end{array}$ & $\begin{array}{c}\text { Pre-Teaching Mean } \\
\text { Score (Maximum } \\
\text { Possible Score } \\
\text { was 20) }\end{array}$ & $\begin{array}{c}\text { Standard } \\
\text { Deviation } \\
\text { (SD) }\end{array}$ & $\begin{array}{c}\text { Difference } \\
\text { Between Groups } \\
\text { Standard } \\
\text { Deviations }\end{array}$ \\
\hline Group 1 & 16 & 1.60 & 0.81 & \\
Group 2 & 16 & 1.63 & 1.02 & 0.21 \\
\hline
\end{tabular}

Based on these data, it is reasonable to assert that the two groups of seventh-grade students, which were formed by random allocation, were not only equal in size in terms of numbers but also with respect to their initial algebraic thinking skills and understanding. One might add that students in both groups seemed to know very little about the algebra represented on the initial pre-teaching version of the Algebra Test.

\section{Defining Desirable Learning Outcomes}

Based on the literature reviews in Chapter 2, and even though there is a lack of consensus about what "structure" and "modeling" lesson sequences should be, in this study the research team clarified the intervention's instructional goals in terms of two distinguishable approaches. One of the most important steps in Herbart's (1904b) analysis of how lessons should be planned was that intended learning outcomes should 
be clearly defined. The current study's planned lesson sequences, together with intended, learning outcomes can be found in Appendix C, Appendix D, Appendix E and Appendix F to this dissertation.

\section{Professional Development in a Theoretical Context}

Liping Ma (1999), after conducting her well-known study of five Chinese elementary school teachers, claimed that most elementary-school mathematics teachers in China have a much deeper knowledge and understanding of the structural side of elementary-school mathematics than do persons teaching at the same level in the United States of America. She argued that unless an elementary or middle-school teacher has a profound understanding of the structural side of elementary mathematics it is unlikely that that teacher will be an effective $\mathrm{K}-8$ mathematics teacher. If Ma's claim is correct then in order to improve elementary and middle-school students' algebra learning it will be important that U.S. middle-school teachers' knowledge of the structural aspects of elementary algebra is raised to the highest possible level.

\section{The Research Team for the Current Study}

Two well-qualified and experienced middle-school mathematics teachers, Mr. X and Mr. Y, who had both been teaching in School W for a number of years, agreed to be actively involved in the study as part of the research team, as did two senior mathematics education researchers, Prof. E and Prof. F. Mr. X and Mr. Y have comparable teaching experiences—each having years of experience teaching mathematics to students at similar grade levels in the same school. The researcher has 
observed them teaching their mathematics classes, and there can be no doubt that both are very effective teachers who are deeply respected by their students.

A "model-lessons" component of the study would be led by Prof. E and Prof. F, who both have strong backgrounds in teaching at the school level and a deep knowledge of algebra-education research and teaching literatures. They have had much experience in teaching actual seventh- and eighth-grade algebra classes, and each has previously conducted model lessons with middle-school classes in School W. It is relevant to comment, too, that School W would not have agreed that the study could go ahead with its middle-school classes unless the Principal of the school and the two participating teachers (Mr. X and Mr. Y) had believed that Prof. E and Prof. F were capable of "producing the goods" so far as teaching middle-school students was concerned.

The writer was the fifth member of the research team. I am an experienced teacher of middle-school mathematics who, through my leadership of the two pilot studies described above, have given much recent thought to theories and practices associated with middle-school algebra.

\section{Model Lessons}

Since the teaching intervention would be a major part of the present study the research team reflected at length on what would be most likely to assist $\mathrm{Mr}$. X and $\mathrm{Mr}$. Y to be well prepared for the classes they would take. It was decided that an approach recommended by Bruce Joyce and Beverley Showers (2002) should be adopted.

Joyce and Showers argued that teachers are most likely to acquire new knowledge and skills if they are able to model their teaching on their observations of high-quality 
lessons which had been conducted in their own classrooms. Toward that end, Mr. X and Mr. Y agreed to observe Prof. E. and Prof. F teaching a Grade 8 class at School W over a period of two weeks, and they would then model their teaching of their seventh-grade classes on what they had observed. It was expected that as a result of their observations, Mr. X and Mr. Y's awareness of "structure" and "modeling" approaches would be enhanced to the point where they would be confident to engage their seventh-grade students in expressive activities which would enable them to learn to interpret and use the main "signs" of middle-school algebra relating to "structure" and "modeling."

The "model-lessons" component of the study was duly led by Prof. E and Prof. F. They prepared the model lessons with the conscious aim of engaging all students actively in discussion and reflection. These lessons were not based on what can be found in any existing textbook. The workshop notes, which are reproduced as Appendices D, E, and F, were originally prepared for use with eighth-grade students at School W-but, with suitable modifications, they were also used with seventh-grade students at School W. For every lesson the main goal was for the students to gain relational understandings of key algebraic concepts through active group discussion, by solving set problems, by posing associated problems, and by reporting their findings to the rest of the class. Each student would be invited to explore, with classmates, how algebraic notations could be used advantageously in curriculum-related structure and modeling situations.

According to Prof. E and Prof. F, the aim of the model lessons was to help middle-school students develop their concepts of a variable in ways consistent with the CCSSM curriculum, and to help them identify and generalize number patterns. Mr. X 
and Mr. Y were pleased to be able to observe the model lessons given to the eighthgrade students and, after doing so, each indicated that he would be happy to teach similar lessons to a Grade 7 class.

\section{Intervention Setting and Theoretical Base}

This study's classroom-based intervention was intended to enhance classroom practice related to seventh-grade algebra. In particular, it was regarded as important that the seventh-grade students' algebraic thinking with respect to structure and functional thinking (or modeling) should improve as a result of their participation in the study. Another important goal of the intervention was to create replicable materials for other researchers who might want to study middle-school students' algebraic reasoning.

\section{The Teaching Approach}

The approach to teaching which would be adopted by the mathematics educators in the model lessons would be based on the "Expanding Modes of Communication" approach developed by Gina Del Campo and M. A. (Ken) Clements (1987, 1990), and reported in Ellerton and Clements (1991). Previous research reported by Clements and Del Campo (1987) showed that often students are happy merely to "receive" what they are taught to the point where they can reproduce it when answering low-level questions on tests. A higher educational goal was to get students to the point where they were not only able to express curriculum-relevant ideas using their own words, but also to move beyond that to solving and posing problems associated with what they have learned. It is the latter kind of learning that Del Campo and Clements (1987) 
described as "expressive learning" (p. 12), and it was that kind of learning that the research team wanted to facilitate among the students participating in the current study

In the study described in this dissertation the main aim was for all of the seventhgrade students to learn to use appropriate expressive language while developing concepts and principles related to the associative properties and the distributive property in middle-school algebra, and to use algebra to model real-life contexts. Before the study began it was not known whether the students who would participate in the study knew much about the associative and distributive properties, or about using algebra to model real-life problems.

The main purpose of the model lessons would be to show how beginning algebra students could engage in expressive activities which would assist them to learn to interpret and use the main "signs" of early algebra, especially those relating to "structure" and "modeling." It was planned that students would regularly be given the opportunity to discuss ideas and concepts in small groups, to construct answers, to pose problems, and then to report their findings to others in their class. Through this approach it was hoped that they would not only come to own the mathematics, but would also feel that it is a natural thing that they should attempt to convince others of its worth.

Another aspect of the planning process was the desire to prepare curriculum materials that would be easily usable by practicing teachers. Of course, most teachers would not be able to observe model lessons in which the materials were used, but the aim was for the curriculum materials to be largely self-explanatory. 
This view of teaching just outlined is consistent with the idea that students need to go beyond merely memorizing verbal knowledge and intellectual skills. They need to develop appropriate imageries, and be able to apply the knowledge, skills, and imageries to new, but related, situations. Del Campo and Clements (1987) argued that if students are given the opportunity to engage in conversations with fellow students, if each student can link his or her verbal knowledge, skills, and imageries, and if the students learn to communicate what they are thinking and learning to other students, then in the future they will have a better chance of establishing cognitive structures which will enable them to solve and pose problems. It is also likely that they will have developed attitudes which will make them want to do that.

\section{Procedures}

The research team set out to develop and adopt an experimental design which would permit pre-teaching, mid-intervention, and post-teaching test measures to be compared legitimately. The interventions would comprise a combination of two lesson sequences which altogether would cover 14 sessions of regular mathematics classroom time spread over a period of six weeks. A paper-and-pencil Algebra Test, developed by the researcher and based on findings from the pilot studies, would be administrated, as a pre-teaching test, to 32 seventh-graders attending School W, and strictly parallel versions of this instrument would subsequently be administered at mid-intervention, post-teaching and retention stages. The retention test, which would be administered to the students 12 weeks after the intervention classes had been completed, would be identical to the pre-teaching form of the Algebra Test. 
The dependent variables for the study would relate to tests scores for two aspects of the algebra curriculum content-structure and modeling. There would be two groups - Group 1 and Group 2-each with 16 students, which would be formed by random allocation from the 32 seventh-grade students at School W who had agreed to participate in the study. There are normally two seventh-grade mathematics classes at School W, and the random allocation procedure would be stratified in the sense that each existing class would provide eight students to each of the experimental groups for the current study. No other form of sample stratification was employed.

One of the groups, which hereafter will be referred to as "Group 1," would first participate in structure classes with Mr. X, and then it would participate in modeling classes with Mr. Y. "Group 2," on the other hand, would first participate in modeling classes with Mr. Y, and then it would participate in structure classes with Mr. X.

So far as the structure classes were concerned, the research team decided that in the time available there should be a focus on just three important field properties - the associative properties for addition and multiplication, and the distributive property. The modeling classes, which would be led by Mr. Y, would introduce students to the concepts of recursive and explicit rules for linear sequences, and would make use of the subscript notation for describing terms of sequences.

After the preliminary professional development sessions - that is to say, after the “model lessons" led by Prof. E and Prof. F, and observed by Mr. X and Mr. Y, had been completed — after the pre-teaching tests had been administered, and after preteaching interviews had been conducted, Mr. X duly led a series of workshops on structure with half of the seventh-grade students (Group 1), and Mr. Y led a series of 
workshops on modeling with the other half of the seventh-grade students (Group 2).

Then, half-way through the intervention period, the two groups swapped teachers and topics. Figure 3 summarizes study components and associated time intervals for the research investigation.

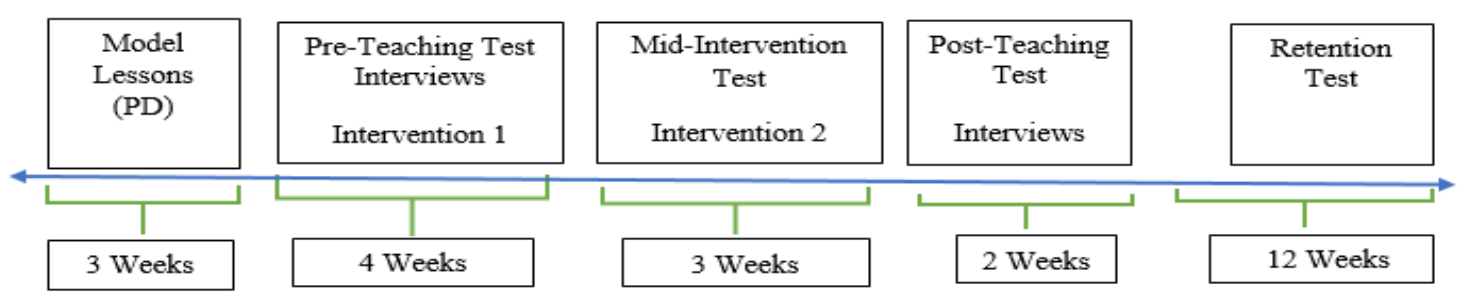

Figure 3. Summary of the design and time intervals for the study.

\section{Intervention Fidelity and Implementation}

In this present study, issues associated with fidelity of implementation for the two curricula did not present any methodological difficulties. Fidelity of implementation was not regarded as an issue because all members of the research team believed that the content to be covered in the workshops, and the methods by which that content would be assessed, were entirely consistent with CCSSM's and School W's expectations.

Table 4 summarizes the study components. Mr. X and Mr. Y observed the modellessons given by Prof. E and Prof. F, and used the printed materials in workshops with their seventh-grade classes. Both teachers were happy to follow the teaching approaches which they had observed in the model lessons, and the research team agreed that at any stage either of Mr. X or Mr. Y could vary the approach if he felt the need to do so. Each of the intervention lessons was observed by at least one member of the research team other than Mr. X or Mr. Y. Any variations from what had taken place in the eighth-grade model lessons were noted. 
Table 4

Summary of the Research Design and Timing in the Planned Research Program

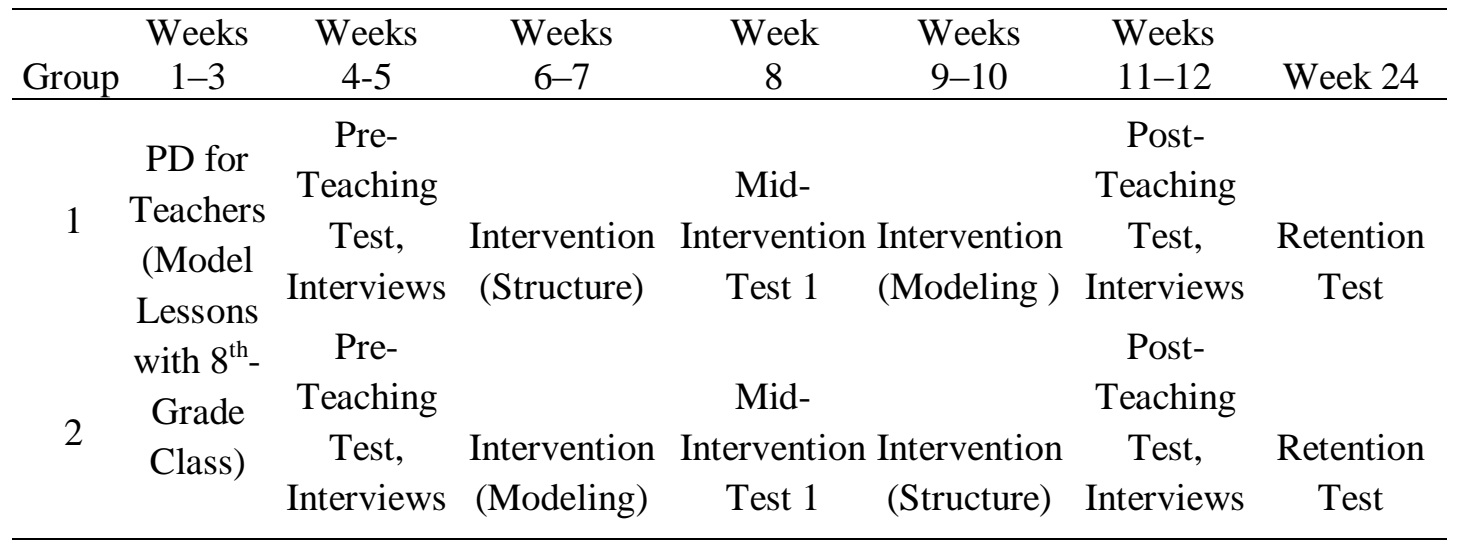

Since the seventh-grade intervention workshops for the two groups occurred at identical times, the researcher was not able to observe all of the intervention lessons fully. Nevertheless, each class was observed by either Prof. E or Prof. F, and during the observations they made handwritten notes on a specially-prepared "lesson observation schedule." The notes were concerned with patterns of classroom interaction between students and students, and between teachers and students. There was a section in the schedule in which any variations from the model lessons introduced by Mr. X or Mr. Y were to be described. The observation schedule is reproduced as Appendix $\mathrm{G}$ to this dissertation.

The next section will describe the development of the research instruments and plans for the interventions.

\section{Instrumentation}

The research team was aware that the weakest part of a teaching intervention in a research study can be the use invalid or unreliable instruments for evaluating the extent and quality of student learning as a result of the intervention (Gersten et al., 2000). 
After agreement had been reached by members of the research team with respect to the aims of the intervention, it was also agreed that the research team should measure students' initial ("pre-teaching") knowledge and understanding with respect to the associative properties for addition and multiplication, the distributive property, and in addition the quality of their modeling, especially in relation to patterns set out as sequences. It was decided that once a pre-teaching instrument was established then parallel mid-intervention, post-teaching, and retention instruments would also be created. It was decided that, in fact, the retention instrument should be identical to the pre-teaching instrument - the two would be administered 21 weeks apart and therefore problems arising from students "learning" from the first administration were not expected to arise.

This section provides background information on the measurement instruments developed and used in the study.

\section{The Main Test Instrument: The Algebra Test}

Based on results on the two pilot studies and on considerations of the nature of the current study's intervention, the present writer, Prof. E, and Prof. F developed and revised a composite pencil-and-paper Algebra Test which would be suitable for administration to a seventh-grade class in a normal 45-minute period of time. That instrument is reproduced in Appendix B to this report. The Algebra Test would be scored out of 20, with 10 of the 20 marks being allocated to structure responses, and 10 to modeling responses. Parallel forms of the instrument, also reproduced in Appendix B, were prepared, and used at the mid-intervention and post-teaching stages of the 
study. As stated above, it was agreed that the original pre-teaching version of the Algebra Test should be re-used at the retention stage of the study.

This Algebra Test was prepared with seventh-and eighth-grade students in mind. Although a few of the questions were adapted from those used in other studies - such as TIMSS, PISA, and NAEP_ no question on any version of the Algebra Test was identical to any question on any other existing test instrument. Many of the questions had been originally developed for use in the first and second pilot studies (Kanbir, 2016), and some questions were modifications of questions used in that study. The Cronbach alpha reliability of the Algebra Test (pre-teaching version) was calculated to be .82 , and those of the two parallel tests were .83 (mid-intervention version) and .85 (post-teaching version).

Figure 4 shows Questions 8, and 13, two typical structure questions on the Algebra Test. With both of these questions a response would be given a mark of 1 if structure was used to obtain a correct answer-otherwise a mark of 0 was allocated. Thus, for example, with Question 8, a student who obtained 720 by first multiplying the 72 by 5 to obtain 360 and then multiplying 360 by 2 to obtain 720 was not given a mark. To obtain the mark, a student needed to associate the 5 with the 2 , and then multiply 72 by 10 to obtain 720 . Similarly, to get the mark for Question 13 a student needed to recognize that the distributive property would be maximally useful—and then correctly multiply 7 by 100 to obtain 700 . It would not be necessary for a student to use the terminology "associative property" or "distributive property" 
Question 8. Without using a calculator find the value of $(72 \times 5) \times 2$, and explain how you got your answer.

Question 13. What would be a quick method of finding the value of $7 \times 97+7 \times 3$ without using a calculator? What is the property which allows you to use that quick method?

Figure 4. Two structure questions (pre-teaching version of the Algebra Test).

Question 14 (see Figure 5) was typical of questions concerned with modeling.

Four marks were allocated to Question 14, one each for responses to Parts $A$ and $B$, and 2 marks for Part $C$. The main interest in relation to the task was whether students would be able to generalize and, if they could do that, then what reasons would they offer for their generalizations. Would the reasons offered be mainly inductive, based purely on numerical patterns, or would students be able to give "reasons for the rule"?

To obtain the mark for Part $B$ an algebraic expression such as $3+n+3+n$ or $2 n+6$ or $6+2 . n$ or $2(3+n)$, or anything else equal to $2 n+6$, needed to be given. To obtain 2 marks for Question $C$ a response had to explain clearly the thinking behind how the algebraic expression, given as the response to Question $B$, was obtained. One mark would be given for what was deemed to be a partially correct explanation. 
Question 14. You have been hired by the Southwestern Fence Company to make pens for holding cows. A cow pen is a wall of blocks that completely surrounds the cow. You must leave at least one unit square in the middle of each pen where a cow would go. A cow needs 1 square unit of space.

The first cow pen that you can build looks like this. It holds just one cow, and there are 8 surrounding blocks altogether:

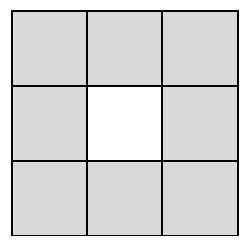

The second cow pen that you can build looks like this. It holds 2 cows.

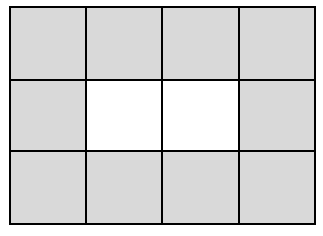

The third cow pen that you can build looks like this. It holds 3 cows.

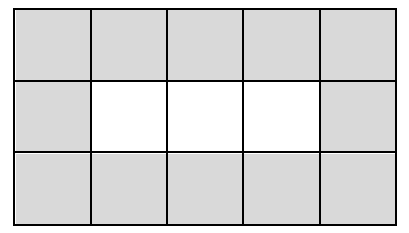

Note that the cow pens must always be in a straight line, left to right.

A. How many surrounding blocks would you need to hold 25 cows?

B. If $S_{n}$ represents the number of surrounding blocks you would need for a pen which would hold $n$ cows, what is the rule giving $S_{n}$ in terms of $n$ ?

C. Explain how you got your rule for Part B.

Figure 5. A modeling question (pre-teaching version of the Algebra Test). 


\section{The Interview Protocol}

The research team recognized that the interview data would prove to be of crucial importance with respect to making qualitative decisions regarding student development with respect to knowledge of signifiers, and with respect to key aspects within cognitive structure. As a result, much effort was put into developing an appropriate interview protocol. The protocol below emerged from experience in the two pilot studies (described earlier).

The same protocol was used by all three interviewers - Prof. E, and Prof. F, and me-for all of the 28 pre-teaching and 28 post-teaching interviews that were conducted. All interviews were tape-recorded. During an interview, the interviewer made the following "equipment" available to the interviewee at appropriate times:

- A sheet of paper with $482+(18+300)$ on it. [See Question (2) in the Protocol.]

- A sheet of paper with value of $4 \times(1 / 4 \times 128)$ on it. [See $(3)$ below.]

- A sheet of paper with $T_{n}=2 n+3$ on it. [See (4) below.]

- A sheet of paper with $T_{n}=5 n-2$ on it. [See (5) below.]

- A sheet of paper with $15-(5-x)=(15-5)-x$ on it. [See (6) below.]

- A sheet of paper showing the Table in Question 7 below.

- A sheet of paper showing the illustration in Question 8 below. During interviews, the Newman interview technique (see Clements, 1980) was used by all three interviewers. Following the interviews, I transcribed all of the text, for all 56 interviews, from audio-recordings. 


\section{Questions asked in interviews, and procedures for conducting interviews.}

1. "I am going to say two words and, as soon as I say them, I want you to say something, or draw something, or do something — do the first thing that comes into your head after I say the words. The words are ... "distributive property." Here are the words again: "distributive property."

2. Without using a calculator, find the value of $482+(18+300)$.

[Once an answer is given ask for the explanation of where that answer came from.]

3. Without using a calculator, find the value of $4 \times(1 / 4 \times 128)$.

[Once an answer is given ask for the explanation of where that answer came from.]

4. If we write $T_{n}=2 n+3$, then we can say $T_{5}$ equals 13 , because 2 times 5 plus 3 equals 13 . What would $T_{11}$ equal?

When the pupil gives an answer, ask her or him to write down how she or he obtained that answer. Also, ask the student to explain what she or he thought, in words.

5. Give the pupil a piece of paper with $T_{n}=5 n-2$ on it and, then ask her or him to say which values of $n$ would make $T_{n}$ greater than 20 .

When the pupil gives an answer, ask her or him to write down how she or he obtained that answer. Also, ask the student to explain what she or he thought, in words. 
6. [Give the pupil a piece of paper with the equation $15-(5-x)=(15-5)-x$ on it, and then, pointing to the $x$, say: "Which numbers could $x$ equal so that you would get a true statement?']

When the pupil gives an answer, ask her or him to write down how she or he obtained that answer. Also, ask the student to explain what she or he thought, in words.

7. Give the pupil a piece of paper with the following table on it:

\begin{tabular}{|c|l|l|l|l|l|l|l|}
\hline $\begin{array}{c}\text { First } \\
\text { Value }\end{array}$ & 1 & 2 & 3 & 4 & 5 & $\ldots$ & $n$ \\
\hline $\begin{array}{c}\text { Second } \\
\text { Value }\end{array}$ & 3 & 5 & 7 & 9 & $?$ & $\ldots$ & $?$ \\
\hline
\end{tabular}

Then ask (pointing): What number should we place under the 5 in the table?

Then ask (pointing): What do you think we should we put under the $n$ ?

8. The diagram below shows how tables and chairs are arranged in a school cafeteria. One table can seat 4 people, and tables can be pushed together (but always in a straight line). When two tables are pushed together, 6 people can sit around the table (as shown), etc.

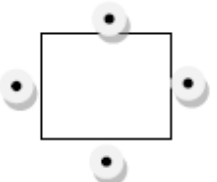

1 Table

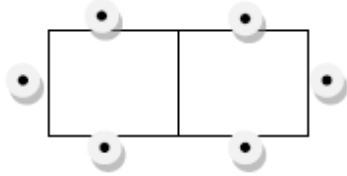

2 Tables

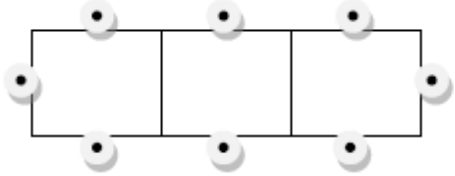

3 Tables

A. If 10 tables were pushed together (in a straight line), how many people could sit around them (assuming the pattern shown above)?

B. If $P_{n}$ represents the number of people who can sit when $n$ tables are pushed together (in a straight line), what is the rule giving $P_{n}$ in terms of $n$ ? 


\section{Research Hypotheses, and Issues Related to the Quantitative Analyses}

Samples from this study's hypothetical population were students in either Group 1 or Group 2, or, sometimes, students in both Group 1 and Group 2. This is summarized in Table 5, which relates to four stages of the study—which are referred to as pre-teaching, mid-intervention, post-teaching, and retention.

Table 5

Subscript Notations for Describing Class Means at Various Points in the Study

\begin{tabular}{cccc}
\hline & $\begin{array}{c}\text { Mean Score on } \\
\text { Structure } \\
\text { Questions } \\
(/ 10)\end{array}$ & $\begin{array}{c}\text { Mean Score on } \\
\text { Modeling } \\
\text { Questions } \\
(/ 10)\end{array}$ & $\begin{array}{c}\text { Total Mean } \\
\text { Score } \\
\text { (Structure + } \\
\text { Modeling)/20 }\end{array}$ \\
\hline $\begin{array}{c}\text { Pre-Teaching } \\
\text { Group 1 }\end{array}$ & $\bar{X}_{11}$ & $\bar{X}_{12}$ & $\bar{Y}_{11}$ \\
Group 2 & $\bar{X}_{21}$ & $\bar{X}_{22}$ & $\bar{Y}_{21}$ \\
\hline Mid-Intervention & $\bar{X}_{13}$ & $\bar{X}_{14}$ & $\bar{Y}_{13}$ \\
Group 1 & $\bar{X}_{23}$ & $\bar{X}_{24}$ & $\bar{Y}_{23}$ \\
Group 2 & $\bar{X}_{15}$ & $\bar{X}_{16}$ & $\bar{Y}_{15}$ \\
\hline Post-Teaching & $\bar{X}_{25}$ & $\bar{X}_{26}$ & $\bar{Y}_{25}$ \\
\hline Group 1 & & $\bar{X}_{18}$ & $\bar{Y}_{17}$ \\
Group 2 & $\bar{X}_{17}$ & $\bar{X}_{28}$ & $\bar{Y}_{27}$ \\
\hline Retention & $\bar{X}_{27}$ & & \\
Group 1 & & & \\
Group 2 & & & \\
\hline
\end{tabular}

Table 5 introduces subscript notations for class mean scores on the structure questions on the Algebra Test (each mean score having a maximum possible value of 10) and on the modeling questions (also with a maximum possible value of 10), and also for the means of the sum of scores for the structure and modeling questions (with a maximum of 20). 
If the random allocation to groups worked efficiently then each pair of preteaching group means, $\bar{X}_{11}$ and $\bar{X}_{21}, \bar{X}_{12}$ and $\bar{X}_{22}$, and $\bar{Y}_{11}$ and $\bar{Y}_{21}$-were expected to be approximately equal, although that was not expected to be the case for the midintervention means.

Because the design of the study involved random allocation to classes, it was possible to use, legitimately, inferential statistics to make decisions, from sample statistics, about population parameters. However, before that could be done there was the difficult task of defining the relevant populations. The task was difficult because Group 1 and Group 2 were both groups of seventh-grade students from one school, School W. Obviously, it would be wrong to assume that the use of inferential statistics based on the two sample groups could enable legitimate inferences to be made about the algebra knowledge of seventh-grade classes outside of School W. So the question arises: Why use inferential statistics at all in this study?

The issue of defining relevant populations was made all the more difficult for the present study because at some stages of the study the same groups of students had studied different types of algebra. At the mid-intervention stage for example, Group 1 students had taken classes in structure but not in modeling, but the reverse was true for Group 2 students.

By using inferential statistical procedures, it should be possible to decide whether mean differences are sufficiently large for one to be able to make confident decisions that they did not occur purely by chance. If that can be done, then the challenge will be for others to replicate the study at other places to see if similar differences persist elsewhere. 
Each of the hypothetical populations would comprise second-semester seventhgrade students who were attending School W and who were taught in heterogeneous algebra classes in which there was a focus on the associative and distributive properties (taught by Mr. X), and on modeling (taught by Mr. Y). However, there could be differences between the hypothetical populations in relation to whether or not they had participated in either or both of the structure and modeling interventions.

These considerations led to null and research hypotheses being formulated. The first eight comparisons related to group mean scores on either the structure or the modeling component of the Algebra Test—we shall assume that all the parallel forms of the structure test can reasonably be regarded as equivalent, and that all the parallel forms of the modeling test can reasonably be regarded as equivalent.

\section{Comparisons of Scores on Tests Administered at the Same Time}

Hypotheses relating to pre-teaching differences. There is a need to consider whether the random allocation to the two groups which was employed in the study actually produced two "equal" groups so far as structure and modeling were concerned. The first and second hypothetical populations would comprise students who had taken the same pre-teaching test, but had yet been interviewed, and had not participated in any of the intervention lessons.

Applying the subscript notation introduced in Table 5 to hypothetical populations, we denoted the mean (out of a possible 10) and standard deviation on the structure component of the initial test, for one of these populations, by $\mu_{11}$ and $\sigma_{11}$, respectively. Similarly, we denoted the mean (out of a possible 10) and standard deviation on the 
modeling component of the initial test, for the second of these populations, by $\mu_{21}$ and $\sigma_{21}$, respectively.

Then, the following null and research hypotheses could be stated.

First null and research hypotheses (relating to pre-teaching structure). The difference between Hypothetical Population 1's mean score on the pre-teaching structure test and Hypothetical Population 2's mean score on the same structure test would be zero. If we denote the null and research hypotheses by $H_{0}$ and $H_{1}$, then:

$\mathrm{H}_{0}: \mu_{11}-\mu_{21}=0$, with distribution from zero being according to the $t$-distribution, $d f=30$, and $\alpha=.05$ (two-tailed).

$\mathrm{H}_{1}: \mu_{11}-\mu_{21} \neq 0$.

Second null and research hypotheses (relating to pre-teaching modeling). The difference between Hypothetical Population 1's mean score on the pre-teaching modeling test and Hypothetical Population 2's mean score on the same modeling test would be zero. If, once again, we denote the null and research hypotheses by $H_{0}$ and $H_{1}$, then:

$\mathrm{H}_{0}: \mu_{12}-\mu_{22}=0$, with distribution from zero being according to the $t$-distribution, $d f=30$, and $\alpha=.05$ (two-tailed).

$\mathrm{H}_{1}: \mu_{12}-\mu_{22} \neq 0$.

A similar pair of hypotheses could be stated for the sum of the structure and modeling scores (with a maximum possible score of 20) — but those will not be stated here.

Hypotheses relating to mid-intervention differences. We wanted to check whether, as would be expected, student participation in structure lessons would result in higher performance on the structure test than student participation in modeling lessons. 
Similarly, we wanted to check whether student participation in modeling lessons would result in higher performance on the modeling test than student participation in structure lessons.

Third null and research hypotheses (relating to mid-intervention structure). The difference between Hypothetical Population 1's mean score on the structure test and Hypothetical Population 2's mean score on the same structure test (after Group 1 had participated in structure lessons but not modeling lessons, and Group 2 in modeling lessons, but not structure lessons) would be zero. Thus:

$\mathrm{H}_{0}: \mu_{13}-\mu_{23}=0$, with distribution from zero being according to the $t$-distribution, $d f=30$, and $\alpha=.05$ (one-tailed).

$\mathrm{H}_{1}: \mu_{13}-\mu_{23}>0$.

Fourth null and research hypotheses (relating to mid-intervention modeling). The difference between Hypothetical Population 1's mean score on the modeling test and Hypothetical Population 2's mean score on the same modeling test (after the first group had participated in structure lessons, but not modeling lessons, and the second in modeling lessons but not structure lessons) would be zero. Thus:

$\mathrm{H}_{0}: \mu_{24}-\mu_{14}=0$, with distribution from zero being according to the $t$-distribution, $d f=30$, and $\alpha=.05$ (one-tailed).

$\mathrm{H}_{1}: \mu_{24}-\mu_{14}>0$

Hypotheses relating to post-teaching differences. We wanted to check whether, as would be expected, student participation in structure lessons then modeling lessons would result in the same performance on the structure test as student participation in modeling lessons then structure lessons. Similarly, we wanted to check whether, as 
would be expected, student participation in structure lessons then modeling lessons would result in the same performance on the modeling test as would student participation in modeling lessons then structure lessons.

Fifth null and research hypotheses (relating to post-teaching structure). The difference between Hypothetical Population 1's mean score on the structure test and Hypothetical Population 2's mean score on the same structure test (after Group 1 had just participated in modeling lessons after having participated in structure lessons, and Group 2 had just participated in structure lessons after having participated in modeling lessons) would be zero. Thus:

$\mathrm{H}_{0}: \mu_{15}-\mu_{25}=0$, with the distribution from zero being according to the $t$ distribution, $d f=30$, and $\alpha=.05$ (two-tailed).

$\mathrm{H}_{1}: \mu_{15}-\mu_{25} \neq 0$.

Sixth null and research hypotheses (relating to post-teaching modeling). The difference between Hypothetical Population 1's mean score on the modeling test and Hypothetical Population 2's mean score on the same modeling test (with Group 1 having just participated in modeling lessons after having participated in structure lessons and Group 2 having just participated in structure lessons after having participated in modeling lessons) would be zero. Thus:

$\mathrm{H}_{0}: \mu_{16}-\mu_{26}=0$, with the distribution from zero being according to the $t$ distribution, $d f=30$, and $\alpha=.05$ (two-tailed).

$\mathrm{H}_{1}: \mu_{16}-\mu_{26} \neq 0$.

Hypotheses relating to retention differences. We wanted to check whether, as would be expected, student participation in structure lessons then modeling lessons, and 
then having a "break" of 12 weeks would generate the same performance on the structure test as student participation in modeling lessons then structure lessons followed by a 12-week break.

Seventh null and research hypotheses (relating to post-teaching structure). The difference between Hypothetical Population 1's mean score on the structure test and Hypothetical Population 2's mean score on the same structure test (after Group 1 had participated in structure lessons, then modeling lessons, and a period of 12 weeks had then elapsed, and Group 2 had participated in modeling lessons, then structure lessons, and a period of 12 weeks had then elapsed) would be zero. Thus:

$\mathrm{H}_{0}: \mu_{17}-\mu_{27}=0$, with the distribution from zero being according to the $t$ distribution, $d f=30$, and $\alpha=.05$ (two-tailed). $\mathrm{H}_{1}: \mu_{17}-\mu_{27} \neq 0$

Eighth null and research hypotheses (relating to post-teaching modeling). The difference between Hypothetical Population 1's mean score on the modeling test and Hypothetical Population 2's mean score on the same modeling test (after Group 1 had participated in structure lessons, then modeling lessons and a period of 12 weeks had then elapsed, and Group 2 had participated in modeling lessons, then structure lessons and a period of 12 weeks had then elapsed) would be zero. Thus:

$$
\begin{aligned}
& \mathrm{H}_{0}: \mu_{18}-\mu_{28}=0, \text { with the distribution from zero according to } t \text {-distribution, } d f= \\
& 30 \text {, and } \alpha=.05 \text { (two-tailed). } \\
& \mathrm{H}_{1}: \mu_{18}-\mu_{28} \neq 0 .
\end{aligned}
$$




\section{Comparisons Between Gain Scores at Different Times}

From a mathematics education research perspective, it was recognized that it would be of some interest to measure and compare group gains on the structure and modeling components of the Algebra Test at various stages of the experiment. It was thought best to regard the pre-teaching scores as representing baseline scores, and then to compare mean gains, for the two groups, measured from the baseline scores to scores at the mid-intervention, post-teaching, and retention stages.

Suppose a student in Group 1 obtained a score of $x_{11}$ on the pre-teaching structure test (obviously, $0 \leq x_{11} \leq 10$ ), and the same student obtained a score of $x_{13}$ on the parallel mid-intervention structure test (again, obviously, $0 \leq x_{13} \leq 10$ ). Then the gain score will be the value of $x_{13}-x_{11}$, which can be positive, zero, or negative depending on whether $x_{13}$ is greater than, or equal to, or less than, $x_{11}$. The mean gain score and standard deviation of the gain scores for Group 1, at the mid-intervention stage, could be found by calculating the mean gain score and standard deviation of the gain scores, for the 16 gain scores. This idea is easily generalizable across the study, to cover mean gain scores, etc., at the post-teaching and retention stages, and for both the structure and modeling tests. Unless otherwise stated, the baseline from which gain-scores will be calculated will be the pre-teaching scores for the group being considered.

Formalization of the comparison of gain scores so that null and research hypotheses with respect to hypothetical populations could be formulated in rigorous statistical terminology, but detailed discussion of the technicalities involved would be distracting here. Further comment on issues involved will be made in the final chapter 
of this dissertation. Here it will suffice to present formal statements of pairs of null and research hypotheses.

Comparing mid-intervention/pre-teaching mean gain scores. Although the following statements are not set out in fully-formalized, statistical language, the type of comparisons to be carried out should be clear in each case.

First mean-gain comparison (structure, mid-intervention versus pre-teaching).

$\mathrm{H}_{0}$ : The difference between the mid-intervention versus pre-teaching mean gain scores for the two hypothetical populations on the structure test would equal zero, with the distribution from zero being according to the $t$-distribution, $d f$ $=30$, and $\alpha=.05$ (one-tailed).

$\mathrm{H}_{1}$ : The difference between the mid-intervention versus pre-teaching mean gain scores for the two hypothetical populations on the structure test would be greater than zero (with Group 1's mean gain score being greater than Group 2's).

Second mean-gain comparison (modeling, mid-intervention versus preteaching).

$\mathrm{H}_{0}$ : The difference between the mid-intervention versus pre-teaching mean gain scores for the two hypothetical populations on the modeling test would equal zero, the distribution from zero being according to the $t$-distribution, $d f=30$, and $\alpha=.05$ (one-tailed).

$\mathrm{H}_{1}$ : The difference between the mid-intervention versus pre-teaching mean gain scores for the two hypothetical populations on the modeling test would be 
greater than 0 (with Group 2's mean gain score being greater than Group 1 's).

Third mean-gain comparison (structure, post-teaching versus pre-teaching).

$\mathrm{H}_{0}$ : The difference between the post-teaching versus pre-teaching mean gain scores for the two hypothetical populations on the structure test would equal zero, the distribution from zero being according to the $t$-distribution, $d f=30$, and $\alpha=.05$ (two-tailed).

$\mathrm{H}_{1}$ : The difference between the post-teaching versus pre-teaching mean gain scores for the two hypothetical populations on the structure test would not equal zero.

Fourth mean-gain comparison (modeling, post-teaching versus pre-teaching).

$\mathrm{H}_{0}$ : The difference between the post-teaching versus pre-teaching mean gain scores for the two hypothetical populations on the modeling test would equal zero, the distribution from zero being according to the $t$-distribution, $d f=30$, and $\alpha=.05$ (two-tailed).

$\mathrm{H}_{1}$ : The difference between the post-teaching versus pre-teaching mean gain scores for the two hypothetical populations on the modeling test would not equal zero.

Fifth mean-gain comparison (structure, retention versus pre-teaching).

$\mathrm{H}_{0}$ : The difference between the retention versus pre-teaching mean gain scores for the two hypothetical populations on the structure test will equal zero, the distribution from zero being according to the $t$-distribution, $d f=30$, and $\alpha=$ .05 (two-tailed). 
$\mathrm{H}_{1}$ : The difference between the retention versus pre-teaching mean gain scores for the two hypothetical populations on the structure test would not equal zero.

Sixth mean-gain comparison (modeling, retention versus pre-teaching).

$\mathrm{H}_{0}$ : The difference between the retention versus pre-teaching mean gains for the two hypothetical populations on the modeling test will equal zero, the distribution from zero being according to the $t$-distribution, $d f=30$, and $\alpha=$ .05 (two-tailed).

$\mathrm{H}_{1}$ : The difference between the retention versus pre-teaching mean gain scores for the two hypothetical populations on the modeling test would not equal zero.

Seventh mean-gain comparison (structure, retention versus post-teaching).

$\mathrm{H}_{0}$ : The difference between the retention versus post-teaching mean gain scores for the two hypothetical populations on the structure test would equal zero, the distribution from zero being according to the $t$-distribution, $d f=30$, and $\alpha$ $=.05$ (two-tailed).

$\mathrm{H}_{1}$ : The difference between the retention versus post-teaching mean gain scores for the two hypothetical populations on the structure test would not equal zero.

Eighth mean-gain comparison (modeling, retention versus post-teaching).

$\mathrm{H}_{0}$ : The difference between the retention versus post-teaching mean gain scores for the two hypothetical populations on the modeling test would equal zero, the distribution from zero being according to the $t$-distribution, $d f=30$, and $\alpha$ $=.05$ (two-tailed). 
$\mathrm{H}_{1}$ : The difference between the retention versus post-teaching mean gain scores for the two hypothetical populations on the modeling test would not equal zero.

\section{Effect Sizes}

It was expected that differential learning occurring during the first half of the main period of intervention, after the pre-teaching data had been gathered and immediately before the mid-intervention data were gathered, would be of special interest to scholars researching middle-school algebra. During that period, 32 students, almost all of the seventh-graders at School W, would be allocated to two classes (16 in Group 1 and 16 in Group 2) on a random-allocation basis. Group 1 students would then participate in a series of 45-minute workshops relating especially to the associative and distributive properties for rational numbers - those workshops would be led by Mr. X.

Simultaneously, Group 2 students would participate in a series of 45-minute workshops relating especially to how elementary algebra arises in modeling-those lessons would be led by Mr. Y. Mr. X and Mr. Y were the normal seventh-grade mathematics teachers at School W, and during the school year all of the participating students had had either Mr. X or Mr. Y as their regular mathematics teacher.

Six questions would be considered. The first four were "effect-size" questions:

1. What would be the Cohen's $d$ effect size (Cohen, 1988) generated by the preteaching to mid-intervention sessions on structure with Group 1? It would be assumed that the control group for this period was Group 2. 
2. What would be the Cohen's $d$ effect size generated by the mid-intervention to post-teaching sessions on structure with Group 2? It would be assumed that the control group for this period was Group 1.

3. What would be the Cohen's $d$ effect size generated by the pre-teaching to mid-intervention sessions on modeling with Group 2? It would be assumed that the control group for this period was Group 1.

4. What would be the Cohen's $d$ effect size generated by the mid-intervention to post-teaching sessions on modeling with Group 1? It would be assumed that the control group for this period was Group 2.

The other two questions to be considered would be:

5. Would the Group 1 students, who participated in structure workshops in which there was no obvious emphasis on modeling, improve their scores on the modeling component of the Algebra Test at the mid-intervention stage?

6. Would the Group 2 students, who participated in modeling workshops in which there was no obvious emphasis on structure, improve their scores on the structure component of the Algebra Test at the mid-intervention stage?

It might be argued that it would be invalid to use Group 2 as a control group for Group 1 for pre-teaching to mid-intervention structure effect-size calculations, because the Group 2 students would also be engaged in algebraic activities. Similarly, it might be argued that it is invalid to use Group 1 as a control group for Group 2 for preteaching to mid-intervention modeling effect-size calculations, because the Group 1 students would also be engaged in algebraic activities. Similarly, it might be argued that it would be invalid to use Group 1 as a control group for Group 2 for mid-intervention 
to post-teaching structure effect-size calculations, because the Group 1 students would also be engaged in algebraic activities. Similarly, it might be argued that it is invalid to use Group 2 as a control group for Group 1 for mid-intervention to post-teaching modeling effect-size calculations, because the Group 2 students would also be engaged in algebraic activities. These possible objections were rejected for the following two reasons:

1. The workshops for both groups would take place during times that the students would normally have mathematics classes, and control group students would be "doing" mathematics — as they normally would be doingat those times.

2. Although structure and modeling can both be regarded as seventh-grade algebra themes they are, in fact, quite different in content. During observations of modeling classes, research-team observers never heard the teacher (Mr. Y) or his students mention any of the words "structure," “associative" or "distributive." Similarly, during observations of structure classes, research-team observers never heard the teacher (Mr. X) or the students mention any of the words "modeling," "sequence", or "subscript."

Although the Group 1 and Group 2 workshops would appropriately be regarded as being part of a middle-school's implemented mathematics curriculum, any intersection of the mathematical content was not at all obvious.

The Cohen's $d$ effect size formula (Cohen, 1988) which would be used to measure the effects of the workshops on student knowledge and understanding was:

$$
d=\left(M_{1}-M_{2}\right) /(\text { Pooled standard deviation })
$$


where $M_{1}$ and $M_{2}$ are the mean gain scores for the treatment group and control group, respectively, and the pooled standard deviation is the square root of the average of the squared standard deviations (Rosnow \& Rosenthal, 1996).

Most education researchers using Cohen's (1988) $d$ statistic have accepted Cohen's guidelines for interpreting effect sizes. According to Cohen, effect sizes around 0.2 are regarded as "small," those around 0.5 as "medium," and those from about 0.8 onwards as "high." A Cohen's $d$ effect size of zero indicates that the mean of the treated group is the same as the mean of the untreated group; An effect size of 0.8 would indicate that the mean of the treated group is at just less than the 80th percentile for the untreated group; and an effect size of 1.7 would indicate that the mean of the treated group is between the $95^{\text {th }}$ and 96 th percentiles for the untreated group.

\section{Post-Hoc Statistical Analyses}

Earlier in this chapter formal statements of null and research hypotheses that would be checked in the study were presented, and effect-size calculations to be determined were also identified. Certainly, though, other post-hoc calculations could be made, to examine issues deemed to be relevant by the research team. Thus, for example, it might be of interest to examine and compare Group 1 and Group 2's total score (out of a possible 20) when the structure and modeling sub-scores are added at the four main stages (pre-teaching, mid-intervention, post-teaching, and retention). Cartesian graphs could be drawn to illustrate patterns of effect, for either or both groups, at different stages. Decisions on which post-hoc calculations might be made, if any, would be left until after data had been gathered and the research team had decided whether it might be profitable to explore patterns which, it seemed, had emerged. 


\section{Issues Related to the Qualitative Analyses}

\section{Semiotic Aspects of the Qualitative Analyses}

In the review of literature emphasis was given to possible semiotic interpretations of data generated by this study. In the qualitative analyses for this study, attention would be given to how knowledge, properties, concepts, images, principles, values and attitudes would best be represented by signifiers in workshop notes, in verbal statements made by the teachers during workshops, and in the Algebra Test. Attention would also be given to the interpretants for the mathematical objects that the signifiers were hoping the students would come to appreciate. It was expected that the students' involvements in workshops, and their written responses to homework tasks, would mold their language and behaviors so that they would not only be enabled to understand the signs being used, receptively, but also to acquire and use the signs themselves, expressively, as they communicated with their fellow students and with their teachers.

Evidence for the growth in appropriate receptive and expressive understandings would be sought by studying classroom discourse patterns during the workshops, especially during group workshop discussions and public presentations by students to the whole class. Toward that end, most of the workshops were audiotaped, in order that continuing analyses of discourse patterns would be possible. It was decided that workshops would not be videotaped because of the fear that the presence of cameras and videotapers might distract teachers and students, and affect discourse patterns (Singh \& Ellerton, 2013).

Potentially important evidence would also be gleaned by studying, from qualitative (and especially semiotic) perspectives, students' handwritten responses to 
questions on the tests, and also their written responses to homework tasks (which would be regularly examined by Prof. E, Prof. F, and me). Photocopies of all of the students' handwritten responses were made in order to facilitate beyond-the-event analyses.

One of the richest forms of qualitative data would be provided by audiotapes of pre- and post-teaching interviews with the students. Twenty-eight of the participating 32 seventh-grade students were interviewed on two different occasions, the interviews being conducted by either Prof. E (22 interviews), Prof. F. (17 interviews) and myself (17 interviews). Each interview occupied between 20 and 40 minutes and was done on a one-to-one basis, in a quiet, private area, in School W's library. The interviews were audiotaped, and handwritten notes were taken by the interviewer. The interview protocol remained the same-it was reproduced earlier in this chapter-for the pre- and post-teaching interviews, and that enabled changes in the interviewees' receptive and expressive languages to be identified. Once the 56 interviews were completed I typed complete transcripts for all of the interviews.

\section{The Qualitative Analyses and Cognitive Structure}

The review of literature also emphasized the Herbartian idea of apperception, with its modifications and extensions by scholars like Charles De Garmo, David Ausubel, Robert Gagné, and Shlomo Vinner. The main idea was that with respect to a given concept, a human's working memory comprises a unique configuration of links between potentially relevant verbal information, imagery, intellectual skills, memories of episodes, and attitudes. A stimulus from a teacher or fellow student can stimulate mental activity in a student, the form and quality of which will be influenced by the unique configuration of that student's working memory as it relates to the input. 
Seen from a cognitive structure (or "concept image") perspective, the teacher's role becomes one of providing the most appropriate inputs which, in the language of Herbart, will be "welcomed into the "soul." That is to say, from a Herbartian's vantage point, a learner's mind is a unique, largely subconscious, combination of fundamental verbal aspects of knowledge, skills, images, memories, and attitudes, and it is the educator's task to present new ideas so that they will most easily be assimilated and accommodated by a learner. The challenge for the seventh-grade mathematics teacher, of course, is that there is not one, but as many different cognitive structures with respect to any new curricular theme to be covered as there are students in the class.

One of the unique contributions of the present study is the attempt to link semiotic theory with neo-Herbartian apperception ideas. As far as we are aware, that has never been attempted before in algebra education research. The main task for the teacher is to provide classroom activities and opportunities which will enable learners to enrich their understandings of the meanings of signs, and their abilities to construct and apply associated concepts and principles. In order to do this, the teacher should recognize the need, for any curricular theme, to enrich each student's ability to acquire and apply pertinent vocabulary, imagery, and skills, and to do so in such a way that the student will be keen to work toward further mental development so far as that curricular theme is concerned. And, hence, the workshops were planned so that semiotic and cognitive aspects of middle-school algebra would be brought together through a healthy combination of the subconscious and conscious.

With a large volume of interview transcripts, and of handwritten pencil-and-paper texts and homework texts, collected at different stages of the study for almost all of the 
participating students, it was deemed to be possible, by examining changes in students' verbal knowledge, imagery, skills, memory of episodes, and attitudes, to document changes in individual students' knowledge and application of key signifiers, and to trace growth towards deeper understandings of mathematical objects - a process which, 25 years ago, Anna Sfard (1991) called reification.

Each interview transcript and each handwritten response by a seventh-grade student will be examined for use of verbal knowledge, imagery, skills, memory of episodes, and attitudes, and the attempt will be made to track changes over time, and thereby to account for cognitive growth, especially with respect to meanings being given to key signifiers.

\section{Concluding Comments}

This chapter has provided details of the design for the current study, and of how principles taken from the literatures on design research, semiotic theory, cognitive structure, and on receptive and expressive involvements in learning, would be applied. In addition, summary plans for implementation of the study with seventh-grade mathematics teachers and students at School W were given. Details of the planning for the structure and modeling workshops were provided as were details of the interview protocol.

Summaries of the quantitative methods to be used to investigate the stated research hypotheses were presented, as were methods for analyzing interview data.

In Chapter 4, data generated from the parallel pencil-and-paper tests on structure and modeling, administered at the pre-teaching, mid-intervention, post-teaching and retention stages of the study, will be presented and analyzed using quantitative methods 
(including inferential statistical methods). Then, in Chapter 5, qualitative data-from interviews, classroom observations, analyses of pencil-and-paper data—will be analyzed. Chapter 6 will draw together conclusions suggested by the quantitative and qualitative analyses; and the six research questions will be answered, question by question. Limitations of the study will also be discussed, and possibilities for future related research outlined. 


\section{CHAPTER IV \\ QUANTITATIVE ANALYSES OF DATA}

This chapter provides quantitative analyses of pre-teaching, mid-intervention, postteaching, and retention data generated by parallel versions of the Algebra Test. Each version of the Test was designed so that it would be suitable for administration to seventh-grade students within a 45-minute class period. The Test comprised two kinds of questions - those concerned with the structural aspects of real numbers (hereafter referred to as "structure" questions) and those concerned with modeling tasks involving linear sequences ("modeling" questions). The retention Test, which was administered to all participating students 12 weeks after the post-teaching Test, was identical to the preteaching Test. The time when the pre-teaching version of the Test was administered will be referred to as the "pre-teaching" stage of the study, and the terms "mid-intervention stage," "post-teaching stage," and "retention stage" will be used in a similar way.

Each of the pre-teaching, mid-intervention, post-teaching, and retention Tests was scored out of 20, with 10 marks being awarded for structure questions and 10 for modeling questions. The Cronbach-alpha reliabilities of each version of the Test was between 0.80 and 0.85 .

The three parallel versions of the Algebra Test are reproduced as Appendix B to this dissertation - it will be recalled the retention version of the Test was identical to the preteaching version. Thus, for example, Question 1, on the pre-teaching and retention versions of the Test was worded in the following way: "If $T_{n}=13-3 n$, where $n$ can 
represent various positive counting numbers, which values of $n$ would make the values of $T_{n}$ positive?" Question 1 on the mid-intervention version was worded in exactly the same way, only " $T_{n}=13-3 n$ " was replaced by " $T_{n}=14-4 n$ "; and on the post-teaching version, " $T_{n}=13-3 n$ " was replaced by " $T_{n}=17-4 n$."

\section{Overview of Quantitative Data}

Table 6 and Table 7 summarize the pre-teaching, mid-intervention, post-teaching and retention scores for all 32 seventh-grade student participants (16 in Group 1, 16 in Group 2). In Figure 6 the overall trends of mean scores at the different stages of the study can be seen. The mean scores for both groups improved for each of the Tests at the midintervention and post-teaching stages, with the greater increases at the mid-intervention stage being associated with the fact that the group with the greater mean score, on a topic, had just received instruction on that topic (and those in the other group had not). Thus, for example, at the mid-intervention stage, Group 1 students who had just participated in workshops which focused on structure had a much greater mean gain on the structure questions than did Group 2, whose students had just participated in workshops which focused on modeling. The reverse was the case for Group 2 students, with Group 2 having a greater mean gain on modeling than on structure. Note that, at the retention stage, both groups gained slightly lower mean scores, on the structure subtest, and one of the groups obtained a lower mean score on the modeling subtest, than they had at the post-teaching stage.

The next three sections of this chapter will provide statistical and other analyses related to the hypotheses and conjectures set out in Chapter 3. 
Table 6

Group 1 Students' Pre-Teaching, Mid-Intervention, Post-Teaching, and Retention Scores for the Structure and Modeling Questions (Out of 10, in Each Case)

\begin{tabular}{|c|c|c|c|c|c|c|c|c|}
\hline $\begin{array}{c}\text { Number and } \\
\text { Sex of } \\
\text { Student }\end{array}$ & $\begin{array}{c}\text { Pre-T } \\
\text { Structure } \\
(/ 10)\end{array}$ & $\begin{array}{c}\text { Pre-T } \\
\text { Modeling } \\
(/ 10)\end{array}$ & $\begin{array}{c}\text { Mid-Int. } \\
\text { Structure } \\
\quad(10)\end{array}$ & $\begin{array}{l}\text { Mid-Int. } \\
\text { Modeling } \\
\quad(/ 10)\end{array}$ & $\begin{array}{c}\text { Post-T } \\
\text { Structure } \\
\quad(/ 10)\end{array}$ & $\begin{array}{l}\text { Post-T } \\
\text { Modeling } \\
(/ 10)\end{array}$ & $\begin{array}{c}\text { Retention } \\
\text { Structure } \\
\quad(/ 10)\end{array}$ & $\begin{array}{c}\text { Retention } \\
\text { Modeling } \\
\quad(/ 10)\end{array}$ \\
\hline $\begin{array}{l}\text { Student } \\
1.1(\mathrm{~F})\end{array}$ & 0 & 1 & 4.5 & 2 & 3 & 3 & 3.5 & 3 \\
\hline $\begin{array}{l}\text { Student } \\
1.2(\mathrm{~F})\end{array}$ & 0 & 2 & 6.5 & 2 & 8.5 & 3.5 & 5 & 5 \\
\hline $\begin{array}{l}\text { Student } \\
1.3(\mathrm{~F})\end{array}$ & 0 & 2 & 10 & 4.5 & 8 & 8 & 9 & 7 \\
\hline $\begin{array}{l}\text { Student } \\
1.4(\mathrm{~F})\end{array}$ & 0.5 & 2 & 6 & 2.5 & 9 & 9 & 5 & 4 \\
\hline $\begin{array}{l}\text { Student } \\
1.5(\mathrm{~F})\end{array}$ & 0 & 1 & 2 & 2.5 & 5 & 2.5 & 6.5 & 4 \\
\hline $\begin{array}{l}\text { Student } \\
1.6(\mathrm{~F})\end{array}$ & 2 & 1.5 & 6 & 2 & 6 & 6 & 4.5 & 7.5 \\
\hline $\begin{array}{l}\text { Student } \\
1.7(\mathrm{~F})\end{array}$ & 0 & 2 & 7 & 2 & 8 & 5 & 7 & 5 \\
\hline $\begin{array}{l}\text { Student } \\
1.8(\mathrm{M})\end{array}$ & 0 & 1 & 8 & 2 & 8 & 3 & 7 & 5 \\
\hline $\begin{array}{l}\text { Student } \\
1.9(\mathrm{M})\end{array}$ & 0 & 1 & 1 & 1 & 2.5 & 2.5 & 3 & 2 \\
\hline $\begin{array}{l}\text { Student } \\
1.10(\mathrm{M})\end{array}$ & 0 & 1 & 1.5 & 1 & 2 & 2 & 2.5 & 1 \\
\hline $\begin{array}{l}\text { Student } \\
1.11(\mathrm{M})\end{array}$ & 0 & 1 & 4 & 3 & 8 & 8 & 6.5 & 7.5 \\
\hline $\begin{array}{l}\text { Student } \\
1.12(\mathrm{~F})\end{array}$ & 0 & 1 & 3 & 1 & 3.5 & 2 & 3 & 2 \\
\hline $\begin{array}{l}\text { Student } \\
1.13(\mathrm{~F})\end{array}$ & 0 & 1 & 7 & 1 & 9 & 6.5 & 6 & 2 \\
\hline $\begin{array}{l}\text { Student } \\
1.14(\mathrm{~F})\end{array}$ & 0 & 2 & 3.5 & 1 & 3 & 5 & 3.5 & 4.5 \\
\hline $\begin{array}{l}\text { Student } \\
1.15(\mathrm{~F})\end{array}$ & 0 & 1 & 1 & 1 & 4 & 1 & 2 & 1 \\
\hline $\begin{array}{l}\text { Student } \\
1.16(\mathrm{~F})\end{array}$ & 0 & 2 & 7 & 1 & 6 & 1.5 & 7 & 2 \\
\hline $\begin{array}{c}\text { Mean } \\
\text { Score/10 }\end{array}$ & 0.16 & 1.41 & 4.88 & 1.84 & 5.84 & 4.28 & 5.06 & 3.91 \\
\hline $\begin{array}{l}\text { Standard } \\
\text { Deviation }\end{array}$ & 0.51 & 0.49 & 2.72 & 0.98 & 2.55 & 2.56 & 2.02 & 2.18 \\
\hline
\end{tabular}


Table 7

Group 2 Students' Pre-Teaching, Mid-Intervention, Post-Teaching, and Retention Scores for the Structure and Modeling Questions (Out of 10, in Each Case)

\begin{tabular}{|c|c|c|c|c|c|c|c|c|}
\hline $\begin{array}{c}\text { Number and } \\
\text { Sex of } \\
\text { Student }\end{array}$ & $\begin{array}{c}\text { Pre-T } \\
\text { Structure } \\
(/ 10)\end{array}$ & $\begin{array}{c}\text { Pre-T } \\
\text { Modeling } \\
(/ 10)\end{array}$ & $\begin{array}{l}\text { Mid-Int. } \\
\text { Structure } \\
\quad(/ 10)\end{array}$ & $\begin{array}{l}\text { Mid-Int. } \\
\text { Modeling } \\
\quad(/ 10)\end{array}$ & $\begin{array}{c}\text { Post-T } \\
\text { Structure } \\
\quad(/ 10)\end{array}$ & $\begin{array}{l}\text { Post-T } \\
\text { Modeling } \\
(/ 10)\end{array}$ & $\begin{array}{c}\text { Retention } \\
\text { Structure } \\
\quad(/ 10)\end{array}$ & $\begin{array}{l}\text { Retention } \\
\text { Modeling } \\
\quad(/ 10)\end{array}$ \\
\hline $\begin{array}{l}\text { Student } \\
2.1(\mathrm{M})\end{array}$ & 0 & 2 & 1 & 5.5 & 4 & 6 & 7 & 5 \\
\hline $\begin{array}{l}\text { Student } \\
2.2(\mathrm{M})\end{array}$ & 0 & 1 & 1 & 6 & 7 & 4.5 & 5.5 & 5.5 \\
\hline $\begin{array}{l}\text { Student } \\
2.3(\mathrm{~F})\end{array}$ & 0 & 1 & 1 & 3.5 & 8 & 6 & 7 & 6.5 \\
\hline $\begin{array}{l}\text { Student } \\
2.4(\mathrm{~F})\end{array}$ & 0.5 & 1 & 2 & 3 & 2 & 1 & 4.5 & 1 \\
\hline $\begin{array}{l}\text { Student } \\
2.5(\mathrm{M})\end{array}$ & 0.5 & 2 & 2.5 & 4 & 4.5 & 3.5 & 5 & 6 \\
\hline $\begin{array}{l}\text { Student } \\
2.6(\mathrm{M})\end{array}$ & 1.5 & 2 & 4 & 5.5 & 7 & 5.5 & 8 & 4 \\
\hline $\begin{array}{l}\text { Student } \\
2.7(\mathrm{~F})\end{array}$ & 2.5 & 2 & 5 & 5.5 & 8 & 8 & 8 & 6.5 \\
\hline $\begin{array}{l}\text { Student } \\
2.8(\mathrm{~F})\end{array}$ & 1 & 2 & 4 & 5 & 7 & 7.5 & 8 & 6 \\
\hline $\begin{array}{l}\text { Student } \\
2.9(\mathrm{~F})\end{array}$ & 0.5 & 1 & 3 & 6.5 & 8 & 7.5 & 6 & 7.5 \\
\hline $\begin{array}{l}\text { Student } \\
2.10(\mathrm{M})\end{array}$ & 0 & 1 & 0 & 1 & 2.5 & 0.5 & 1 & 1.5 \\
\hline $\begin{array}{l}\text { Student } \\
2.11(\mathrm{M})\end{array}$ & 0 & 1 & 0.5 & 1.5 & 5 & 1.5 & 5 & 2 \\
\hline $\begin{array}{l}\text { Student } \\
2.12(\mathrm{M})\end{array}$ & 0 & 1 & 0 & 1 & 6 & 2 & 6 & 1.5 \\
\hline $\begin{array}{l}\text { Student } \\
2.13(\mathrm{~F})\end{array}$ & 0 & 1 & 0.5 & 0 & 4.5 & 1 & 4 & 2 \\
\hline $\begin{array}{l}\text { Student } \\
2.14(\mathrm{~F})\end{array}$ & 0 & 1 & 0 & 3.5 & 5.5 & 3.5 & 3 & 2.5 \\
\hline $\begin{array}{l}\text { Student } \\
2.15(\mathrm{~F})\end{array}$ & 0 & 1 & 1 & 4 & 8 & 6.5 & 6 & 7 \\
\hline $\begin{array}{l}\text { Student } \\
2.16(\mathrm{M})\end{array}$ & 1 & 1 & 0.5 & 5.5 & 5 & 4.5 & 3 & 7 \\
\hline $\begin{array}{l}\text { Mean } \\
\text { Score/10 }\end{array}$ & 0.47 & 1.31 & 1.63 & 3.81 & 5.75 & 4.31 & 5.44 & 4.47 \\
\hline $\begin{array}{l}\text { Standard } \\
\text { Deviation }\end{array}$ & 0.72 & 0.48 & 1.61 & 2.03 & 1.95 & 2.54 & 2.08 & 2.34 \\
\hline
\end{tabular}




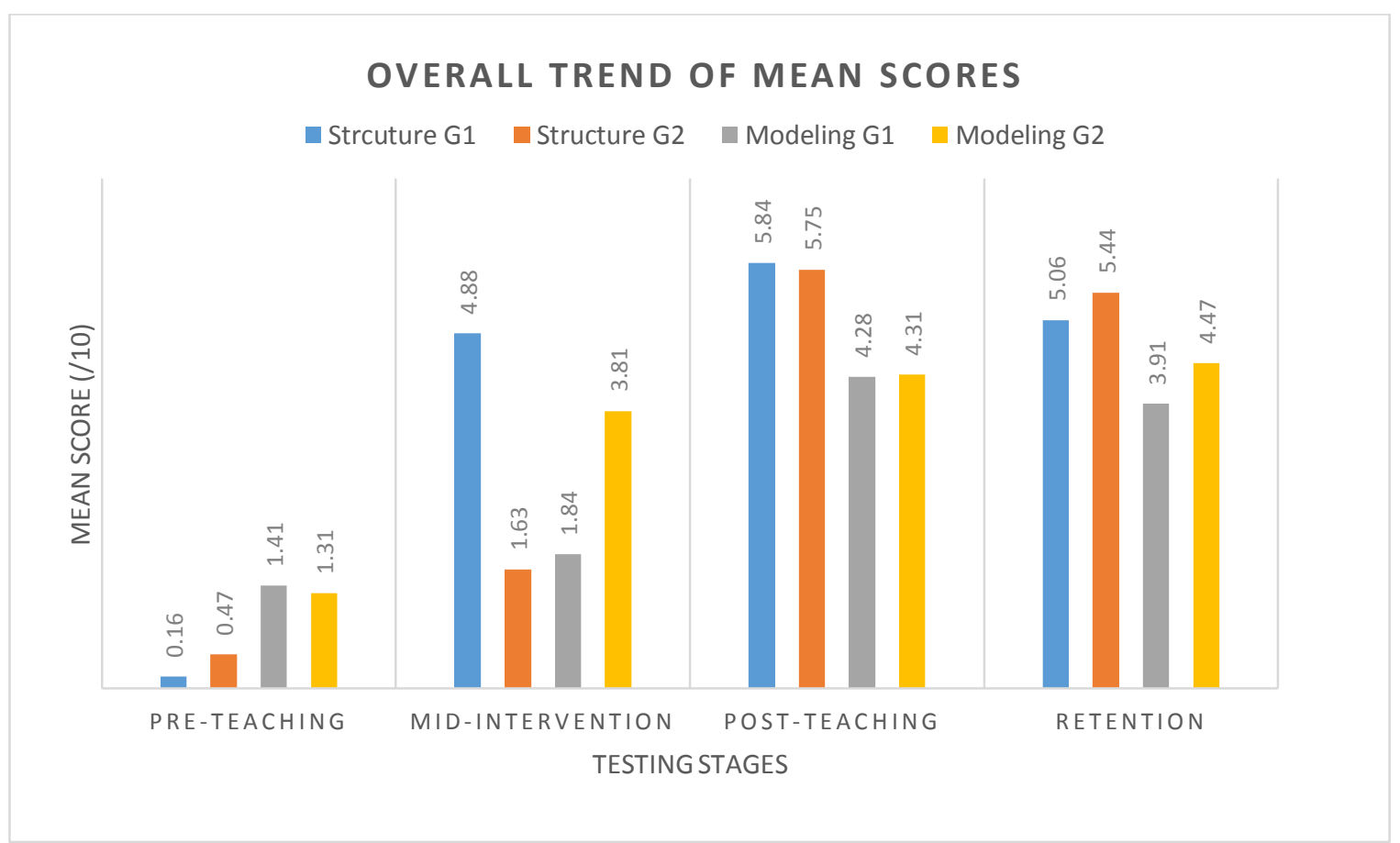

Figure 6. Bar graphs, showing mean scores of the two groups at different stages, on the structure and modeling subtests.

\section{Analyses of Pre-Teaching Data}

Because random sampling procedures were adopted in this study when Group 1 and Group 2 were being formed, the first and second hypothetical populations should have comprised students who were very similar in their characteristics. The relevant samples from these populations comprised seventh-grade students at School W who, at the beginning of the study, had not taken the pre-teaching version of the Algebra Test, had not been interviewed, and had not participated in any of the intervention lessons. Entries in Table 6 and Table 7 show, among other things, the mean scores of Group 1 and Group 2 students on the pre-teaching tests for structure and modeling (the maximum possible score, for each test, was 10). 


\section{Pre-Teaching Group Differences with Respect to Structure}

The first null hypothesis to be considered was that the difference between Hypothetical Population 1's mean score on the pre-teaching structure subtest and Hypothetical Population 2's mean score on the same structure subtest would be zero. If we denote the null and research hypotheses by $H_{0}$ and $H_{1}$, then:

$\mathrm{H}_{0}: \mu_{11}-\mu_{21}=0$, with distribution from zero being according to the (independent samples) $t$-distribution, $d f=30$, and $\alpha=.05$ (two-tailed). $\mathrm{H}_{1}: \mu_{11}-\mu_{21} \neq 0$.

Entries in Tables 6 and 7 indicate that the relevant sample means and standard deviations for structure were, respectively, 0.16 and 0.51 (for Group 1) and 0.47 and 0.72 (for Group 2). An independent samples $t$-test analysis gave $t=-1.42$, and with 30 degrees of freedom, the null hypothesis was accepted. At the pre-teaching stage there was no statistically significant difference between the two groups with respect to knowledge of structure.

Obviously, at the pre-teaching stage both groups knew very little about those questions on the Algebra Test concerned with the "structure of rational numbers."

\section{Pre-Teaching Group Differences with Respect to Modeling}

The second null hypothesis to be considered was that the difference between Hypothetical Population 1's mean score on the pre-teaching modeling subtest and Hypothetical Population 2's mean score on the same modeling subtest would be zero. If we denote the null and research hypotheses by $H_{0}$ and $H_{1}$, then: 
$\mathrm{H}_{0}: \mu_{12}-\mu_{22}=0$, with distribution from zero being according to the $t$ distribution, $d f=30$, and $\alpha=.05$ (two-tailed).

$\mathrm{H}_{1}: \mu_{12}-\mu_{22} \neq 0$.

Entries in Tables 6 and 7 indicate that the relevant sample means and standard deviations for modeling were, respectively, 1.41 and 0.49 (for Group 1) and 1.31 and 0.48 (for Group 2). An independent samples $t$-test analysis gave $t=.58$, and with 30 degrees of freedom, the null hypothesis was accepted. There was no statistically significant difference between the two groups with respect to knowledge of modeling at the pre-teaching stage.

Obviously, at the pre-teaching stage both groups knew very little about the kind of modeling represented by the questions on the Test.

\section{Mid-Intervention Group Differences with Respect to Structure}

The third null hypothesis to be considered was that the difference between Hypothetical Population 1's mean score on the mid-intervention structure subtest and Hypothetical Population 2's mean score on the same structure subtest would be zero. If we denote the null and research hypotheses by $H_{0}$ and $H_{1}$, then:

$\mathrm{H}_{0}: \mu_{13}-\mu_{23}=0$, with distribution from zero being according to the $t$-distribution,

$$
\begin{aligned}
& d f=30, \text { and } \alpha=.05 \text { (one-tailed). } \\
& \mathrm{H}_{1}: \mu_{13}-\mu_{23}>0
\end{aligned}
$$

Entries in Tables 6 and 7 indicate that the relevant sample means and standard deviations for structure were, respectively, 4.88 and 2.72 (for Group 1) and 1.63 and 1.61 (for Group 2). A $t$-test analysis gave $t=4.19$, and with 30 degrees of freedom, and assuming a 1-tailed test, the null hypothesis was rejected. It is reasonable to assume, 
therefore, that from the point of view of structure, there was a statistically significant difference between the two groups with respect to knowledge of structure at the midintervention stage, and that Group 1 students (who had only recently participated in structure workshops) had come to know more about the structure of real numbers than had the Group 2 students (who had participated in modeling workshops). That said, the Group 1 students still had much to learn with respect to structure.

\section{Mid-Intervention Group Differences with Respect to Modeling}

The fourth null hypothesis to be considered was that the difference between Hypothetical Population 1's mean score on the mid-intervention modeling subtest and Hypothetical Population 2's mean score on the same modeling subtest would be zero. If we denote the null and research hypotheses by $H_{0}$ and $H_{1}$, then:

$\mathrm{H}_{0}: \mu_{24}-\mu_{14}=0$, with distribution from zero being according to the $t$-distribution,

$$
d f=30 \text {, and } \alpha=.05 \text { (one-tailed). }
$$

$\mathrm{H}_{1}: \mu_{24}-\mu_{14}>0$.

Entries in Tables 6 and 7 indicate that the relevant sample means and standard deviations for modeling were, respectively, 1.84 and 0.98 (for Group 1) and 3.59 and 2.30 (for Group 2). A $t$-test analysis gave $t=3.48$, and with 30 degrees of freedom and assuming a 1-tailed test, the null hypothesis was rejected. There was a statistically significant difference between the two groups with respect to knowledge of modeling at the mid-intervention stage, and the Group 2 students (who had only recently participated in modeling workshops) had come to more about modeling than had the Group 1 students (who had been involved in structure workshops). That said, the Group 2 students still had much to learn with respect to modeling. 


\section{Post-Teaching Group Differences with Respect to Structure}

The fifth null hypothesis to be considered was that the difference between Hypothetical Population 1's mean score on the post-teaching structure subtest and Hypothetical Population 2's mean score on the same structure subtest would be zero. If we denote the null and research hypotheses by $H_{0}$ and $H_{1}$, then:

$\mathrm{H}_{0}: \mu_{15}-\mu_{25}=0$, with distribution from zero being according to the $t$-distribution,

$$
d f=30, \text { and } \alpha=.05 \text { (two-tailed). }
$$

$\mathrm{H}_{1}: \mu_{15}-\mu_{25}=0$.

Entries in Tables 6 and 7 indicate that the relevant sample means and standard deviations for structure were, respectively, 5.84 and 2.55 (for Group 1) and 5.75 and 1.95 (for Group 2). A $t$-test analysis gave $t=.12$, and with 30 degrees of freedom and assuming a 2-tailed test, the null hypothesis was accepted. There was no statistically significant difference between the two groups with respect to knowledge of structure at the post-teaching stage. Nevertheless, both Group 1 and the Group 2 students still had much to learn with respect to structure.

\section{Post-Teaching Group Differences with Respect to Modeling}

The sixth null hypothesis to be considered was that the difference between Hypothetical Population 1's mean score on the post-teaching modeling subtest and Hypothetical Population 2's mean score on the same modeling subtest would be zero. If we denote the null and research hypotheses by $H_{0}$ and $H_{1}$, then:

$\mathrm{H}_{0}: \mu_{16}-\mu_{26}=0$, with the distribution from zero being according to the $t$ distribution, $d f=30$, and $\alpha=.05$ (two-tailed).

$\mathrm{H}_{1}: \mu_{16}-\mu_{26} \neq 0$. 
Entries in Tables 6 and 7 indicate that the relevant sample means and standard deviations for modeling were, respectively, 4.28 and 2.56 (for Group 1) and 4.31 and 2.54 (for Group 2). A $t$-test analysis gave $t=-.04$, and with 30 degrees of freedom and assuming a 2-tailed test, the null hypothesis was accepted. There was no statistically significant difference between the two groups with respect to knowledge of modeling at the post-teaching stage. That said, both Group 1 and Group 2 students still had much to learn with respect to modeling.

\section{Retention Group Differences with Respect to Structure}

The seventh null hypothesis to be considered was that the difference between Hypothetical Population 1's mean score on the retention structure subtest and Hypothetical Population 2's mean score on the same structure subtest would be zero. If we denote the null and research hypotheses by $H_{0}$ and $H_{1}$, then:

$\mathrm{H}_{0}: \mu_{17}-\mu_{27}=0$, with distribution from zero being according to the $t$ distribution, $d f=30$, and $\alpha=.05$ (two-tailed).

$\mathrm{H}_{1}: \mu_{17}-\mu_{27}=0$.

Entries in Tables 6 and 7 indicate that the relevant sample means and standard deviations for structure were, respectively, 5.06 and 2.02 (for Group 1) and 5.44 and 2.08 (for Group 2). A $t$-test analysis gave $t=-.53$, and with 30 degrees of freedom and assuming a 2-tailed test, the null hypothesis was accepted. There was no statistically significant difference between the two groups with respect to knowledge of structure at the retention stage. That said, both Group 1 and the Group 2 students still had much to learn with respect to structure. 


\section{Retention Group Differences with Respect to Modeling}

The eighth null hypothesis to be considered was that there would be no difference between Hypothetical Population 1's mean score on the retention modeling subtest and Hypothetical Population 2's mean score on the same modeling subtest. If we denote the null and research hypotheses by $H_{0}$ and $H_{1}$, then:

$\mathrm{H}_{0}: \mu_{18}-\mu_{28}=0$, with distribution from zero being according to the $t$ distribution, $d f=30$, and $\alpha=.05$ (two-tailed).

$\mathrm{H}_{1}: \mu_{18}-\mu_{28}=0$.

Entries in Tables 6 and 7 indicate that the relevant sample means and standard deviations for modeling were, respectively, 3.91 and 2.18 (for Group 1) and 4.47 and 2.34 (for Group 2). A $t$-test analysis gives $t=-.70$, and with 30 degrees of freedom and assuming a 2-tailed test, the null hypothesis was accepted. There was no statistically significant difference between the two groups with respect to knowledge of modeling at the retention stage. That said, both Group 1 and the Group 2 students still had much to learn with respect to modeling.

\section{Comparisons Between Mean Gain Scores at Different Times}

Eight comparisons of group gain scores were made. For the first six of these, Group 1 students' mean gain scores were compared with Group 2's mean gain scores, with the pre-teaching scores being regarded as baseline scores; then mean gains from the baseline scores were compared for the two groups at the mid-intervention, postteaching, and retention stages. 


\section{First Mean-Gain Comparison (Structure, Mid-Intervention Versus Pre- Teaching)}

The null and research hypotheses were based on the assumption that since students in Group 1 had participated in structure workshops but students in Group 2 had not, the mean gain for Group 1 should be greater than the mean gain for Group 2. The null and research hypotheses were:

$\mathrm{H}_{0}$ : The difference between the mid-intervention versus pre-teaching mean gain scores for the two hypothetical populations on the structure subtest would equal zero, with the distribution from zero being according to the $t$ distribution, $d f=30$, and $\alpha=.05$ (one-tailed).

$\mathrm{H}_{1}$ : The difference between the mid-intervention versus pre-teaching mean gain scores for the two hypothetical populations on the structure subtest would be greater than zero (with Group 1's mean gain score being greater than Group 2's).

Gain scores for individual students could be calculated from the entries in Tables 6 and 7. For this first mean-gain comparison, which compared the mid-intervention versus pre-teaching mean gains for Group 1 and Group 2 on the structure subtest, the mean gain for Group 1 was 4.72 (standard deviation 2.70), and the mean gain for Group 2 was 1.16 (standard deviation 1.08). A $t$-test analysis yielded $t=4.91$, and with 30 degrees of freedom and assuming a 1-tailed test, the null hypothesis was rejected. The research hypothesis, that the mean mid-intervention versus pre-teaching gain score for Group 1 on structure was greater than the mean gain score for Group 2 on structure, was accepted. 


\section{Second Mean-Gain Comparison (Modeling, Mid-Intervention Versus Pre-Teaching)}

The null and research hypotheses were based on the assumption that because students in Group 2 had recently participated in modeling workshops but students in Group 1 had not, the mean gain for Group 2 on the modeling subtest should be greater than the mean gain for Group 1. The null and research hypotheses were:

$\mathrm{H}_{0}$ : The difference between the mid-intervention versus pre-teaching mean gain scores for the two hypothetical populations on the modeling test would equal zero, with the distribution from zero being according to the $t$ distribution, $d f=30$, and $\alpha=.05$ (one-tailed).

$\mathrm{H}_{1}$ : The difference between the mid-intervention versus pre-teaching mean gain scores for the two hypothetical populations on the modeling test would be greater than zero (with Group 2's mean gain score being greater than Group 1's).

Gain scores for individual students can be calculated from the entries in Tables 6 and 7. For this second mean-gain comparison, which compared the mid-intervention versus pre-teaching mean gains for Group 2 and Group 1 on the modeling test, the mean gain for Group 2 was 2.49 (standard deviation 1.87), and the mean gain for Group 1 was .44 (standard deviation .96). A $t$-test analysis yielded $t=3.91$, and with 30 degrees of freedom and assuming a 1-tailed test, the null hypothesis was rejected and the research hypothesis, that the mean mid-intervention versus pre-teaching gain score for Group 2 on modeling was greater than the mean gain score for Group 1 on modeling, was accepted. 


\section{Third Mean-Gain Comparison (Structure, Post-Teaching Versus Pre-Teaching)}

The null and research hypotheses were based on the assumption that since students in both Group 1 and Group 2 had recently participated in structure workshops led by the same teacher, the difference between the mean gains for Group 1 and Group 2 on the structure subtest should, theoretically, be zero. The null and research hypotheses were:

$\mathrm{H}_{0}$ : The difference between the post-teaching versus pre-teaching mean gain scores for the two hypothetical populations on the structure subtest would equal zero, with the distribution from zero being according to the $t$ distribution, $d f=30$, and $\alpha=.05$ (two-tailed).

$\mathrm{H}_{1}$ : The difference between the post-teaching versus pre-teaching mean gain scores for the two hypothetical populations on the structure subtest would not equal zero.

Gain scores for individual students can be calculated from the entries in Tables 6 and 7. For this third mean-gain comparison, which compared the post-teaching versus pre-teaching mean gains for Group 1 and Group 2 on the structure subtest, the mean gain for Group 1 was 5.69 (standard deviation 2.55), and the mean gain for Group 2 was 5.28 (standard deviation 1.85). A $t$-test analysis yielded $t=.52$, and with 30 degrees of freedom and assuming a 2-tailed test, the null hypothesis was accepted. The mean postteaching versus pre-teaching gain scores for Group 1 and Group 2 on structure were not statistically significantly different. 


\section{Fourth Mean-Gain Comparison (Modeling, Post-Teaching Versus Pre-Teaching)}

The null and research hypotheses were based on the assumption that since students in both Group 1 and Group 2 had recently participated in modeling workshops led by the same teacher the difference between the mean gains for Group 1 and Group 2 should, theoretically, be zero. The null and research hypotheses were:

$\mathrm{H}_{0}$ : The difference between the post-teaching versus pre-teaching mean gain scores for the two hypothetical populations on the modeling subtest would equal zero, with the distribution from zero being according to the $t$ distribution, $d f=30$, and $\alpha=.05$ (two-tailed).

$\mathrm{H}_{1}$ : The difference between the post-teaching versus pre-teaching mean gain scores for the two hypothetical populations on the modeling subtest would not equal zero.

Gain scores for individual students can be calculated from the entries in Tables 6 and 7. For this fourth mean-gain comparison, which compares the post-teaching versus pre-teaching mean gains for Group 1 and Group 2 on the modeling subtest, the mean gain for Group 1 was 2.88 (standard deviation 2.41), and the mean gain for Group 2 was 3.00 (standard deviation 2.35). A $t$-test analysis yielded $t=-.15$, and with 30 degrees of freedom and assuming a 2-tailed test, the null hypothesis was accepted. The mean postteaching versus pre-teaching gain scores for Group 1 and Group 2 on modeling were not statistically significantly different.

\section{Fifth Mean-Gain Comparison (Structure, Retention Versus Pre-Teaching)}

The null and research hypotheses were based on the assumption that since the students in both Group 1 and Group 2 had participated in structure workshops led by 
the same teacher, the difference between the mean gains for Group 1 and Group 2 on the structure subtest should, theoretically, be zero. The null and research hypotheses were:

$\mathrm{H}_{0}$ : The difference between the retention versus pre-teaching mean gain scores for the two hypothetical populations on the structure subtest would equal zero, with the distribution from zero being according to the $t$-distribution, $d f=30$, and $\alpha=.05$ (two-tailed).

$\mathrm{H}_{1}$ : The difference between the retention versus pre-teaching mean gain scores for the two hypothetical populations on the structure subtest would not be equal.

Gain scores for individual students can be calculated from the entries in Tables 6 and 7. For this fifth mean-gain comparison, which compares the retention versus preteaching mean gains for Group 1 and Group 2 on the structure subtest, the mean gain for Group 1 was 4.91 (standard deviation 2.12), and the mean gain for Group 2 was 4.97 (standard deviation 1.79). A $t$-test analysis yielded $t=-.09$, and with 30 degrees of freedom and assuming a 2-tailed test, the null hypothesis was accepted. The mean retention versus pre-teaching gain scores for Group 1 and Group 2 on structure were not statistically significantly different.

\section{Sixth Mean-Gain Comparison (Modeling, Retention Versus Pre-Teaching)}

The null and research hypotheses were based on the assumption that both Group 1 and Group 2 had participated in modeling workshops led by the same teacher and therefore the mean gains for Group 1 and Group 2 on the modeling subtest should, theoretically, be equal. The null and research hypotheses were: 
$\mathrm{H}_{0}$ : The difference between the retention versus pre-teaching mean gain scores for the two hypothetical populations on the modeling subtest would equal zero, with the distribution from zero being according to the $t$-distribution, $d f=30$, and $\alpha=.05$ (two-tailed).

$\mathrm{H}_{1}$ : The difference between the retention versus pre-teaching mean gain scores for the two hypothetical populations on the modeling subtest would not equal zero.

Gain scores for individual students can be calculated from the entries in Tables 6 and 7. For this sixth mean-gain comparison, which compares the retention versus preteaching mean gains for Group 1 and Group 2 on the modeling subtest, the mean gain for Group 1 was 2.50 (standard deviation 2.06), and the mean gain ffor Group 2 was 3.16 (standard deviation 2.24). A $t$-test analysis yielded $t=-.86$, and with 30 degrees of freedom and assuming a 2-tailed test, the null hypothesis was accepted. The difference between the mean retention versus pre-teaching gain scores for Group 1 and Group 2 on modeling was not statistically significantly different from zero.

\section{Seventh Mean-Gain Comparison (Structure, Retention Versus Post-Teaching)}

There was a 12-week period between the times when the post-teaching and parallel retention Tests were administered and it was a matter of interest whether Group 1 students would retain whatever they had learned during the structure workshops over that period more than would Group 2 students. During the 12 intervening weeks the participating students did not focus on either structure or modeling in their mathematics classes. 
This seventh mean-gain comparison checks whether the difference between mean gain scores for Group 1 and Group 2 on the retention versus post-teaching structure subtests differed from zero.

$\mathrm{H}_{0}$ : The difference between the retention versus post-teaching mean gain scores for the two hypothetical populations on the structure subtest would equal zero, with the distribution from zero being according to the $t$-distribution, $d f=30$, and $\alpha=.05$ (two-tailed).

$\mathrm{H}_{1}$ : The difference between the retention versus post-teaching mean gain scores for the two hypothetical populations on the structure subtest would not equal zero.

Gain scores for individual students can be calculated from the entries in Tables 6 and 7. For this seventh mean-gain comparison, which compares the retention versus postteaching mean gains for Group 1 and Group 2 on the structure subtest, the mean gain for

Group 1 was -0.78 (standard deviation 1.70), and the mean gain for Group 2 was -0.31 (standard deviation 1.63). A $t$-test analysis yielded $t=.80$, and with 30 degrees of freedom and assuming a 2-tailed test, the null hypothesis was accepted. The difference between the mean retention versus pre-teaching gain scores for Group 1 and Group 2 on structure was not statistically significantly different from zero.

\section{Eighth Mean-Gain Comparison (Modeling, Retention Versus Post-Teaching)}

This eighth mean-gain comparison checks whether the difference between mean gain scores for Group 1 and Group 2 on the retention versus post-teaching modeling subtests equaled zero. 
$\mathrm{H}_{0}$ : The difference between the retention versus post-teaching mean gain scores for the two hypothetical populations on the modeling subtests would equal zero, with the distribution from zero being according to the $t$-distribution, $d f=30$, and $\alpha=.05$ (two-tailed).

$\mathrm{H}_{1}$ : The difference between the retention versus post-teaching mean gain scores for the two hypothetical populations on the modeling tests would not equal zero.

Gain scores for individual students can be calculated from the entries in Tables 6 and 7. For this eighth mean-gain comparison, which compares the retention versus postteaching mean gains for Group 1 and Group 2 on the modeling subtests, the mean gain for Group 1 was -0.38 (standard deviation 1.95), and the mean gain for Group 2 was 0.16 (standard deviation 1.28). A $t$-test analysis yielded $t=-.91$, and with 30 degrees of freedom and assuming a 2-tailed test, the null hypothesis was accepted. The difference between the mean retention versus pre-teaching gain scores for Group 1 and Group 2 on modeling was not statistically significantly different from zero.

\section{Calculation of Effect Sizes}

The following four Cohen's (1988) $d$ effect sizes were computed:

1. Effect of pre-teaching to mid-intervention workshop sessions on structure with Group 1 (it was assumed that the control group for this period was Group 2);

2. Effect of mid-intervention to post-teaching workshop sessions on structure with Group 2 (it was assumed that the control group for this period was Group 1); 
3. Effect of pre-teaching to mid-intervention workshop sessions on modeling with Group 2 (it was assumed that the control group for this period was Group 1);

4. Effect of mid-intervention to post-teaching workshop sessions on modeling with Group 1 (it was assumed that the control group for this period was Group 2);

Summary results of the calculations are shown in Table 8.

Table 8

Effect Sizes for Four Intervention Workshops

\begin{tabular}{ccccc}
\hline $\begin{array}{c}\text { Type of } \\
\text { Workshop } \\
\text { (Structure or } \\
\text { Modeling }\end{array}$ & $\begin{array}{c}\text { Period } \\
\text { (Pre-T to Mid-I, } \\
\text { or Mid-I to Pre- } \\
\text { T) }\end{array}$ & $\begin{array}{c}\text { Group Involved in } \\
\text { Relevant Workshops } \\
\text { (Group 1 or Group 2) }\end{array}$ & $\begin{array}{c}\text { Control } \\
\text { Group }\end{array}$ & $\begin{array}{c}\text { Cohen's } d \\
\text { Effect } \\
\text { Size }\end{array}$ \\
\hline $\begin{array}{c}\text { Structure } \\
\text { Structure }\end{array}$ & Pre-T to Mid-I & Group 1 & Group 2 & 1.74 \\
Modeling & Pre-T to Mid-I & Group 2 & Group 1 & 1.70 \\
Modeling & Mid-I to Post-T & Group 1 & Group 2 & 1.38 \\
\hline
\end{tabular}

Adopting Cohen's (1988) criteria, whereby effect sizes around 0.2 are "small," those around 0.5 are "medium," and those more than 0.8 onwards are "large," It can be seen, from entries in Table 8, that the effects on performance on the structure subtest of the structure workshops were very large, for both Group 1 and Group 2. The effects for performance on the modeling subtest of the modeling workshops were also large, especially for the Group 2 students. This conclusion is amplified by Figure 7 and Figure 8 in which the mean subtest scores at four stages are depicted and corresponding mean scores for each group are joined by line intervals. 


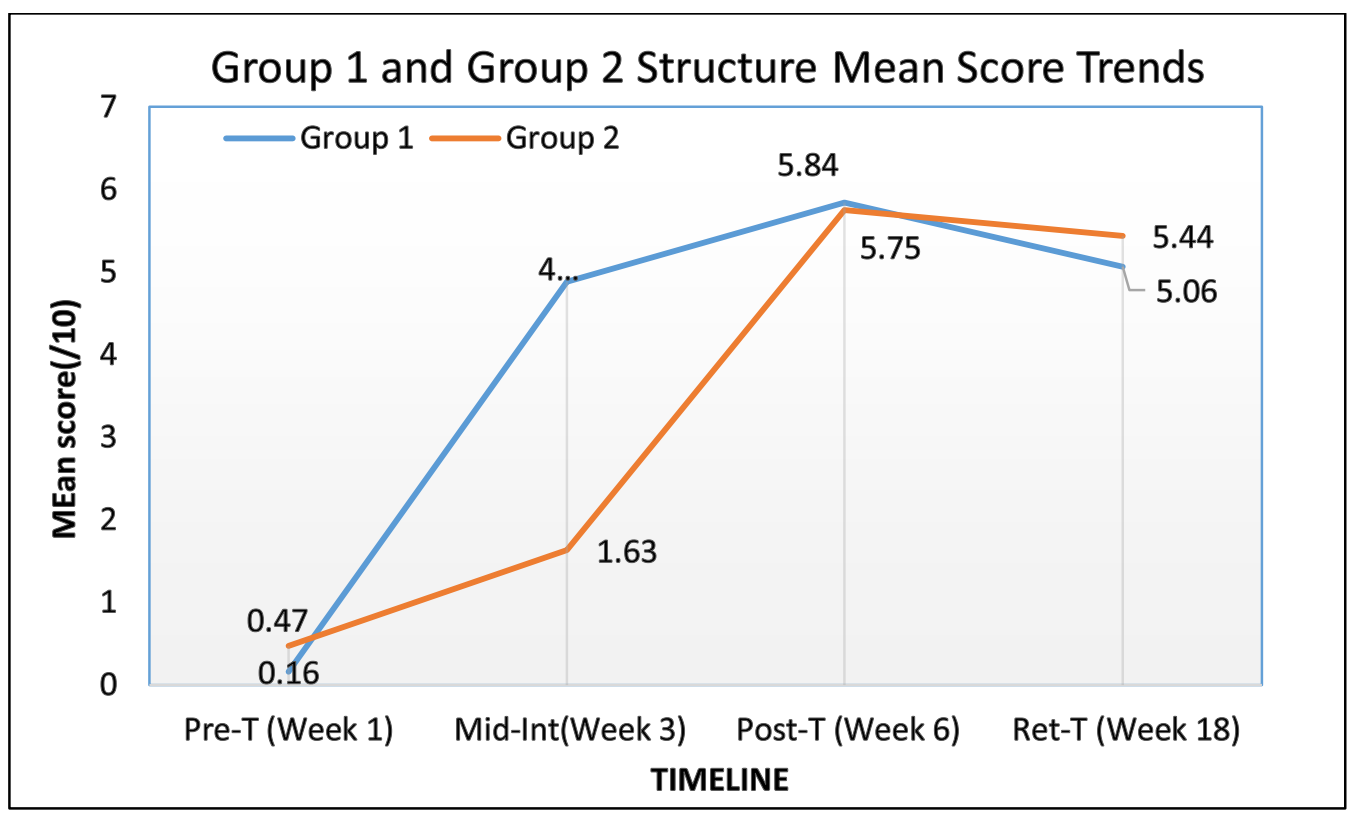

Figure 7. Group 1 and Group 2 students' pre, mid-, post-teaching, and retention mean scores on the structure subtest (maximum possible score was 10).

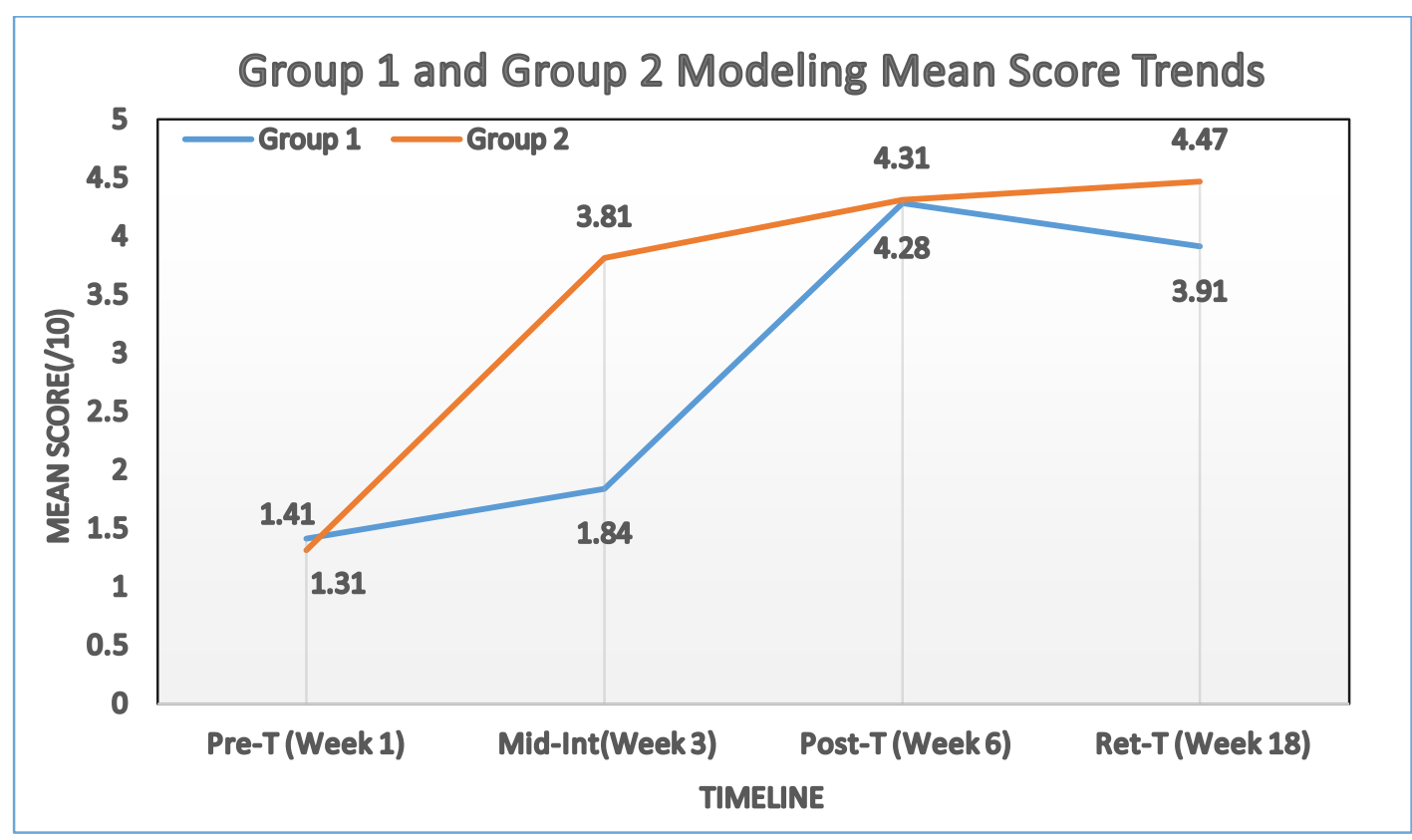

Figure 8. Group 1 and Group 2 students' pre-, mid-, post-teaching, and retention mean scores on the modeling subtest (maximum possible score was 10).

In Figure 7 and Figure 8 the "fall-off" in scores between the administrations of the post-teaching Test and the retention Test is exaggerated with respect to time. That is 
because whereas the time between the pre-teaching and mid-intervention administrations of the test was about only three weeks, and the same was true for the period between the mid-intervention and post-teaching administrations of the tests, the time between the post-teaching and retention administrations of the Test was about 12 weeks.

Nevertheless, the fall-off does raise important issues which could usefully be taken up by future researchers.

\section{Summary and Concluding Comments on the Quantitative Analyses}

The random allocation to groups was successful in that the initial, pre-teaching mean scores of the two groups so formed were approximately equal on both the structure and modeling subtests within the Algebra Test.

The structure intervention workshops were highly effective in that they generated large mean gains on the structure tests (for Group 1 at the mid-intervention stage, and for Group 2 at the post-teaching stage). The modeling intervention workshops were also very effective in that they generated impressive mean gains on the modeling tests for both groups. The gains for modeling were not as large as the gains for structure.

Analyses of student responses to questions on the retention tests (which were administered 12 weeks after the post-teaching tests) indicated that for both groups there had been a slight (statistically non-significant) fall-off in student understanding, between the post-teaching and retention stages for structure, but Group 2 had actually gained on modeling.

The pattern for the results was very similar to that reported by Zhang, Clements and Ellerton (2015), with a study involving fifth-grade students which had a similar design to the study reported in this dissertation. In that study, which also took place at School W, 
fifth-grade students were randomly allocated to two groups. One of the groups took part in multiple-embodiment workshops while the other group did not take classes in mathematics; then, the second group participated in the same type of multipleembodiment workshops while the first group did not take classes in mathematics. The same pattern of results found in the current study was obtained. Immediately after the multiple-embodiment workshops the first group had a large mean gain on a fractions test but the other group (which had not yet participated in the workshop) did not have a statistically significant mean gain. However, after the second group had participated in the workshops, it had a large mean gain on the fractions test, and the two groups obtained almost identical mean scores on the test. Then, after a 12-week break, a parallel retention test was administered to both groups and it was found that although the mean score for one of the groups had fallen a little from its post-teaching high, there were still very large pre-teaching to retention mean gains. None of the "fall-offs" for the groups was statistically significant.

Two additional comments should be made. First, Vaiyavutjamai (2003) showed that highly statistically significant gains and large effect sizes do not necessarily correspond to educationally significant results. And second, in the current study we were challenged by the same question that Zhang et al. (2015) faced: "What was there about the teaching interventions that generated such apparently impressive results?" Answers to that question with respect to the present study will be offered in the final chapter of this dissertation. However, some light will be shed on the question, and on possible answers to it, in the next chapter - which provides a summary and analyses of qualitative data. 
CHAPTER V

\section{QUALITATIVE ANALYSES OF DATA}

\section{Introduction: Intended and Attained Common Core Curricula}

Proceeding from a design-research philosophy, I wanted to frame my research around a theoretical base which would be most helpful in solving a problem that I had formulated as a result of my quantitative and qualitative analyses of data from seventhand eighth-grade students in two pilot studies (Kanbir, 2014, 2016). Despite statements in the CCSSM (2010) curriculum which suggested that the pilot-study analyses should have generated different results, the students appeared to know very little about key structural properties of rational numbers. They also struggled when asked to apply the concept of a variable in contexts which invited the application of elementary mathematical modeling language and principles.

Interviews with the seventh-graders in the pilot study, as well as analysis of preteaching data for the current study, revealed that if, for example, seventh- or eighth-grade interviewees were shown a sign like "Find the value of $64 \times\left(\frac{1}{32} \times 120\right)$," most of them would not link, in their minds, the 64 and the $\frac{1}{32}$. Rather, they would proceed by trying to find the value of $\frac{1}{32} \times 120$, and having done that, they would then multiply that result by 64 . I interpreted that finding as evidence that the students had not really received the 
intended message of the person(s) who created the sign "Find the value of $64 \times\left(\frac{1}{32} \times 120\right)$

The reader might protest that the request "Find the value of $64 \times\left(\frac{1}{32} \times 120\right)$ " is a sentence, and is not really a "sign." But, from a Peircean perspective it is a sign: whoever framed the request had a mathematical object in mind - that object was the associative property of multiplication of real numbers. Students who responded by initially trying to find the product of $\frac{1}{32}$ and 120 had seen the sign, but had not known its meaning or its implications for action. When the same students were asked to say whether $(a \times b) \times c$ was always, or sometimes, or never, equal to $a \times(b \times c)$, where $a, b$, and $c$ were numbers, they did not grasp the meaning of the question, and none of them used the words "associative property of multiplication."

Similarly, when shown a sign like "describe a quick method for finding the value of $7 \times 97+7 \times 3$," none of the pilot-study students, or the students at the pre-teaching stage of the current study, immediately recognized that $7 \times 97+7 \times 3$ was equal to 7 times $(97$ +3 ), or 700. None of them gave any indication that the task might be related to what the CCSSM curriculum for elementary and middle schools calls the "distributive property." Instead, the interviewees proceeded to try to use, in a rote way, the PEMDAS ("Please Excuse My Dear Aunt Sally)" order-of-operations mnemonic.

Expressive understandings of the seventh-grade pilot-study students and the students in the current study at the pre-teaching stage were no better than their receptive understandings of the structural properties of numbers. When specifically asked to give verbal descriptions of the associative property for addition, or the associative property for 
multiplication, or the distributive property of multiplication over addition, none of them knew the meanings of those terms (although a few of them recalled that they had heard their teachers use such expressions earlier, in elementary and middle-school mathematics classes).

The same conclusion was also reached with respect to the students' responses to modeling tasks. Whereas, they were capable of identifying recursive rules, such as "add 3," when asked to summarize successive terms in sequences which were expressed in tables of values, they were not able to identify explicit rules by writing generalized statements such as "the $n$th term is equal to $3 n-1$." More basically, their comprehension of the inter-connectedness of terms in tables of values was limited.

At the pre-teaching stage, then, the pilot-study students had neither receptive nor expressive understandings of key algebraic symbols which the authors of the CCSSM curriculum, of the NCTM Standards (National Council of Teachers of Mathematics, 2000), and of middle-school textbooks (e.g., Charles, Branch-Boyd, Illingworth, Mills \& Reeves, 2004), presumed that they should know. It is one thing to argue that "when teachers ask students to represent relationships that already make sense to them, the transition from words to variables actually is not as difficult as might be expected" (Knuth, Stephens, Blanton \& Gardiner, 2016, p. 66, original emphasis retained), but it is another thing to work out what the reality of the situation is with middle-school students in real schools which have not been part of large early-algebra intervention projects such as those described by Maria Blanton and her associates (see, e.g., Blanton, Brizuela, Gardiner, Sawrey \& Newman-Owens, 2015; Blanton, Stephens, Knuth, Gardiner, Isler \& Kim, 2015). 
The question arose: what can be done in ordinary schools to assist middle-school students and their teachers to make sense of the relationships? The current study represents an effort to answer that question.

\section{Peirce's Triadic Semiotic Position and Herbart's Theory of Apperception}

The pilot-study students did not recognize or know the meanings of important signs, and it was obviously impossible for them to reach out and grasp the associated "mathematical objects" which were prescribed in the curriculum until they had acquired receptive and expressive knowledge of the meanings of the signs. With Peirce's triadic theory, interpretants were placed as kinds of bridges between the "signs" and the "mathematical objects" being signified. Before the students could learn the meanings of the signs intended by those who framed the CCSSM curriculum they would need to be involved in relevant educative situations (Campos, 2010). It was my recognition of that state of affairs which led me to Herbart's theory of apperception, and to a decision to apply that theory in the lesson planning for the workshop interventions in the current study.

Research team members decided to design an early-algebra intervention which would include the collection and analysis of initial, pre-intervention pencil-and-paper test and interview data as well as the collection and analysis of middle- and post-intervention data. Before, during, and after the intervention component of the study, the research team would gather data relating to the students' receptive and expressive understandings of the key signs.

Johann Friedrich Herbart (1904a; 1904b), a German philosopher, educator, and psychologist, emphasized the need for teachers to take account of what modern scholars 
have called students" “cognitive structures" (Gagné \& White, 1978) or "concept images" (Tall \& Vinner, 1981) with respect to the mathematical object which it is intended the students will learn (Hayward, 1904). During the second-half of the nineteenth century, and in the early years of the twentieth century, Herbartian thinking on this matter became a cause célèbre among educators in many parts of the world (see, e.g., Adams 1897; Cole, 1912; Ellerton \& Clements, 2005) but, suddenly, early in the twentieth century, Herbartianism lost favor. Harold B. Dunkel's (1970) scholarly book, Herbart and Herbartianism: An Educational Ghost Story, in tracing the influence of Herbartianism in the United States, sought to explain why Herbartianism's “fame blazed up like a meteor and meteor-like was extinguished" (p. 4). A discussion of why that occurred is beyond the scope of the present study (but see Ellerton and Clements, 2005).

Richard Selleck (1968), the distinguished historian, stated that whatever reservations commentators might have of Herbart's views, "his work has a complexity, subtlety and coherence which make it more impressive than the writings of comparative amateurs such as Froebel or Pestalozzi” (p. 227). Such an assessment is hardly an exaggeration, for Herbart was a philosopher good enough to hold the Chair in Philosophy at Königsberg University not long after it had been held by Immanuel Kant. I chose Herbart's writings as a complement to Peirce's triadic theory for the current study because, it could be argued, it was Herbart's ideas which were behind the emphasis of some modern education researchers on the need to take account, when planning instruction, of what is already "in the students' heads."

Although, probably, twentieth-century writers such as David Ausubel, Robert Gagné, and Shlomo Vinner, would not have considered themselves to be neo- 
Herbartianists, each of them was nevertheless concerned with planning instruction so that it would take maximum advantage of what prospective learners already knew, and how they would be likely to think about the topic which was about to be taught. In the current study, the neo-Herbartian position on apperception was chosen to form the connecting idea between Peirce's concepts of "signifier" and "mathematical object."

In an influential review, Gagné and Richard White (1978) argued that cognitive structure could be regarded as being made up of four separable components-verbal knowledge, intellectual skills, imagery, and episodes. Elsewhere, Gagné added “attitudes" and "motor skills" to the list (see Gagné, 1985; Gagné \& Merrill, 1985). Although these components were conceptually separable, Gagné argued that it was the idiosyncratic cognitive links between them already existing in a learner's working memory which most influenced what and how that learner would learn from an instructional sequence.

Ian Westbury's (1980) distinction between intended, implemented and attained curriculum is particularly important for interpreting the qualitative analyses carried out in this chapter. The attained curriculum for an individual learner might be thought of as that individual's cognitive structure, with respect to a desired mathematical "object," which is the result of the student having participated in an instructional intervention aimed at helping students achieve that mathematical object. The attained curriculum is not the scores which the student obtains on post-teaching or retention tests-those scores are generated by a student's attained curriculum and the student's responses to the signs which appeared on the pencil-and-paper post-teaching and retention tests. The attained curriculum for an individual learner is not fixed in time. From that perspective, it is a 
matter of interest, in the current study, to investigate whether, and how, a participating student's cognitive structure immediately after the intervention differed from the cognitive structure 12 weeks after the intervention.

In this chapter the qualitative analyses will be mainly, but not solely, based on data gathered with respect to the pre- and post-intervention cognitive structures which characterized the thinking of the participating seventh-grade students, especially in relation to the associative properties for addition and multiplication, the distributive property, and to the elementary notions of modeling which required some knowledge of the concept of a variable. Data will be analyzed in an attempt to describe the participating students' pre- and post-intervention cognitive structures in terms of verbal knowledge, intellectual skills, imagery, episodes, and attitudes_-with Gagné's "motor skills" not being considered relevant to this study. The aim will be to show how the students' understandings of the mathematical objects associated with key middle-school algebra concepts were enhanced as a result of developments in verbal knowledge, intellectual skills, imagery, episodes, and attitudes. This kind of analysis will not only require the identification of changes in the separable components of cognitive structures, but also some discussion of how the links in cognitive structure between those components changed.

\section{Analyses of Qualitative Data Generated by the "Structure" Intervention}

In Chapter 2, I indicated that a focus of the current study would be to describe the extent to which the participating seventh-grade students learned to make associative and distributive transformations, with addition and multiplication of real numbers (which, in the context of the current study, was of rational numbers only, for irrational numbers 
were not considered). This required the gathering of data from students both before and after they participated in lessons emphasizing associative and distributive properties of rational numbers. As part of this focus, the investigation gathered data on whether students responded confidently and accurately, both receptively and expressively, to signs for which the mathematical objects under consideration were the associative and distributive properties of rational numbers, and aspects of the kind of algebra needed to deal with tasks modeled by linear sequences.

Of course, it is not possible to "videotape" what is going on in a student's mindwhat a learner knows, and how he or she thinks, has to be inferred from what is said or done in situations involving (or possibly involving) the mathematical objects under consideration. Table 9 summarizes types of data likely to be generated by certain activities and tasks related to students' responses to associative and distributive properties, and suggests how students' responses might be interpreted. In Table 9 a distinction is made between receptive and expressive responses by the students. Clements and Del Campo (1987) showed that, in fractions learning, for example, it is more difficult for middle-school students to learn to respond expressively than receptively. A similar result was expected for the current study, only with respect to the participating students' cognitive growth in algebraic structures and modeling.

Herbartian apperception theory was deemed to be especially useful for thinking in terms of bridging the educational gap between interpreting signs (used to signify structures and linear relationships) and the mathematical objects themselves — which were clearly regarded as important by those who constructed CCSSM's (2010) middle-school algebra curriculum. 
Table 9

Evidences for Qualities of Components of Students' Concept Images with Respect to

the Associative and Distributive Properties

\begin{tabular}{|c|c|c|c|}
\hline $\begin{array}{l}\text { Component } \\
\text { of Working } \\
\text { Memory }\end{array}$ & $\begin{array}{l}\text { Examples of Receptive } \\
\text { Outcomes for "Structure" }\end{array}$ & $\begin{array}{c}\text { Examples of Expressive } \\
\text { Outcomes for } \\
\text { "Structure" }\end{array}$ & $\begin{array}{l}\text { Evidences for Aspects of } \\
\text { Concept Image for } \\
\text { "Structure" }\end{array}$ \\
\hline $\begin{array}{c}\text { Verbal } \\
\text { Knowledge }\end{array}$ & $\begin{array}{l}\text { Can say, or write down, } \\
\text { accurately and from } \\
\text { memory, what has been } \\
\text { learned about the } \\
\text { associative and distributive } \\
\text { properties. There is no need } \\
\text { for this to be verbatim } \\
\text { (Gagné \& White, 1978) }\end{array}$ & $\begin{array}{l}\text { Can explain the } \\
\text { meanings of the } \\
\text { properties accurately, } \\
\text { and can apply them in } \\
\text { relevant but unrehearsed } \\
\text { situations. }\end{array}$ & $\begin{array}{l}\text { Verbal knowledge can be } \\
\text { tested through pencil-and- } \\
\text { paper tests, or through } \\
\text { task-based interviews. } \\
\text {. }\end{array}$ \\
\hline $\begin{array}{l}\text { Intellectual } \\
\text { Skills }\end{array}$ & $\begin{array}{l}\text { Can follow a demonstration } \\
\text { for a task-like, for } \\
\text { example: } \\
17+84=17+(83+1)= \\
(17+83)+1=100+1= \\
101, \\
\text { and appreciates the sense of } \\
\text { proceeding in that way. }\end{array}$ & $\begin{array}{l}\text { Can express why } \\
\text { PEMDAS rules for order } \\
\text { of operations are } \\
\text { superseded by the } \\
\text { associative and } \\
\text { distributive properties- } \\
\text { and generate examples } \\
\text { showing this. }\end{array}$ & $\begin{array}{l}\text { Willingness to employ } \\
\text { directly an associative } \\
\text { property, or a distributive } \\
\text { property, with tasks like, } \\
\text { "Find the cost of } 7 \text { apples } \\
\text { at } 99 \text { cents each." }\end{array}$ \\
\hline Imagery & $\begin{array}{l}\text { Recognize visual patterns } \\
\text { in arithmetic when these } \\
\text { are pointed out-e.g., } \\
\text { recognizes after someone } \\
\text { has pointed it out, that both } \\
97 \times 5+3 \times 5 \text { and } 17 \times \\
5.01+83 \times 5.01 \text { have } \\
\text { "common" factors and } \\
\text { therefore can be dealt with } \\
\text { using the distributive } \\
\text { property. }\end{array}$ & $\begin{array}{l}\text { Can generate visual } \\
\text { patterns of calculations } \\
\text { for which the associative } \\
\text { and distributive } \\
\text { properties would be } \\
\text { appropriate-e.g., } 398+ \\
403 \text {. } \\
\text { Can draw diagrams } \\
\text { illustrating the sense of } \\
\text { the number properties. }\end{array}$ & $\begin{array}{l}\text { The middle-school CCSSM } \\
\text { (2010) curriculum refers to } \\
\text { diagrams illustrating the } \\
\text { sense of } m(a+b)=m a+m b \text {, } \\
\text { and } a(b c)=(a b) c \text {. However, } \\
\text { many seventh-graders find it } \\
\text { difficult to link the diagrams } \\
\text { to the algebraic statements, } \\
\text { and also to realize that the } m \text {, } \\
a, b \text { and } c \text { are being used as } \\
\text { variables. }\end{array}$ \\
\hline Episodes & $\begin{array}{l}\text { Remembers episodes in } \\
\text { mathematics classes when } \\
\text { someone explained how } \\
\text { useful it could be to use the } \\
\text { associative and distributive } \\
\text { properties in mental } \\
\text { calculations. }\end{array}$ & $\begin{array}{l}\text { Recalls episodes in } \\
\text { mathematics classes } \\
\text { when someone explained } \\
\text { how useful it can be to } \\
\text { use the associative and } \\
\text { distributive properties in } \\
\text { mental calculations. }\end{array}$ & $\begin{array}{l}\text { Recalls working with other } \\
\text { students in group work, and } \\
\text { planning for and making } \\
\text { associated group } \\
\text { presentations on number } \\
\text { properties. Recalls details of } \\
\text { the number topics which were } \\
\text { the subject of group } \\
\text { discussion and presentation. }\end{array}$ \\
\hline Attitudes & $\begin{array}{l}\text { Makes observable positive } \\
\text { or negative responses when } \\
\text { number properties are } \\
\text { being studied }\end{array}$ & $\begin{array}{l}\text { Makes explicit } \\
\text { comments on the } \\
\text { (ir)relevance and value } \\
\text { of number properties. }\end{array}$ & $\begin{array}{l}\text { Of special interest is whether } \\
\text { a student's positive or } \\
\text { negative responses affect the } \\
\text { quality of his or her learning } \\
\text { of the number properties. }\end{array}$ \\
\hline
\end{tabular}


Since no other researchers had ever combined Peircean triadic semiotic theory with Herbart's theory of apperception, it was recognized from the outset that the analyses for this study might generate qualitatively different results from those obtained by other scholars researching the teaching and learning of middle-school algebra.

The choice of apperception as a bridging theory resulted in the decision to seek qualitative evidence of students' verbal knowledge, intellectual skills, imagery, episodes and attitudes, for both structure and for modeling, and to investigate how those separate components related to each other in an individual student's mind. In the remainder of this chapter qualitative evidence will be presented from various sources. Written statements by the seventh-grade students - including statements in responses to questions on the various parallel forms of the Algebra Test —will be analyzed, as will comments made by students and teachers in the intervention classes and in interviews.

The most comprehensive set of qualitative data was obviously generated by responses by participating students in the 56 one-to-one interviews ( 28 at the pre-teaching stage, and 28 at the post-teaching stage). Those interviews were audiotaped, with each interview lasting approximately 30 minutes. The writer prepared written transcripts for all of the interviews from the audiotapes. Clearly, there is a huge amount of interview data, and it was recognized, from the outset, that it would not be possible, in this dissertation, to do justice to all of it. Although the interview data would provide the foundation for the analysis which will now be presented, not all of it will be summarized in this chapter. It is intended that a fuller account of changes that occurred in students' cognitive structures as a result of their participation in the intervention workshops will be prepared at a later time. 
After all of the pencil-and-paper data had been collected, and the pencil-and-paper test and homework data were analyzed, the five members of the research team (Mr. X, Mr. Y, Prof. E, Prof. F, and the writer) met to discuss aspects of the study, and that discussion was audiotaped. Statements made in that discussion were regarded as qualitative data, and will be summarized toward the end of Chapter 6 .

In order to simplify the analyses, qualitative data for the "structure" aspect of the study will be dealt with before data from the "modeling" aspect of the study.

\section{Analyzing Samples of Interview Data Relating to "Structure"}

Each pre-teaching and post-teaching interview began with the interviewer making the following statement:

I am going to say two words to you and, as soon as I say them, I want you to say something, or draw something, or do something — do the first thing that comes into your head after I say the words. Here are the words ... "distributive property."

Here are the words again: "distributive property." What comes into your mind?"

The excerpts in Figure 9 come from a pre-teaching interview transcript. Student 2.5 's initial response was the only answer at the pre-teaching stage in which a student gave evidence of remembering previous knowledge of the distributive property and of being able to express it verbally. However, the student confused the associative property for multiplication with the distributive property for multiplication over addition, and did not give a correct instance illustrating either the distributive property or the associative property for multiplication (see Appendix $\mathrm{H}$ and Appendix I). 
Student 2.5, Pre-Teaching Interview: I remember from my lower grades. I don't remember exactly but it is something about when you take something and you put something somewhere else. You do one thing at a time.

Interviewer: That is something you will be learning about. Did you have anything or any problem come in your mind? Can you describe what you are saying or illustrate what you are saying?

Student 2.5, Pre-Teaching Interview: Okay, I have written something. In parentheses 3 times 7 and times 4 outside of the parentheses. And I switched around and it becomes 4 times in parentheses 3 times 7.

Figure 9. A student's vague (pre-teaching) "understanding" of the distributive property.

During the post-teaching interview, the same student responded to the same request - to say or do something in response to the words "distributive property — in the following terms:

Student 2.5, Post-Teaching Interview: You will be multiplying 37 times 4 and you would break down as 30 times 4 and you add with 7 times 4 you and you get 148 .

Other interview data indicated that not only had Student 2.5 's concept image changed with respect to verbal knowledge, but also with respect to intellectual skills, imagery, and episodes (see Appendix H).

The concept image of another student, Student 2.6, also obviously changed between the pre- and post-teaching stages. Data in Figure 10 show how, at the two stages, he responded to the initial request (regarding the distributive property) in qualitatively different ways. It should be noted that at the post-teaching stage both Student 2.5 and Student 2.6 were able to generate their own examples to illustrate the use of the distributive property. 
Student 2.6, Pre-Teaching Interview: Distributing numbers from multiple numbers [He could not provide any examples or any extra information].

Student 2.6, Post-Teaching Interview: Here is an example if you have 2 times 15 and 2 times 85 you would do this as 2 times in parenthesis 15 plus 85 and get 2 times 100 which is 200

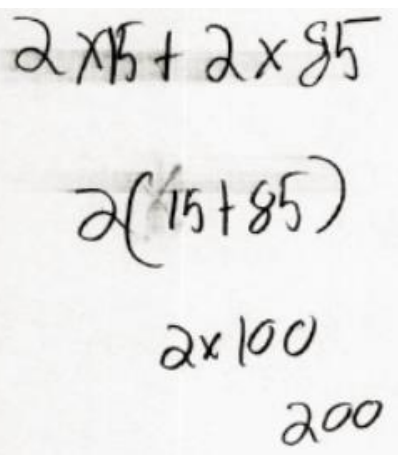

Figure 10. Student 2.6's written pre- and post-teaching interview responses to the request regarding the "distributive property."

Student 2.6's concept image with respect to structure also changed for the associative property of multiplication. One of the interview questions was "Without using a calculator, find the value of $4 \times(1 / 4 \times 128)$," and Figure 11 shows his responses at the pre- and post-teaching interviews. 
Task: Without using a calculator find the value of $4 \times\left(\frac{1}{4} \times 128\right)$ without using a calculator.

Student 2.6, Pre-Teaching Interview: I would first make $1 / 4$ into a decimal. Then I would make $1 / 4$ have a 10,000 or 100 denominator. I could get to 100 by multiplying 4 times 25. Then you multiply 0.25 and 128 .

Student 2.6, Post-Teaching Interview: I switched this parenthesis around these first two numbers. From there, 4 times one fourth and I got 1, and I multiplied it by 128 and got 128 .

$$
\begin{aligned}
& \left(4 \times \frac{1}{4}\right) \times 128 \\
& 1 \times 128=128
\end{aligned}
$$

Figure 11. Student 2.6's written pre- and post-teaching interview responses to a question concerned with the associative property for multiplication.

With the situation illustrated in Figure 12, Student 1.7 knew what to do, and was able to articulate the correct idea for what she did, but did not give the correct name for the property.

$$
\text { Task: "Find the value of } 98 \times 6+98 \times 4 \text {." }
$$

Student 1.7, Post-Teaching Interview: 980. I did 6 plus 4 is 10 and I multiplied 98 times 10 so I got 980 .

Interviewer: What is the name of the property you just used?

Student 1.7, Post-Teaching Interview: Associative.

Figure 12. A student demonstrating a correct expressive understanding of a property, without knowing its name.

Student 1.7's responses (see Figure 12) illustrate the fact that someone's concept image with respect to some topic is not made up solely of separate components (verbal, skills, imagery, episodes, attitudes). Cognitive links, or relationships between the 
components, are also important in defining the concept image. The quality of a student's response to a task is likely to be determined by the student responding to the cognitive "push" of the dominant component(s) of the concept image that she or he associates with the task.

For the "98 $\times 6+98 \times 4$ " task, knowledge of the actual name of the property which needed to be used was not really important. However, it is easy to imagine a classroom situation in which it could be important. Consider what might happen, for example, if the teacher were to be talking about the associative property for multiplication, or the distributive property, but the student mixed the labels. The end result might be that the student would not understand what the teacher was saying.

In order to collect evidence relating to a student's memory of episodes and their attitudes toward what the mathematics with which they had been concerned in the intervention workshops, students were asked directly what they remembered most about the workshops, what they liked most about the workshops, and what they liked least about them. Although it is recognized that an interviewee might give guarded, less-thanfrank, answers to such questions, the responses could nevertheless be revealing. In the current study, the responses helped me to map students' cognitive structures (see Appendix H). Figure 13 shows the response by Student 1.1 to a post-teaching interview question. The student indicated that she remembered, most of all, her participation in the "crossing-the-river" task - which is interesting because of all the tasks in which the students engaged, for both the structure and modeling interventions, the "crossing-theriver" task was the only task for which students used hands-on manipulations of special equipment. 
Interviewer: Think about the special lessons you've just had (with both teachers). What is the thing that you remember most?

Student 1.1, Post-Teaching Interview: I remember most about pattern and visualizing the crossing-the-river problem. Mr. X. taught us the distributive and the associative properties and how to use parentheses.

Interviewer: What did you like least about the lessons?

Student 1.1, Post-Teaching Interview: I was okay mostly but with the associative property sometimes I forget how to use a parenthesis and how to work with the problems.

Figure 13. Student 1.1 indicated that although she really liked the "crossing-the-river" modeling task, the associative properties sometimes confused her.

Cognitive growth in structure-related content domains. Immediately before the first intervention workshops the 32 participating students were asked to respond in writing to the written question: "Do you have any idea what the distributive property for multiplication over addition for real numbers states?" Of the 32 responses, 4 replied "Yes," and 28 replied "No." When asked to explain in writing what the distributive property was all about, none of the four who answered "Yes," gave a mathematically adequate reply - their four statements were:

- "When you distribute something or divide it."

- "It is when you do multiplication over addition first."

- "When you write out numbers in word form and solve the problem."

- "You distribute the numbers to multiply."

Although there were no elaborations of these statements it seems to have been the case that at the pre-teaching stage none of the 32 students knew what the distributive property was - despite the fact that that property is much emphasized in CCSSM's (2010) middleschool intended curriculum. 
Qualitative analysis of responses to questions on the pre-teaching version of the pencil-and-paper Algebra Test revealed that the lack of knowledge concerning structure was not confined to the distributive property. Among the questions on structure on the Algebra Test were:

2. A really important property for numbers and for algebra is called the associative property for multiplication. Describe this property in your own words?

3. Suppose you were asked to calculate the value of $940+(60+403)$ in your head (without writing anything down, or using a calculator). How would you do it, and which property would you be using?

8. Without using a calculator find the value of $(72 \times 5) \times 2$, and explain how you got your answer.

11. If $20 \times(10+5)=(20 \times 10)+(20 \times y)$, what must $y$ equal? Explain how you got your answer.

13. What would be a quick method of finding the value of $7 \times 97+7 \times 3$ without using a calculator? What is the property which allows you to use that quick method?

15. What would be a quick method of finding the value of $64 \times\left(\frac{1}{32} \times 120\right)$, without using a calculator?

A careful reading of these questions will reveal that the students were encouraged to write what they knew about the associative properties for addition (Question 3), the associative property for multiplication (Questions 2, 8, and 15) and the distributive property (Questions 11 and 13). 
During the test administration at the pre-teaching stage, students were asked to provide answers to every question — and, not surprisingly, therefore, written responses to all questions were provided by all 32 students. In fact, hardly any of the 32 students gave a correct response to any of the above questions. Most of them did not give correct verbal definitions, and they obviously did not know what the associative properties for addition and multiplication, or the distributive property, were. Four of the 32 students indicated that they had vague memories of having, at some time in the past, dealt with the properties in mathematics classes, but they could not remember what the properties were. For Question 3, only one student combined the 940 and 60 before adding 403; for Question 8, no student multiplied 5 by 2 before multiplying by 72 . And so on. There could be no other conclusion than this: at the pre-teaching stage, the 32 students did not know the relevant structures, and could not apply them.

At the post-teaching stage, however, we shall see that more than half of the participating students were able to demonstrate a relatively strong knowledge of the properties.

Changes in concept images for the associative property of addition. The question on the associative property of addition was such that only 1 of the 32 students gave a correct answer at the pre-teaching stage, but 26 of them did so at the post-teaching stage. For a question on the associative property of multiplication, the numbers of students correct at pre-teaching and post-teaching stages were 1 and 27, respectively. And, for a question on the distributive property for multiplication over addition, the preteaching and post-teaching numbers were 1 and 24 , respectively. These gains are so large that it will worth reflecting on what happened in the students' minds. 
Table 10 summarizes pre-teaching and post-teaching qualitative data for all 28 interviewees in terms of their reactions to, and knowledge of, the associative property of addition of rational numbers. The data summary is not just based on interview responses, but also on responses to pencil-and-paper questions at the pre- and post-teaching stages. Note that the concept images of 23 of the 28 students (i.e., about $82 \%$ ) changed in educationally significant ways as a result of the intervention lessons (see, also, data reported in Appendix $\mathrm{H})$.

Table 10

Summary of Data from 28 Interviewees in Relation to Concept Images for the Associative Property for Addition

\begin{tabular}{|c|c|c|c|c|c|c|c|c|c|c|}
\hline & \multicolumn{5}{|c|}{$\begin{array}{l}\text { Evidence for Pre-Teaching } \\
\text { Component in Working } \\
\text { Memory }\end{array}$} & \multicolumn{5}{|c|}{$\begin{array}{c}\text { Evidence for Post-Teaching } \\
\text { Component in Working } \\
\text { Memory }\end{array}$} \\
\hline & $\begin{array}{l}\bar{\pi} \\
\stackrel{0}{0} \\
>\end{array}$ & $\frac{\bar{\nabla}}{\sqrt{n}}$ & 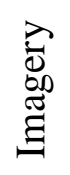 & 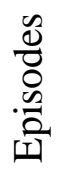 & 导 & $\begin{array}{l}\bar{\pi} \\
\overline{0} \\
\end{array}$ & $\frac{\bar{Z}}{\sqrt{\Delta}}$ & 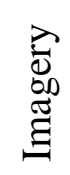 & 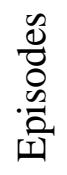 & 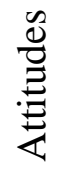 \\
\hline $\begin{array}{c}\text { Strong } \\
\text { Evidence }\end{array}$ & 0 & 0 & 0 & 0 & 0 & 18 & 21 & 20 & 21 & 21 \\
\hline $\begin{array}{c}\text { Some } \\
\text { Evidence }\end{array}$ & 0 & 0 & 0 & 1 & 1 & 5 & 2 & 3 & 2 & 2 \\
\hline $\begin{array}{c}\text { No } \\
\text { Evidence }\end{array}$ & 28 & 28 & 28 & 27 & 27 & 5 & 5 & 5 & 5 & 5 \\
\hline
\end{tabular}

In Table 10, the five "cognitive structure" components—-verbal knowledge, intellectual skills, imagery, episodes, and attitudes—are mentioned for the pre- and postteaching stages. The term "strong evidence" was used to indicated that there was definite evidence that the students had a sound knowledge of the concept, or had developed relevant skills, or could evoke appropriate imagery, or could recall relevant episodes, or had 
developed positive or otherwise appropriate attitudes. "Some evidence" implied that although there was evidence, it was not strong; and "no evidence" indicated that evidence did not exist in relation to that component of working memory. The movement from "no evidence" toward "strong evidence" is striking, and it is interesting that it occurred with respect to each of the five cognitive structure components.

\section{Changes in concept images for the associative property of multiplication.}

Qualitative analysis of pre- and post-teaching student responses to pencil-and-paper and interview questions revealed that at the pre-teaching stage none of the participating students had a well-formed knowledge of, or appreciation of the power of, the associative property for multiplication. They lacked knowledge of definitions (verbal knowledge), did not have well-developed and appropriate intellectual skills, and could not evoke appropriate images. A few of them remembered having heard the expression "associative property for multiplication" being used by the teacher at same stage in their schooling, but they did not remember details, and they had no well-developed attitudes because it was not something they had ever known or thought about.

Entries in Table 11 show that evidence for the absence or presence of, and connections between, each the five "cognitive structure" components—verbal knowledge, intellectual skills, imagery, episodes, and attitudes — was sought at the pre- and post-teaching stages. There can be no doubt that major changes occurred in the thinking of most of the participating students with respect to the associative property for multiplication as a result of the intervention. In fact, with both the associative property for addition and the associative property for multiplication about $75 \%$ of the participating students displayed an obvious movement from "no evidence" toward "strong evidence" for all five categories of working memory. 
Table 11

Summary of Data from 28 Interviewees in Relation to Concept Images for the Associative Property for Multiplication

\begin{tabular}{|c|c|c|c|c|c|c|c|c|c|c|}
\hline & \multicolumn{5}{|c|}{$\begin{array}{c}\text { Evidence for Pre-Teaching } \\
\text { Component in Working } \\
\text { Memory }\end{array}$} & \multicolumn{5}{|c|}{$\begin{array}{c}\text { Evidence for Post-Teaching } \\
\text { Component in Working } \\
\text { Memory }\end{array}$} \\
\hline & $\begin{array}{l}\overline{0} \\
\frac{0}{0} \\
>\end{array}$ & $\frac{\bar{\nabla}}{\sqrt{n}}$ & 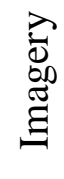 & $\begin{array}{l}\tilde{d} \\
\frac{0}{0} \\
\frac{\mathscr{n}}{2} \\
\text { 푀 }\end{array}$ & $\stackrel{\frac{\mathscr{d}}{E}}{\stackrel{\Xi}{\Xi}}$ & $\begin{array}{l}\overline{0} \\
\stackrel{0}{0} \\
\overline{0}\end{array}$ & $\frac{\bar{\nabla}}{\sqrt{s}}$ & 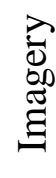 & 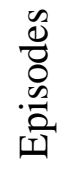 & 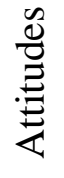 \\
\hline $\begin{array}{c}\text { Strong } \\
\text { Evidence }\end{array}$ & 1 & 0 & 0 & 1 & 1 & 16 & 15 & 18 & 18 & 18 \\
\hline $\begin{array}{c}\text { Some } \\
\text { Evidence }\end{array}$ & 0 & 1 & 1 & 0 & 0 & 10 & 7 & 3 & 3 & 3 \\
\hline $\begin{array}{c}\text { No } \\
\text { Evidence }\end{array}$ & 27 & 27 & 27 & 27 & 27 & 2 & 6 & 7 & 7 & 7 \\
\hline
\end{tabular}

\section{Changes in concept images for the distributive property for multiplication}

over addition. Entries in Table 12 show that for each of the five "cognitive structure" components — verbal knowledge, intellectual skills, imagery, episodes, and attitudes — major changes occurred, as a result of the intervention, in the thinking of most of the participating students with respect to the distributive property for multiplication. As was the case with the changes for the associative properties for addition and multiplication, about three-fourth of the students displayed an obvious movement from "no evidence" toward "strong evidence," and the changes related to each of the five cognitive structure components. More details related to changes in students' cognitive structures with respect to the associative properties for addition and multiplication, and for the distributive property for multiplication over addition, will be given later in this chapter when interview data for individual participating students will be examined. 
Table 12

Summary of Data from 28 Interviewees in Relation to Concept Images for the

Distributive Property for Multiplication Over Addition

\begin{tabular}{|c|c|c|c|c|c|c|c|c|c|c|}
\hline & \multicolumn{5}{|c|}{$\begin{array}{l}\text { Evidence for Pre- } \\
\text { Teaching Component } \\
\text { in Working Memory }\end{array}$} & \multicolumn{5}{|c|}{$\begin{array}{l}\text { Evidence for Post- } \\
\text { Teaching Component in } \\
\text { Working Memory }\end{array}$} \\
\hline & $\begin{array}{l}\bar{\pi} \\
\overline{0} \\
\overline{0} \\
\end{array}$ & $\frac{\bar{\nabla}}{\sqrt{\Delta}}$ & 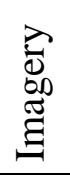 & 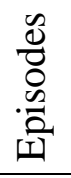 & 兽 & $\begin{array}{l}\bar{\pi} \\
\stackrel{0}{0} \\
>\end{array}$ & $\frac{\bar{\nabla}}{\sqrt{n}}$ & \begin{tabular}{l}
$\overparen{0}$ \\
$\dot{0}$ \\
\multirow{\Xi}{\Xi}{} \\
$\Xi$
\end{tabular} & 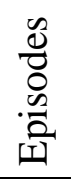 & 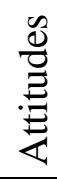 \\
\hline $\begin{array}{l}\text { Strong } \\
\text { Evidence }\end{array}$ & 0 & 0 & 0 & 0 & 0 & 15 & 19 & 20 & 20 & 20 \\
\hline $\begin{array}{l}\text { Some } \\
\text { Evidence }\end{array}$ & 0 & 0 & 0 & 3 & 0 & 6 & 3 & 3 & 3 & 3 \\
\hline $\begin{array}{l}\text { No } \\
\text { Evidence }\end{array}$ & 28 & 28 & 28 & 25 & 28 & 7 & 6 & 5 & 5 & 5 \\
\hline
\end{tabular}

\section{Analyses of Qualitative Data Generated by the Modeling Intervention}

Table 13 summarizes types of data generated when students engaged in tasks associated with the algebra of modeling. Actually, almost all of the relationships which the students were asked to consider were those arising from linear sequences - that is to say, functions whose domain was either the set of natural numbers or the set of natural numbers and zero. Entries in Table 13 suggest how students' responses might be interpreted. Once again, a distinction is made between receptive and expressive responses by the students. 
Table 13

Evidences for Qualities of Components of Students' Concept Images with Respect to Modeling Relationships

\begin{tabular}{|c|c|c|c|}
\hline $\begin{array}{l}\text { Component } \\
\text { of Working } \\
\text { Memory }\end{array}$ & $\begin{array}{l}\text { Examples of Receptive } \\
\text { Outcomes for Modeling }\end{array}$ & $\begin{array}{l}\text { Examples of Expressive } \\
\text { Outcomes for Modeling }\end{array}$ & $\begin{array}{c}\text { Evidences for Aspects of } \\
\text { Cognitive Structure for } \\
\text { Modeling }\end{array}$ \\
\hline $\begin{array}{c}\text { Verbal } \\
\text { Knowledge }\end{array}$ & $\begin{array}{l}\text { Can remember the } \\
\text { meanings of terms such } \\
\text { as "table of values," } \\
\text { "first term," "second } \\
\text { term." }\end{array}$ & $\begin{array}{l}\text { Can explain the } \\
\text { meanings of terms such } \\
\text { as "first term, "second } \\
\text { term," and " } n \text {th term" } \\
\text { accurately, and can } \\
\text { apply them in } \\
\text { unrehearsed situations. }\end{array}$ & $\begin{array}{l}\text { Knows, and can express } \\
\text { the difference between } \\
\text { recursive and explicit } \\
\text { descriptions of sequences. }\end{array}$ \\
\hline $\begin{array}{l}\text { Intellectual } \\
\text { skills }\end{array}$ & $\begin{array}{l}\text { Can follow discussion } \\
\text { related to linear } \\
\text { sequences-e.g., if the } \\
\text { teacher states that } \\
\text { "because the } n \text {th term } \\
\text { equals } 5 n \text { then the sixth } \\
\text { term equals } 30 \text { " then } \\
\text { will be able to state the } \\
\text { values of the first, } \\
\text { second, third, etc. }\end{array}$ & $\begin{array}{l}\text { Can discuss a given } \\
\text { table of values for a } \\
\text { linear sequence. Learns } \\
\text { to use the subscript } \\
\text { notation for describing } \\
\text { sequences. }\end{array}$ & $\begin{array}{l}\text { Is aware that tables of } \\
\text { values can express the } \\
\text { values of terms in a linear } \\
\text { sequence, and of } \\
\text { conventions (e.g., "..." } \\
\text { indicates the need to leap } \\
\text { to the } n \text {th term). }\end{array}$ \\
\hline Imagery & $\begin{array}{l}\text { Recognizes that with } \\
\text { linear sequences there } \\
\text { is a constant difference } \\
\text { between successive } \\
\text { terms. Can follow } \\
\text { someone's explanation } \\
\text { of relationships } \\
\text { between terms and the } \\
\text { real situation. }\end{array}$ & $\begin{array}{l}\text { Can generate visual } \\
\text { descriptions of } \\
\text { relationships between } \\
\text { the terms of a sequence } \\
\text { (e.g., "It starts at } 1 \text {, and } \\
\text { goes up by } 3 \text { each } \\
\text { time"). }\end{array}$ & $\begin{array}{l}\text { With situations relevant to } \\
\text { real-life, students can give a } \\
\text { "reason for the rule," and } \\
\text { often this is accompanied by } \\
\text { imagery. }\end{array}$ \\
\hline Episodes & $\begin{array}{l}\text { Remembers when a } \\
\text { teacher explained how } \\
\text { to interpret tables of } \\
\text { values and stated that } \\
\text { with recursive } \\
\text { specifications one } \\
\text { needs to give the first } \\
\text { term and the rule for }\end{array}$ & $\begin{array}{l}\text { Is able to identify and } \\
\text { describe, verbally and } \\
\text { in writing, recursive } \\
\text { and explicit } \\
\text { specifications from } \\
\text { tables of values }\end{array}$ & $\begin{array}{l}\text { Recalls working with other } \\
\text { students in group work, and } \\
\text { planning for and making } \\
\text { associated group } \\
\text { presentations on number } \\
\text { properties. }\end{array}$ \\
\hline Attitudes & $\begin{array}{l}\text { "going to the next } \\
\text { term." } \\
\text { Makes positive or } \\
\text { negative responses } \\
\text { when working in } \\
\text { groups or when giving } \\
\text { presentations to others. }\end{array}$ & $\begin{array}{l}\text { Makes positive or } \\
\text { negative comments to } \\
\text { others on the value of } \\
\text { studying linear } \\
\text { sequences. }\end{array}$ & $\begin{array}{l}\text { Declines to participate } \\
\text { actively in group discussion; } \\
\text { or displays leadership when } \\
\text { organizing a group. }\end{array}$ \\
\hline
\end{tabular}




\section{Interview Data: Student Responses to Modeling Tasks}

The first piece of data relates to Student 1.16's responses, in the pre- and postteaching interviews, to the task described at the top of Figure 14.

Task [The interviewee is shown a piece of paper on which " $T_{n}=2 n+3$ " is written, in large print. Then the interviewer states "If you write $T_{n}=2 n+3$, then $T_{n}$ equals 2 times $n$ and plus 3. So if we write that, then we can say $T_{5}$ equals 13 , because 2 times 5 plus 3 equals 13. So what do you think $T_{11}$ would equal?’]

Student 1.16's response in the pre-teaching interview: 143

Interviewer: Is that your final answer?

Student 1.16: Yeah.

Interviewer: Could you explain why you think the answer is 143?

Student 1.16: I got 13 from here and times 11 and I got 143.

The above response suggested that Student 1.16 had not comprehended the question - in other words, she had not understood the meaning of the sign which comprised the question.

Student 1.16's response in the post-teaching interview: 25.

Interviewer: How did you get that so quickly?

Student 1.16: So you do 2 times 11 plus 3.

Figure 14. Learning to comprehend subscript notation for linear sequences.

Student 2.12's pre- and post-teaching responses to the interview question shown in Figure 15 revealed his improvement with respect to the concept of a variable.

Task [The interviewee is shown a piece of paper on which " $T_{n}=5 n-2$ " is written, in large print. Then the interviewer states " "If $T_{n}=5 n-2$. Tell me which values of $n$ would make $T_{n}$ greater than 20 . ']

Student 2.12's response in the pre-teaching interview: First I tried 2 for $n .5$ times 2 is 10 and minus 2 is 8 . Later I multiplied 8 by 2 is 16 that is my answer.

Student 2.12's response in the post-teaching interview: I am thinking about "above 5." Because 5 times 5 is 25 minus 2 is 23. But 4 makes it 18.

Figure 15. Evidence for having learned to comprehend subscript notation. 
The captions for Figure 14 and Figure 15 refer to the verb "comprehend," which implies "knowing the meaning of the sign which has been used"-and, therefore the discussion will benefit if we enter the world of Peircean semiotics. The mathematical object being presented in each of the tasks, in Figure 14 and Figure 15, is a linear sequence (or arithmetic progression), and there is a large amount of learning needed to comprehend fully the meaning of the signs. In Figure 15, for example, Student 2.12 only partly knew the mean of the sign at the pre-teaching stage, and his interpretation of the sign's meaning was not appropriate. But, at the post-teaching stage, he knew that $n$ was being used as a variable which could take natural-number values only, and that for some of natural-number values the statement would be true and for some it would be false. By a process of trial-and-error, he determined that the answer was "above 5," which was almost correct—correct was "greater than or equal to 5."

Student 2.12's cognitive development between the pre-teaching and the postteaching stages was impressive. He was developing appropriate verbal knowledge, intellectual skills, and imagery. Undoubtedly, too, at the post-teaching stage he would have been able to relate relevant episodes from the workshops. In the post-teaching interview, it was clear that he had gained an interest in the mathematics of modeling.

The next example to be discussed is in relation to Student 1.13's pre-and postteaching responses to a table-of-values task. In the interview a sheet of paper displaying the following table of values was placed in front of her.

\begin{tabular}{c|c|c|c|c|c|c|c}
$\begin{array}{c}\text { First } \\
\text { Value }\end{array}$ & 1 & 2 & 3 & 4 & 5 & $\cdots$ & $n$ \\
\hline $\begin{array}{c}\text { Second } \\
\text { Value }\end{array}$ & 3 & 5 & 7 & 9 & $?$ & $\cdots$ & $?$
\end{tabular}

The pre-teaching interview proceeded in this way: 
Interviewer [pointing]: What number should we place under the 5 in the table?

Student 1.13: Eleven.

Interviewer: Tell me how you got your answer?

Student 1.13: It looks like the second row of numbers has odd numbers. The numbers are already there, three, five, seven, and nine. So, I was thinking that those are odd numbers. So I just added to eleven.

Interviewer: What do you think we should put under the $n$ ?

Student 1.13: Fifteen.

Interviewer: How did you get that?

Student: Because if you continue the same odd number order, the next one would be thirteen and the next question mark [pointing under the $n$ ] would be fifteen.

In this excerpt, Student 1.13 failed to recognize that there was a relationship between the two rows of numerals. The number below the "5" was to be " 11 ," she said, because the numbers along the bottom row were odd numbers, and 11 was the next odd number. There appeared to be no recognition that each number below was 1 more than twice the number above. Also, Student 1.13 did not know the convention that the three dots, ..., were intended to convey an instruction to make a cognitive leap from the particular to the general. But, after all, why should she have known that? Probably, she had never been introduced to the meaning of the "..." convention. And, because she was not aware of that convention, and because she did not see a need to relate entries in the first row with entries in the second, it was only to expected that she would say that 15 should be below the " $n$." There was no recognition of the overall meaning of the sign, and therefore she had no way of doing what, cognitively, the task "wanted" her to do. 
But, data from the post-teaching interview with Student 1.13 revealed an altogether different story (see Figure 16). The evidence for impressive pre-teaching to postteaching cognitive growth is strong.

\section{Student 1.13, post-teaching interview}

Interviewer: What about under the $n$ ?

Student 1.13: If you find a recursive rule ... you cannot do times because three times three is nine ... so you have to do it a different way [she is thinking out loud]. 2 times 3 is 6 and minus 1 does not work [she is guessing and checking]. Is it okay if I make a table here?

Interviewer: Yes.

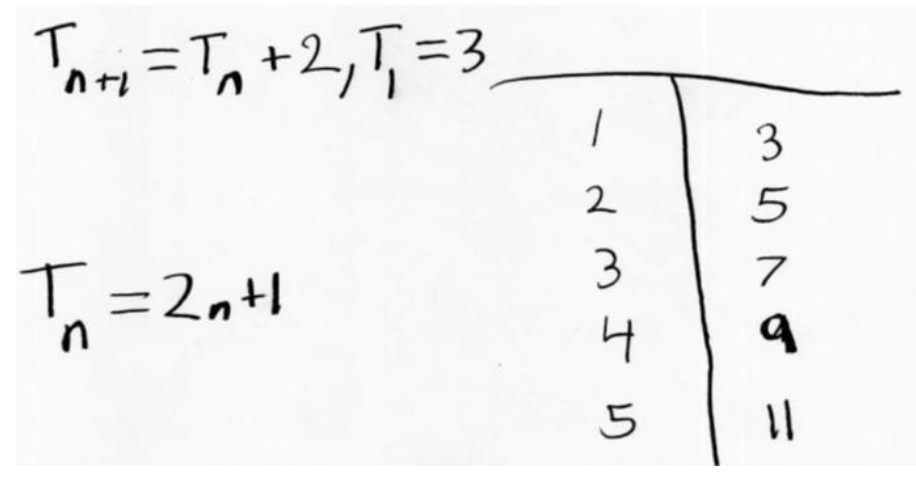

Student 1.13: You could do a recursive rule which pluses 2 each time, and write $T_{n+1}=$ $T_{n}+2, T_{1}=3$. You could also write an explicit rule which is 2 times $n$ plus one, $T_{n}=$ $2 n+1$.

Figure 16. Student 1.13 's post-teaching interview response to the "table-of-values" task.

Figure 16 points to Student 1.13 having developed appropriate verbal language and symbols. She has learned to identify and use appropriate intellectual skills, and has responded appropriately to a table of values whose orientation differed from those she had been used to seeing in class. Most importantly, she demonstrated a newly-found ability to express the explicit and recursive specifications of linear sequences in formally correct ways. All of this was done by Student 1.13 with great confidence and enthusiasm. 


\section{Cognitive Growth in Modeling Related to the Subscript Notation for a Sequence}

Each of the parallel versions of the pencil-and-paper Algebra Test included four questions in which the subscript notation for specifying the $n$th term of a linear sequence was specifically used in the wording of the question. At the pre-teaching stage, none of the participating students had been taught that notation and, therefore, it was only to be expected that the students would not know the meaning of the sign. In fact, on the preteaching version of the Algebra Test, only 2 of the 32 participating students gave correct responses to these questions; but, for the post-teaching version of the test, 17 of them gave correct answers.

The pre-teaching entries in Table 14 suggest that a few of the students had a strong intuitive idea of what the subscript notation meant, and others had some idea. The level of understanding of the meaning of the notation obviously improved as a result of the students' participation in the modeling workshops.

Analysis of classroom-observation data showed that although most of the seventhgrade students developed a receptive understanding of the subscript notation, many experienced difficult learning to use the notation in an expressive way. Often students did not know whether the variable $n$ should appear as a subscript or at the "normal" level. 
Table 14

Summary of Data from 28 Interviewees in Relation to the Use of the Subscript Notation in Modeling Tasks (Associated with Linear Sequences)

\begin{tabular}{|c|c|c|c|c|c|c|c|c|c|c|}
\hline & \multicolumn{5}{|c|}{$\begin{array}{l}\text { Evidence for Pre-Teaching } \\
\text { Component in Working } \\
\text { Memory }\end{array}$} & \multicolumn{5}{|c|}{$\begin{array}{c}\text { Evidence for Post-Teaching } \\
\text { Component in Working } \\
\text { Memory }\end{array}$} \\
\hline & $\begin{array}{l}\bar{\pi} \\
\overline{0} \\
\bar{D}\end{array}$ & $\begin{array}{l}\bar{\nabla} \\
\bar{n}\end{array}$ & 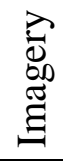 & $\begin{array}{l}\frac{0}{0} \\
\frac{\infty}{2} \\
\text { प्工ा }\end{array}$ & $\stackrel{\frac{0}{E}}{\stackrel{\Xi}{\Xi}}$ & $\begin{array}{l}\overline{0} \\
\overline{0} \\
\overline{0}\end{array}$ & $\frac{\bar{\nabla}}{\sqrt{2}}$ & $\begin{array}{l}\text { 己̇ं } \\
\text { oD } \\
\stackrel{\Xi}{\Xi}\end{array}$ & $\begin{array}{l}\frac{0}{8} \\
\frac{0}{2} \\
\text { 푀 }\end{array}$ & : \\
\hline $\begin{array}{l}\text { Strong } \\
\text { Evidence }\end{array}$ & 3 & 3 & 3 & 0 & 3 & 21 & 21 & 20 & 21 & 21 \\
\hline $\begin{array}{l}\text { Some } \\
\text { Evidence }\end{array}$ & 0 & 15 & 15 & 0 & 14 & 0 & 4 & 4 & 0 & 4 \\
\hline $\begin{array}{l}\text { No } \\
\text { Evidence }\end{array}$ & 25 & 10 & 10 & 28 & 11 & 7 & 3 & 4 & 7 & 3 \\
\hline
\end{tabular}

The analysis of data summarized in Table 14, when considered in relation to the fact that at the post-teaching stage only about half of the participating students were coping with the subscript notation, suggests that more time was needed before seventhgrade students would gain receptive and expressive understandings of the notation. Whether that is the case might be determined by further research - certainly, the issue is an important one because it would be foolish to allow difficulties with notation to stand in the way of greater positive involvement in linear sequence tasks inviting generalizations.

\section{Cognitive Growth in Modeling Related to Generalizing for the $n$th Term}

Each of the parallel versions of the pencil-and-paper Algebra Test included four questions in which respondents, having been given a pattern or set of circumstances 
which would enable the $n$th term to be determined, were asked to specify the $n$th term of a linear sequence. None of the participating students could do that at the preteaching stage, but 15 of them $(47 \%)$ consistently did it correctly at the post-teaching stage. Classroom-observation data indicated that many students found it difficult to generalize linear patterns, and some of the difficulty was related to the students' lack of confidence in using the subscript notation. Entries in Table 15 reveal that although considerable progress was made so far as generalizing to the $n$th case was concerned, 11 of the 32 participating students continued to struggle to make generalizations for linear sequence patterns, even at the post-teaching stage.

Table 15

Summary of Data from 28 Interviewees in Relation to Generalizing for the nth Case

\begin{tabular}{|c|c|c|c|c|c|c|c|c|c|c|}
\hline & \multicolumn{5}{|c|}{$\begin{array}{l}\text { Evidence for Pre-Teaching } \\
\text { Component in Working } \\
\text { Memory }\end{array}$} & \multicolumn{5}{|c|}{$\begin{array}{c}\text { Evidence for Pre-Teaching } \\
\text { Component in Working } \\
\text { Memory }\end{array}$} \\
\hline & $\begin{array}{l}\bar{\pi} \\
\overline{0} \\
\overline{0}\end{array}$ & $\frac{\overline{7}}{\sqrt{3}}$ & 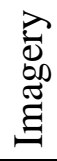 & 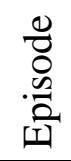 & : & $\begin{array}{l}\bar{\pi} \\
\overline{0} \\
\overline{0}\end{array}$ & $\overline{\bar{\nabla}}$ & 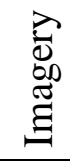 & 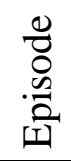 & 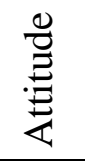 \\
\hline $\begin{array}{l}\text { Evidence } \\
\text { Found }\end{array}$ & 0 & 0 & 0 & 0 & 0 & 17 & 17 & 17 & 17 & 17 \\
\hline $\begin{array}{l}\text { Some } \\
\text { Evidence }\end{array}$ & 2 & 2 & 2 & 2 & 2 & 6 & 6 & 6 & 6 & 6 \\
\hline $\begin{array}{l}\text { No } \\
\text { Evidence }\end{array}$ & 26 & 26 & 26 & 26 & 26 & 5 & 5 & 5 & 5 & 5 \\
\hline
\end{tabular}

All writers on middle-school algebra, and the CCSSM curriculum, place great importance on developing middle-school students' abilities to generalize, and clearly for both structure and modeling workshop interventions in the current study one of the most 
important aims was to assist the students to "grow" so far as their appreciation and understanding of the mathematical object of generalization was concerned.

With the structure sessions, one important aim was for students to gain receptive and expressive understandings of the idea that if $a, b, c$, represent any rational numbers then the value of $a(b+c)$ must be equal to $a b+a c$-with the caveat that whatever value $a$ is given in the expression $a(b+c)$ must also be the value $a$ is given in $a b+a c$, etc. For mathematicians, and for most school teachers of mathematics, that caveat is not a matter of concern, but for many seventh-grade students the generality of the number properties is something which is difficult to understand. The achievement of an understanding requires a cognitive leap so far as the concept of a variable is concerned. That is why one of the most important aims of the structure workshops was for students to come to realize that the associative and distributive properties are true for all kinds of real numbers. In the workshops the students considered whether they were true for natural numbers, integers (positive and negative, and zero) and fractions. Although there has been some recent attention given to aspects of teaching middle-school students to develop more "abstract representations" so far as the number properties are concerned (see, e.g., Ding \& Li, 2014), there is a dearth of reported research on the matter.

The main mathematical object with the modeling workshops was to assist the seventh-grade students to generalize by finding, describing, and applying the $n$th term of a linear sequence. Radford (2006) identified a sequence of levels of generalization that might be applied to the thinking of middle-school students as they develop their algebraic thinking — factual generalization, contextual generalization, and symbolic generalization - with respect to linear functions. In Table 16, I included his three 
"levels" and, having recognized the difficulty which many of the participating seventhgrade students experienced in regard to the subscript notation for linear sequences, I added a fourth level, which I called "post-symbolic generalization."

Table 16

Examples of Students' Generalizations on Various Written Test Items

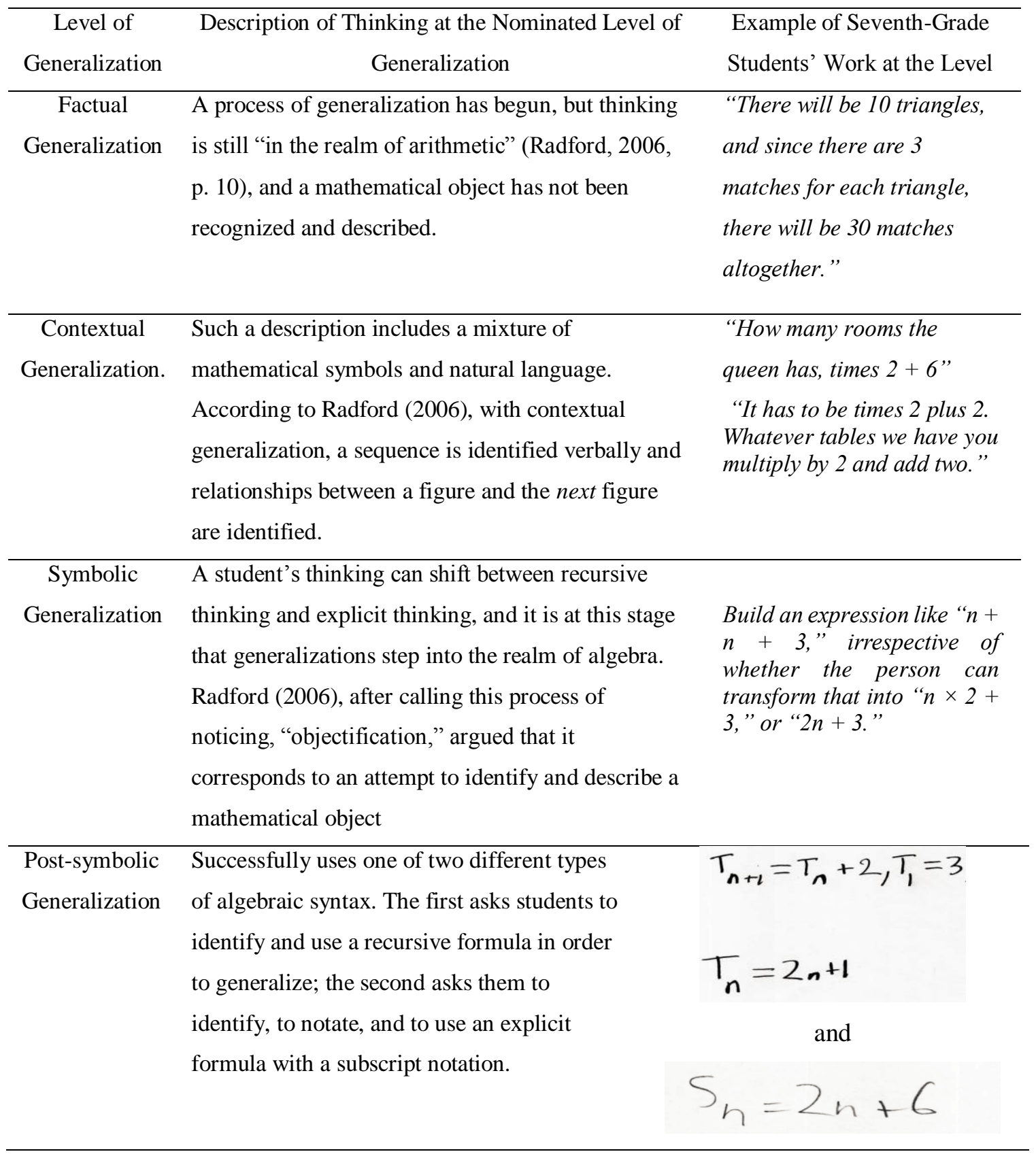


In classroom observations of the workshops it appeared to be the case that although the structure workshops and the modeling workshops were both regarded, by the teachers and students alike, as being concerned with legitimate forms of school "algebra," the signs being used, the forms of speech, and the kinds of generalizations aimed for in the structure workshops were different from the generalizations sought in the modeling workshops. Although student generalization has received much attention in the algebra education research literature over the past two decades (see, e.g., Blanton, Brizuela, Gardiner, Sawrey \& Newman-Owens, 2015; Kieran, 2011), not much attention has been paid to generalization in the context of numerical structures.

In Figure 17 an analysis of student responses at the pre- and post-teaching stages for two "horizontal table-of-values" interview task discussed earlier in this chapter is given. Levels of generalization achieved by the 28 interviewees at the two stages are shown. The cognitive growth away from the inappropriate "factual generalization" strategies, which were very common at the pre-teaching stage, toward higher levels of generalization is evident.

A similar phenomenon is illustrated, for two different tasks, in Figure 18. It can be seen that, at the pre-teaching stage, most students used inappropriate counting-on strategies, and did not understand what was needed to answer the question about what should be associated, in the sequence, with the value $n$. At the post-teaching stage, most of the students had shown some "progress," but it was still the case that about one-fourth of them were using the inappropriate factual generalization approach, despite their having participated in the workshop sessions on modeling. 


\begin{tabular}{|c|c|c|c|c|c|c|c|c|c|}
\hline \multirow{2}{*}{\multicolumn{5}{|c|}{$\begin{array}{l}\text { Student Thinking on a Modeling Task } \\
\text { Related to the } n \text {th Case and Three }(. . .) \\
\text { Dots on a Horizontal Table } \\
\text { Pre-Teaching }\end{array}$}} & \multirow{2}{*}{\multicolumn{5}{|c|}{$\begin{array}{l}\text { Student Thinking on a Modeling Task } \\
\text { Related to the } n \text {th Case and Three (...) } \\
\text { Dots on a Horizontal Table } \\
\text { Post-Teaching }\end{array}$}} \\
\hline & & & & & & & & & \\
\hline 28 & 0 & 0 & 0 & 0 & 9 & 2 & 3 & 3 & 11 \\
\hline 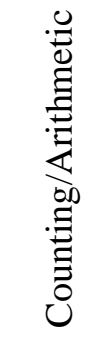 & 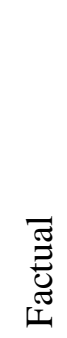 & 葛 & 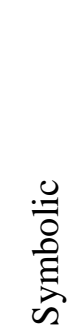 & 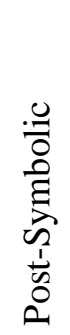 & 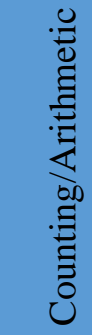 & 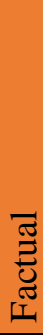 & 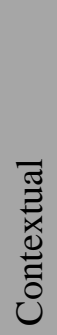 & $\begin{array}{l}: \frac{0}{0} \\
\text { है } \\
\text { ज }\end{array}$ & 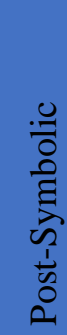 \\
\hline 26 & 1 & 1 & 0 & 0 & 5 & 4 & 3 & 6 & 10 \\
\hline \multicolumn{5}{|c|}{ Pre-Teaching } & \multicolumn{5}{|c|}{ Post-Teaching } \\
\hline \multicolumn{5}{|c|}{$\begin{array}{l}\text { Student Thinking on a Modeling Task } \\
\text { Related to } n \text {th Case Generalization }\end{array}$} & \multicolumn{5}{|c|}{$\begin{array}{l}\text { Student Thinking on a Modeling Task } \\
\text { Related to } n \text {th Case Generalization }\end{array}$} \\
\hline
\end{tabular}

Figure 17. Student generalizations in the pre-and post-teaching interviews.

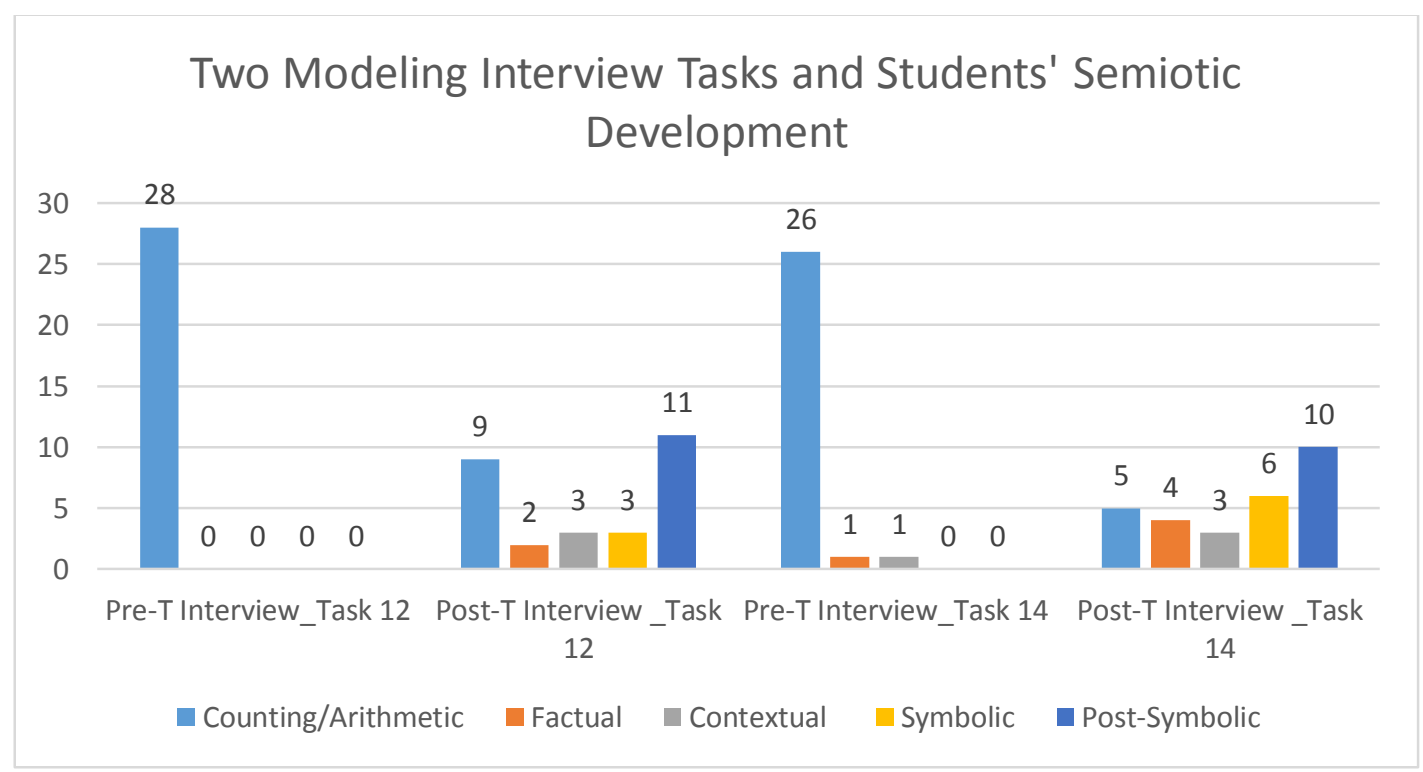

Figure 18. Seventh-grade students' cognitive growth on two different tasks inviting students to state the rule for the $n$th term. 


\section{Analyses of Student Responses to Six Interview Questions}

This section will summarize responses given in pre- and post-teaching interviews by six students (one low, one average. and one high achiever from Group 1, and one low, one average and one high achiever from Group 2) to each of six interview questions. The basis for classification and selection of the students (as low, average, high) was the score obtained on the pre-teaching version of the Algebra Test.

There are two aims for this section. The first is to show the effect of the intervention workshops on students' cognitive structures. When pre-teaching and postteaching responses are compared, effects of instruction are suggested. The second aim is to enable the reader to judge differences in cognitive growth patterns between low, average and high achievers.

The method of presentation will be as follows: first the task will be stated, and then responses of the two low achievers, the two average achievers, and the two high achievers, at pre-teaching and post-teaching stages, will be shown. The symbol "S" will be used to denote "Student."

Occasionally, a student gave an appropriate answer at the pre-teaching stage, but answers at the post-teaching stage tended to be much more confident, and indicative of cognitive growth toward understanding of the mathematical objects being considered. One only has to examine the CCSSM (2010) middle-school curriculum carefully to come to realize that generalization is regarded as an important objective for the curriculum, but the following evidence would suggest that learning to generalize is something much more difficult than is commonly recognized. Readers are invited to keep that thought in mind as they take account of the data. 
Task: "I am going to say two words to you and, as soon as I say them, I want you to say something, or draw something, or do something - do the first thing that comes into your head after I say the words. The first sets of words are ... "distributive property." Here are the words again: "distributive property." What comes to your mind?

\section{Pre-Teaching Interview}

Student

1.1

(Low

Score)

Student

2.5

(Low

Score)

S: Breaking the problem down example what do you mean by that? 4 times 2 which equals 8 .

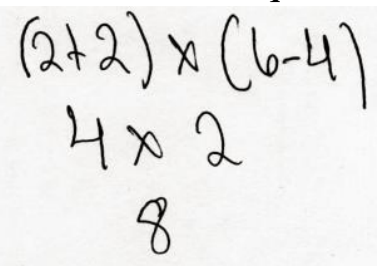

S: I remember from my lower take something and you put Interviewer: Can you give me an

S: 2 plus 2 times 6 minus 4 equals grades. I don't remember exactly, but it is something about ... You something else. You do one thing at a time.

Interviewer: Can you describe or illustrate what you are saying?

S: Okay. I have written something. In parentheses, 3 times 7 and times 4 outside of the parentheses. And I switched it around and it becomes 4 times in the parentheses 3 times 7.

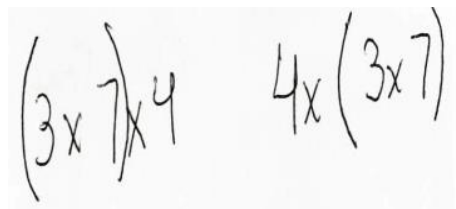

Student S: I think of "parentheses." 1.6 Interviewer: Could you write (Average something down or draw Score) something? What else? S: An addition sign.

\section{Post-Teaching Interview}

S: Breaking down a problem and moving parentheses.

Interviewer: Can you write an example?

S:

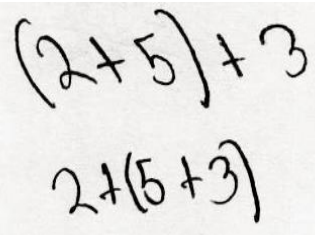

S: You will be multiplying 37 times 4 and you would break it down as 30 times 4 and you add 7 times 4, and you get 148 .
S: Parentheses. Breaking down to numbers.

Interviewer: Can you write an example?

S: 94 times 4 can be written as 90 times 4 plus 4 times 4 . 


\begin{tabular}{|c|c|c|}
\hline & & $\begin{array}{l}94 \times 4 \\
4 \times 90=360 \\
4 \times 4=16\end{array}$ \\
\hline $\begin{array}{l}\text { Student } \\
2.2 \\
\text { (Average } \\
\text { Score) }\end{array}$ & $\begin{array}{l}\text { S: "Parentheses," "exponent," } \\
\text { "addition," and "subtraction." } \\
\text { Interviewer: Can you give an } \\
\text { example? } \\
\text { S: I would do seven plus } 2 \text { in } \\
\text { parentheses first. I got } 9 \text {, and then } \\
9 \text { minus } 4 \text { gives } 5 \text {. }\end{array}$ & $\begin{array}{l}\text { S: If you want to calculate } 9 \\
\text { times } 110 \text { you could do first } 9 \\
\text { times } 100 \text { plus } 9 \text { times } 10 \text {. It } \\
\text { would make this calculation } \\
\text { easier. } \\
\qquad 9 \times 110\end{array}$ \\
\hline $\begin{array}{l}\text { Student } \\
1.11 \\
\text { (High } \\
\text { Score) }\end{array}$ & $\begin{array}{l}\text { S: I have "method" and } \\
\text { "subtraction." } \\
\text { Interviewer: Why did you write } \\
\text { those? } \\
\text { S: Those are of two things that } \\
\text { first came to my mind. Because I } \\
\text { remember something about the } \\
\text { distribution (sic.) property. } \\
\text { Interviewer: Thanks for that. }\end{array}$ & $\begin{array}{l}\text { S: I wrote "easier and faster" } \\
\text { because the properties are used } \\
\text { to make harder math equations } \\
\text { go by quicker. } \\
\text { Interviewer: What does the } \\
\text { distributive property actually } \\
\text { mean? } \\
\text { S: I don't remember if it is } \\
\text { distributive or associative, but } \\
\text { if there is an equation that has } \\
\text { two of the numbers say } 44 \text { and } \\
\text { you can just combine those } \\
\text { together and as one but then } \\
\text { the remaining numbers ... }\end{array}$ \\
\hline $\begin{array}{l}\text { Student } \\
2.7 \\
\text { (High } \\
\text { Score) }\end{array}$ & $\begin{array}{l}\text { S: "Math." } \\
\text { Interviewer: Anything else? What } \\
\text { is the distributive property? } \\
\text { S: I don't know. }\end{array}$ & $\begin{array}{l}\text { S: "Multiplication." } \\
\text { Interviewer: Why did you } \\
\text { write multiplication? } \\
\text { S: Because when I think of } \\
\text { that, it's easier to do } \\
\text { multiplication than addition } \\
\text { and subtraction. } \\
\text { Interviewer: Give me an } \\
\text { example. Why do you think } \\
\text { it is easier? }\end{array}$ \\
\hline & & $\begin{array}{c}3(a+b) \\
3 a+3 b\end{array}$ \\
\hline
\end{tabular}


Task: "Without using a calculator, find the value of $482+(18+300)$."

Pre-Teaching Interview

Student $1.1 \quad$ S: I did 300 plus 18 which is 318.

(Low Score) Then 482 plus 318 which equals 800 .

Student 2.5 S: First I added 18 plus 300 in

(Low Score) the parenthesis. And then I got

318 by adding two numbers, and then I added 482 with 318 and got 800 .

Student 1.6

(Average

Score)

Student 2.2

(Average

Score)
S: First I did 482 plus 18 makes it 490; and 300 more--I got 790.

Post-Teaching Interview

S: 800. I did 482 plus 18 and got 500. And I added 300 and got 800 .

S: 800.

Interviewer: How did you get that?

S: I added first 482 plus 300 which is 782 and plus 18 . Interviewer: What is the name of the property?

S: The associative property.

S: You could do 482 plus 18 which would be 500 and plus 300 and you would get 800 .

S: I did 482 plus 18 which is 500, and I added 300 and got 800.

Interviewer: Do you know the name of the property?

S: I used the associative property and moved the parentheses.

S: So I would move the parentheses around 482 plus 18. And then add those two together which would get 500. Then 500 plus 300 which is 800 .

Interviewer: Do you know the name of the property you just used?

S: Distributive? Or associative? I think it is associative.

$$
(482+(18)+300)
$$


Student $2.7 \quad$ S: I did 300 plus 18. Then, I did S: 800 .Because I put the (High Score) 482 plus 318. I did first $300 \quad$ parentheses around 482 plus plus 400 which is 700 and then 18 , and plus 300 , which is 800 . 82 plus 18 which is 100 and I Interviewer: Why are you added 700 and 100 . allowed to do that? S: The associative property. 
Task: "Without using a calculator, find the value of $4 \times(1 / 4 \times 128)$."

\section{Pre-Teaching Interview}

Student

1.1

(Low

Score)
S: So far I have done 128 times 25 and I got 3200 .

Interviewer: What are you going to do now?

S: Times 4 and I got 12800 .
Post-Teaching Interview

S: I got 2048. I did 4 times 4 which is 16 and I did 16 times 128 .

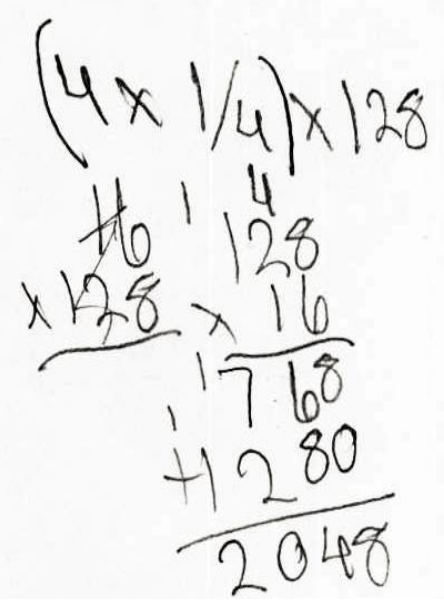

S: First I would multiply onefourth times 128 because the parentheses come first; and I would get 128 over 4 which is 32. Finally, 4 times 32 gets 128 .

S: You could do 4 times onefourth and times 128. I did four over one times one over four which is one and times 128 . I got 128.

Interviewer: What is the name of the property you just used? S: The associative property of addition.

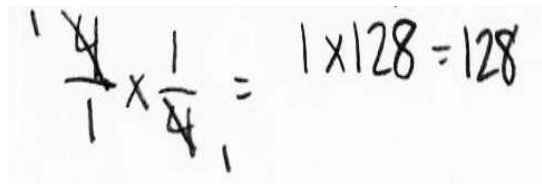


Student S: I would first multiply one-fourth

2.2

(Average

Score)

times 128 and make that into an

improper fraction.
Interviewer: Okay. You divided 128 by 4 and you got 32 .

S: Yes. I think 32 times 4 . I would then multiply it by four and get 128 .

Student

1.11

(High

Score)
S: First, one-fourth times 128. It would be 128 over 4 . That is an improper fraction. The method we used is called "tip over" and multiply it. I would do 128 over 4 and it is 32 . But, still I have to multiply by 4 . Which means 128 .

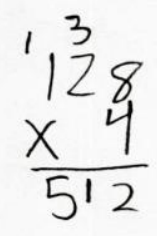

S: I changed the parentheses around 4 times one-fourth which is 1 ; and I multiplied it by 128 and got 128 .

Interviewer: Do you know the name of the property?

S: This would be the distributive property.

S: I would move the parentheses around 4 and multiply 4 times one-fourth first. What I would do, 4 as a fraction is 4 over 1 so 4 over 1 times 1 over 4 you do cross simplify and the problem becomes one over one and problem becomes 128 times 1 . So the answer is 128 .

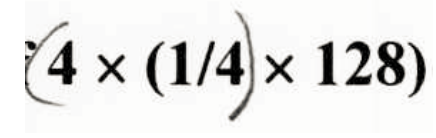


Task: "If $T_{n}=5 n-2$. Tell me which values of $n$ would make $T_{n}$ greater than $20 . "$

Pre-Teaching Interview

Student S: 10 .

1.1

(Low

Score)

Interviewer: Why did you choose 10 ?

S: If you 5 times 10 you get 50 which is greater than 20. I was just thinking 20 and how you do 2 times 10 to get 20 and 10 times 5 which is more than 20

Student S: A value could be 5 .

2.5

(Low

Score)

Interviewer Okay. What made you decide that?

S: Because 5 times 5 is 25 and minus 2 which is 23 . It is still higher than 20 .

Interviewer: Is that the only number that could make $T_{n}$ greater than 20 ?

S: Any number higher than 5 could work.

Student S: 5 would work. Because 5

1.6 times 5 is 25 and minus 2 is 23

(Average which is greater than 20.

Score) Interviewer: What values did you find?

S: Five.
Post-Teaching Interview

$\mathrm{S}: n$ equals 6 . So 5 times 6 is 30 and minus 2 is 28 .

Interviewer: Do you think this is the only value which makes it greater than 20 ?

S: You can also do it with 5. 5 also makes it greater than 20 .

S: It would probably be 5 and up. Because if we put 5 times 4 and subtract two that would be 18 [ $\left.T_{4}\right]$. But you can do $T_{5}$ which is 5 times 5 minus 2, which is 23 .
S: It could be 5 because $T_{5}$ equals 5 times 5 minus 2 which is more than 20 . So $T_{6}$ also works as well. Any number bigger than 5 makes it greater than 20 .

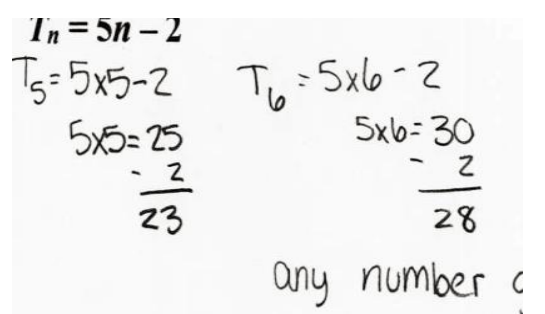

S: Any number greater than 5. If you take 5 times 5 and minus 2 is more than 20. You could do the same thing for $6,7,8$, and so on. 
S: Yes. Anything over 5. Because 5 times 5 is 25 and minus 2 is 23 which is more than 20 .

Student S: Well! I did math in my head. $1.11 \quad$ First number would be 5 .

(High Because 5 times 5 is 25 and

Score) subtract 2 which gives me 23. Any number above 5 would be an answer.

Student S: Six times five minus 2 equals

2.7

(High

Score) 28

Interviewer: What else?

S: 6,7 , and then 8 .

$$
\begin{gathered}
T_{5}=25-2=23 \\
T_{6}=30-2=28 \\
5 \text { or more }
\end{gathered}
$$

S: I just decided to pick a number, I starter with a 4 and 5 times 4 is 20 and minus 2 is 18 . I decided to go up one number and put it in because 4 becomes less than 20. My answer is 5 and above.

S: 5, 6, 7, 8, and like more...

Interviewer: What about 4 ?

S: No. 5 times 4 minus 2 is 18 which is less than 20 . 
Task: Give the pupil a piece of paper with the following table on it:

\begin{tabular}{|c|c|c|c|c|c|c|c|}
\hline $\begin{array}{c}\text { First } \\
\text { Value }\end{array}$ & 1 & 2 & 3 & 4 & 5 & $\cdots$ & $n$ \\
\hline $\begin{array}{c}\text { Second } \\
\text { Value }\end{array}$ & 3 & 5 & 7 & 9 & $?$ & $\cdots$ & $?$ \\
\hline
\end{tabular}

Then ask (pointing): What number should we place under the $\mathbf{5}$ in the table?

Then ask (pointing): What do you think we should we put under the $n$ ?

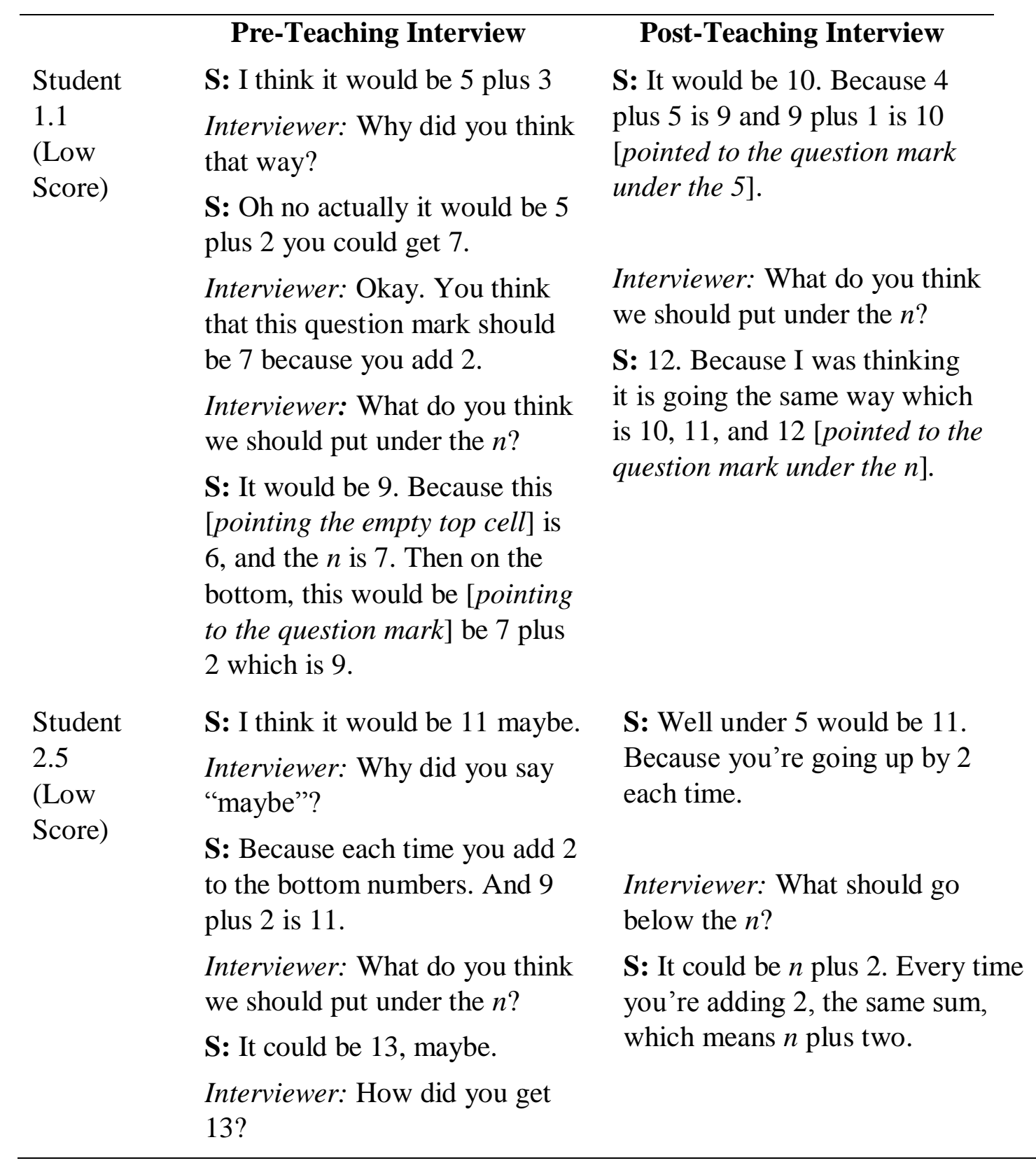


$\mathrm{S}$ : Because this question mark on the top would be 7 and on the bottom would be 13 .

Student S: I think it would be 11.

1.6

(Average

Score)

Student

2.2

(Average

Score) 15.
Student

1.11

(High

Score)
Interviewer: What do you think we should put under the $n$ ?

S: I think it is 14 . I think that it's going up by like 2, 3, 4, 5, and 6 . If there would 6 it goes up by 7 and then this would go up by 8 . Wait ... that would be

S: 11. Would be 11. Because it goes up by two [pointing out the second values] 3 plus 2 is 5,5

plus 2 is 7 , and this one [pointing beneath the 5] 9 plus 2 is 11 .

Interviewer: What do you think we should put under the $n$ ?

S: 15 . Because. This one [pointing the blank part of the second row] would be 13 and two more would be 15 .

S: First, I would find a pattern. I could subtract second row minus first row numbers, because, the second row numbers are always bigger. Each time the difference between the numbers grows by 1. Last set up number difference before the comma is 5 . I would add 6 to 5 which gives me 11 .
S: 11. It is plus three, plus four, plus five, and plus 6 which is 5 plus 6.

Interviewer: What do you think we should put under the $n$ ?

S: $T_{n}$ equals $2 n$ plus 1

$\left[T_{n}=2 n+1\right]$

Interviewer: What do you call this rule?

S: It is an explicit formula.

S: This would be 11. Because every timer this goes up by 2 . So 9 plus 2 is 11 .

Interviewer: What do you think we should put under the $n$ ?

S: Would it be $T n$ ?

Interviewer: Can you try to find $T_{n}$ ?

S: $2 n$ plus $1 . T_{n}=2 n+1$.
S: The difference between each row goes up each time by 1.4 then 9 which is the difference is 5 and then the next difference will be 6 . So, the number under the 5 is 11 .

Interviewer: What is your final answer?

S: 11 .

Interviewer: What should go below the $n$ ? 
Interviewer: What is your final answer?

S: I would say the question mark is equal to 11 .

Interviewer: What should go below the $n$ ?

S: To get to that, I would look at the next two empty boxes. The top one would 7 because the first row goes up by 1 and the bottom row goes up by 2 which is 7 to 13 . Then, the bottom number right below the $n$ will be 15 .

Student

2.7

(High

Score)
$\mathrm{S}$ : So the pattern is the difference between the second row and the first row is 1 , and goes up each time by 1 . I have to go up by 6 from 5 so the first question mark would be 11 . Then for the question mark below $n$... I believe it would be $T_{n}$.

Interviewer: So what do you think $T_{n}$ would be equal?

S: In order to find that we have to find the explicit rule. But I am not sure how to write this.

The difference goes up by 1 each time. $T_{n}$ equals $n$ times 2 plus 1 .

$$
T_{n}=2 n+1
$$

S: 11

Interviewer: Why is it 11 ?

S: To get 3 here you do 1 times 2 plus 1 and 5 times 2 and plus 1 is 11. plus 2 is 9 , and 9 plus 2 is 11 .

Interviewer: What should go below the $n$ ?

S: 15 .

Interviewer: What should go below the $n$ ?

Interviewer: Why do you think the answer is 15 ?

S: Because, you are adding 2 to each number.

S: This is $T_{n}$ equals $2 n$ plus one [writes down $T_{n}=2 n+1, T_{1}=3$ ], and $T_{1}$ equals 3 .

Interviewer: Okay. Well done!

Interviewer: Thank you. Write down your final answer.
$T_{n}=2 n+1, T_{1}=3$ 


\section{Task:}

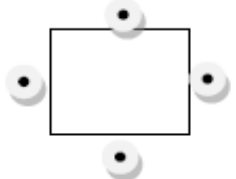

1 Table

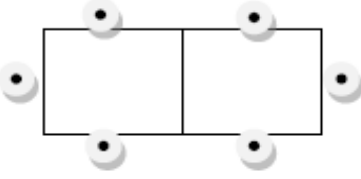

2 Tables

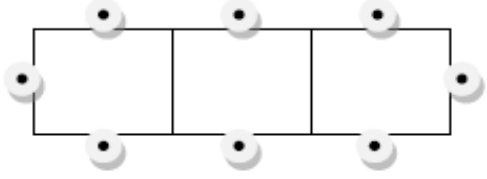

3 Tables

A. If 10 tables were pushed together (in a straight line), how many people could sit around them (assuming the pattern shown above)?

B. If $\boldsymbol{P}_{\boldsymbol{n}}$ represents the number of people who can sit when $\boldsymbol{n}$ tables are pushed together (in a straight line), what is the rule giving $P_{n}$ in terms of $n$ ?

\begin{tabular}{|c|c|c|}
\hline & Pre-Teaching Interview & Post-Teaching Interview \\
\hline $\begin{array}{l}\text { Student } \\
1.1 \\
\text { (Low } \\
\text { Score) }\end{array}$ & $\begin{array}{l}\text { S: You could have } 30 \text { people. } \\
\text { Interviewer: How did you do } \\
\text { it? } \\
\text { S: You have to take } 2 \text { people } \\
\text { off the ends. First I took one } \\
\text { person from each table. } 40 \\
\text { minus } 10 \text { which is } 30 \text { people. } \\
\text { Interviewer: What about the } n \text { - } \\
\text { table case? } \\
\text { S: You would do } 5 \text { tables. You } \\
\text { will have } 15 \text { people. } \\
\text { Interviewer: How did you get } \\
15 \text { ? } \\
\text { S: I did } 5 \text { times } 3 \text {. I though } 15 \\
\text { people could sit around } 5 \\
\text { tables. } \\
\text { Interviewer: Because you look } \\
\text { at } 3 \text { people around the table } \\
\text { and multiply by three? } \\
\text { S: Yes. }\end{array}$ & $\begin{array}{l}\text { S: Each time they are adding } 2 \\
\text { more people. I counted and got } 22 \text {. } \\
\text { Interviewer: Okay. What about the } \\
n \text {-table case? } \\
\text { S: You want me to write an } \\
\text { explicit something? } \\
\text { Interviewer: Yes. Can you come } \\
\text { up with the explicit formula? } \\
\text { S: } P_{n+1} \text { equals } n+22 \text {. }\end{array}$ \\
\hline $\begin{array}{l}\text { Student } \\
2.5 \\
\text { (Low } \\
\text { Score) }\end{array}$ & $\begin{array}{l}\text { S: I got } 22 . \\
\text { Interviewer: Did you count } \\
\text { them all? }\end{array}$ & $\begin{array}{l}\text { S: There will be one person on each } \\
\text { side you can sit on. Three people } \\
\text { get one table each time. There will } \\
\text { be } 10 \text { people on top side and } 10\end{array}$ \\
\hline
\end{tabular}




\begin{tabular}{|c|c|c|}
\hline & $\begin{array}{l}\text { S: Yes. These two first and I } \\
\text { kept adding each one. } \\
\text { Interviewer: What about the } n \text { - } \\
\text { table case? } \\
\text { S: } n \text { tables ... We can find what } \\
\text { the } n \text { is and count to see how } \\
\text { many people there would be } \\
\text { around the } n \text { tables. }\end{array}$ & $\begin{array}{l}\text { people on bottom side and } 2 \text { on } \\
\text { each ends. Total, } 22 \text { people. } \\
\text { Interviewer: What about the } n \text { - } \\
\text { table case? } \\
\text { S: } n \text { would equal three plus } n \\
\text { because it depends on how many } \\
\text { there are and then subtract one if } \\
\text { you are between two tables. }\end{array}$ \\
\hline $\begin{array}{l}\text { Student } \\
1.6 \\
\text { (Average } \\
\text { Score) }\end{array}$ & $\begin{array}{l}\text { S: Total } 22 \text { people. } 10 \text { people } \\
\text { could sit on each side and } 2 \\
\text { people at the ends. } \\
\text { Interviewer: What about the } n \text { - } \\
\text { table case? } \\
\text { S: Would still be add the sides } \\
\text { and } 2 \text { ends. } \\
\text { Interviewer: What if you had } \\
50 \text { tables? } \\
\text { S: } 102 \text {. } \\
\text { Interviewer: What if you have } \\
n \text { tables? You can create your } \\
\text { general rule about this design. } \\
\text { S: Add the sides and ends. } \\
\text { Interviewer: Ends means plus } 2 \\
\text { right? } \\
\text { S: Yes. }\end{array}$ & $\begin{array}{l}\text { S: } 22 \text { people. If there is } 10 \text { tables } 10 \\
\text { people for each sides and } 2 \text { people } \\
\text { at the ends. So } 10 \text { times } 2 \text { pus } 2 \text {. } \\
\text { Interviewer: What about the } n \text {-table } \\
\text { case? What if you have } n \text { tables? } \\
\text { S: } P n \text { equals } P_{2} \text { plus } 2 \text {. } \\
P_{n}=10 \times 2+\tau \\
P_{n}=\text { sides plus ends }\end{array}$ \\
\hline \multirow[t]{2}{*}{$\begin{array}{l}\text { Student } \\
2.2 \\
\text { (Average } \\
\text { Score) }\end{array}$} & $\begin{array}{l}\text { S: } 22 \text { people can sit around } 10 \\
\text { tables. } \\
\text { Interviewer: Tell me more } \\
\text { about it. } \\
\text { S: I have } 10 \text { people here and } \\
\text { one more which is } 11 \text { and I } \\
\text { have another } 10 \text { there (bottom } \\
\text { or top of ten tables) and then } \\
\text { one more then total would be } \\
22 . \\
\text { Interviewer: Okay. What about } \\
\text { the } n \text {-table case? }\end{array}$ & $\begin{array}{l}\text { Interviewer: What about the } n \text {-table } \\
\text { case? You wrote down a formula } \\
\text { there. What type of rule is that? } \\
\text { S: Explicit rule. } \\
\text { Interviewer: How did you get that? } \\
\text { S: You add } 2 \text { each times it } \\
\text { increases, based on a pattern. } P_{n} \\
\text { equals } 2 n \text { plus } 2\end{array}$ \\
\hline & $\begin{array}{l}\text { S: Take two sides which is } \\
\text { multiplying by two. You would }\end{array}$ & \\
\hline
\end{tabular}


do the number of tables times 2

and plus two. Because two

people on each end of the

table.

Student

1.11

(High

Score)
Student

2.7

(High

Score)
S: 3 tables makes, 3 bottom and 3 top and 2 ends which is 8 people. If you think 10 tables, the answer would be 22 .

Interviewer: How did you get that?

S: Because on each sides [pointing to the top and bottom] the numbers are equal-10 plus 10 . It would be 22.

Interviewer: 10 plus 10 plus one plus one which is 22 people.

Interviewer: What about the $n$ table case?

S: It is difficult.

Interviewer: If you have 100 tables?

S: It would be 202 people.

Interviewer: What about 50 tables?

S: It would be 102 people.

Interviewer: Can you verbalize your formula based on $n$ tables?

S: I don't know.

S: Twenty-two people. Because it depends how many tables, so if you have 10 tables, 10 people on one side and 10 people on the other side. And one for each side of the tables [Pointed to the ends of the first and the last table].
S: 3 tables makes, 3 bottom and 3 top and always 2 ends which is 8 people. If you think 10 tables, the answer would be 22 .

IB: How did you get that?

S: By multiplying 10 times 2 and 2 extra ends.

Interviewer: What about the $n$ table case?

S: I believe it will have to be a variable. For example, $T_{n}$. Interviewer: What does $T_{n}$ equal? S: $\mathrm{T}_{n}$ would equal $n$ times 2 plus 2.

Interviewer: How would you write it?

S: I wrote $T_{n}=2 n+2$.

Interviewer: How would you get

22 from that, if you have 10

tables?

S: You would follow how the rule goes. If $n$ were 10 and it would be 10 times 2 plus 2 equals 22 .
S: 22 . Because there are 3 [people] on each end and 3 times 2 plus the middle tables (on top and bottom) 8 plus 8 and total would be 22 .

Interviewer: What about the $n$ table case? 


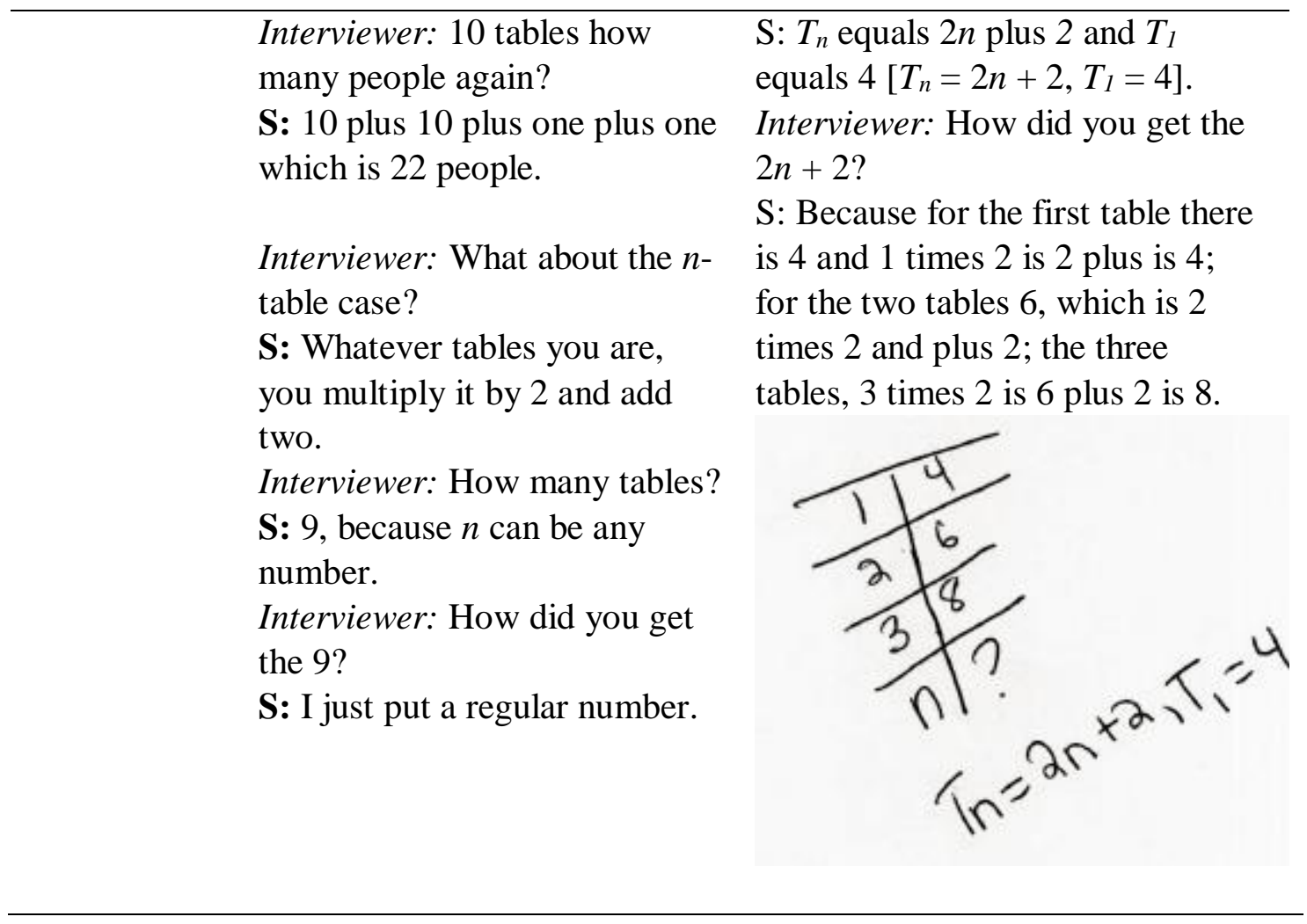

\section{Qualitative Analyses of the Implemented Curriculum}

Details of the implemented curriculum were well documented (see Appendices D, E, F), the aim being to provide sufficient documentation to enable the study to be replicated - either at School W or at any other middle school. The quantitative analyses in Chapter 4 and the qualitative analyses in this chapter generated results that had a sufficiently clear interpretation to make it worthwhile for the study to be replicated.

Much of the printed documentation for aspects of the implemented curriculum are given in Appendices A, B, C, D, E, F and G which appear toward the end of this dissertation. These appendices are titled:

Appendix A: Protocol for Algebra Interviews with Seventh-Graders Appendix B: Algebra Tests (Three Parallel Versions are Reproduced) 
Appendix C: "Questionnaire" Completed by Seventh-Grade Students at School W at the Beginning of the Algebra Workshops on "Structure"

Appendix D: Statement of Instructional Aims for the Structure Workshops with the Seventh-Grade Students at School W

Appendix E: Detailed Lesson Plans for Four Workshops on "Structure" for SeventhGrade Students at School W, Including Homework Challenges for Each Workshop

Appendix F: Detailed Plans for Group Tasks in the Modeling Workshops: Finding Recursive and Explicit Rules for Patterns Appendix G: Classroom Observation Schedule Appendix H: Pre-Teaching to Post-Teaching "Growth" with Respect to the Five Basic Cognitive Structure Components Appendix I: Generalization Categories (After Radford, 2006)

It will not be possible to provide much discussion in this dissertation on what actually transpired in the intervention workshops in which the students in Group 1 and Group 2, and Mr. X and Mr. Y were active participants. However, since each workshop was observed by at least one of Prof. E, Prof. F, and myself, and since an observation schedule was completed for each workshop, it was possible to make some reasonably objective comments about the intervention.

\section{Fidelity of Implementation of Workshops}

Both Mr. X and Mr. Y had observed Prof. E and Prof $F$ lead very similar workshops with an eighth-grade class at School W, and when they themselves led workshops with seventh-grade students at School W they distributed almost the same 
workshop notes to the seventh-graders as Prof. E and Prof. F had distributed to the eighth-graders. The seventh-grade classes proceeded in almost exactly the same way as had been modeled in the eighth-grade classes, and the same homework "challenges" were used. Those observing the lessons believe that both Mr. X and Mr. Y faithfully based their workshops on what they had observed in the model lessons. That statement should not be read to imply that the two teachers did not exercise their own initiatives. They often added their own interpretations of the mathematics under consideration, and linked activities to the special interests of the participating students-all of whom were well known to both teachers.

For all the workshop classes there were absolutely no discipline problems - all students seemed to be highly motivated to learn the algebra under consideration. Class sizes were small (there were usually 15 or 16 students present in workshop sessions) and, because of the random sampling, each class could be described as "heterogeneous," covering a wide range of mathematical performance. School W is a smallish, rural public school, and mathematics performance data gathered in previous years would suggest that although the school is by no means "selective" so far as its intakes are concerned, the school maintains good academic standards—-probably slightly better than "average." The three observers agreed that almost all the participating students, and both the participating teachers, seemed to enjoy responding to the challenges presented in the algebra workshops.

\section{The Receptive-Expressive Balance}

The workshop notes which were issued to participating students had been especially prepared for the intervention classes, and these notes became the basis for 
how the workshops proceeded. The notes are reproduced in Appendix E (for structure workshops) and Appendix F (for modeling workshops).

A careful examination of the notes will reveal that the desirability of implementing an educationally sound and balanced receptive-expressive approach to teaching and learning (Del Campo \& Clements, 1987) was taken very seriously in this intervention study. In all workshop sessions, the students spent much time (usually about half of the allocated lesson time) discussing the mathematics under consideration with fellow students in small groups. Group members knew that they would be expected to give detailed reports on their thoughts and findings to the whole class, and that each student would be expected to participate actively when their groups were reporting to the whole class. The classroom observers (Prof. E, Prof. F, and the writer) believe that the above description could be applied to each workshop session in the intervention.

Of course, Mr. X and Mr. Y also participated actively in the workshop sessions, introducing topics, monitoring group discussions, chairing student-presentation sessions, commenting on aspects of the topics which many of the groups were finding difficult, and adding interesting "extras." Homework was set for each session (see Appendix E), and students submitted written responses to homework tasks to their teachers. The last session for each of the structure and modeling workshops took place in the form of a whole-class overview, led by either Mr. X or Mr. Y, but with inputs from Prof. E and Prof. F.

It should be possible for replications outside of School W to occur. Prof. F has already trialled the workshops with prospective middle-school teachers taking an "Algebra for Middle-School Teachers" course, and it proved to be very successful and 
helpful for those students. Hopefully, middle-school teachers and teacher educators will attempt to replicate the study, and it will be interesting to note variations which will be needed, given different students, teachers and circumstances.

\section{Concluding Comments with Respect to the Qualitative Analyses}

The qualitative analyses complemented the quantitative analyses, both suggesting that the invention had been successful. The quantitative analyses revealed that gains were statistically significant, and that effect sizes were large. The qualitative analyses revealed that most of the participating students' concepts images were considerably improved as a result of their involvement in the workshops. In both the structure and modeling workshops, verbal knowledge of relevant concepts was enhanced, intellectual skills improved, imagery evoked, episodes committed to memory, and positive attitudes engendered. Linking Peirce's triadic semiotic theory to Herbart's theory of apperception provided an ideal theoretical base, with the emphasis on concept image development providing the needed bridge from the sign-rich environments of structure and modeling. Most of the students made worthwhile progress toward the pertinent mathematical objects which were expressed in the workshops' aims.

It is important though, to draw attention to some of the difficulties experienced. At the retention stage, there were slight decreases from the post-teaching highs in performance that had occurred for Groups 1 and 2 for structure, and for Group 1 for modeling. That finding should provide the challenge for all interested persons to take the next step by providing additional workshops on structure and modeling during the next year or so, at least. It should be noted, too, that there was evidence indicating that about 
one-fourth of the participating students did not always cope with the mathematical complexities with which they were confronted in the workshops.

Structure and modeling are parts of the middle-school mathematics curriculum, but the mathematical objects that they address are more sophisticated than is often realized. Teachers should not attempt to "teach" them in a few lessons. No matter what has been written elsewhere, my experiences in the two pilot studies and in this intervention study at School W leave me in no doubt that many middle-school students begin their seventhgrade studies knowing hardly anything about the associative and distributive properties for real numbers, and many struggle to identify and state explicit rules for even simple linear sequences. Whether the qualifier "many" (used twice in the last sentence) should be replaced by "most" is something that should be determined by research.

Structure and modeling are much emphasized at different levels in the commoncore mathematics curriculum (CCSSM, 2010). They are themes which should be consciously built into curricula at all grade levels in the middle-school. The success of the receptive-expressive approach in the structure and modeling workshops in the current study suggests that attempts to replicate and extend the study should be encouraged.

In order to make sense of the qualitative data, particularly the pre-and postteaching interview data, I created ordered pairs which were indicative of the strength of the presence of a component in cognitive structure. For a particular component, the extent of evidence was assessed on a three-point scale, 0 (corresponding to no evidence), 1 (some evidence), and 2 (strong evidence). The term "strong evidence" was used to indicate that there was definite evidence that a student had a sound verbal 
comprehension of the concept, or was able to identify and use relevant intellectual skills, or could evoke appropriate imagery, or could recall relevant episodes, or had developed positive or otherwise appropriate attitudes. "Some evidence" implied that although there was evidence, it was not strong; and "no evidence" indicated that evidence did not exist in relation to that component of working memory (see Appendix $\mathrm{H}$ ).

The first coordinate of an ordered pair indicates the extent of the evidence for the presence of the component at the pre-teaching stage, and the second indicates the extent of evidence at the post-teaching stage. I also created a coding for "overall growth," which was based on the sum of five memory components with a maximum score of 10 . I defined "significant growth" as corresponding to an overall growth-for the five components — of at least 7, "modest growth" corresponds to a growth ranging from 3 through 6, and "no growth" corresponds to an overall growth of at most 2 (see Appendix I) 


\section{CHAPTER VI \\ CONCLUSIONS AND DISCUSSION}

In this final chapter, answers to the six main research questions are given, and issues that arose as the study progressed are discussed. Then, implications for the teaching and learning of middle-school algebra are considered, and recommendations for future research are stated. Finally, comments on limitations of the current study are presented.

\section{Answer to Research Question 1}

Question 1: What did the Grade 7 participating students know about each of the associative property for addition, the associative property for multiplication, and the distributive property, before the intervention lessons took place?

This intervention study was a form of design research and, as such, the research team made decisions on its design, and on how the perceived problem would be investigated. The team decided that it needed to identify and describe starting pointsthat is to say, the knowledge and understandings of the seventh-grade participating students with respect to the associative properties (for addition and multiplication of real numbers), and the distributive property for multiplication over addition for real numbers. 
In Chapter 1, I identified and summarized statements in CCSSM's (2010) core curriculum which elaborated what might reasonably have been expected of the seventhgrade students so far as structure was concerned - from the perspective of those who developed the CCSSM curriculum. I also examined the treatment and expectations with respect to structure in the textbook, by Charles, Branch-Boyd, Illingworth, Mills, and Reeves (2004), which was used by the seventh-graders in their mathematics classes.

My document analysis revealed that by the seventh grade it is a common-core expectation that students will know and be able to apply all of the field properties, including the associative and distributive properties. Even for Grade 1 students, the associative property for addition is specifically mentioned in the common-core mathematics curriculum. Hung-Hsi Wu, a University of California mathematician and one of the authors of the common-core curriculum — and an often-quoted author of textbooks for schools adopting the common-core curriculum (Wu, 2011) - is clearly under the impression that "by the sixth grade most students already know about the associative and commutative laws of addition and multiplication" (Wu, 2007). The current study generated data which cast doubt on the truth of that assertion.

Quantitative analyses of pre-teaching Algebra Test structure scores indicated that the means for both Group 1 and Group 2 on the structure subtest were extremely low. Out of a maximum score of 10 , the sample mean scores, and corresponding standard deviations, were, 0.16 and 0.51 (for Group 1) and 0.47 and 0.72 (for Group 2). In other words, it seems that the students remembered virtually nothing about the associative properties for addition and multiplication, and the distributive property. That finding was entirely consistent with the results I obtained in two recent pilot studies (Kanbir, 2014, 
2016) - the data for which were generated by seventh- and eighth-grade students at another midwestern middle school (located about 50 miles away from School W).

Qualitative analyses of pre-teaching interview data for the current study, and of data generated by student responses to an initial structural knowledge questionnaire, complemented the results from the pre-teaching quantitative analyses. Immediately before the first intervention workshops, the 32 participating students were asked to respond in writing to written questions seeking knowledge on whether they knew the meanings of the terms "associative property for addition," "associative property for multiplication," and "distributive property" (see Appendix C). Analysis of the student responses indicated that none of the 32 participating students had a firm knowledge of any of the properties.

When, in pre-teaching interviews, the participating students in the current study were specifically asked to give verbal descriptions of the distributive property, none of them could give an accurate definition. In the interviews, none of the students recognized signs pointing to the mathematical "objects" which, according to CCSSM's (2010) specifications, they ought to have known.

To sum up, then, with respect to all three structural properties under consideration, at the pre-teaching stage the students had no appropriate receptive or expressive knowledge or understandings. Some of them had vague memories of having heard the names of the properties before, but they did not know what the properties actually stated, and they had no relevant imagery with respect to them. In Herbartian apperception terms, their cognitive structures, or concept images, were deficient—-the students did not know how to define the properties, or when they could be useful. Yet, textbook authors (e.g., 
Charles, et al, 2004), and those who developed the common-core middle-school curriculum (e.g., Hung-Hsi Wu) seemed to think that it was reasonable to expect that the students would have known the properties.

For example, when the 28 pre-teaching interviewees were shown the sign "Find the value of $4 \times\left(\frac{1}{4} \times 128\right)$," none of them linked, in their minds, the 4 and the $\frac{1}{4}$. Most of them proceeded by trying to find the value of $\frac{1}{4}$ by 128 and, having done that, then to multiply that result by 4 . They proceeded in that way because the first letter in the PEMDAS mnemonic ("Please Excuse My Dear Aunt Sally") was "P," and "M" came later: therefore, they had to attend to what was inside the parentheses first. The students had not really recognized the intended message of the person(s) who created the sign "Find the value of $4 \times\left(\frac{1}{4} \times 128\right)$."

Similarly, when shown a sign like "describe a quick method for finding the value of $6 \times 97+4 \times 97$," none of the students in the pre-teaching interviews recognized that that was equal to 97 times $(6+4)$. None of them gave any indication that the task might be related to what the CCSSM curriculum for elementary and middle-school calls the "distributive property." Instead, most of the interviewees proceeded according to PEMDAS, and because " $\mathrm{M}$ " came before " $\mathrm{A}$ " in that mnemonic, they carried out the multiplications first, before any additions.

To sum up, pre-teaching student responses to pencil-and-paper and interview questions revealed that none of the participating students had a well-formed knowledge of, or appreciation of the power of, the associative property for addition the associative property for multiplication, or the distributive property for multiplication over addition. 
They lacked knowledge of definitions (verbal knowledge), did not have well-developed and appropriate intellectual skills, and could not evoke appropriate images. A few of them remembered having heard expressions like "associative property" and "distributive property" being used by teachers, but they did not remember details, and they had no well-developed attitudes because it was not something they had ever known or thought about.

From the perspective of the concept of a variable, at the pre-teaching stage none of the participating students seemed to be aware that with a statement like "if $a, b$ and $c$ represent any rational numbers then $a+(b+c)=(a+b)+c$," the letters $a, b$ and $c$ are being used as variables. The idea of a variable was not something that the students linked with the three properties that were under special consideration in the current study.

\section{Answer to Research Question 2}

Question 2: To what extent were the Grade 7 participating students able to recognize patterns and to model relationships by using variables before the intervention lessons took place?

The Common Core curriculum (CCSSM, 2010) indicates that by the seventh grade, students should be sufficiently familiar with the concept of a variable that they will be able to engage in elementary aspects of functional thinking - that is to say, they will be able to use algebraic syntax to express relationships between well-defined sets of variables. For example, fifth-grade students are supposed to learn the concepts of explicit and recursive rules for sequences. Middle-school teachers are encouraged to introduce the signs of algebra (including letters for variables) to their students well before asking them 
to use manipulate algebraic symbols formally. Thus, the students are to become acquainted with the semantics of algebraic formulations - with how the signs relate to corresponding mathematical objects and real-life situations- - before they pay much attention to the syntax of such formulations.

At the pre-teaching stages, before the actual classroom intervention began, analyses of paper-and-pencil test data and interview data indicated that the students' thinking with respect to modeling was not well advanced. For example, the students did not know the meanings of the terms "recursive rule," "explicit rule," and "sequence." The pencil-andpaper Algebra Test and the interview protocol included questions and tasks involving modeling which were closely aligned to CCSSM (2010) expectations for seventh-graders, and the research team was interested in determining the extent to which the students were able, at the pre-teaching stage, to use recursive and explicit modeling language and concepts to describe sequence patterns. The team was also interested to explore whether the participants had any idea of the meaning of the most pertinent modeling signs. At the outset, for example, could they make sense of the sign "If $n$ can represent any natural number, or zero, then $T_{n}=3 n-1$ '? And, were they able to associate that statement with the ordered set of numbers $-1,2,5,8, \ldots$ ? Did they know what the term "natural number" meant? Since there was an intention to use the subscript notation for sequences in the current study, answers to these questions were of special interest.

Two issues could be identified: first, could the students themselves interpret statements in which someone else had used the subscript notation? And, second, were they themselves fluent in using the notation to describe sequences? 
Quantitative analysis of pre-teaching responses to questions on the modeling subtest of the Algebra Test indicated that before they began to participate in the study the Group 1 and Group 2 students had virtually no receptive or expressive understanding of functional relationships. With a maximum possible score of 10 , the recorded sample mean scores and standard deviations on the modeling subtest were, respectively, 1.41 and 0.49 (for Group 1) and 1.31 and 0.48 (for Group 2). Overall, only 2 of the 32 students displayed some idea of how to handle the subscript notation or to specify the $n$th term of a linear sequence. Only one interviewee seemed to know that the use of three dots (...) in a "horizontal table of values" was an invitation to give the general rule for the $n$th case. The terms "recursive" and "explicit" rules were not known. As stated previously, that finding was consistent with the results of two pilot studies which I had conducted at another school (Kanbir, 2014, 2016).

Analyses of qualitative data, related to modeling aspects of the study, from the preteaching interviews pointed to identical conclusions to those from the pencil-and-paper data. Before the intervention lessons took place, students had neither receptive nor expressive understandings of key functional-thinking concepts which the authors of the CCSSM (2010) curriculum presumed that seventh-grade students should know.

For example, consider some of the data with respect to the three dots (“...") in the following table of values.

\begin{tabular}{c|c|c|c|c|c|c|c}
$\begin{array}{c}\text { First } \\
\text { Value }\end{array}$ & 1 & 2 & 3 & 4 & 5 & $\ldots$ & $n$ \\
\hline $\begin{array}{c}\text { Second } \\
\text { Value }\end{array}$ & 3 & 5 & 7 & 9 & $?$ & $\ldots$ & $? ?$
\end{tabular}


In pre-teaching interviews conducted for the second pilot study, and for the preteaching interviews in the current study, the seventh-graders did not know the convention represented by the three dots, and thought that the $n$ (in the last upper cell) represented 7 ("because $5+1+1$ equals 7"). In a similar way, they thought that the symbol "??" represented 15 ("because $9+2+2+2$ equals 15 ”). Student responses to this "horizontal tables of values" task made it very clear that seventh-grade students who have never been exposed to tables in which they are expected to make a cognitive leap to the " $n$th case" will not understand the meaning of certain sign conventions and, therefore, unless they are helped, will find it almost impossible to reach out and grasp the corresponding mathematical object — which is concerned with generalizing. Whereas, a few students ( 2 out of 28 ) identified simple recursive rules, such as "add 2," when asked to summarize successive terms in sequences which were expressed in tables of values, they were not able to identify and communicate explicit rules by saying, or writing, generalized statements such as "the $n$th term is equal to $2 n+1$ " or " $S_{n}=2 n+1$." Basically, both quantitative and qualitative pre-teaching data showed that at the pre-teaching stage most of the students (around 95\% of them) were not able to "see" what Radford (2006) called "symbolic mathematical" objects. The reason was simplethey did not know the meaning of the signs pointing to the object and, in any case, had never sought to explore the mathematical object. It was not surprising, therefore, that the students did not apply the concept of a variable using the subscript (sequence) notation, for at that stage the notation was meaningless to them.

To sum up, pre-teaching student responses to pencil-and-paper and interview questions revealed that none of the participating students had a well-formed knowledge 
of, or appreciation of the power of, the concept of an " $n$th term" of a linear sequence. They could not make explicit generalizations, largely because that mathematical object was unfamiliar to them. They had never used the subscript notation, and therefore had neither receptive nor expressive understanding of it. They did not know how to introduce and use a variable to represent an important aspect of a given real-life situation. They lacked knowledge of definitions (verbal knowledge), did not have welldeveloped and appropriate intellectual skills, and could not evoke appropriate images. They did not recall ever having seen the symbol " $T_{n}$," and were unaware of the "three dots (...)" convention. They had not developed attitudes towards modeling because modeling was not something they had ever known or thought about. Although some of them remembered seeing tables of values which were presented in vertical form, tables of values with a different orientation were confusing.

\section{Answer to Research Question 3}

Question 3: What changes in the knowledge and understanding of participating students with respect to structure and modeling were evident in the middle of the intervention period (when either the structure or the modeling lessons were completed, but not both)?

On the mid-intervention structure subtest of the Algebra Test, the sample means (with a maximum possible score of 10) and the standard deviations were, respectively, 4.88 and 2.72 (for Group 1) and 1.63 and 1.61 (for Group 2). Mid-intervention mean scores and standard deviations for the modeling subtest were, respectively, 1.84 and 0.98 (for Group 1) and 3.59 and 2.30 (for Group 2) (see Figures 19 and 20). 
At the mid-intervention stage, each group's mean score was considerably higher, on one of the subtests - but not on both subtests - than had been the case at the preteaching stage. The increases at the mid-intervention stage were associated with the fact that one of the groups had just participated in workshops in which they had dealt with matters which related to questions on half of the test. Thus, for example, at the midintervention stage, Group 1 had just participated in workshops which focused on structure, and Group 1 showed a much greater mean gain on the structure questions than did Group 2, whose students had just participated in workshops which focused on modeling. The reverse was the case for Group 2, with Group 2 students having a greater mean gain on modeling than the Group 1 students.

The mean gains for the two groups suggest that the structure intervention led to an educationally significant increase in the performance of Group 1 students on the structure subtest, and the modeling intervention led to an educationally significant increase in the performance of Group 2 students on the modeling subtest. The Group 1 students also showed a small (but statistically not significant) gain on the modeling subtest, and Group 2 students showed a small (but statistically not significant) gain on the structure subtest. It seemed that the structure workshops did not have an important effect on Group 1 students' learning with respect to modeling, and modeling workshops did not have an important effect on Group 2 students' learning with respect to structure. 


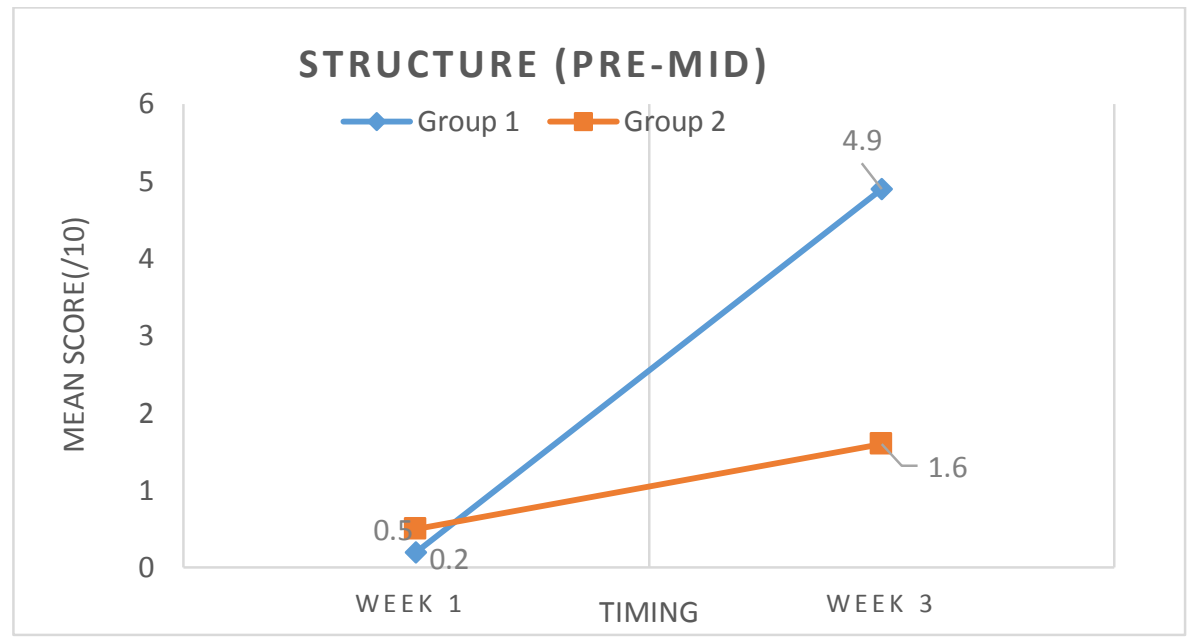

Figure 19. Comparison of pre-teaching and mid-intervention structure means, Group 1 and Group 2.

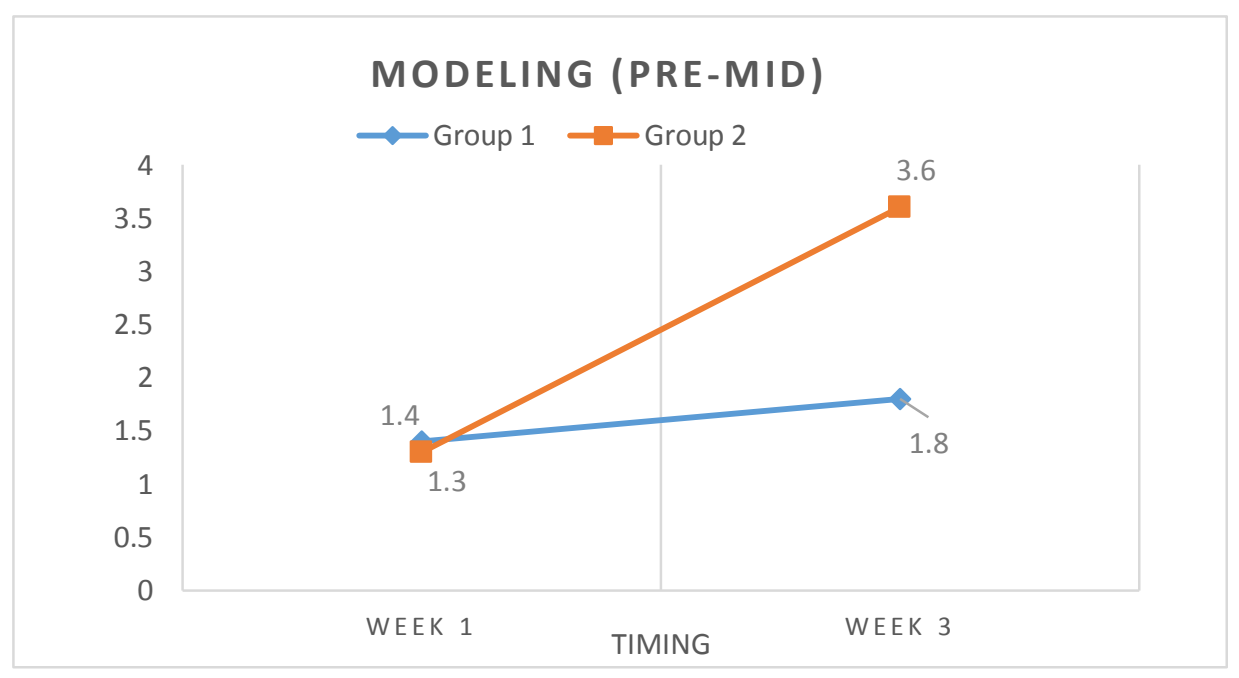

Figure 20. Comparison of pre-teaching and mid-intervention modeling means, Group 1 and Group 2.

Values calculated for Cohen's $d$ (1988) effect sizes for the interventions were consistent with the trends depicted in Figure 19 and Figure 20. The effect size of the preteaching to mid-intervention workshop sessions on structure was calculated for Group 1 (it was assumed that the control group for this period was Group 2). Similarly, the effect 
size for Group 2 was calculated for the pre-teaching to mid-intervention workshop sessions on modeling (it was assumed that the control group for this period was Group 1). A summary of the results of the calculations is given in Table 17 .

Table 17

Effect Sizes for Intervention Workshops, Pre-Teaching to Mid-Intervention

\begin{tabular}{ccccc}
\hline $\begin{array}{c}\text { Type of } \\
\text { Workshop } \\
\begin{array}{c}\text { Structure or } \\
\text { Modeling }\end{array}\end{array}$ & $\begin{array}{c}\text { Period } \\
\text { (Pre-T to Mid-I, } \\
\text { or Mid-I to Pre- } \\
\text { T) }\end{array}$ & $\begin{array}{c}\text { Group Involved } \\
\text { in Relevant } \\
\text { Workshops } \\
\text { (Group 1 or } \\
\text { Group 2) }\end{array}$ & $\begin{array}{c}\text { Control } \\
\text { Group }\end{array}$ & $\begin{array}{c}\text { Cohen's } d \\
\text { Effect Size }\end{array}$ \\
\hline Structure & Pre-T to Mid-I & Group 1 & Group 2 & 1.74 \\
Modeling & Pre-T to Mid-I & Group 2 & Group 1 & 1.38 \\
\hline
\end{tabular}

According to Cohen (1988), effect sizes above 0.8 can be regarded as "large." It can be seen, from entries in Table 17, that the effect of the structure workshops on Group 1's performance on the structure subtest was very large. Similarly, the effect of the modeling workshops on Groups 2's performance on the modeling subtest of the modeling was also very large.

\section{Answer to Research Question 4}

Question 4: Immediately after both groups had participated in both the structure and modeling workshops, were there statistically significant differences between the two groups' mean gain scores in structural understanding and modeling? Also, what were the Cohen's $d$ effect sizes for the two groups for the first half and for the second half of the intervention? 
On the structure subtest on the post-teaching version of the Algebra Test, 14 of the 32 participating students scored at least $70 \%$, with 11 getting at least $80 \%$ and 23 of the 32 students getting at least $50 \%$. On the modeling subtest questions on the Algebra Test a similar, but slightly lower result, was obtained by the students. Of 32 participants, 8 of them scored at least $70 \%$, with 6 of them around $80 \%$, and 16 of them getting at least 50\%. A post-teaching versus pre-teaching mean gain analysis for Group 1 and Group 2 on the structure subtest, showed that the mean gain for Group 1 was 5.69 (standard deviation 2.55), and the mean gain for Group 2 was 5.28 (standard deviation 1.85). The post-teaching versus pre-teaching mean gains for Group 1 and Group 2 on the modeling subtest, were 2.88 (standard deviation 2.41), for Group 1, and 3.00 (standard deviation 2.35) for Group 2. The mean post-teaching versus pre-teaching gain scores for Group 1 and Group 2 on structure were not statistically significantly different. Similarly, the mean post-teaching versus pre-teaching gain scores for Group 1 and Group 2 on modeling were not statistically significantly different.

In Figure 21, the overall trends of mean scores at the pre- and post-teaching stages of the study can be seen. The mean scores for both groups improved for each of the subtests at the post-teaching stage. 


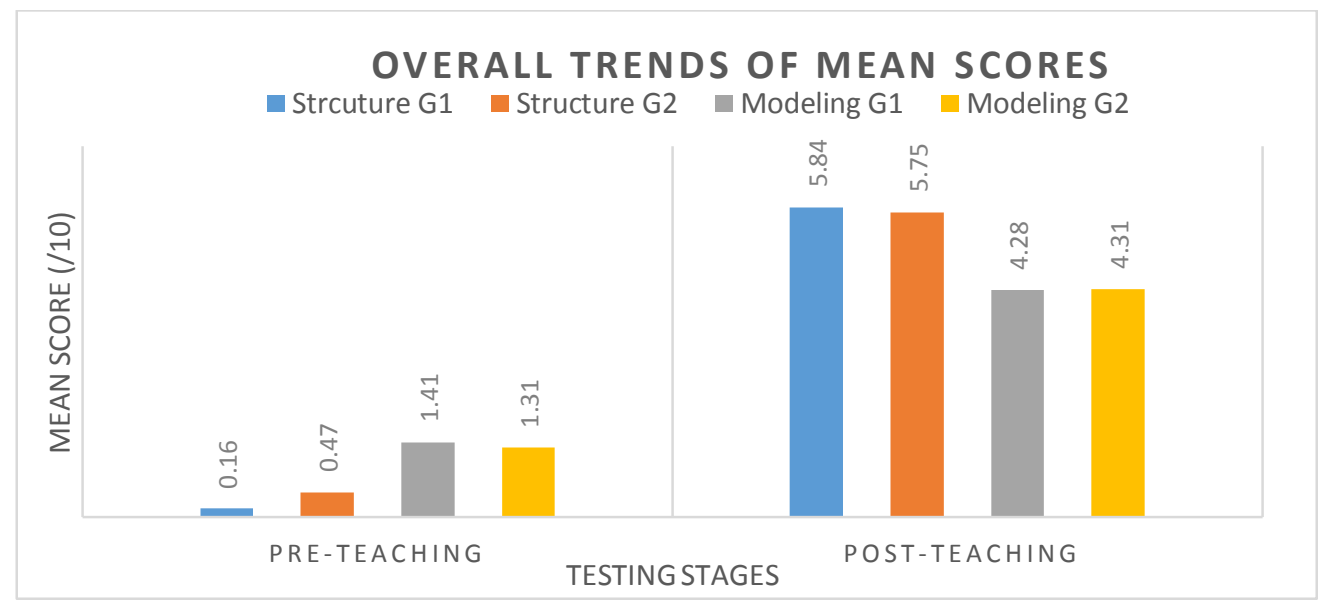

Figure 21. Bar graphs, showing mean scores of the two groups at pre-teaching and post-teaching stages, on the Structure and Modeling Subtests.

It will be recalled that pre-teaching to mid-intervention effect sizes were reported in Table 17. It was also possible to calculate mid-intervention to post-teaching effect sizes (see Table 18). Once again the effect sizes were very large, and it seemed to be the case that the structure intervention workshops had were particularly effective.

Table 18

Effect Sizes for Four Intervention Workshop Periods

\begin{tabular}{ccccc}
\hline $\begin{array}{c}\text { Type of } \\
\text { Workshop } \\
\begin{array}{c}\text { Structure or } \\
\text { Modeling }\end{array}\end{array}$ & $\begin{array}{c}\text { Period } \\
\text { (Pre-T to Mid-I, } \\
\text { or Mid-I to Pre- } \\
\text { T) }\end{array}$ & $\begin{array}{c}\text { Group Involved in } \\
\text { Relevant Workshops } \\
\text { (Group 1 or Group 2) }\end{array}$ & $\begin{array}{c}\text { Control } \\
\text { Group }\end{array}$ & $\begin{array}{c}\text { Cohen's } d \\
\text { Effect Size }\end{array}$ \\
\hline Structure & Pre-T to Mid-I & Group 1 & Group 2 & 1.74 \\
Structure & Mid-I to Post-T & Group 2 & Group 1 & 1.70 \\
Modeling & Pre-T to Mid-I & Group 2 & Group 1 & 1.38 \\
Modeling & Mid-I to Post-T & Group 1 & Group 2 & 1.07 \\
\hline
\end{tabular}




\section{Answer to Research Question 5}

Question 5: Immediately after both the structure and modeling workshops were completed, were there educationally noticeable differences between the concept images of the students, with respect to the concept of a variable, in comparison with the concept images that the students had before the intervention began?

The qualitative analyses of data in Chapter 5 took into consideration Westbury's (1980) distinction between intended, implemented, and attained curricula. It was important for the research team to recognize, and take account of, the fact that the attained curriculum for an individual student was something much more educationally significant than mere improvement in his or her scores on two subtests. Rather, the attained curriculum for an individual was seen to be the realignment of that individual's concept images with respect to important mathematical objects. This process of objectification was consistent with Charles Sanders Peirce's triadic theory by which interpretants could be thought of as bridges between the "signs" and the "mathematical objects" being signified.

The need to bridge signs and mathematical objects was closely linked to Johann Friedrich Herbart's theory of apperception, which emphasized the need to take account of the apperceptive process - although, each learner would construct new knowledge, the construction was to be achieved by encouraging the learner to link what they already knew to what they being expected to learn. There is a sense in which this process was rediscovered by Lev Vygotsky early in the twentieth century, following the neo-Herbartian thrust around the world in the second half of the nineteenth century. 
Vygotsky emphasized the importance of scaffolding from what a learner already knew to what he or she would learn. From Vygotsky's (1930) social constructivist position, it is the teacher's role to provide the right kind of scaffolding.

The detailed analyses of quantitative data presented in Chapter 5 revealed that about 80 percent of the participating students' concept images with respect to structure changed in educationally significant ways. The structure workshops helped students idiosyncratically connect important "cognitive structure" components-verbal knowledge, intellectual skills, imagery, episodes, and attitudes - in ways which enabled at least some of them began to visualize relationships between concepts and principles in new ways. And, because many students took the opportunity to construct their own concept images, they were likely to remember much of what they had learned. However, some of the students continued to struggle to "see" the mathematical objects which were on the agenda. Furthermore, even those who benefited the most still had much to learn so far as the desired mathematical objects were concerned.

The effect sizes for the modeling workshop were large, but not as large as those for structure. It appeared to be the case that about half of the students' concept images for modeling were constructed and reconstructed in educationally significant ways. Most participants recognized that they were being given the opportunity to generalize, but about half of them struggled as they attempted to grasp the mathematical object that they could only partially see ahead of them.

\section{Changing Attitudes: "I was Really Good at All that Stuff"}

Almost all of the participating students indicated that they believed that they had benefited greatly from being involved in the workshops. In post-teaching interviews, 
many of them spontaneously expressed very positive feelings about the workshops. Among their comments were:

Student 1.4, Post-Teaching Interview: I remember the distributive and associative problems, because I was really good at all that stuff. But with the recursive and explicit ideas, I found that it was very hard to write a rule.

Student 1.5, Post-Teaching Interview: The $T_{n}$ one was kind of unusual because I never seen a subscription (sic.) before. That was kind of interesting. Student 1.6, Post-Teaching Interview: I liked the charts with the explicit and recursive rules.

Student 1.7, Post-Teaching Interview: I liked getting to learn a lot of new things ... Even my Mom, who is an advanced math teacher, said she does not teach recursive and explicit rules, and my sister-she is a junior-does not know that stuff. I like it, and remember at all.

Student 1.8, Post-Teaching Interview: I really liked the distributive property with Mr. X. I will mostly remember changing the problem so that I made it an easier problem. In the beginning I did not know what I was doing [referring to the modeling lessons]. Later I got to know how to do some of the problems. Student 1.14, Post-Teaching Interview: When we switched over lessons I thought the patterns were really fun. They can be hard but eventually you will find them out. It just takes a lot of processes and thinking. I remember just doing all the patterns. When we did the crossing-the-river problem my group figured out the formula very fast. When you do the recursive rule you lower the $n$ and when you do the second part you put a number up, and $n$ down. 
Student 2.2, Post-Teaching Interview: I learned more about the associative and the distributive property. I did not know much about them before. Sequences, also, I did know anything about them. I thought it was very cool.

Student 2.3, Post-Teaching Interview: I remember most the $T_{n+1}$, because I really got that. It was pretty easy. But, I did not like switching the teachers. Because it was hard for me to schedule and remember Mr. X or Mr. Y's class. Not so much about the mathematics.

Student 2.4, Post-Teaching Interview: I learned how to get a recursive and an explicit formula. Also, how to deal with an equation that involves the distributive or the associative property.

Student 2.5, Post-Teaching Interview: I liked how we learned about the distributive and associative properties. Because the distributive property would be very useful with some giant problems.

Student 2.8, Post-Teaching Interview: I liked the distributive and associative properties. I liked the worksheets and the homework questions.

Student 2.9, Post-Teaching Interview: I liked the modeling lessons because we had not learned to do that before. I liked it, even though it was not easy to write things [referring to the subscript notation and the recursive representation] and to find some of the formulas. I also liked Mr..X's class [on structure]. If I had to do like some real-life problems, it would be easy, like, to break it down and make it easier [referring to the distributive property].

Student 2.13, Post-Teaching Interview: I remember mostly some of the recursive rules and I also remember the associative property. 
Student 2.15, Post-Teaching Interview: If you have a separate multiplication problem and two different numbers and you are multiplying it the same numbers you just add the different numbers in the parentheses and multiply the same number.

As I read these comments, all of which were made by real seventh-graders who had participated in the study, all I could think to myself was "Wow. Those workshops really made more of a difference than I had imagined, even when I was observing the classes." The last of the above quotations, from Student 2.15 , was made by a girl who made impressive gains on the Algebra Test, for both the structure and modeling subtests. Although I found it difficult to follow what she was trying to say to me, in the passage quoted, it was clear to me that she knew what she meant, and that she felt very positive about what she had experienced in the workshops. She had constructed new knowledge, and she knew that that knowledge was important for her.

\section{Answer to Research Question 6}

Question 6: Twelve weeks after both the structure and modeling lessons were completed, were there statistically significant differences between the two groups' mean gain scores with respect to the retention of what had been learned in regard to structural understanding and modeling?

As I explained before, the attained curriculum for an individual learner is not fixed in time. From that perspective, it was a matter of interest, in the current study, to investigate whether, and how, a participating student's cognitive structure immediately after the intervention (which might be thought of as that student's "attained 
curriculum") differed from the cognitive structure 12 weeks after the intervention (which might be thought of as his or her "retained curriculum").

Analyses of the collected retention data (12 weeks after the post-teaching tests and 20 weeks after the pre-teaching tests) enabled the research team to evaluate how well seventh-grade students had retained the structural and functional knowledge and understandings that they had developed during the intervention lessons. Like Gersten, Baker and Lloyd (2000), we asked an important question about the effects of our teaching intervention study: "Do the effects last beyond a very brief period over time, or beyond the duration of the study" (p. 3).

The differences between the mean retention versus pre-teaching gain scores for Group 1, for both structure and modeling, were highly statistically significantly different from zero. The same was true for Group 2. Similarly, the mean gains for Group 1 and Group 2 on the modeling test, when retention scores were compared with pre-teaching scores on modeling, were highly statistically significant. That said, it was noted that for three of the four comparisons there were declines during the retention period. The declines were not statistically significant but from a mathematics education perspective, they were interesting results (see Figure 22). 


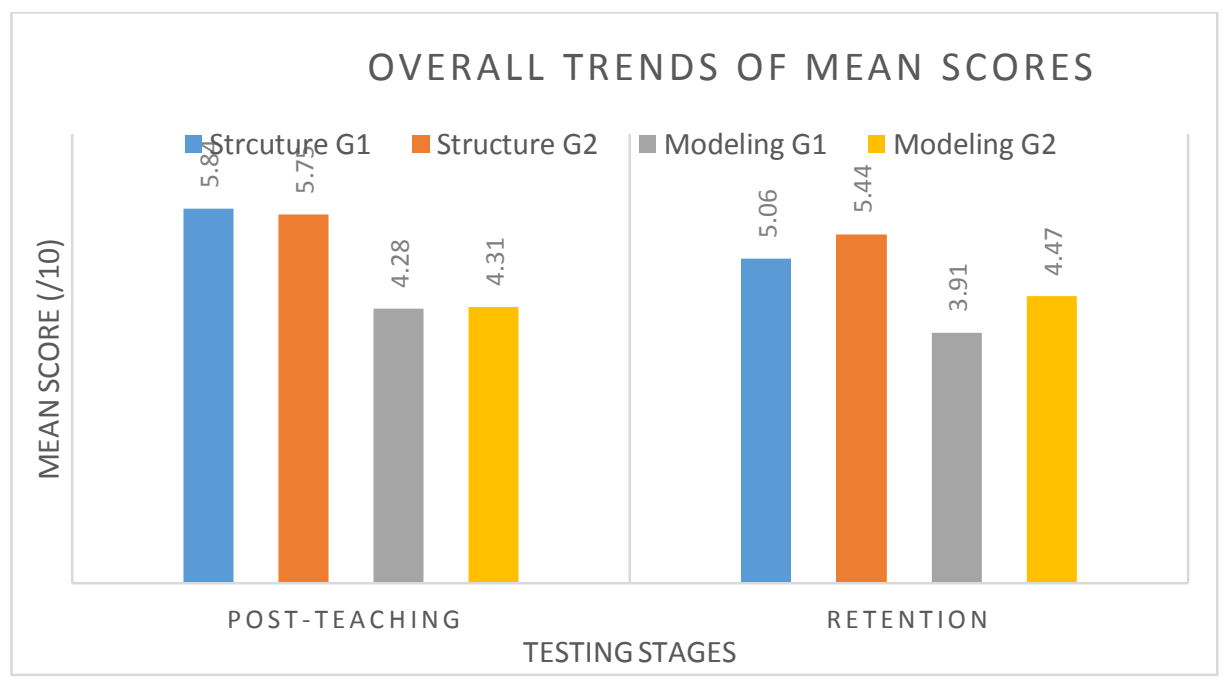

Figure 22. Bar graphs, showing mean scores of the two groups at post-teaching and retention stages, on the structure and modeling subtests.

The decline in mean scores during the retention period-for all but Group 2 for the modeling subtest, for which there was a small gain —-served as a timely reminder. It is not enough simply to teach a topic and, then, after having assessed the students' learning, proceed to the next topic and "forget" what was done before.

\section{Limitations of the Study}

Despite CCSSM's (2010) emphasis on the importance of structural properties with respect to elementary and middle-school algebra, other than the commendable research by Melvia Ding and Xiaobao Li $(2010,2014)$, there has not been much research reported in scholarly outlets on the teaching and learning of such properties in middle schools. For the current study, the decision was made to limit the investigation of structural properties to the associative properties for addition and multiplication and to the distributive property, and it was decided that only Grade 7 students should participate.

Time constraints - for the researcher and also for School W-meant that conducting a larger study which took into account closure properties, commutative 
properties, identity elements, inverse properties, and also order properties, and with a wider range of middle-school students, was not possible. A study which tried to deal with all major structural features of elementary algebra would have been unrealistic. Future researchers might profitably extend the scope of the study reported in this dissertation by covering other structural aspects of elementary and middle-school algebra, and by involving students from a wider range of grade levels.

So far as the modeling aspect of the study was concerned, there has been much recent research on aspects of modeling with respect to the teaching and learning of school algebra. However, analysis of data generated by the two pilot studies conducted by the researcher (Kanbir, 2014, 2016) raised the possibility that many seventh- and eighth-grade students are unaware of mathematical conventions with respect to descriptions of generalizations and, in particular, to the subscript notation for specifying recursive and explicit rules for sequences. So, one of the important aspects of the analysis of the effects of the modeling lessons in the current study was to explore whether most of the seventh-grade students were capable of learning how to use the subscript notation effectively and with understanding. There are many other aspects of modeling covered in the recent literature which were not addressed in the study-despite the already large volume of related research, more research is needed on this theme.

There is a sense in which the study, with only 32 participating students and two participating teachers, was not a large one. However, almost the complete cohort of the seventh-graders students attending a public school was involved in the study, and random allocation to treatment groups for the intervention was achieved. Extensive, and hopefully rich, interview data arising from a carefully-developed interview protocol, 
were generated. Clearly, the large volume of the amount of data which was generated was both a strength and a weakness of the study - the volume of data was too large to do justice to it in this dissertation. The study was unfunded, and all five members of the research team were very busy doing what they normally do.

The design of the study was limited because it allowed for the possibility of a teacher effect which could possibly have biased the data. That was because one of the teachers (Mr. X) taught all the seventh-grade "structure" lessons, and the other teacher (Mr. Y) taught all the "modeling" lessons. Prof. E, Prof. F, and I, who observed the workshop sessions, fully appreciated the hard work and enthusiasm of both teachers, who were experienced, well qualified, and diligent.

\section{Possibilities for Future Related Research}

Despite the above limitations, the results of the study are, I believe, important. This is the first major study on algebra education to combine the theories of Peirce and Herbart, and the results are sufficiently interesting, and potentially important, to warrant replications of the study.

There are other possibilities for related research. We need to know, for example, when the subscript notation should be introduced as part of the common-core curriculum. We need to know whether mathematics teacher-education graduates are beginning their teaching careers without strong understandings of the structural and modeling approaches to middle-school algebra. We need to investigate whether the structure and modeling approaches are mutually independent of each other and, if so, what the implications of that for curriculum design might be. We need to know whether middle-school students, and their teachers, realize that PEMDAS, the order-of- 
operations mnemonic which is so widely used in schools, has, from a mathematical perspective, severe limitations. In fact, often students and their teachers are not aware that the associative and distributive properties should take priority over PEMDAS in teaching and in learning.

There are many other issues, and in that sense this dissertation can be regarded as the end of the beginning for the writer. Appendix $\mathrm{H}$ and Appendix I present tables that include data which suggest further possibilities for creative analysis and design. In Appendix $\mathrm{H}$ there are five tables which are intended to show the strength of evidence for the presence of the five fundamental components of cognitive structure-verbal knowledge, intellectual skills, imagery, episodes and attitudes—with respect to welldefined mathematical objects (such as the distributive property). A method for "measuring" growth is described. The analyses and the method are tentative, but the results arising from the analyses are interesting and consistent with the results from the quantitative and qualitative analyses presented in Chapter 4 and Chapter 5, respectively. There would appear to be considerable scope for tightening and developing the ideas implicit in the analyses given in Appendix $\mathrm{H}$.

Appendix I provides another tentative analysis of data. It assumes Radford's (2006) theory, in which he outlined three levels of generalization with modeling tasks. I have added a fourth level of my own - post-symbolic generalization. This approach has not been further developed in this dissertation, because it seemed to be less useful for classifying students' movement toward generalization within the "structure of rational numbers" aspect of the study than it was for the modeling component of the study. However, there would be much scope for further development of the ideas. 
The CCSSM (2010) curriculum emphasizes the importance of structure throughout its elementary and middle-school courses, but there seems to have been an attitude among researchers, curriculum developers and textbook writers that students will, somehow, automatically grow into an acceptable knowledge of the main structural properties. Analyses of data in the current study, and in the pilot studies, indicated that it is unlikely that expectation is realistic. Much more research is needed on the issue. Important questions need to be answered—like, for example, "How well do middleschool students, and their teachers, understand that the all-important concept of a variable is central to an understanding of the structural properties of real numbers?"

\section{Final Comments on the Workshop "Lessons"}

The excerpts in which students expressed their reactions to the workshops were sufficiently positive that I was persuaded to re-examine the notes which were handed to the students for the workshops. When I examined the notes, the following six points became clear to me:

1. In the structure component of the study, the mathematics in the notes started "where the students were at." The students had spent much time in recent years studying operations with counting numbers, fractions and, more recently, negative numbers. In the structure workshops they were able, immediately, to discuss the mathematics to which they were being introduced in the notes.

2. Both the structure and modeling notes uncompromisingly took a mathematical approach — the associative and distributive properties, and the mathematics of linear sequences, were addressed in mathematically honest, but unadorned ways. 
Properties were clearly illustrated, and it became clear to the students that they would be expected to remember the rather long names (associative, distributive, recursive, etc.).

3. The notes, for both the structure and modeling workshops, assumed that the students would be placed in groups, and that they would spend much of the lesson time discussing the mathematics that they were expected to learn. Also, the notes recognized that each small group of students would be expected to make presentations about what they "discovered" to the whole class.

4. The students knew that they would be tested on what they were learning, and for most of them it became important that they came to "know" the mathematics which they were studying.

5. For each lesson, homework exercises were set, and student responses were submitted to the research team for examination. Written comments were made on the submissions by members of the research team — and most of the students liked that.

6. With the modeling workshops, the students particularly liked the "crossing-theriver" task, which involved them in manipulating simple equipment (colored blocks and rulers). They also responded very positively to the challenge to pose their own sequence problems — which they loved reporting to the whole class.

The notes were consciously developed with the aim of getting students to think “expressively" (Del Campo \& Clements, 1987). The reader can examine the workshop notes, which have been reproduced as Appendix E and Appendix F to this dissertation. 


\section{Comments on the Study by the Two Participating Teachers}

It will be appropriate to end the dissertation with comments made by the two participating teachers on their impressions of the study. The two participating teachers, Mr. X and Mr. Y, met with Prof. E, Prof F, and me after the retention data had been gathered, and the discussion which ensued was audiotaped. Both teachers indicated that they had enjoyed being involved in the study, and that they felt that they had profited, personally and professionally, from their participation. They said that they intended to use the workshop notes with students in future years.

Mr. X and Mr. Y also commented that despite their overall very positive feelings about the study, their involvement and their students' involvement in it had placed pressure on them. They were expected to follow the school's syllabus, and the time spent by the students on tests added to an already sizeable amount of time that the students had had to spend on tests that were outside of the normal schedule.

Some of the actual questions that Prof. E, Prof. F, and I asked of Mr. X and Mr. $\mathrm{Y}$, and their responses, are reproduced below:

Prof. E: From your perspective, was the study worth doing? Think about the amount of time it took, disruptions to normal schedule, new content, the amount of effort you had to expend, etc.

$M r . X$ : It fitted the seventh-grade curriculum.

Mr. $Y$ : The time could have been tighter. There were some breaks and interruptions. But, I enjoyed seeing the model lessons and then presenting them to the seventh-graders. The quality of what was there was good, and the students' interaction with each other was also good. 


\section{Prof. F: How did you randomly allocate the students to the two groups}

for this study?

$M r . X$ : I put all the names in a hat and then got Group 1 and Group 2 by withdrawing names from the hat.

\section{Sinan K: What was your overall impression about the students' progress?}

$M r . X$ : They are considerably better as a result of having participated in this study. Some of the students obtained detailed understandings of most of the concepts, but some concepts weren't understood fully. As for retention, they remember the skills and applications, but didn't always remember the names of the properties.

$M r . Y$ : I enjoyed having kids working in groups on the different tasks. The groups then shared what they'd done. I liked it, and I also think that the kids liked it.

Prof. E: Is there anything that you will do differently, in the future, as a result of your involvement in this study?

$M r . X$ : I will definitely incorporate the ideas on the structure properties when we do operations at the beginning of seventh-year. That would fit in nicely. I have also thought about Mr. Y's lessons on modeling. I think there is a strong connection between linear functions and the structure of the modeling tasks. $M r . Y$ : I will incorporate the modeling content and graphing. We can look at the patterns and at their graphs. The tasks provide good representations of linear 
progressions and of how math can predict the future. Graphing would be a kind of extension on what we were doing.

\section{Sinan K: What was the highlight of the study, for you?}

$M r . X$ : I remember the day before a presentation when the kids knew they would have to talk to the rest of the class/ They were summarizing the structures that they had been working on. Everybody was working together in small groups on assigned tasks. That was very beneficial and convenient—very impressive. $M r . Y$ : When they came together in a group and they had to come up with examples, they made up some very creative and unique examples. They created great questions and it worked perfectly. Some of the students really went well beyond what I expected. It was really good for the kids.

\section{A Call to Action}

The teachers' comments drew attention to the fact that planning and conducting effective education research in classroom settings is a difficult thing to do in these times when mandated tests and curricula have increasingly become part of what is normally done in schools. Nevertheless, I believe the answers that have been provided in this chapter to the six main research questions are important from a mathematics education perspective. The study will have been worthwhile if those answers are noticed and acted upon by teachers, curriculum developers, and mathematics education researchers. 


\section{REFERENCES}

Adams, J. A. (1897). The Herbartian psychology applied to education. Boston, MA: D. C. Heath.

Ausubel, D. P. (1968). Educational psychology: A cognitive view. New York, NY: Holt, Rinehart and Winston.

Blanton, M. L., Brizuela, B. M., Gardiner, A. M., Sawrey, K., \& Newman-Owens, A. (2015). A learning trajectory in 6-year-olds' thinking about generalizing functional relationships. Journal for Research in Mathematics Education, 46(5), 511-558.

Blanton, M. L., \& Kaput, J. J. (2011). In J. Cai \& E. Knuth (Eds.), Early algebraization: A global dialogue from multiple perspectives (pp. 5-23). Heidelberg, Germany: Springer.

Blanton, M. L., Stephens, A., Knuth, E., Gardiner, A. M. Isler, I., \& Kim, J-S (2015). The development of children's algebraic thinking: The impact of a comprehensive early algebra intervention in third grade, Journal for Research in Mathematics Education, 46(1), 39-87.

Borko, H. (2004). Professional development and teacher learning: Mapping the terrain. Educational Researcher, 33, 3-15.

Britt, M. S., \& Irwin, K. C. (2011). Algebraic thinking with and without algebraic representation: A pathway for learning. In J. Cai \& E. Knuth (Eds.), Early. algebraization: A global dialogue from multiple perspectives (pp. 137-157). Heidelberg, Germany: Springer. 
Brown, A. L. (1992). Design experiments: Theoretical and methodological challenges in creating complex interventions. Journal of the Learning Sciences, 2, 141-178.

Cai, J., \& Knuth, E. (Eds.). (2011). Early algebraization: A global dialogue from multiple perspectives. Heidelberg, Germany: Springer.

Cai, J., Moyer, J. C., Wang, N., \& Nie, B. (2011). Examining students' algebraic thinking in a curricular context: A longitudinal study. In J. Cai \& E. Knuth (Eds.), Early algebraization: A global dialogue from multiple perspectives (pp. 161-185). Heidelberg, Germany: Springer.

Campbell, D. T., \& Stanley, J. C. (1963). Experimental and quasi-experimental designs for research on teaching. In N. L. Gage (Ed.), Handbook of research on teaching (pp. 171-246). Washington, DC: American Educational Research Association.

Campos, D. G. (2010). Peirce's philosophy of mathematical education: Fostering reasoning abilities for mathematical inquiry. Studies in Philosophy and Education, 29, 421-429.

Cañadas, M. C., Brizuela, B. M., \& Blanton, M. (2016). Second graders articulating ideas about co-variation with linear functions. Journal of Mathematical Behavior, 41, 87103.

Carraher, D. W., Schliemann, A. D., \& Schwartz, J. L. (2008). Early algebra is not the same as algebra early. In J. J. Kaput, D. W. Carraher, \& M. Blanton (Eds.), Algebra in the early grades (pp. 235-272). New York, NY: Lawrence Erlbaum Associates. (CCSSM) National Governors Association Center for Best Practices, \& Council of Chief State School Officers. (2010). Common Core State Standards for Mathematics. Washington, DC: Authors. 
Charles, R. I., Branch-Boyd, J. C., Illingworth, M., Mills, D., \& Reeves, A. (2004). Mathematics course 2. Needham, MA: Pearson Prentice Hall.

Clements, M. A. (1980). Analyzing children's errors on written mathematical tasks. Educational Studies in Mathematics, 11(1), 1-21.

Clements, M. A. (2011). Design research: Its potential for meeting Brunei Darussalam's educational needs. In I. Cheong (Ed.), Design research in education: Empowering teachers, learners and researchers (pp. 22-40). Gadong, Brunei Darussalam: Universiti Brunei Darussalam.

Clements, M. A. (2014). A historical overview of visualization and visualizing in mathematics. In M. Fried \& T. Dreyfus (Eds.), Mathematics and mathematics education: Searching for common ground (pp. 177-192). New York, NY: Springer.

Clements, M. A., \& Del Campo, G. (1987). Fractional understanding of fractions: Variations in children's understanding of fractional concepts across embodiments, Grades 2 through 5. In J. Novak (Ed.), Proceedings of the Second International Seminar on Misconceptions and Educational Strategies in Science and Mathematics (Vol. 3, 98-110). Ithaca, NY: Cornell University.

Cobb, P., Confrey, J., diSessa, A., Lehrer, R., \& Schauble, L. (2003). Design experiments in educational research. Educational Researcher, 32(1), 9-13.

Cobb, P., \& Gravemeijer, K. (2008). Experimenting to support and understand learning processes. In A. E. Kelly, R. Lesh, \& J. Baek (Eds.), Handbook of design research methods in education: Innovations in science, technology, engineering, and mathematics learning and teaching (pp. 68-95). New York, NY: Routledge. 
Cohen, J. (1988). Statistical power analysis for the behavioral sciences (2nd ed.). Hillsdale, NJ: Lawrence Erlbaum Associates.

Cole, P. R. (1912). Johann Friedrich Herbart. In P. Monroe (Ed.), A cyclopaedia of education (Vol. 3, pp. 250-254). New York, NY: Macmillan.

Common Core Writing Team. (2011, May 29). Progression for the Common Core State Standards in Mathematics (draft). Comment at commoncoretools.wordpress.com. 1.

De Garmo, C. (Ed.). (1900). Apperception: A monograph on psychology and pedagogy. Boston, MA: D. C. Heath \& Co.

Del Campo, G., \& Clements, M. A. (1987). A manual for the professional development of teachers of beginning mathematicians. Melbourne, Australia: Association of Independent Schools of Victoria.

Del Campo, G., \& Clements, M. A. (1990). Expanding the modes of communication in mathematics classrooms. Journal für Mathematik-Didaktik, 11(1), 45-99.

de Saussure, F. (1959). Course in general linguistics. New York, NY: The Philosophical Library.

de Saussure, F. (1974). Cours de linguistique générale (edited by C. Bally and A. Sechehaye). Paris, France: Payot.

Ding, M., \& Li, X. (2010). A comparative analysis of the distributive property in U.S. and Chinese elementary mathematics textbooks. Cognition and Instruction, 28(2), $146-180$.

Ding, M., \& Li, X. (2014). Transition from concrete to abstract representations: The distributive property in a Chinese textbook series. Educational Studies in Mathematics, 87, 103-121. 
Ding, M., Li, X, \& Capraro, M. M. (2013). Preservice elementary teachers' knowledge for teaching the associative property of multiplication: A preliminary analysis. The Journal of Mathematical Behavior, 32, 36-52.

Dreyfus, T., \&, Eisenberg, T. (1982). Intuitive functional concepts: A baseline study on intuitions. Journal for Research in Mathematics Education, 13, 360-380.

Dunkley, H. B. (1970). Herbart and Herbartianism: An educational ghost story. Chicago, IL: University of Chicago Press.

Ellerton, N. F., \& Clements, M. A. (1991). Mathematics in language: A review of language factors in mathematics learning. Geelong, Australia: Deakin University.

Ellerton, N. F., \& Clements, M. A. (2005). A mathematics education ghost story: Herbartianism and school mathematics. In P. Clarkson, A. Downton, D. Gronn, M. Horne, A. McDonagh, R. Pierce \& A. Roche (Eds.), Building connections: Research, theory and practice (pp. 313-320). Sydney, Australia: Mathematics Education Research Group of Australasia.

Ellerton, N. F., \& Clements, M. A. (2011). Prospective middle-school mathematics teachers' knowledge of equations and inequalities. In J. Cai \& E. Knuth (Eds.), Early algebraization (pp. 379-408). New York, NY: Springer.

Ellis, A. B. (2011). Algebra in the middle school: Developing functional relationships through quantitative reasoning. In J. Cai \& E. Knuth (Eds.), Early algebraization: A global dialogue from multiple perspectives (pp. 215-238). Heidelberg, Germany: Springer.

Fried, M. (2008). History of mathematics in mathematics education: A Saussurean perspective. The Montana Mathematics Enthusiast, 5(2-3), 185-198. 
Fujii, T., \& Stephens, M. (2001). Fostering an understanding of algebraic generalizations through numerical expressions. In K. Stacey, H. Chick \& M. Kendal (Eds.), Proceedings of the 12th Conference of the International Commission on Mathematical Instruction: The future of the teaching and learning of algebra (Vol. 1, pp. 258-264). Melbourne, Australia: The University of Melbourne.

Gagné, R. (1985). The conditions of learning (4 ${ }^{\text {th }}$ ed.). New York, NY: Holt, Rinehart \& Winston.

Gagné, R. M., \& Merrill, M. D. (1990). Integrative goals for instructional design. Educational Technology Research and Development, 38(1), 23-30.

Gagné, R. M., \& White, R. T. (1978). Memory structures and learning outcomes. Review of Educational Research, 48(2), 187-222.

Gavin, M. K., \& Sheffield, L. J. (2015). A balancing act: Making sense of algebra. Mathematics Teaching in the Middle School, 20(8), 460-466.

Gersten, R., Baker, S., \& Lloyd, J. W. (2000). Designing high quality research in special education: Group experimental design. Journal of Special Education, 34, 2-18.

Hayward, F. H. (1904). The secret of Herbart. London, United Kingdom: Sonnenschein. Herbart, J. F. (1898). Letters and lectures on education (translated by H. M. and E. Felkin). London, United Kingdom: Swan Sonnenschein \& Co.

Herbart, J. F. (1904a). Outlines of educational doctrine. New York, NY: Macmillan. Herbart, J. F. (1904b). The science of education. London, United Kingdom: Sonnenschein.

Hewitt, D. (1998). Approaching arithmetic algebraically. Mathematics Teaching, 163, 19-29. 
Jeon, K. (2012). Reflecting on PEMDAS. Teaching Children Mathematics, 18(6), 370377.

Joyce, B., \& Showers, B. (2002). Student achievement through staff development (3rd ed.). Alexandria, VA: Association for Supervision and Curriculum Development.

Kanbir, S. (2014, November). Two approaches: Beginning algebra students' variable concept development. Professional project presented at Illinois State University, Normal, IL.

Kanbir, S. (2016, April 12). Three different approaches to middle-school algebra: Results of a pilot study. Paper presented at the 2016 Research Conference of the National Council of Teachers of Mathematics, held in San Francisco, CA.

Kaput, J. (2008). What is algebra? What is algebraic reasoning? In J. Kaput, D. Carraher, \& M. Blanton (Eds.), Algebra in the early grades (pp. 1-18). Mahwah, NJ: Lawrence Erlbaum/Taylor \& Francis Group, \& National Council of Teachers of Mathematics.

Kelly, A. E., \& Lesh, R. A. (Eds.). (2000). Handbook of research design in mathematics and science education. Mahwah, NJ: Lawrence Erlbaum.

Kelly, A. E., Lesh, R. A., \& Baek, J. Y. (Eds.). (2008). Handbook of design research methods in education: Innovations in science, technology, engineering and mathematics learning and teaching. New York, NY: Routledge.

Kieran, C. (2006). Research on the learning and teaching of algebra. In A. Gutiérrez \& P. Boero (Eds.), Handbook of research on the psychology of mathematics education: Past, present and future (pp. 11-49). Rotterdam, The Netherlands: Sense Publishers. 
Kieran, C. (2007). Learning and teaching algebra at the middle school through college levels: Building meaning for symbols and their manipulation. In F. K. Lester (Ed.), Second handbook of research on mathematics teaching and learning (pp. 707-762). Charlotte, NC: Information Age Publishing; and Reston, VA: National Council of Teachers of Mathematics.

Kieran, C. (2011). Overall commentary on early algebraization: Perspectives for research and teaching. In J. Cai \& E. Knuth (Eds.), Early algebraization: A global dialogue from multiple perspectives (pp. 579-593). Heidelberg, Germany: Springer.

Knuth, E. Stephens, A., Blanton, M., \& Gardiner, A. (2016, March). Build an early foundation for algebra success. Kappanmagazine.org, 97(6), 65-68.

Lannin, J. K., Barker, D. D., \& Townsend, B. E. (2006). Recursive and explicit rules: How can we build student algebraic understanding? The Journal of Mathematical Behavior, 25, 299-317.

Lesh, R., \& Sriraman, B. (2005). Mathematics education as a design science. ZDM-The International Journal on Mathematics Education, 37(6), 490-505.

Lüken, M. M. (2012). Young children's structure sense. Journal für MathematikDidaktik, 33, 263-285.

Ma, L. (1999). Knowing and teaching elementary mathematics: Teachers' understanding of fundamental mathematics in China and the United States. Mahwah, NJ: Erlbaum. Mackenzie, A. A., \& White, R. T. (1982). Field-work in geography and long-term memory structures. American Educational Research Journal, 19(4), 623- 632.

Moss, J., \& McNab, S. L. (2011). An approach to geometric and numeric patterning that fosters second grade students' reasoning and generalizing about functions and co- 
variation. In J. Cai \& E. Knuth (Eds.), Early algebraization: A global dialogue from multiple perspectives (pp. 277-301). Heidelberg, Germany: Springer.

National Council of Teachers of Mathematics. (2000). Principles and standards for school mathematics. Reston, VA: Author.

National Governors Association Center for Best Practices, \& Council of Chief State School Officers. (2010). Common Core State Standards for Mathematics. Washington, DC: Authors.

Otte, M. (1998). Limits of constructivism: Kant, Piaget and Peirce. Science and Education, 7(5), 425-450.

Otte, M. F. (2011). Evolution, learning and semiotics from a Peircean point of view. Educational Studies in Mathematics, 77, 313-329.

Peirce, C. S. (1992). The essential Peirce: Selected philosophical writings (Volume 1, 1867-1893). Bloomington, IN: Indiana University Press.

Peirce, C. S. (1998). The essential Peirce (Volume 2). Bloomington, IN: Indiana University Press.

Presmeg, N. (2014). Mathematics education research embracing arts and sciences. In M. Fried \& T. Dreyfus (Eds.), Mathematics and mathematics education: Searching for common ground (pp. 361-378). New York, NY: Springer.

Radford, L. (2003). Gestures, speech, and the sprouting of signs. Mathematical Thinking and Learning, 5(1), 37-70.

Radford, L. (2004). Syntax and meaning. In M. J. Høines \& A. B. Fuglestad (Eds.), Proceedings of the 26th Conference of the International Group for the Psychology 
of Mathematics Education (Vol. 1, pp. 161-166). Bergen, Norway: International Group for the Psychology of Mathematics Education.

Radford, L. (2006). Algebraic thinking and the generalization of patterns: A semiotic perspective. In S. Alatorre, J. L. Cortina, M. Sáiz, \& A. Méndez (Eds.), Proceedings of the 28th Annual Meeting of the North American Chapter of the International Group for the Psychology of Mathematics Education (Vol. 1, pp. 221). Mérida, México: International Group for the Psychology of Mathematics Education.

Radford, L. (2008). Connecting theories in mathematics education: Challenges and possibilities. ZDM-The International Journal on Mathematics Education, 40, 317 327.

Radford, L. (2011). Grade 2 students' non-symbolic algebraic thinking. In J. Cai \& E. Knuth (Eds.), Early algebraization: A global dialogue from multiple perspectives (pp. 303-322). Heidelberg, Germany: Springer.

Radford, L. (2015). The epistemological foundations of the theory of objectification. Isonomia (online journal http://isonomia.uniurb.it/epistemologica), 127-149.

Rivera, F. D. (2013). Teaching and learning patterns in school mathematics: Psychological and pedagogical considerations. Dordrecht, The Netherlands: Springer.

Rosnow, R. L., \& Rosenthal, R. (1996). Computing contrasts, effect sizes, and counternulls on other people's published data: General procedures for research consumers. Psychological Methods, 1, 331-340. 
Schoenfeld, A. H. (2006). What doesn't work: The challenge and failure of the What Works Clearinghouse to conduct meaningful reviews of studies of mathematics curricula. Educational Researcher, 35, 13-21.

Schoenfeld, A. H. (2013). On forests, trees, elephants and classrooms: A brief for the study of learning ecologies. ZDM-The International Journal on Mathematics Education, 45(3), 491-495.

Selleck, R. J. W. (1968). The new education 1870-1914. London, United Kingdom: Sir Isaac Pitman and Sons.

Sfard, A. (1991). On the dual nature of mathematical conceptions: Reflections on processes and objects as different sides of the same coin. Educational Studies in Mathematics, 22(1), 1-36.

Sfard, A. (2008). Thinking as communicating. Cambridge, United Kingdom: Cambridge University Press.

Singh, P., \& Ellerton, N. F. (2013). International collaborative studies in mathematics education. In M. A. Clements, A. Bishop, C. Keitel, J. Kilpatrick, \& F. Leung (Eds.), Third international handbook of mathematics education (pp. 806-839). New York, NY: Springer.

Slavin, R. E. (2004). Educational research can and must address "what works" questions. Educational Researcher, 33(1), 27-28.

Sriraman, B. (2009). What's all the commotion about commognition? The Montana Mathematics Enthusiast, 6(3), 541-544. 
Sriraman, B., \& Lee, K-H. (2011). Commentary on Part II. In J. Cai \& E. Knuth (Eds.), Early algebraization: A global dialogue from multiple perspectives (pp. 367-373). Heidelberg, Germany: Springer.

Stylianides, A. J., \& Stylianides, G. J. (2013). Seeking research grounded solutions to problems of practice: Classroom-based interventions in mathematics education. ZDM-The International Journal on Mathematics Education, 45(3), 333-342.

Tall, D., \& Vinner, S. (1981). Concept image and concept definition in mathematics with particular reference to limits and continuity. Educational Studies in Mathematics, $12(2), 151-169$.

Taylor-Cox, J. (2003). Algebra in the early years? Yes! Young Children, 58(1), 14-21.

Trochim, W., \& Land, D. (1982). Designing designs for research. The Researcher, 1, 16.

Vaiyavutjamai, P. (2003). Dilemmas associated with quantitative analyses of effects of traditional mathematics teaching. In H. S. Dhindsa, S. B. Lee, P. Achleitner, \& M. A. Clements (Eds.), Studies in science, mathematics and technical education (pp. 259-268). Gadong, Brunei Darussalam: Universiti Brunei Darussalam.

Vinner, S., \& Dreyfus, T. (1989). Images and definitions for the concept of function. Journal for Research in Mathematics Education, 20(4), 356-366.

Vinner S., \& Hershkowitz, R. (1980). Concept images and some common cognitive paths in the development of some simple geometric concepts. In R. Karplus (Ed.), Proceedings of the Fourth International Conference for the Psychology of Mathematics Education (pp. 177-184). Berkeley, CA: International Group for the Psychology of Mathematics Education. 
Vygotsky, L. S. (1978/1930). Mind in society: The development of higher psychological processes (M. Cole, V. John-Steiner, S. Scribner, \& E. Souberman, Trans.). Cambridge, MA: Harvard University Press.

Wartofsky, M. (1979). Models, representation and the scientific understanding. Dordrecht, The Netherlands: D. Reidel.

Westbury, I. (1980). Change and stability in the curriculum: An overview of the questions. In H. G. Steiner (Ed.), Comparative studies of mathematics curricula: Change and stability 1960-1980 (pp. 12-36). Bielefeld, Germany: Institut für Didaktik der Mathematik-Universität Bielefeld.

Whitacre, I., \& Nickerson, S. D. (2016). Prospective elementary teachers making sense of multidigit multiplication: Leveraging resources. Journal for Research in Mathematics Education, 47(3), 270-307.

Whitehurst, G. J. (2003). Research on mathematics education. Washington, DC: U.S. Department of Education.

Wu, H. (2001). How to prepare students for algebra. American Educator, 25(2), 10-17. Wu, H-S (2007, September 13). "Order of operations" and other oddities in school mathematics. Retrieved from https://math.berkeley.edu/ wu/order5.pdf

Wu, H-S (2011). Understanding numbers in elementary school mathematics. Providence, RI: American Mathematical Society.

Zhang, X., Clements, M. A., \& Ellerton, N. F. (2015). Conceptual (mis)understandings of fractions: From area models to multiple embodiments. Mathematics Education Research Journal. 27(2), 233-261. 


\section{APPENDICES}

Appendix Page

A Protocol for Algebra Interviews with Seventh-Graders 244

B Algebra Test (Three Parallel Versions are Reproduced) 247

C "Questionnaire" Completed by Seventh-Grade Students at

School W at the Beginning of the Algebra Workshops on "Structure" 258

D Statement of Instructional Aims for the Structure Workshops with the Seventh-Grade Students at School W

E Detailed Lesson Plans for Four Workshops on "Structure" for SeventhGrade Students at School W, Including Homework Challenges for Each Workshop

F Detailed Plans for Group Tasks in the Modeling Workshops: Finding Recursive and Explicit Rules for Patterns 276

G Classroom Observation Schedule 301

$\mathrm{H} \quad$ Pre-Teaching to Post-Teaching "Growth" with Respect to the Five Basic Cognitive Structure Components 303

I Generalization Categories (After Radford, 2006) 309 


\section{APPENDIX A \\ PROTOCOL FOR ALGEBRA INTERVIEWS WITH \\ SEVENTH-GRADERS}

1. The interviews should be tape-recorded.

2. The interviewer should have the following:

(a) A sheet of paper with $482+(18+300$ on it. [See (2) below.]

(b) A sheet of paper with value of $4 \times(1 / 4 \times 128)$ on it. [See (3) below.]

(c) A sheet of paper with $T_{n}=2 n+3$ on it. [See (4) below.]

(d) A sheet of paper with $T_{n}=5 n-2$ on it. [See (5) below.]

(e) A sheet of paper with $15-(5-x)=(15-5)-x$ on it. [See (6) below.]

(f) A sheet of paper showing the Table in Question 7 below.

(g) A sheet of paper showing the illustration in Question 8 below.

1. "I am going to say two words and, as soon as I say them, I want you to say something, or draw something, or do something - do the first thing that comes into your head after I say the words. The words are ... "distributive property." Here are the words again: "distributive property."

2. Without using a calculator, find the value of $482+(18+300)$.

[Once an answer is given ask for the explanation of where that answer came from.]

3. Without using a calculator, find the value of $4 \times(1 / 4 \times 128)$.

[Once an answer is given ask for the explanation of where that answer came from.] 
4. If we write $T_{n}=2 n+3$, then we can say $T_{5}$ equals 13 , because 2 times 5 plus 3 equals 13 . What would $T_{11}$ equal?

When the pupil gives an answer, ask her or him to write down how she or he obtained that answer. Also, ask the student to explain what she or he thought, in words.

5. Give the pupil a piece of paper with $T_{n}=5 n-2$ on it, then ask her or him to say which values of $n$ would make $T_{n}$ greater than 20 .

When the pupil gives an answer, ask her or him to write down how she or he obtained that answer. Also, ask the student to explain what she or he thought, in words.

6. [Give the pupil a piece of paper with the equation $15-(5-x)=(15-5)-x$ on it, and then, pointing to the $x$, say: "Which numbers could $x$ equal so that you would get a true statement?']

When the pupil gives an answer, ask her or him to write down how she or he obtained that answer. Also, ask the student to explain what she or he thought, in words.

7. Give the pupil a piece of paper with the following table on it:

\begin{tabular}{|l|c|c|c|c|c|c|c|}
\hline $\begin{array}{l}\text { First } \\
\text { Value }\end{array}$ & 1 & 2 & 3 & 4 & 5 & $\ldots$ & $n$ \\
\hline $\begin{array}{l}\text { Second } \\
\text { Value }\end{array}$ & 3 & 5 & 7 & 9 & $?$ & $\ldots$ & $?$ \\
\hline
\end{tabular}

Then ask (pointing): What number should we place under the 5 in the table?

Then ask (pointing): What do you think we should we put under the $n$ ?

8. The diagram below shows how tables and chairs are arranged in a school cafeteria. One table can seat 4 people, and tables can be pushed together (but always in a straight 
line). When two tables are pushed together, 6 people can sit around the table (as shown), etc.

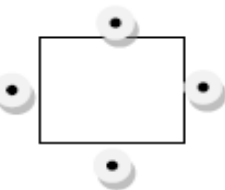

1 Table

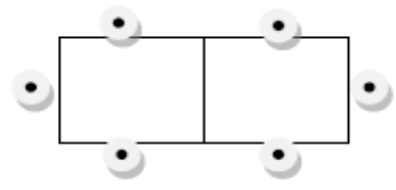

2 Tables

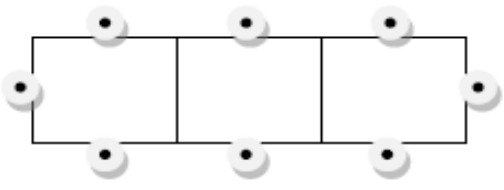

3 Tables

C. If 10 tables were pushed together (in a straight line), how many people could sit around them (assuming the pattern shown above)?

D. If $P_{n}$ represents the number of people who can sit when $n$ tables are pushed together (in a straight line), what is the rule giving $P_{n}$ in terms of $n$ ? 


\section{APPENDIX B \\ ALGEBRA TEST (THREE PARALLEL VERSIONS \\ ARE REPRODUCED)}

\section{Algebra Test (Pre-Teaching Version, and also the Retention Version)}

1. If $T_{n}=13-3 n$, where $\mathrm{n}$ can be any whole number. Which values of $n$ would make the values of $T_{n}$ positive?

2. A really important property for numbers and for algebra is called the associative property for multiplication. Describe this property in your own words?

3. Suppose you were asked to calculate the value of $940+(60+403)$ in your head (without writing anything down, or using a calculator. How would you do it, and which property would you be using?

4. If $S_{n}=101+50 n$, where $n$ can be any whole number, what is the value of $S_{4}$ ?

5. A student is creating towers out of unit cubes. Each unit cube, by itself, has 6 square faces, but when two unit cubes are stuck together, one exactly on top of the other, there are only 10 faces in the tower (including the top and the bottom). The first tower has 1 unit cube and 6 faces. The second tower has 2 unit cubes, one on top of the other, and the third tower has 3 unit cubes, etc. We say that the surface area of the first tower is 6 units, of the second tower is 10 units, etc.

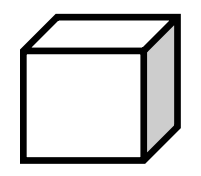

$n=1$

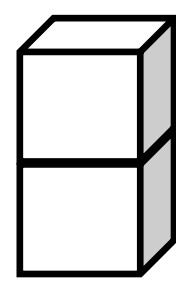

$n=2$

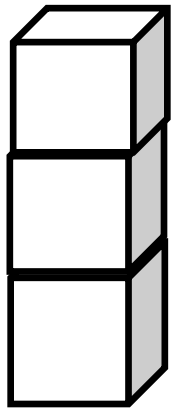

$n=3$

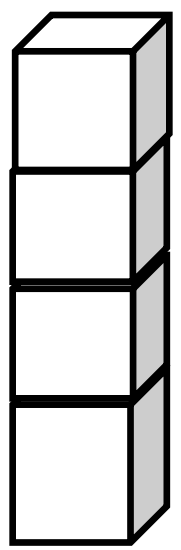

$$
n=4
$$

What is the surface area of a tower with 50 cubes? 
6. If $T_{n}=2 n+5$, what is value of $T_{n+1}-T_{n}$ ?

7. Which values of $x$ would make this statement true? $\quad 5(x-3)=5 x-10$. Explain how you got your answer.

8. Without using a calculator find the value of $(72 \times 5) \times 2$, and explain how you got your answer.

9. What must $x$ equal if $12-(8-4)=(12-x)-4$ ? Explain how you got your answer.

10. If $96=16 y+32 y$, what must $y$ equal?

Explain how you got your answer.

11. If $20 \times(10+5)=(20 \times 10)+(20 \times y)$, what must $y$ equal?

Explain how you got your answer. 
12. (a) What number should replace the question mark below 5 in the second row of the following table?

\begin{tabular}{|c|c|c|c|c|c|c|c|}
\hline $\begin{array}{c}\text { First row of } \\
\text { numbers }\end{array}$ & 1 & 2 & 3 & 4 & 5 & $\ldots$ & $n$ \\
\hline $\begin{array}{c}\text { Second row } \\
\text { of numbers }\end{array}$ & 3 & 6 & 9 & 12 & $?$ & $\ldots$ & $?$ \\
\hline
\end{tabular}

(b) In the table above, what should replace the question mark which is below the $n$ ?

13. What would be a quick method of finding the value of $7 \times 97+7 \times 3$ without using a calculator? What is the property which allows you to use that quick method?

14. You have been hired by the Southwestern Fence Company to make pens for holding cows.

A cow pen is a wall of blocks that completely surrounds the cow. You must leave at least one unit square in the middle of each pen where a cow would go. A cow needs 1 square unit of space.

The first cow pen that you can build looks like this. It holds just one cow, and there are 8 surrounding blocks altogether:

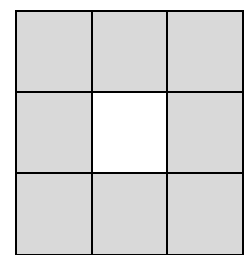

The second cow pen that you can build looks like this. It holds 2 cows.

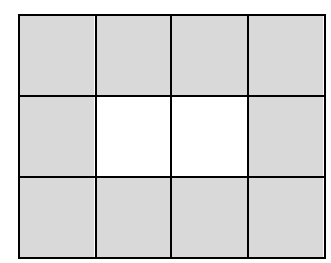


The third cow pen that you can build looks like this. It holds 3 cows.

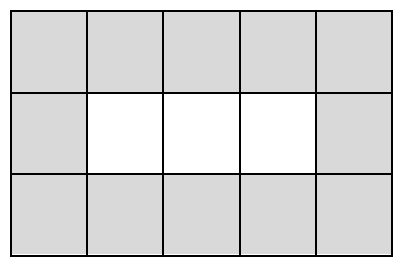

Note that the cow pens must always be in a straight line, left to right.

How many surrounding blocks would you need to hold 25 cows?

If $S_{n}$ represents the number of surrounding blocks you would need for a pen which would hold $n$ cows, what is the rule giving $S_{n}$ in terms of $n$ ?

Explain how you got your rule for Part (b).

15. What would be a quick method of finding the value of $64 \times\left(\frac{1}{32} \times 120\right)$, without using a calculator? 


\section{Algebra Test (Mid-Intervention Version)}

1. In this question $T_{n}=14-4 n$, where $n$ can represent various positive counting numbers, which values of $n$ would make the values of $T_{n}$ positive?

2. A really important property for numbers and for algebra is called the associative property for addition. Describe this property in your own words

3. Suppose you were asked to calculate the value of $910+(90+463)$ in your head (without writing anything down, or using a calculator. How would you do it, and which property would you be using?

4. If $S_{n}=101+40 n$, where $n$ can be any whole number, what is the value of $S_{5}$ ?

5. Mr. Y wants to know how many students can sit around row of hexagonal shaped desks. If one desk is by itself then six students can sit around it, but if two desks are pushed together, then only 10 students can sit around the pattern of tables. If three desks are pushed together in a row, as shown above, then 14 students can sit around the pattern of tables

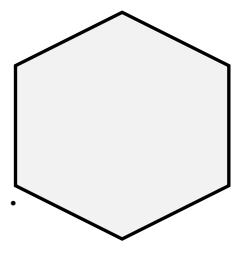

$n=1$

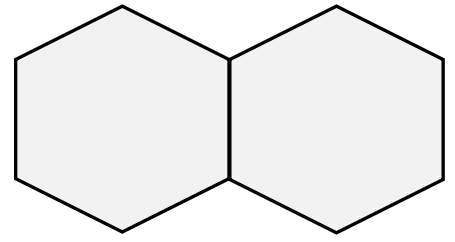

$n=2$

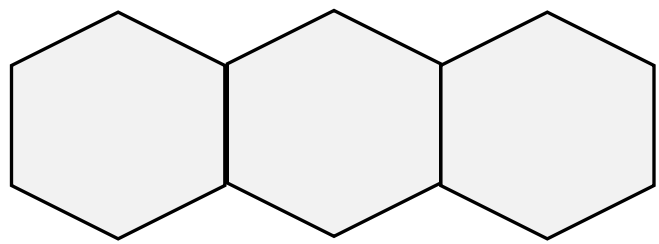

$n=3$

How many students could sit around a pattern of 50 hexagonal tables arranged in a long straight row, like the patterns shown?

6. If $T_{n}=3 n+2$, what is value of $T_{n+1}-T_{n}$ ? 
7. Which values of $x$ would make this statement true? $\quad 4(x-3)=4 x-6$.

Explain how you got your answer.

8. Without using a calculator find the value of $(36 \times 5) \times 2$, and explain how you got your answer.

9. What must $x$ equal if $15-(10-5)=(15-x)-5$ ? Explain how you got your answer.

10. If $72=12 x+24 x$, what must $x$ equal?

Explain how you got your answer.

11. If $30 \times(10+4)=(30 \times 10)+(30 \times y)$, what must $y$ equal?

Explain how you got your answer.

12. (a) What number should replace the question mark below 5 in the second row of the following table?

\begin{tabular}{|c|c|c|c|c|c|c|c|}
\hline $\begin{array}{c}\text { First row of } \\
\text { numbers }\end{array}$ & 1 & 2 & 3 & 4 & 5 & $\cdots$ & $n$ \\
\hline $\begin{array}{c}\text { Second row } \\
\text { of numbers }\end{array}$ & 4 & 8 & 12 & 16 & $?$ & $\cdots$ & $?$ \\
\hline
\end{tabular}

(b) In the table above, what should replace the question mark which is below the $n$ ?

13. What would be a quick method of finding the value of $8 \times 96+8 \times 4$ without using a calculator? What is the property which allows you to use that quick method? 
14. A king is building a house for his queen, but there has to be security rooms all around the queen's bedroom, as shown in the first diagram below. You can see that there are 8 surrounding security rooms altogether:

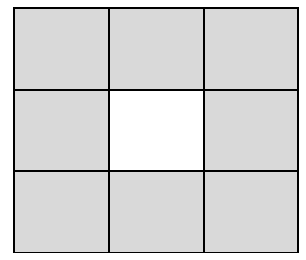

The queen complained that one room was not enough for her, so the king arranged for a two-room version to be built, like this. There were 10 security rooms needed.

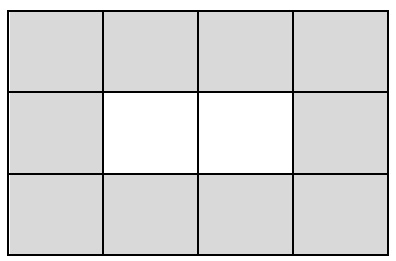

But, after a while, the queen said she needed three rooms, so the king arranged for the following to be built.

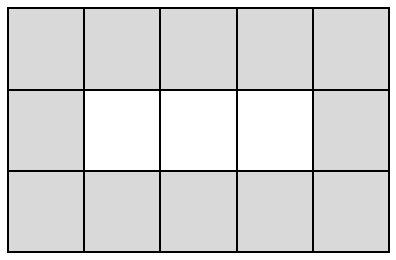

Notice that the queen's rooms must always be in a straight line, left to right.

How many surrounding security rooms would you need if the queen had 25 rooms?

If $R_{n}$ represents the number of surrounding security rooms needed if the queen had $n$ rooms, what is the rule giving $R_{n}$ in terms of $n$ ?

Explain how you got your rule for Part (b).

15. What would be a quick method of finding the value of $48 \times\left(\frac{1}{24} \times 120\right)$, without using a calculator? 


\section{Algebra Test (Post-Teaching Version)}

1. If $T_{n}=17-4 n$, where $n$ can represent various positive counting numbers, which values of $n$ would make the values of $T_{n}$ positive?

2. A really important property for numbers and for algebra is called the associative property for multiplication. Describe this property in your own words?

3. Suppose you were asked to calculate the value of $920+(80+533)$ in your head (without writing anything down, or using a calculator. How would you do it, and which property would you be using?

4. If $S_{n}=102+40 n$, where $n$ can be any whole number, what is the value of $S_{5}$ ?

5. A student is creating towers out of unit cubes. Each unit cube, by itself, has 6 square faces, but when two unit cubes are stuck together, one exactly on top of the other, there are only 10 faces in the tower (including the top and the bottom). The first tower has 1 unit cube and 6 faces. The second tower has 2 unit cubes, one on top of the other, and the third tower has 3 unit cubes, etc. We say that the surface area of the first tower is 6 units, of the second tower is 10 units, etc.

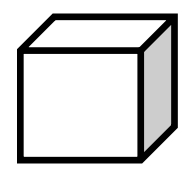

$n=1$

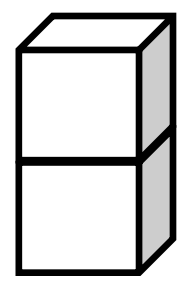

$n=2$

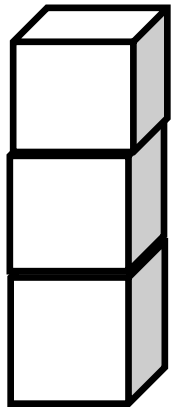

$n=3$

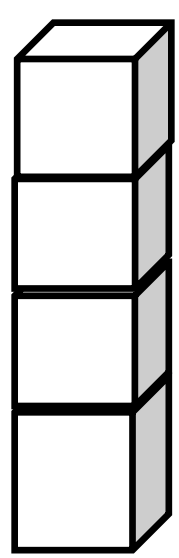

$$
n=4
$$

What is the surface area of a tower with 50 cubes?

6. If $T_{n}=3 n+4$, what is value of $T_{n+1}-T_{n}$ ? 
7. Which values of $x$ would make this statement true?

$$
4(x-3)=4 x-10
$$

Explain how you got your answer.

8. Without using a calculator find the value of $(36 \times 5) \times 2$, and explain how you got your answer.

9. What must $x$ equal if $15-(10-5)=(15-x)-5$ ? Explain how you got your answer.

10. If $72=12 y+24 y$, what must $y$ equal?

Explain how you got your answer.

11. If $50 \times(10+5)=(50 \times 10)+(50 \times y)$, what must $y$ equal?

Explain how you got your answer. 
12. (a) What number should replace the question mark below 5 in the second row of the following table?

\begin{tabular}{|c|c|c|c|c|c|c|c|}
\hline $\begin{array}{c}\text { First row of } \\
\text { numbers }\end{array}$ & 1 & 2 & 3 & 4 & 5 & $\cdots$ & $n$ \\
\hline $\begin{array}{c}\text { Second row } \\
\text { of numbers }\end{array}$ & 4 & 8 & 12 & 16 & $?$ & $\cdots$ & $?$ \\
\hline
\end{tabular}

(b) In the table above, what should replace the question mark which is below the $n$ ?

13. What would be a quick method of finding the value of $8 \times 96+8 \times 4$ without using a calculator? What is the property which allows you to use that quick method?

14. You have been hired by the Southwestern Fence Company to make pens for holding cows.

A cow pen is a wall of blocks that completely surrounds the cow. You must leave at least one unit square in the middle of each pen where a cow would go. A cow needs 1 square unit of space.

The first cow pen that you can build looks like this. It holds just one cow, and there are 8 surrounding blocks altogether:

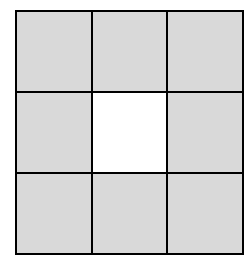


The second cow pen that you can build looks like this. It holds 2 cows.

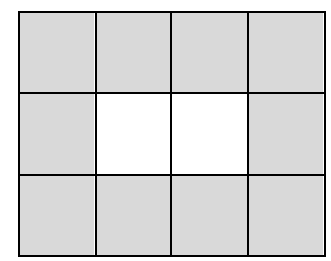

The third cow pen that you can build looks like this. It holds 3 cows.

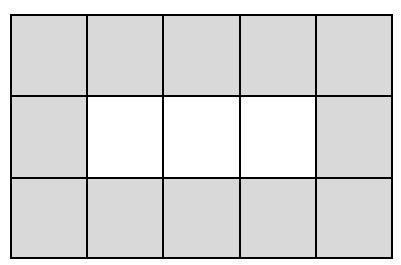

Note that the cow pens must always be in a straight line, left to right.

How many surrounding blocks would you need to hold 25 cows?

If $S_{n}$ represents the number of surrounding blocks you would need for a pen which would hold $n$ cows, what is the rule giving $S_{n}$ in terms of $n$ ?

Explain how you got your rule for Part (b).

15. What would be a quick method of finding the value of $48 \times\left(\frac{1}{24} \times 150\right)$, without using a calculator? 


\author{
APPENDIX C \\ "QUESTIONNAIRE" COMPLETED BY SEVENTH-GRADE STUDENTS AT \\ SCHOOL W AT THE BEGINNING OF THE ALGEBRA \\ WORKSHOPS ON "STRUCTURE"
}

1. Do you have any idea of what the associative property for addition for real numbers states?

Your Answer: Circle whichever is appropriate for you- Yes

No

If your answer was "Yes," write down, in your own words what you think the associative property for addition for real numbers is:

2. Do you have any idea of what the associative property for multiplication for real numbers states?

Your Answer: Circle whichever is appropriate for you- Yes

No

If your answer was "Yes," write down, in words what you think the associative property for multiplication for real numbers is:

3. Do you have any idea of what the distributive property connecting multiplication and addition of real numbers states?

Your Answer: Circle whichever is appropriate for you- Yes

No

If your answer was "Yes," write down, in words what you think the associative property the distributive property connecting multiplication and division of real numbers states: 


\title{
APPENDIX D \\ STATEMENT OF INSTRUCTIONAL AIMS FOR THE STRUCTURE WORKSHOPS \\ WITH THE SEVENTH-GRADE STUDENTS
}

AT SCHOOL W

\begin{abstract}
Aims:
1. To identify how well the students know, before any of the planned lessons take place, the formal statements associated with the following field properties with respect to real numbers:
\end{abstract}

(a) The associative property for addition [i.e., if $a, b, c$ represent any real numbers then $(a+b)+c=a+(b+c)]$

(b) The associative property for multiplication [i.e., if $a, b, c$ represent any real numbers then $(a \times b) \times c=a \times(b \times c)$ ]

(c) The distributive property combining addition and multiplication [i.e., if $a$, $b, c$ represent any real numbers then $a \times(b+c)=(a \times b)+(a \times c)]$.

2. To engage the seventh-grade students in meaningful discussions with fellow students about how knowledge of the above three properties can facilitate calculations, especially mental calculations.

3. To identify how well the seventh-grade students learn to apply the associative and distributive properties with respect to simple, but appropriate, mental calculations.

4. To assist the students to develop confidence as well as competence with respect to understanding and applying the three properties which are the special focus of the sessions.

\section{Preparation of Material:}

1. Workshop 1 (Group Task 1) and Workshop 1 (Group Task 2) are handouts for students. It is intended that these handouts be completed by the seventh-grade students, as they engage in group discussions. The class would be subdivided into groups of 3 or 4, with half of the groups being assigned Group Task 1 (which is concerned with the associative property for addition) and the other half of the groups being assigned to Group 2 (which is concerned with the associative property for multiplication).

2. An initial questionnaire has been prepared. The aim of this is to glean information about what the students already know about the associative property for addition and 
multiplication of real numbers, and what they already know about the distributive property.

3. Typed homework materials, for each of the first two sessions, have also prepared. These materials are to be submitted to the teacher at the beginning of the second and third sessions. The two homework sheets will be mostly review, but there will also be a "challenging questions" on each sheet.

4. This "summary sheet" has also been prepared, the main purpose of which is to indicate clearly the intended sequence for the first two sessions.

\section{Intended Sequence for the First Two Sessions:}

1. Introduction. Students will each have a folder in which to keep all of their worksheets and homework. This should greatly facilitate opportunities for the researchers to look at students' work.

2. Allocation to groups and re-arrangement of tables and administration of questionnaire.

3. Group discussion should focus on the questions asked on printed handouts (for either Workshop Group Task 1 and Workshop Group Task 2). Half of the groups will have the Task 1 handout, and the other half will have the Task 2 handout. The students will be told that in their group they should read the materials, agree on good answers to the questions, and then decide who will teach the students doing the other task that day when they meet the next day. On the second day, group members will be responsible for teaching students in the other group the mathematical ideas that they learned on the first day. Note that on the second day, all of the students will have, and be able to refer to, both the handouts for Workshop Group Task 1 and Workshop Group Task 2.

4. At the end of each of the first two sessions, each of the students will be given a "homework" sheet which he or she will be expected to complete overnight and submit to the teacher at the beginning of the next session. The quality of the students' responses on these homework sheets will be assessed before being returned to the students.

\section{Brief Comments on the Expected Forms of Sessions 3 through 5:}

1. Note that during the third and fourth sessions all students will work in their groups, with a printed handout on two key aspects the distributive property- "expanding" parentheses, and factoring - will be made available to the students. It is expected that the pattern will again be group discussions in the third session, followed by groups teaching of the "other" groups during the fourth session.

2. Then, in the fifth session, the teacher will provide a review of what has been covered during the first four sessions. The aim of this review is to bring into focus the main concepts and principles that the students have been grappling with.

3. This set of 5 sessions will then be repeated with a second set of seventh-grade students at School W (beginning soon after the set of 5 sessions is completed). 
APPENDIX E

DETAILED LESSON PLANS FOR FOUR WORKSHOPS ON “STRUCTURE” FOR

SEVENTH-GRADE STUDENTS AT SCHOOL W, INCLUDING

HOMEWORK CHALLENGES FOR EACH WORKSHOP

\section{Workshop 1: Notes for the First Workshop Sessions on "Structure"-An Important Number Property: The Associative Property for Addition}

INSTRUCTIONS: You will be working with two or three others, and your group's task is to discuss the questions, work out what they mean, and then answer them.

Question 1.1: If $a=12, b=6$ and $c=2$, what are the values of each of the following?

$a+(b+c)$

$(a+b)+c$

$a-(b-c)$

$(a-b)-c$

$(a-b)+c$

Now write down what you've found, neatly in the space below:

Question 1.2: Repeat each of the five parts of Question 1.1, only this time let $a=51, b=$ 26 , and $c=12$. Then, write down what you've found neatly in the space below:

Question 1.3. Repeat Question 1.1, only this time let $a=1 \frac{1}{4}, b=3 / 4$, and $c=1 / 2$. 
Question 1.4. Repeat Question 1.1, only this time let $a=-3, b=-2$, and $c=1$.

Question 1.5: Repeat Question 1.1, only this time let $a, b$ and $c$ be any three real numbers that your group chooses. Then, write down what you've found neatly in the space below:

Question 1.6: Do you think $a+(b+c)$ will always equal $(a+b)+c$, no matter which numerical values you allow $a, b$ and $c$ to be?

Talk about that question, and decide who, from your group, will tell the whole class, during the mathematics class tomorrow morning, about what your group was thinking.

Question 1.7: Do you think $a-(b-c)$ will always equal $(a-b)-c$, no matter which number values you allow $a, b$ and $c$ to represent?

Talk about this, and decide who, from your group, will tell the whole class tomorrow morning, about what your group was thinking.

Question 1.8: Do you think $a-(b-c)$ will always equal $(a-b)+c$, no matter which number values you allow $a, b$ and $c$ to represent? Talk about this, and decide who, from your group, will tell the whole class, during the next mathematics class, about what your group was thinking

\section{An Important Number Property Which You Must Remember}

Here is an important number property for you to learn and remember.

If $a, b, c$ represent any three real numbers then $(a+b)+c$ always equals $a+(b+c)$. This is called the associative property for addition. It is always true, no matter which values you give $a, b$ and $c$.

But, as we have found, the associative property does NOT hold for subtraction, because, in most cases, $a-(b-c)$ does not equal $(a-b)-c$.

Discuss: Under what circumstances will $a-(b-c)$ equal $(a-b)-c$ ? Write down your conclusions. 


\section{Workshop 2: Notes for the Second Workshop Sessions on "Structure"-An Important Number Property: The Associative Property for Multiplication}

INSTRUCTIONS: You will be working with two or three others, and your group's task is to discuss the questions, work out what they mean, and then answer them.

Question 1.1: If $a=24, b=12$ and $c=4$, what are the values of each of the following?

$a \times(b \times c)$

$(a \times b) \times c$

$a \div(b \div c)$

$(a \div b) \div c$

$(a \div b) \times c$

Now write down what you've found, neatly in the space below:

Question 1.2: Repeat each of the five parts of Question 1.1, only this time let $a=-16, b=$ 8 , and $c=-2$. Then, write down what you've found neatly in the space below:

Question 1.3. Repeat Question 1.1, only this time let $a=1 \frac{1}{4}, b=2 / 5$, and $c=1 / 2$.

Question 1.4. Repeat Question 1.1, only this time let $a=-3, b=-2$, and $c=1$.

Question 1.5: Repeat Question 1.1, only this time let $a, b$ and $c$ be any three real numbers, other than 0 , that your group chooses. Why did we exclude zero from this task? Write down what you've found neatly in the space below: 
Question 1.6: Do you think $a \times(b \times c)$ will always equal $(a \times b) \times c$, no matter which numerical values you allow $a, b$ and $c$ to be?

Talk about that question, and decide who, from your group, will tell the whole class, during the mathematics class tomorrow morning, about what your group was thinking.

Question 1.7: If we exclude zero from the possible values, do you think $a \div(b \div c)$ will always equal $(a \div b) \div c$, no matter which number values you allow $a$, $b$ and $c$ to represent?

Talk about this, and decide who, from your group, will tell the whole class tomorrow morning, about what your group was thinking.

Question 1.8: Do you think $a \div(b \div c)$ will always equal $(a \div b) \times c$, no matter which number values you allow $a, b$ and $c$ to represent? Talk about this, and decide who, from your group, will tell the whole class, during the next mathematics class, about what your group was thinking

\section{An Important Number Property Which You Must Remember}

Here is an important number property for you to learn and remember.

If $a, b, c$ represent any three real numbers then $(a \times b) \times c$ always equals $a \times(b \times c)$. This is called the associative property for multiplication. It is always true, no matter which real-number values you give $a, b$ and $c$.

But, as we have found, the associative property does NOT hold for division, because, in most cases, $a \div(b \div c)$ does not equal $(a \div b) \div c$. Now discuss: Under what circumstances will $a \div(b \div c)$ equal $(a \div b) \div c$ ? Write down your conclusions. 


\section{Workshop 3: Notes for the Third Workshop Sessions on "Structure"-An Important Number Property: The Distributive Property for Multiplication Over Addition, Part I}

INSTRUCTIONS: You will be working with two or three others, and your group's task is to discuss the questions, work out what they mean, and then answer them.

Question 1.1: If $a=12, b=6$ and $c=2$, what are the values of each of the following?

$a \times(b+c)$

$a \times b+a \times c$

$a \times(b-c)$

$a \times b-a \times c$

$(b+c) \times a$

Now write down what you've found, neatly in the space below:

Question 1.2: Repeat each of the five parts of Question 1.1, only this time let $a=51, b=$ 26 , and $c=12$. Then, write down what you've found neatly in the space below:

Question 1.3: Repeat Question 1.1, only this time let $a=11 / 2, b=3 / 4$, and $c=1 / 4$

Question 1.4: Repeat Question 1.1, only this time let $a=-3, b=-2$, and $c=1$. 
Question 1.5: Repeat Question 1.1, only this time let $a, b$ and $c$ be any three real numbers that your group chooses. Then, write down what you've found neatly in the space below:

Question 1.6: Do you think $a \times(b+c)$ will always equal $a \times b+a \times c$, no matter which numerical values you allow $a, b$ and $c$ to be?

Talk about that question, and decide who, from your group, will tell the whole class, during the mathematics class tomorrow morning, about what your group was thinking.

Question 1.7: Do you think $a \times(b-c)$ will always equal $a \times b-a \times c$, no matter which number values you allow $a, b$ and $c$ to represent?

Talk about this, and decide who, from your group, will tell the whole class tomorrow morning, about what your group was thinking.

Question 1.8: What do you think $(a-b) \times c$ might equal, no matter which number values you allow $a, b$ and $c$ to represent? Check your conjecture with some numbers. Decide who, from your group, will tell the whole class, during the next mathematics class, about what your group was thinking

\section{An Important Number Property Which You Must Remember (Also, Remember its Name!)}

Here is an important number property for you to learn and remember.

If $a, b, c$ represent any three real numbers then $a \times(b+c)$ is always equal to $a \times b+a \times$ $c$. This is called the distributive property for multiplication over addition. It is always true, no matter which values you give $a, b$ and $c$.

Discuss: What are the main differences between the associative property for addition, the associative property for multiplication, and the distributive property linking multiplication and addition? 


\section{Workshop 4: Notes for the Fourth Workshop Sessions on "Structure"-An Important Number Property: The Distributive Property for Multiplication Over Addition, Part II}

INSTRUCTIONS: You will be working with two or three others, and your group's task is to discuss the questions, work out what they mean, and then answer them.

We say "the factors of 12 are 1, 2, 3, 4, 6 and 12." What do we mean when we say that 4 (for example) is a factor of 12 ?

Question 1.1: If $a=11, b=8$ and $c=5$, calculate the values of $a b+a c$. Then answer the following questions:

Is 11 a factor of the value of $a b+a c$ ?

Is 13 a factor of value of $a b+a c$ ?

Is it true that $a \times(b+c)$ equals $(a \times b)+(a \times c)$ ? Notice that in algebra this is usually written

$$
a(b+c)=a b+a c,
$$

with the multiplication signs on the left and right sides dropped, and the two pairs of parentheses on the right side also dropped.

If you swap the sides you get

$$
a b+a c=a(b+c),
$$

and that emphasizes that $a$ and $(b+c)$ are both factors of $a b+a c$.

We say that $a$ is a "common factor" of $a b$ and $a c$ because $a$ is common to $a b$ and $a c$. The other factor, $(b+c)$, represents the sum of what is left over after the $a$ is removed.

\section{Question 1.2}

If $a, b$ and $c$ represent any three numerical values, must the value of $a$ be a factor of both $a b+a c$ and $a b-a c$ ?

If $a, b$ and $c$ represent any three numerical values, must the value of $(b+c)$ be a factor of $a b+a c$ ?

If $a, b$ and $c$ represent any three numerical values, must the value of $(b-c)$ be a factor of $a b-a c$ ?

Explain why, in algebra, $(a \times b)+(a \times c)$ must always equal $a \times(b+c)$, no matter which real-number values you allow $a, b, c$ to be.

Explain why, in algebra, $(a \times b)-(a \times c)$ must always equal $a \times(b-c)$, no matter which real-number values you allow $a, b, c$ to be. 
6. What are factors of: $3 x-15$ ?

7. What are factors of $2 x^{2}+4 x$ ?

Question 1.3: Repeat each of the parts of Question 1.1, only this time let $a=51, b=26$, and $c=12$. Then, write down what you've found neatly in the space below:

Question 1.4. Repeat the parts of Question 1.1, only let $a=1 \frac{1}{2}, b=3 / 4$, and $c=1 / 4$

Question 1.5. Repeat the parts of Question 1.1, only let $a=-3, b=-2$, and $c=1$.

Question 1.6: Do you think $a b+a c+a d$ will always equal $a(b+c+d)$, no matter which numerical values you allow $a, b$ and $c$ to be?

Talk about that question, and decide who, from your group, will tell the whole class, during the mathematics class tomorrow morning, about what your group was thinking.

Question 1.7: Do you think $5 x+3 x+2$ will always equal $10 x$, no matter which number values you allow $x$ to represent?

Talk about this, and decide who, from your group, will tell the whole class tomorrow morning, about what your group was thinking.

Question 1.8: Do you think $3 a+3 b$ will always equal $6 a b$. no matter which number values you allow $a$ and $b$ to represent?

\section{An Important Number Property Which You Must Remember. (Also, Remember its Name!)}

Here is an important number property for you to learn and remember.

If $a, b, c$ represent any three real numbers then $a(b+c)$ is always equal to $a b+a c$. This is called the distributive property for multiplication over addition. It is always true, no matter which values you give $a, b$ and $c$. Since $a(b+c)$ is always equal to $a b+a c$ it follows that $a$ and $(b+c)$ are factors of $a(b+c)$.

Discuss: What are the main differences between the associative property for addition, the associative property for multiplication, and the distributive property linking multiplication and addition? 


\section{Homework Challenges for Distribution to Seventh-Grade Students Following Workshop 1}

1. Using mental arithmetic only (don't write down anything), calculate the following:

(a) $102+798$

(b) $89+101+10$

Write a short paragraph below about how the associative property for addition can be used to find the answers to (a) and (b) quickly.

2. How could you use an associative property for addition to find an answer to the following?

(a) $8500+601+899$

Write a short paragraph below about how the associative property for addition can be used to find the answer.

(b) $3 \frac{1}{2}+16 \frac{1}{4}+1 / 4$ 
Write a short paragraph, at the top of the back of this page, which makes clear how the associative property for addition can be used to find the answer.

(c) This final homework question is mathematically very challenging. If any seventhgrade student gets its completely right, with correct reasoning, then he or she will be doing very well!

Under what circumstance will it be true that, if $a, b$ and $c$ represent real numbers then $(a-b)-c=a-(b-c)$ ?

Remember, too, members of your group should be ready to talk about the first workshop at the next session (tomorrow). 


\section{Homework Challenges for Distribution to Seventh-Grade Students Following Workshop 2}

1. Using mental arithmetic only (don't write down anything), calculate the following:

$$
25 \times(4 \times 19)
$$

Write a short paragraph below about how the associative property for multiplication can be used to find the answer quickly.

2. Using mental arithmetic only (don't write down anything), calculate the following:

$$
(-2.5 \times 0.93) \times 4
$$

Write a short paragraph below about how the associative property for multiplication can be used to find the answer quickly.

3. How could you use an associative property to find answers to the following?
(a) $48 \times 52 \times 1 / 12$
(b) $-3 \frac{1}{2} \times 16 \times-4 / 7$ 
Write two short paragraphs below about how the associative property for multiplication could be used to find the answers to (a) and (b).

\section{A FINAL, VERY CHALLENGING HOMEWORK QUESTION}

If any seventh-grade student gets its completely right, then he or she will be doing very well!

Under what circumstance will it be true that, if $a, b$ and $c$ represent real numbers then $(a \div b) \div c=a \div(b \div c)$ ?

Remember, too, members of your group should be ready to talk about the second workshop at the next session (tomorrow). 


\section{Homework Challenges for Distribution Following Workshop 3}

1. Using mental arithmetic only (don't write down anything, and don't use a calculator), calculate the following:

(a) How much would 11 apples cost at $\$ 0.99$ each?

(b) How much would 9 newspapers cost at 55 cents each?

(c) If one book weighs 11/4 pounds, how much would 12 of the books weigh?

Write a short paragraph below about how the distributive property can be used to find the answers to (a), (b) and (c) quickly.

2. How could you use the distributive property to find an answer to the following?

(a) $17 \times 97+17 \times 3$

(b) $11 \times 9.9+89 \times 9.9$ 
Write a short paragraph, at the top of the back of this page, which makes clear how the distributive property could be used to find the answer quickly.

3. Explain why the truth of the statement $5 x+3 x=8 x$ could be justified by referring to the distributive property.

4. Simplify, as much as possible: $5 x(1-x)-4+5 x^{2}$. When did you use the distributive property when doing the simplification?

Remember, too, members of your group should be ready to talk about the third workshop at the next session (tomorrow). 


\section{Homework Challenges for Distribution Following Workshop 4}

1. Using mental arithmetic only (don't write down anything), calculate the following:

$$
24 \times 4+76 \times 4
$$

Write a short paragraph below about how the distributive property can be used to find the answer quickly.

2. Using mental arithmetic only (don't write down anything), calculate the following:

$$
(-2.5 \times 6)+(4 \times-2.5)
$$

Write a short paragraph below about how the distributive property could be used to find the answer quickly.

3. Simplify as much as possible $5 x+4-3(x-2)$, justifying each step.

Remember, too, members of your group should be ready to talk about the fourth workshop at the next session (tomorrow). 


\section{APPENDIX F \\ DETAILED PLANS FOR GROUP TASKS IN THE MODELING WORKSHOPS: \\ FINDING RECURSIVE AND EXPLICIT RULES \\ FOR PATTERNS}

\section{Workshop Group Tasks: Finding Recursive and Explicit Rules for Patterns}

INSTRUCTIONS: You will be working with two or three others, and your group's task is to work out what are called the "recursive" and "explicit" rules for patterns which you identify for your two tasks.

But first we'll go over an example.

\section{Worked Example:}

(a) See if you can work out

the pattern, and then

replace the question marks

in the table.

(b) In this question we

could summarize the

pattern by writing " $S_{1}=$

2 , and $S_{n+1}=S_{n}+5$."

\begin{tabular}{c|c}
\hline$n$ & $S_{n}$ \\
\hline 1 & 2 \\
\hline 2 & 7 \\
\hline 3 & 12 \\
\hline 4 & 17 \\
\hline $\mathbf{5}$ & $? ?$ \\
\hline$? ?$ & $\ldots$ \\
\hline$n$ & 37 \\
\hline
\end{tabular}

That means the first term, $S_{1}$, is 2 , and you get the next term from the previous term by adding 5. Thus $S_{2}=2+5=7 ; S_{3}=7+5=\mathbf{1 2}, S_{4}=\mathbf{1 2}+5=17$, etc. The expression " $S_{n+1}$ $=S_{n}+5$ " is said to be the recursive rule for the pattern, and you should also give the first $\operatorname{term} S_{1}$. 
If you want to find $S_{20}$, for example, you start with 2 (which is $S_{1}$ ), add 5 to get $S_{2}$, and then just keep on adding 5 until you get to $S_{20}$. But it could take you a long time to get to $S_{20}$.

Often it is quicker to look for an explicit form of the rule.

In this question the $n$th term, $S_{n}$, is equal to $5 n-3$. Can you see where the " 5 " comes from? Where did the " -3 " come from?

" $S_{n},=5 n-3$ " is called an explicit rule for the pattern.

Now let's see if you can work out recursive or explicit rules (sometimes just one of them, sometimes both) for the tasks allocated to your group. Then, your group will also be expected to create a pattern of its own, and then see if can get others in the class to understand what your pattern is.

\section{FIVE TASKS FOR GROUP 1}

You should work together to find the recursive and explicit rules for the patterns in the first two tasks. With Task 3, "Crossing the River," your teacher will take the lead, and the whole class will work on it together. Then, Task 4 is harder, and for that task you only need to find an explicit rule. Finally, for Task 5, your group will be expected to create a pattern of its own.

\section{Task 1 (for Group 1):}

Talk together and work out the pattern between the two variables - the number of days and the number of completed weeks. Then, find the missing values.

\begin{tabular}{c|c}
\hline $\begin{array}{c}\text { Completed } \\
\text { Weeks } n\end{array}$ & $\begin{array}{c}\text { Days } \\
D_{n}\end{array}$ \\
\hline 1 & 7 \\
\hline 2 & 14 \\
\hline 3 & $?$ \\
\hline$\ldots$ & $\ldots$ \\
\hline 10 & $?$ \\
\hline$\ldots$ & $\ldots$ \\
\hline$?$ & 364 \\
\hline$\ldots$ & $\ldots$ \\
\hline$n$ & $?$ \\
\hline
\end{tabular}

(a) What is the recursive rule for the pattern? 
(b) What is the explicit rule for the pattern?

(c) What is the value of $n$ if $D_{n}=2562$ ?

How are you going to explain this pattern to the rest of the class? Who will do the talking? Task 2 (for Group 1):
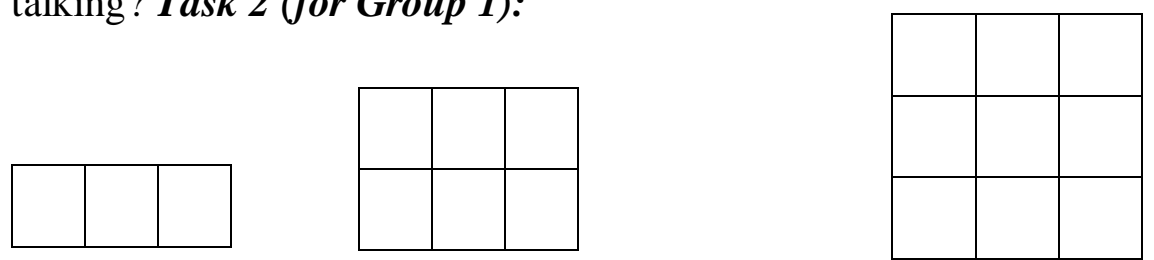

Figure 1

Figure 2

Figure 3

The first three terms for the pattern of the tiles shown above are $T_{1}=3, T_{2}=6$, and $T_{3}=9$.

\begin{tabular}{c|c}
\hline $\begin{array}{c}\text { Number of Figure } \\
(n)\end{array}$ & $\begin{array}{c}\text { Number of Tiles in } \\
\text { that Figure }\left(T_{n}\right)\end{array}$ \\
\hline 1 & 3 \\
\hline 2 & 6 \\
\hline 3 & 9 \\
\hline$\ldots$ & $\ldots$ \\
\hline 8 & $?$ \\
\hline 9 & $?$ \\
\hline$\ldots$ & $\ldots$ \\
\hline$?$ & 120 \\
\hline$\ldots$ & $\ldots$ \\
\hline$n$ & $?$ \\
\hline
\end{tabular}

(a) What is the recursive rule for the pattern?

(b) What is the explicit rule for the pattern?

(c) How many tiles would there be in Figure 80 ? Why?

Now work on how you are going to explain the pattern to the rest of the class. Who will do the talking? 


\section{Task 3 for Group 1: "Crossing the River"}

(This will be done by all students in the class, but you will still work on the task in your group)

Some armed robbers are chasing 8 adults and 2 very strong and fit children who have found gold in a long-lost cave out in the desert. The 8 adults and 2 children, who are about 4 miles ahead of the robbers, come to a river which is infested with very many man-eating crocodiles. There is a little old boat, and someone has left handwritten instructions:

CAREFUL: This old boat will sink if you try to have 2 adults in it. It will even sink if you try to have 1 adult and 1 child in it. But it can carry 1 child, or 2 children, or 1 adult.

The problem is: What is the least number of crossings with the boat so that all 8 adults and the $\mathbf{2}$ children get to the other side of the river? A crossing is going across to the other side - so, going across to the other side and then coming back would count as two (2) crossings.

Once you arrive at your answer for the least number of crossings check that you're correct with a teacher. Then complete the following table (which applied to the situation where there are always 2 very strong children, but $n$ adults needing to cross the river):

\begin{tabular}{c|c}
\hline $\begin{array}{c}\text { Number of adults } \\
\text { needing to cross } \\
(n)\end{array}$ & $\begin{array}{c}\text { Smallest possible } \\
\text { number of } \\
\text { crossings }\left(C_{n}\right)\end{array}$ \\
\hline 1 & $?$ \\
\hline 2 & $?$ \\
\hline 3 & $?$ \\
\hline$\ldots$ & $\ldots$ \\
\hline 8 & $?$ \\
\hline 9 & $?$ \\
\hline$\ldots$ & 121 \\
\hline$?$ & $\ldots$ \\
\hline$n$ & $?$ \\
\hline
\end{tabular}

Now answer these questions.

(a) What is the recursive rule for the pattern?

(b) What is the explicit rule for the pattern? 


\section{Task 4 (for Group 1)—This is a harder task!}

(a) You don't have to find the recursive pattern for this one but you do have to find an explicit pattern. Talk together and work out an explicit pattern connecting $n$ and $S_{n}$. Then, find the missing values, complete the table, and answer the questions in (b), (c) and (d) below.

\begin{tabular}{c|c}
\hline Value of $n$ & Value of $S_{n}$ \\
\hline 1 & 2 \\
\hline 2 & 5 \\
\hline 3 & 10 \\
\hline 4 & 17 \\
\hline$\ldots$ & $\ldots$ \\
\hline 10 & $?$ \\
\hline$\ldots$ & $\ldots$ \\
\hline$n$ & $?$ \\
\hline
\end{tabular}

(b) What is the value of $S_{100}$ ?

(c) If $S_{n}=1297$, what is the value of $n$ ?

(d) Now work out how you are going to explain the pattern to the rest of the class. Who will do the talking?

[Note: There is a recursive pattern for this - but it is VERY hard to find it. If you're brave you might try to find it!]

\section{Task 5 (for Group 1):}

Your group should make up an interesting pattern task — not too easy, not too hard.

During the next session you will be asked to explain how to do one of your tasks to the whole class. You may also be asked to present, to the whole class, the pattern that your group made up for Task 5. 


\section{FIVE TASKS FOR GROUP 2}

You should work together to find the recursive and explicit rules for the patterns in the first two tasks. With Task 3, "Crossing the River," your teacher will take the lead, and the whole class will work on it together. Then, Task 4 is harder, and for that task you only need to find an explicit rule. Finally, for Task 5, your group will be expected to create a pattern of its own.

\section{Task 1 (for Group 2):}

(a) Talk together and work out the pattern between the two variables - cars and tires. Then, find the missing values in the following tables

\begin{tabular}{c|c}
\hline Cars $(n)$ & Tires $\left(S_{n}\right)$ \\
\hline 1 & 4 \\
\hline 2 & 8 \\
\hline 3 & $?$ \\
\hline$?$ & 240 \\
\hline$\ldots$ & $\ldots$ \\
\hline 100 & $?$ \\
\hline$\ldots$ & $\ldots$ \\
\hline$n$ & $?$ \\
\hline
\end{tabular}

(b) What is the recursive rule for the pattern?

(c) What is the explicit rule for the pattern? What is the value of $n$ if $S_{n}=172$ ?

(d) Now work out how you are going to explain the pattern to the rest of the class. Who will do the talking? 


\section{Task 2 (for Group 2):}

Mr. Y wants to know how many students can sit around a row of hexagonal shaped desks. The challenge is to be able to answer (a), (b) and (c) and be able explain to the class, the formula for $S_{n}$ for the pattern.
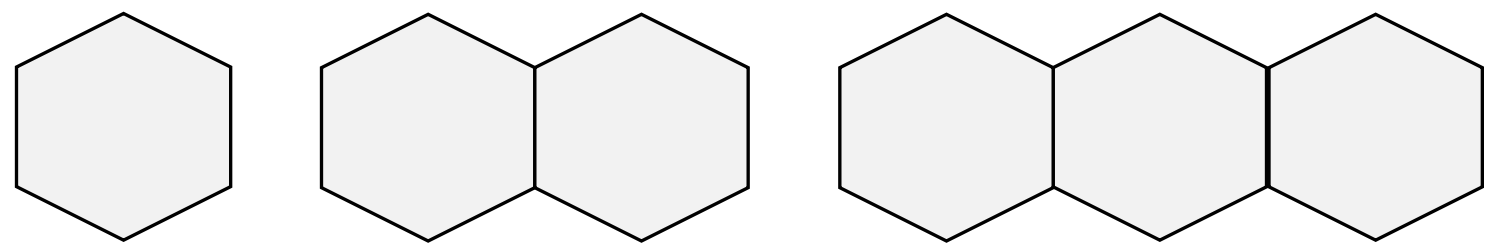

If one desk is by itself then six students can sit around it. If two desks are pushed together, then 10 students can sit around the pattern of table. If three desks are pushed together in a row, as shown above, then 14 students can sit around the pattern of tables.

(a) Fill in the following table.

\begin{tabular}{c|c}
\hline $\begin{array}{c}\text { Number of } \\
\text { hexagonal desks }\end{array}$ & $\begin{array}{c}\text { Number of } \\
\text { students that can sit } \\
\text { around the desks } \\
S_{n}\end{array}$ \\
\hline 1 & 6 \\
\hline 2 & 10 \\
\hline 3 & 14 \\
\hline 4 & \\
\hline 5 & \\
\hline 6 & \\
\hline 7 & \\
\hline 8 & \\
\hline$\ldots$ & \\
\hline$n$ & \\
\hline
\end{tabular}

(b) What is the recursive rule for the pattern?

(c) What is the explicit rule for the pattern? What is the value of $n$ if $S_{n}=172$ ?

(d) Imagine that 100 of the hexagonal desks were pushed together in a row. How many students could sit around that pattern of desks?

Now work how you are going to explain the pattern to the rest of the class. Who will do the talking? 


\section{Task 3 for Group 2: "Crossing the River"}

(This will be done by all students in the class, but you will still work on the task in your group)

Some armed robbers are chasing 8 adults and 2 very strong and fit children who have found gold in a long-lost cave out in the desert. The 8 adults and 2 children, who are about 4 miles ahead of the robbers, come to a river which is infested with very many man-eating crocodiles. There is a little old boat, and someone has left handwritten instructions:

CAREFUL: This old boat will sink if you try to have 2 adults in it. It will even sink if you try to have 1 adult and 1 child in it. But it can carry 1 child, or 2 children, or 1 adult.

The problem is: What is the least number of crossings with the boat so that all 8 adults and the $\mathbf{2}$ children get to the other side of the river? A crossing is going across to the other side - so, going across to the other side and then coming back would count as two (2) crossings.

Once you arrive at your answer for the least number of crossings check that you're correct with a teacher. Then complete the following table (which applied to the situation where there are always 2 very strong children, but $n$ adults needing to cross the river):

\begin{tabular}{c|c}
\hline $\begin{array}{c}\text { Number of adults } \\
\text { needing to cross } \\
(n)\end{array}$ & $\begin{array}{c}\text { Smallest possible } \\
\text { number of } \\
\text { crossings }\left(C_{n}\right)\end{array}$ \\
\hline 1 & $?$ \\
\hline 2 & $?$ \\
\hline 3 & $?$ \\
\hline$\ldots$ & $\ldots$ \\
\hline 8 & $?$ \\
\hline 9 & $?$ \\
\hline$\ldots$ & $\ldots$ \\
\hline$?$ & $\ldots$ \\
\hline$\ldots$ & $?$ \\
\hline$n$
\end{tabular}

Now answer these questions.

(a) What is the recursive rule for the pattern?

(b) What is the explicit rule for the pattern? 


\section{Task 4 (for Group 2)—This is a harder task!}
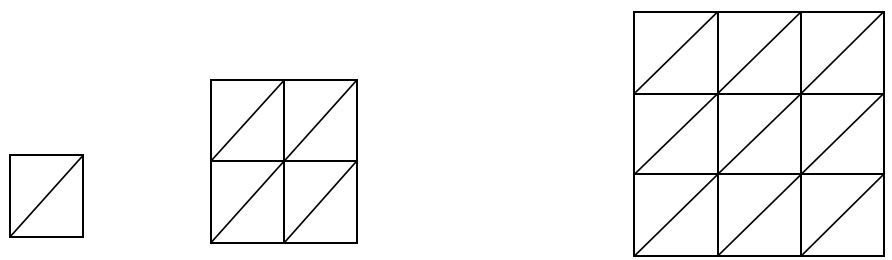

Figure 1 Figure 2

Figure 3

The first three terms for the pattern of small triangular tiles shown above are 2,8 , and 18 .

(a) Complete this table:

\begin{tabular}{c|c}
\hline $\begin{array}{c}\text { Figure Number } \\
(n)\end{array}$ & $\begin{array}{c}\text { Numbers of } \\
\text { Small Triangles } \\
\left(T_{n}\right)\end{array}$ \\
\hline 1 & 2 \\
\hline 2 & 8 \\
\hline 3 & 18 \\
\hline 4 & \\
\hline 5 & \\
\hline 6 & \\
\hline$\ldots$ & $S_{n}=$ \\
\hline$n$ &
\end{tabular}

(b) What is an explicit rule for the pattern?

(c) How many tiles would there be in Figure 80? Why?

(d) Now work how you are going to explain the pattern to the rest of the class. Who will do the talking?

\section{Task 5 (for Group 2):}

Your group should make up an interesting pattern task - not too easy, not too hard.

During the next session you will be asked to explain how to do one of your tasks to the whole class. You may also be asked to present, to the whole class, the pattern that your group made up for Task 5. 


\section{FIVE TASKS FOR GROUP 3}

You should work together to find the recursive and explicit rules for the patterns in the first two tasks. With Task 3, "Crossing the River," your teacher will take the lead, and the whole class will work on it together. Then, Task 4 is harder, and for that task you only need to find an explicit rule. Finally, for Task 5, your group will be expected to create a pattern of its own.

\section{Task 1 (for Group 3):}

At a fun park it costs $\$ 10$ for entry and then $\$ 3$ for each ride. Talk together and work out the pattern between the two variables - total cost $\$ C_{n}$ and the number of rides you have. Then, find the missing values.

\begin{tabular}{c|c}
\hline Rides $(n)$ & Cost $\left(\$ C_{n}\right)$ \\
\hline 0 & 10 \\
\hline 1 & 13 \\
\hline 2 & 16 \\
\hline 3 & $?$ \\
\hline$\ldots$ & $\ldots$ \\
\hline 20 & $?$ \\
\hline$?$ & 103 \\
\hline$\ldots$ & $\ldots$ \\
\hline$n$ & $?$ \\
\hline
\end{tabular}

(a) What is the recursive rule for the pattern?

(b) What is an explicit rule for the pattern?

(c) What is the value of $n$ if $C_{n}=79$ ?

Now work out how you are going to explain the pattern to the rest of the class. Who will do the talking? 


\section{Task 2 (for Group 3):}

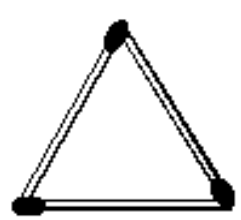

Figure 1

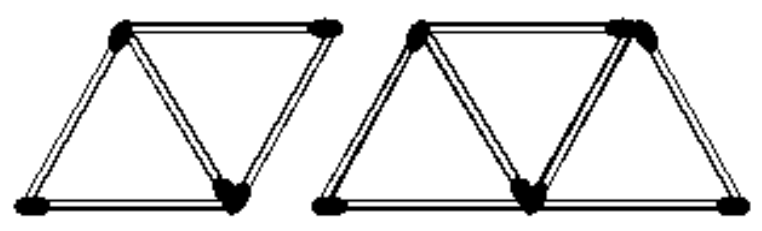

Figure 3

Based on the same pattern, draw Figure 4, and then complete the following table which should be based on the number of matches $M_{n}$, in Figure $n$ (for different values of $n$ ).

\begin{tabular}{c|c}
\hline $\begin{array}{c}\text { Figure } \\
n\end{array}$ & $\begin{array}{c}\text { Number of } \\
\text { Matches, } M_{n}, \\
\text { Making up } \\
\text { Figure } n\end{array}$ \\
\hline 1 & 3 \\
\hline 2 & 5 \\
\hline 3 & $?$ \\
\hline 4 & $?$ \\
\hline$\ldots$ & \\
\hline
\end{tabular}

(a) What is the recursive rule for the pattern?

(b) What is the explicit rule for the pattern? [Careful: It's not $M_{n}=2 n+3$.]

(c) What is the value of $n$ if $M_{n}=201$ ?

Now work how you are going to explain the pattern to the rest of the class. Who will do the talking? 


\section{Task 3 for Group 3: "Crossing the River"}

(This will be done by all students in the class, but you will still work on the task in your group)

Some armed robbers are chasing 8 adults and 2 very strong and fit children who have found gold in a long-lost cave out in the desert. The 8 adults and 2 children, who are about 4 miles ahead of the robbers, come to a river which is infested with very many man-eating crocodiles. There is a little old boat, and someone has left handwritten instructions:

CAREFUL: This old boat will sink if you try to have 2 adults in it. It will even sink if you try to have 1 adult and 1 child in it. But it can carry 1 child, or 2 children, or 1 adult.

The problem is: What is the least number of crossings with the boat so that all 8 adults and the $\mathbf{2}$ children get to the other side of the river? A crossing is going across to the other side - so, going across to the other side and then coming back would count as two (2) crossings.

Once you arrive at your answer for the least number of crossings check that you're correct with a teacher. Then complete the following table (which applied to the situation where there are always 2 very strong children, but $n$ adults needing to cross the river):

\begin{tabular}{c|c}
\hline $\begin{array}{c}\text { Number of adults } \\
\text { needing to cross } \\
(n)\end{array}$ & $\begin{array}{c}\text { Smallest possible } \\
\text { number of } \\
\text { crossings }\left(C_{n}\right)\end{array}$ \\
\hline 1 & $?$ \\
\hline 2 & $?$ \\
\hline 3 & $?$ \\
\hline$\ldots$ & $?$ \\
\hline 8 & $?$ \\
\hline 9 & \\
\hline$\ldots$ & $?$ \\
\hline$?$ & $?$ \\
\hline$n$ & \\
\hline
\end{tabular}

Now answer these questions.

(a) What is the recursive rule for the pattern?

(b) What is the explicit rule for the pattern? 


\section{Task 4 (for Group 3)-This is a harder task:}

(a) You don't have to find the recursive pattern for this one but you do have to find an explicit pattern. Talk together and work out an explicit pattern connecting $n$ and $S_{n}$. Then, find the missing values, and answer the questions in (b), (c) and (d) below.

\begin{tabular}{c|c}
\hline Value of $n$ & Value of $S_{n}$ \\
\hline 1 & 2 \\
\hline 2 & 6 \\
\hline 3 & 12 \\
\hline 4 & 20 \\
\hline 10 & 110 \\
\hline$\ldots$ & $\ldots$ \\
\hline$n$ & $?$ \\
\hline
\end{tabular}

(b) What is the value of $S_{20}$ ?

(c) If $S_{n}=90$, what is the value of $n$ ?

(d) Now work how you are going to explain the pattern to the rest of the class. Who will do the talking?

[Note: There is a recursive pattern for this — but it is VERY hard to find it. If you're brave you might try to find it! If you think you've found it tell a teacher!]

\section{Task 5 (for Group 3):}

Your group should make up an interesting pattern task-not too easy, not too hard.

During the next session you will be asked to explain how to do one of your tasks to the whole class. You may also be asked to present, to the whole class, the pattern that your group made up for Task 5. 


\section{FIVE TASKS FOR GROUP 4}

You should work together to find the recursive and explicit rules for the patterns in the first two tasks. With Task 3, "Crossing the River," your teacher will take the lead, and the whole class will work on it together. Then, Task 4 is harder, and for that task you only need to find an explicit rule. Finally, for Task 5, your group will be expected to create a pattern of its own.

\section{Task 1 (for Group 4):}

A young salesman agreed to a contract in which he has a starting salary of $\$ 1000$ per month. His monthly salary will increase by $\$ 120$ at the beginning of each new month. Talk together and work out the pattern between his monthly income $\$ S_{n}$ and the number of months that he has completed at work. Then, find the missing values.

\begin{tabular}{c|c}
\hline $\begin{array}{c}\text { Number of } \\
\text { Completed } \\
\text { Months }(n)\end{array}$ & $\begin{array}{c}\text { Monthly } \\
\text { Salary } \\
\left(\$ S_{n}\right)\end{array}$ \\
\hline 0 & 1000 \\
\hline 1 & 1120 \\
\hline 2 & 1240 \\
\hline 3 & $?$ \\
\hline$\ldots$ & $\ldots$ \\
\hline$?$ & 3400 \\
\hline$\ldots$ & $\ldots$ \\
\hline$n$ & $?$ \\
\hline
\end{tabular}

(a) What is the recursive rule for the pattern?

(b) What is the explicit rule for the pattern?

(c) What is the value of $n$ if $S_{n}=4960$ ?

(d) Now work how you are going to explain the pattern to the rest of the class. Who will do the talking? 


\section{Task 2 (for Group 4):}

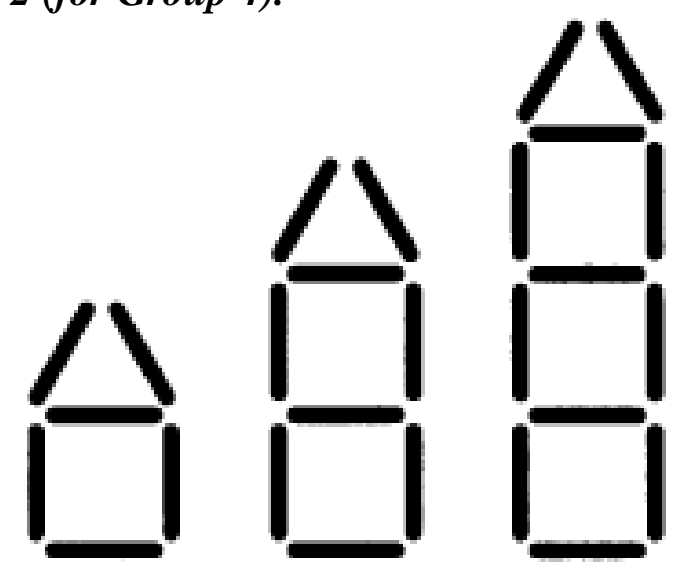

Figure $1 \quad$ Figure 2 Figure 3

(a) Based on the same pattern, draw the fourth figure. Then complete the table. Suppose the symbol $T_{n}$ is used to represent the number of matches needed for Figure $n$.

\begin{tabular}{c|c}
\hline $\begin{array}{c}\text { Number of Figure } \\
n\end{array}$ & $\begin{array}{c}\text { Number of matches } \\
\text { in the Figure } \\
T_{n}\end{array}$ \\
\hline 1 & 6 \\
\hline 2 & 9 \\
\hline 3 & 12 \\
\hline 4 & $? ?$ \\
\hline $\mathbf{5}$ & $? ?$ \\
\hline$?$ & 39 \\
\hline$\ldots$ & $\ldots$ \\
\hline$n$ & $? ?$ \\
\hline
\end{tabular}

(b) What is the recursive rule for the pattern?

(c) What is the explicit rule for the pattern?

(d) What is the value of $n$ if $T_{n}=201$ ?

Now work how you are going to explain the pattern to the rest of the class. Who will do the talking? 


\section{Task 3 for Group 4: "Crossing the River"}

(This will be done by all students in the class, but you will still work on the task in your group)

Some armed robbers are chasing 8 adults and 2 very strong and fit children who have found gold in a long-lost cave out in the desert. The 8 adults and 2 children, who are about 4 miles ahead of the robbers, come to a river which is infested with very many man-eating crocodiles. There is a little old boat, and someone has left handwritten instructions:

CAREFUL: This old boat will sink if you try to have 2 adults in it. It will even sink if you try to have 1 adult and 1 child in it. But it can carry 1 child, or 2 children, or 1 adult.

The problem is: What is the least number of crossings with the boat so that all 8 adults and the $\mathbf{2}$ children get to the other side of the river? A crossing is going across to the other side - so, going across to the other side and then coming back would count as two (2) crossings.

Once you arrive at your answer for the least number of crossings check that you're correct with a teacher. Then complete the following table (which applied to the situation where there are always 2 very strong children, but $n$ adults needing to cross the river):

\begin{tabular}{c|c}
\hline $\begin{array}{c}\text { Number of adults } \\
\text { needing to cross } \\
(n)\end{array}$ & $\begin{array}{c}\text { Smallest possible } \\
\text { number of } \\
\text { crossings }\left(C_{n}\right)\end{array}$ \\
\hline 1 & $?$ \\
\hline 2 & $?$ \\
\hline 3 & $?$ \\
\hline$\ldots$ & $\ldots$ \\
\hline 8 & $?$ \\
\hline 9 & $\ldots$ \\
\hline$\ldots$ & 121 \\
\hline$?$ & $\ldots$ \\
\hline$\ldots$ & $?$ \\
\hline
\end{tabular}

Now answer these questions.

(a) What is the recursive rule for the pattern?

(b) What is the explicit rule for the pattern? 


\section{Task 4 (for Group 4)-This is a quite a difficult task:}

(a) You don't have to find the recursive pattern for this one but you do have to find an explicit pattern. Talk together and work out an explicit pattern connecting $n$ and $S_{n}$. Then, find the missing values, and answer the questions in (b), (c) and (d) below.

\begin{tabular}{c|c}
\hline $\begin{array}{c}\text { Value of } \\
n\end{array}$ & $\begin{array}{c}\text { Value of } \\
S_{n}\end{array}$ \\
\hline 1 & 1 \\
\hline 2 & 3 \\
\hline 3 & 6 \\
\hline 4 & 10 \\
\hline 5 & 15 \\
\hline$\ldots$ & $\ldots$ \\
\hline$n$ & $?$ \\
\hline
\end{tabular}

(b) What is the value of $S_{20}$ ?

(c) If $S_{n}=5050$, what is the value of $n$ ?

Now work how you are going to explain the pattern to the rest of the class. Who will do the talking?

\section{Task 5 (for Group 4):}

Your group should make up an interesting pattern task — not too easy, not too hard.

During the next session you will be asked to explain how to do one of your tasks to the whole class. You may also be asked to present, to the whole class, the pattern that your group made up for Task 5. 


\section{FIVE TASKS FOR GROUP 5}

You should work together to find the recursive and explicit rules for the patterns in the first two tasks. With Task 3, "Crossing the River," your teacher will take the lead, and the whole class will work on it together. Then, Task 4 is harder, and for that task you only need to find an explicit rule. Finally, for Task 5, your group will be expected to create a pattern of its own.

\section{Task 1 (for Group 5):}

A new car salesman has a retaining salary of $\$ 2500$ per month and is then paid an additional $\$ 700$ for every car he sells during the month.

\begin{tabular}{c|c}
\hline $\begin{array}{c}\text { Cars sold in } \\
\text { the month } \\
(n)\end{array}$ & Income \\
$\left(\$ W_{n}\right)$ \\
\hline 0 & 2500 \\
\hline 1 & 3200 \\
\hline 2 & 3900 \\
\hline 3 & $?$ \\
\hline$\ldots$ & $\ldots$ \\
\hline$?$ & 24200 \\
\hline$\ldots$ & $\ldots$ \\
\hline$n$ & $?$ \\
\hline
\end{tabular}

(a) Talk together and work out the pattern between his monthly income $\$ W_{n}$ and the number of cars he sells Then, find the missing values.

(b) What is the recursive rule for the pattern?

(c) What is the explicit rule for the pattern?

(d) What is the value of $n$ if $W_{n}=10200$ ?

Now work how you are going to explain the pattern to the rest of the class. Who will do the talking? 


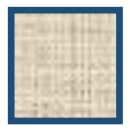

Position 1

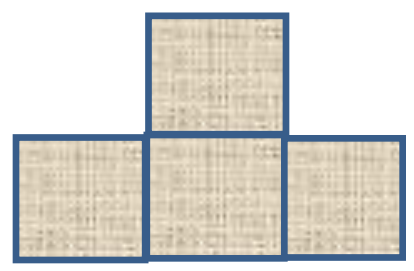

Position 2

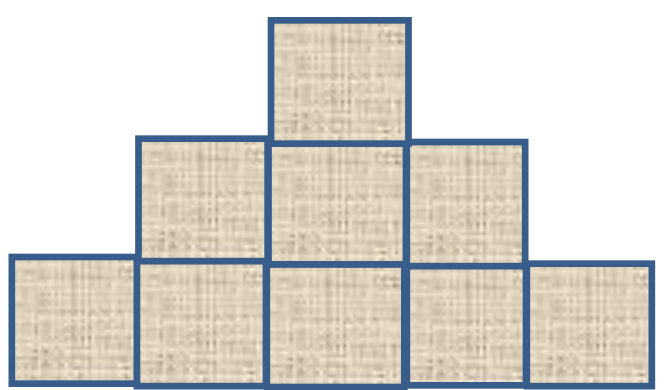

Position 3

A pattern of tiles is shown, and the following table shows the area for the first two Figures. Replace the question marks in the following table.

\begin{tabular}{c|c}
\hline Position & $\begin{array}{c}\text { Area of the shape in that } \\
\text { position, } A_{n} \text { square units }\end{array}$ \\
\hline 1 & 1 square unit \\
\hline 2 & 4 square units \\
\hline 3 & $?$ \\
\hline 4 & \\
\hline$\ldots$ & $A_{n}=?$ square units \\
\hline
\end{tabular}

Suppose the symbol $A_{n}$ is used to represent the area of Figure $n$ (in square units)

(a) What is the recursive rule for the pattern?

(b) What is the explicit rule for the pattern?

(c) What is the value of $n$ if $A_{n}=441$ ?

(d) Now work how you are going to explain the pattern to the rest of the class. Who will do the talking? 


\section{Task 3 for Group 5: "Crossing the River"}

(This will be done by all students in the class, but you will still work on the task in your group)

Some armed robbers are chasing 8 adults and 2 very strong and fit children who have found gold in a long-lost cave out in the desert. The 8 adults and 2 children, who are about 4 miles ahead of the robbers, come to a river which is infested with very many man-eating crocodiles. There is a little old boat, and someone has left handwritten instructions:

CAREFUL: This old boat will sink if you try to have 2 adults in it. It will even sink if you try to have 1 adult and 1 child in it. But it can carry 1 child, or 2 children, or 1 adult.

The problem is: What is the least number of crossings with the boat so that all 8 adults and the $\mathbf{2}$ children get to the other side of the river? A crossing is going across to the other side - so, going across to the other side and then coming back would count as two (2) crossings.

Once you arrive at your answer for the least number of crossings check that you're correct with a teacher. Then complete the following table (which applied to the situation where there are always 2 very strong children, but $n$ adults needing to cross the river):

\begin{tabular}{c|c}
\hline $\begin{array}{c}\text { Number of adults } \\
\text { needing to cross } \\
(n)\end{array}$ & $\begin{array}{c}\text { Smallest possible } \\
\text { number of } \\
\text { crossings }\left(C_{n}\right)\end{array}$ \\
\hline 1 & $?$ \\
\hline 2 & $?$ \\
\hline 3 & $?$ \\
\hline$\ldots$ & $\ldots$ \\
\hline 8 & $?$ \\
\hline 9 & $?$ \\
\hline$\ldots$ & 121 \\
\hline$?$ & $\ldots$ \\
\hline$\ldots$ & $?$ \\
\hline$n$
\end{tabular}

Now answer these questions.

(a) What is the recursive rule for the pattern?

(b) What is the explicit rule for the pattern? 


\section{Task 4 (for Group 5)-This is a quite a difficult task.}

You don't have to find the recursive pattern for this one but you do have to find an explicit pattern.

(a) Talk together and work out an explicit pattern connecting $n$ and $T_{n}$. Then, find the missing values, and answer the questions in (b) and (c) below.

\begin{tabular}{c|c}
\hline $\begin{array}{c}\text { Value of } \\
n\end{array}$ & $\begin{array}{c}\text { Value of } \\
T_{n}\end{array}$ \\
\hline 1 & 0.1 \\
\hline 2 & 0.4 \\
\hline 3 & 0.9 \\
\hline 4 & 1.6 \\
\hline 5 & 2.5 \\
\hline$\ldots$ & $\ldots$ \\
\hline$n$ & $?$ \\
\hline
\end{tabular}

(b) What is the value of $T_{20}$ ?

(c) If $T_{n}=129.6$, what is the value of $n$ ?

Now work how you are going to explain the pattern to the rest of the class. Who will do the talking?

\section{Task 5 (for Group 5):}

Your group should make up an interesting pattern task - not too easy, not too hard.

During the next session you will be asked to explain how to do one of your tasks to the whole class. You may also be asked to present, to the whole class, the pattern that your group made up for Task 5. 


\section{FIVE TASKS FOR GROUP 6}

You should work together to find the recursive and explicit rules for the patterns in the first two tasks. With Task 3, "Crossing the River," your teacher will take the lead, and the whole class will work on it together. Then, Task 4 is harder, and for that task you only need to find an explicit rule. Finally, for Task 5, your group will be expected to create a pattern of its own.

\section{Task 1 (for Group 6):}

The cost to rent a construction crane is $\$ 500$ per day, plus $\$ 220$ per hour that you use the crane.

A. Complete the following table o showing the cost if the crane was used for 2, 3, 4, or 5 hours on a day. [Note that an extra part of an hour is counted as a full hour.]

\begin{tabular}{c|c}
$\begin{array}{c}\text { Number of } \\
\text { Hours (or Part } \\
\text { Hours) that } \\
\text { the Crane is } \\
\text { Used }(n)\end{array}$ & $\begin{array}{c}\text { Total } \\
\text { Cost of } \\
\text { Hire, in } \\
\text { Dollars } \\
\left(T_{n}\right)\end{array}$ \\
\hline 0 & 500 \\
\hline 1 & 720 \\
\hline 2 & \\
\hline 3 & \\
\hline 4 & \\
\hline 5 & $T_{n}=$ \\
\hline$\ldots$ &
\end{tabular}

(a) How much would it cost on a day when the crane was used for 15 hours?

(b) How much would it cost on a day when the crane was used for 14 hours and 35 minutes?

(c) What is the recursive rule for the pattern?

(d) What is the explicit rule for the pattern?

(e) What is the value of $n$ if $T_{n}=2920$ ?

How are you going to explain the pattern to the rest of the class? Who will do the talking? 


\section{Task 2 for Group 6: Trapezoidal Tables}

Suppose you could seat 5 people comfortably at a table shaped like a trapezoid.
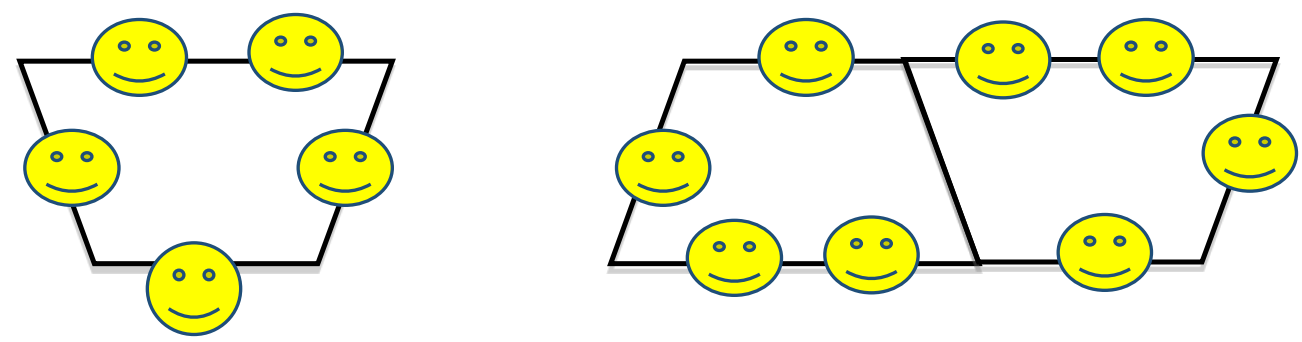

If you joined 2 trapezoid tables back-to-back, 8 people can seat at the two tables.

(a) How many people could be comfortably if you joined 3 trapezoid tables back to back (in a straight line)? Now complete this table, in which $S_{n}$ represents the number of people who could be comfortably seated if you joined $n$ trapezoid tables back to back (in a straight line).

\begin{tabular}{c|c}
$\begin{array}{c}\text { Number of Tables } \\
n\end{array}$ & $\begin{array}{c}\text { Number of People } \\
\text { Seated } S_{n}\end{array}$ \\
\hline 1 & 5 \\
\hline 2 & 8 \\
\hline 3 & $?$ \\
\hline 4 & $?$ \\
\hline$\ldots$ & $\ldots$ \\
\hline$?$ & 41 \\
\hline$\ldots$ & \\
\hline$n$ & $?$ \\
\hline
\end{tabular}

(b) What is the recursive rule for the pattern?

(c) What is the explicit rule for the pattern?

(d) What is the value of $n$ if $S_{n}=110$ ?

How are you going to explain the pattern to the rest of the class? Who will do the talking? 


\section{Task 3 for Group 6: "Crossing the River"}

(This will be done by all students in the class, but you will still work on the task in your group)

Some armed robbers are chasing 8 adults and 2 very strong and fit children who have found gold in a long-lost cave out in the desert. The 8 adults and 2 children, who are about 4 miles ahead of the robbers, come to a river which is infested with very many man-eating crocodiles. There is a little old boat, and someone has left handwritten instructions:

CAREFUL: This old boat will sink if you try to have 2 adults in it. It will even sink if you try to have 1 adult and 1 child in it. But it can carry 1 child, or 2 children, or 1 adult.

The problem is: What is the least number of crossings with the boat so that all 8 adults and the $\mathbf{2}$ children get to the other side of the river? A crossing is going across to the other side - so, going across to the other side and then coming back would count as two (2) crossings.

Once you arrive at your answer for the least number of crossings check that you're correct with a teacher. Then complete the following table (which applied to the situation where there are always 2 very strong children, but $n$ adults needing to cross the river):

\begin{tabular}{c|c}
\hline $\begin{array}{c}\text { Number of adults } \\
\text { needing to cross } \\
(n)\end{array}$ & $\begin{array}{c}\text { Smallest possible } \\
\text { number of } \\
\text { crossings }\left(C_{n}\right)\end{array}$ \\
\hline 1 & $?$ \\
\hline 2 & $?$ \\
\hline 3 & $?$ \\
\hline$\ldots$ & $\ldots$ \\
\hline 8 & $?$ \\
\hline 9 & $?$ \\
\hline$\ldots$ & 121 \\
\hline$?$ & \\
\hline$\ldots$ & $?$ \\
\hline
\end{tabular}

Now answer these questions.

(a) What is the recursive rule for the pattern?

(b) What is the explicit rule for the pattern? 


\section{Task 4 (for Group 6)-This is a harder task!}

(a) You don't have to find the recursive pattern for this one but you do have to find an explicit pattern. Talk together and work out an explicit pattern connecting $n$ and $S_{n}$. Then, find the missing values, and answer the questions in (b), (c) and (d) below.

\begin{tabular}{c|c}
\hline Value of $n$ & Value of $S_{n}$ \\
\hline 1 & 0 \\
\hline 2 & 3 \\
\hline 3 & 8 \\
\hline 4 & 15 \\
\hline$\ldots$ & $\ldots$ \\
\hline 10 & $?$ \\
\hline$\ldots$ & $\ldots$ \\
\hline$n$ & $?$ \\
\hline
\end{tabular}

(b) What is the value of $S_{100}$ ?

\section{Task 5 (for Group 6):}

Your group should make up an interesting pattern task - not too easy, not too hard.

During the next session you will be asked to explain how to do one of your tasks to the whole class. You may also be asked to present, to the whole class, the pattern that your group made up for Task 5 . 
APPENDIX G

CLASSROOM OBSERVATION SCHEDULE

Teacher:

Date:

Observer:

Topic:

1. Any resources (e.g., handouts) used by the teacher and by the students

2. Number of students present:

3. Name(s) of any absent student(s) (if known):

4. Were there any noticeable differences between this lesson and the corresponding model lesson (with eighth-grade students)? Comment. 
5. What were interesting questions asked publicly by the teacher?

6. What were interesting comments/questions made by a student?

7. Comment on how well groups of students worked together.

8. Did the teacher talk to the whole class about the algebra, and if so what did he say?

9. Were there any especially memorable episodes in the lesson? (Details)

10. Did most students seem to engage and learn the algebra well? (Comments)

11. Observer's Overview of the Lesson 


\section{APPENDIX H \\ PRE-TEACHING TO POST-TEACHING “GROWTH” WITH RESPECT TO THE FIVE BASIC COGNITIVE STRUCTURE COMPONENTS}

The tables in this Appendix include ordered pairs which are intended to indicate the "extent of evidence" for the presence of a component in cognitive structure at the pre- and postteaching stages, for each of the 28 interviewees (13 from Group 1, 15 from Group 2). For each component, the extent of evidence was assessed on a three-point scale: $0=$ no evidence, $1=$ some evidence, and $2=$ strong evidence. The first coordinate of an ordered pair indicates the extent of the evidence for the presence of the component at the pre-teaching stage, and the second coordinate indicates the extent of evidence at the post-teaching stage. Thus, for example, $(0,2)$ would indicate that there was no evidence of presence of that component at the preteaching stage, but strong evidence at the post-teaching stage.

An indicator of pre-post-teaching "overall growth" is also given, for each student, in the columns on the right of the tables. For example, an ordered pair, $(0,2)$ is taken to indicate a "growth" of 2 (because $2-0=2$ ) for a particular component and the "overall growth," for a student, is the sum of the growths for the five separate components.

Note that ${ }^{++}$indicates "significant growth," from a cognitive structure perspective, during the intervention period; and + indicates "modest growth." The term "significant growth" corresponds to an overall growth of at least 7, and "modest growth" corresponds to growth ranging from 3 through 6. 


\section{DISTRIBUTIVE PROPERTY, COGNITIVE \\ STRUCTURE GROWTH, 28 INTERVIEWEES \\ (DISTRIBUTIVE PROPERTY)}

Table H1

Summary of Pre-Teaching to Post-Teaching "Growth" for the Five Basic Cognitive Structure Components, with Respect to the Distributive Property for Multiplication Over Addition, of the 13 Group 1 and the 15 Group 2 Interviewees

\begin{tabular}{|c|c|c|c|c|c|c|}
\hline & Verbal & Skills & Imagery & Episodes & Attitudes & "Growth" \\
\hline Student 1.1 & $(0,2)$ & $(0,1)$ & $(0,1)$ & $(0,1)$ & $(0,1)$ & $0 \rightarrow 6^{+}$ \\
\hline Student 1.2 & $(0,2)$ & $(0,2)$ & $(0,2)$ & $(0,2)$ & $(0,2)$ & $0 \rightarrow 10^{++}$ \\
\hline Student 1.3 & $(0,2)$ & $(0,2)$ & $(0,2)$ & $(0,2)$ & $(0,2)$ & $0 \rightarrow 10^{++}$ \\
\hline Student 1.4 & $(0,1)$ & $(0,2)$ & $(0,2)$ & $(0,2)$ & $(0,2)$ & $0 \rightarrow 9^{++}$ \\
\hline Student 1.5 & $(0,2)$ & $(0,2)$ & $(0,2)$ & $(0,2)$ & $(0,2)$ & $0 \rightarrow 10^{++}$ \\
\hline Student 1.6 & $(0,2)$ & $(0,2)$ & $(0,2)$ & $(0,2)$ & $(0,2)$ & $0 \rightarrow 10^{++}$ \\
\hline Student 1.7 & $(0,2)$ & $(0,2)$ & $(0,2)$ & $(1,2)$ & $(0,2)$ & $1 \rightarrow 10^{++}$ \\
\hline Student 1.8 & $(0,2)$ & $(0,2)$ & $(0,2)$ & $(0,2)$ & $(0,2)$ & $0 \rightarrow 10^{++}$ \\
\hline Student 1.11 & $(0,2)$ & $(0,2)$ & $(0,2)$ & $(0,2)$ & $(0,2)$ & $0 \rightarrow 10^{++}$ \\
\hline Student 1.12 & $(0,0)$ & $(0,0)$ & $(0,0)$ & $(0,0)$ & $(0,0)$ & $0 \rightarrow 0$ \\
\hline Student 1.13 & $(0,2)$ & $(0,2)$ & $(0,2)$ & $(0,2)$ & $(0,2)$ & $0 \rightarrow 10^{++}$ \\
\hline Student 1.15 & $(0,0)$ & $(0,0)$ & $(0,0))$ & $(0,0)$ & $(0,0)$ & $0 \rightarrow 0$ \\
\hline Student 1.16 & $(0,2)$ & $(0,2)$ & $(0,2)$ & $(0,2)$ & $(0,2)$ & $0 \rightarrow 10^{++}$ \\
\hline & Verbal & Skills & Imagery & Episodes & Attitudes & "Growth" \\
\hline Student 2.1 & $(0,2)$ & $(0,2)$ & $(0,2)$ & $(0,2)$ & $(0,2)$ & $0 \rightarrow 10^{++}$ \\
\hline Student 2.2 & $(0,2)$ & $(0,2)$ & $(0,2)$ & $(0,2)$ & $(0,2)$ & $0 \rightarrow 10^{++}$ \\
\hline Student 2.3 & $(0,2)$ & $(0,2)$ & $(0,2)$ & $(0,2)$ & $(0,2)$ & $0 \rightarrow 10^{++}$ \\
\hline Student 2.4 & $(0,0)$ & $(0,0)$ & $(0,0)$ & $(0,0)$ & $(0,0)$ & $0 \rightarrow 0$ \\
\hline Student 2.5 & $(0,2)$ & $(0,2)$ & $(0,2)$ & $(0,2)$ & $(0,2)$ & $0 \rightarrow 10^{++}$ \\
\hline Student 2.6 & $(0,2)$ & $(0,2)$ & $(0,2)$ & $(0,2)$ & $(0,2)$ & $0 \rightarrow 10^{++}$ \\
\hline Student 2.7 & $(0,2)$ & $(0,2)$ & $(0,2)$ & $(0,2)$ & $(0,2)$ & $0 \rightarrow 10^{++}$ \\
\hline Student 2.8 & $(0,1)$ & $(0,2)$ & $(0,2)$ & $(0,2)$ & $(0,2)$ & $0 \rightarrow 9^{++}$ \\
\hline Student 2.9 & $(0,2)$ & $(0,2)$ & $(0,2)$ & $(0,2)$ & $(0,2)$ & $0 \rightarrow 10^{++}$ \\
\hline Student 2.10 & $(0,0)$ & $(0,0)$ & $(0,0)$ & $(0,0)$ & $(0,0)$ & $0 \rightarrow 0$ \\
\hline Student 2.11 & $(0,1)$ & $(0,2)$ & $(0,2)$ & $(0,2)$ & $(0,2)$ & $0 \rightarrow 9^{++}$ \\
\hline Student 2.12 & $(0,2)$ & $(0,1)$ & $(0,1)$ & $(0,1)$ & $(0,1)$ & $0 \rightarrow 5^{+}$ \\
\hline Student 2.13 & $(0,2)$ & $(0,0)$ & $(0,0)$ & $(0,0)$ & $(0,0)$ & $0 \rightarrow 2$ \\
\hline Student 2.14 & $(0,1)$ & $(0,1)$ & $(0,1)$ & $(0,1)$ & $(0,1)$ & $0 \rightarrow 5^{+}$ \\
\hline Student 2.15 & $(0,1)$ & $(0,2)$ & $(0,2)$ & $(0,2)$ & $(0,2)$ & $0 \rightarrow 9^{++}$ \\
\hline
\end{tabular}

Twenty of the 28 interviewees experienced significant growth, and three (Students 1.1, 2.12 and 2.14)) experienced modest growth. For five students (Students 1.12. 1.15, 2.4, 2.10 and 2.13), however, there was no noticeable growth. 


\section{ASSOCIATIVE PROPERTY FOR ADDITION, COGNITIVE STRUCTURE GROWTH, 28 INTERVIEWEES}

Table H2

Summary of Pre-Teaching to Post-Teaching "Growth" for the Five Basic Cognitive Structure Components, with Respect to the Associative Property for Addition, of the 13 Group 1 and the 15 Group 2 Interviewees

\begin{tabular}{lcccccl}
\hline & Verbal & Skills & Imagery & Episodes & Attitudes & "Growth" \\
& & & & & & \\
Student 1.1 & $(0,2)$ & $(0,2)$ & $(0,2)$ & $(0,2)$ & $(0,2)$ & $0 \rightarrow 10^{++}$ \\
Student 1.2 & $(0,2)$ & $(0,2)$ & $(0,2)$ & $(0,2)$ & $(0,2)$ & $0 \rightarrow 10^{++}$ \\
Student 1.3 & $(0,2)$ & $(0,2)$ & $(0,2)$ & $(0,2)$ & $(0,2)$ & $0 \rightarrow 10^{++}$ \\
Student 1.4 & $(0,2)$ & $(0,2)$ & $(0,2)$ & $(0,2)$ & $(0,2)$ & $0 \rightarrow 10^{++}$ \\
Student 1.5 & $(0,2)$ & $(0,2)$ & $(0,2)$ & $(0,2)$ & $(0,2)$ & $0 \rightarrow 10^{++}$ \\
Student 1.6 & $(0,2)$ & $(0,2)$ & $(0,2)$ & $(0,2)$ & $(0,2)$ & $0 \rightarrow 10^{++}$ \\
Student 1.7 & $(0,1)$ & $(0,1)$ & $(0,1)$ & $(0,1)$ & $(0,1)$ & $0 \rightarrow 5^{+}$ \\
Student 1.8 & $(0,1)$ & $(0,2)$ & $(0,2)$ & $(0,2)$ & $(0,2)$ & $0 \rightarrow 9^{++}$ \\
Student 1.11 & $(0,2)$ & $(0,2)$ & $(0,2)$ & $(0,2)$ & $(0,2)$ & $0 \rightarrow 10^{++}$ \\
Student 1.12 & $(0,0)$ & $(0,0)$ & $(0,0)$ & $(0,0)$ & $(0,0)$ & $0 \rightarrow 0$ \\
Student 1.13 & $(0,1)$ & $(0,2)$ & $(0,2)$ & $(0,2)$ & $(0,2)$ & $0 \rightarrow 9^{++}$ \\
Student 1.15 & $(0,0)$ & $(0,0)$ & $(0,0)$ & $(0,0)$ & $(0,0)$ & $0 \rightarrow 0$ \\
Student 1.16 & $(0,2)$ & $(0,2)$ & $(0,2)$ & $(0,2)$ & $(0,2)$ & $0 \rightarrow 10^{++}$ \\
& & & & & & \\
Verbal & Skills & Imagery & Episodes & Attitudes & “Growth" \\
Student 2.1 & $(0,2)$ & $(0,2)$ & $(0,2)$ & $(0,2)$ & $(0,2)$ & $0 \rightarrow 10^{++}$ \\
Student 2.2 & $(0,2)$ & $(0,2)$ & $(0,2)$ & $(0,2)$ & $(0,2)$ & $0 \rightarrow 10^{++}$ \\
Student 2.3 & $(0,2)$ & $(0,2)$ & $(0,2)$ & $(0,2)$ & $(0,2)$ & $0 \rightarrow 10^{++}$ \\
Student 2.4 & $(0,0)$ & $(0,0)$ & $(0,0)$ & $(0,0)$ & $(0,0)$ & $0 \rightarrow 0$ \\
Student 2.5 & $(0,1)$ & $(0,1)$ & $(0,1)$ & $(0,1)$ & $(0,1)$ & $0 \rightarrow 5^{+}$ \\
Student 2.6 & $(0,2)$ & $(0,2)$ & $(0,2)$ & $(0,2)$ & $(0,2)$ & $0 \rightarrow 10^{++}$ \\
Student 2.7 & $(0,2)$ & $(0,2)$ & $(0,2)$ & $(0,2)$ & $(0,2)$ & $0 \rightarrow 10^{++}$ \\
Student 2.8 & $(0,2)$ & $(0,2)$ & $(0,2)$ & $(0,2)$ & $(0,2)$ & $0 \rightarrow 10^{++}$ \\
Student 2.9 & $(0,2)$ & $(0,2)$ & $(0,2)$ & $(0,2)$ & $(0,2)$ & $0 \rightarrow 10^{++}$ \\
Student 2.10 & $(0,0)$ & $(0,0)$ & $(0,0)$ & $(0,0)$ & $(0,0)$ & $0 \rightarrow 0$ \\
Student 2.11 & $(0,2)$ & $(0,2)$ & $(0,2)$ & $(0,2)$ & $(0,2)$ & $0 \rightarrow 10^{++}$ \\
Student 2.12 & $(0,2)$ & $(0,2)$ & $(0,2)$ & $(0,2)$ & $(0,2)$ & $0 \rightarrow 10^{++}$ \\
Student 2.13 & $(0,0)$ & $(0,0)$ & $(0,0)$ & $(0,0)$ & $(0,0)$ & $0 \rightarrow 0$ \\
Student 2.14 & $(0,1)$ & $(0,1)$ & $(0,1)$ & $(0,2)$ & $(0,2)$ & $0 \rightarrow 7^{+}$ \\
Student 2.15 & $(0,2)$ & $(0,2)$ & $(0,2)$ & $(0,2)$ & $(0,2)$ & $0 \rightarrow 10^{++}$ \\
& & & & & & \\
\hline
\end{tabular}

Twenty of the 28 interviewees experienced significant growth, and three (Students 1.7, 2.5 and 2.14)) experienced modest growth. For five students (Students 1.12. 1.15, 2.4, 2.10 and 2.13), however, there was no noticeable growth. 


\section{ASSOCIATIVE PROPERTY FOR MULTIPLICATION, COGNITIVE STRUCTURE GROWTH, 28 INTERVIEWEES}

Table H3

Summary of Pre-Teaching to Post-Teaching "Growth" for the Five Basic Cognitive Structure Components, with Respect to the Associative Property for Multiplication, of the 13 Group 1 and the 15 Group 2 Interviewees

\begin{tabular}{|c|c|c|c|c|c|c|}
\hline & Verbal & Skills & Imagery & Episodes & Attitudes & "Growth" \\
\hline Student 1.1 & $(0,1)$ & $(0,0)$ & $(0,0)$ & $(0,0)$ & $(0,0)$ & $0 \rightarrow 1$ \\
\hline Student 1.2 & $(0,2)$ & $(0,1)$ & $(0,2)$ & $(0,2)$ & $(0,2)$ & $0 \rightarrow 9^{++}$ \\
\hline Student 1.3 & $(0,2)$ & $(0,2)$ & $(0,2)$ & $(0,2)$ & $(0,2)$ & $0 \rightarrow 10^{++}$ \\
\hline Student 1.4 & $(0,2)$ & $(0,2)$ & $(0,2)$ & $(0,2)$ & $(0,2)$ & $0 \rightarrow 10^{++}$ \\
\hline Student 1.5 & $(0,2)$ & $(0,1)$ & $(0,2)$ & $(0,2)$ & $(0,2)$ & $0 \rightarrow 9^{++}$ \\
\hline Student 1.6 & $(0,2)$ & $(0,2)$ & $(0,2)$ & $(0,2)$ & $(0,2)$ & $0 \rightarrow 10^{++}$ \\
\hline Student 1.7 & $(0,1)$ & $(0,1)$ & $(0,2)$ & $(0,2)$ & $(0,2)$ & $0 \rightarrow 8^{++}$ \\
\hline Student 1.8 & $(0,2)$ & $(0,2)$ & $(0,2)$ & $(0,2)$ & $(0,2)$ & $0 \rightarrow 10^{++}$ \\
\hline Student 1.11 & $(0,2)$ & $(0,2)$ & $(0,2)$ & $(0,2)$ & $(0,2)$ & $0 \rightarrow 10^{++}$ \\
\hline Student 1.12 & $(0,0)$ & $(0,0)$ & $(0,0)$ & $(0,0)$ & $(0,0)$ & $0 \rightarrow 0$ \\
\hline Student 1.13 & $(0,2)$ & $(0,2)$ & $(0,2)$ & $(0,2)$ & $(0,2)$ & $0 \rightarrow 10^{++}$ \\
\hline Student 1.15 & $(0,1)$ & $(0,0)$ & $(0,0))$ & $(0,0)$ & $(0,0)$ & $0 \rightarrow 1$ \\
\hline \multirow[t]{2}{*}{ Student 1.16} & $(0,2)$ & $(0,2)$ & $(0,2)$ & $(0,2)$ & $(0,2)$ & $0 \rightarrow 10^{++}$ \\
\hline & Verbal & Skills & Imagery & Episodes & Attitudes & "Growth" \\
\hline Student 2.1 & $(0,2)$ & $(0,2)$ & $(0,2)$ & $(0,2)$ & $(0,2)$ & $0 \rightarrow 10^{++}$ \\
\hline Student 2.2 & $(0,1)$ & $(0,2)$ & $(0,2)$ & $(0,2)$ & $(0,2)$ & $0 \rightarrow 9^{++}$ \\
\hline Student 2.3 & $(0,2)$ & $(0,2)$ & $(0,2)$ & $(0,2)$ & $(0,2)$ & $0 \rightarrow 10^{++}$ \\
\hline Student 2.4 & $(0,1)$ & $(0,0)$ & $(0,0)$ & $(0,0)$ & $(0,0)$ & $0 \rightarrow 1$ \\
\hline Student 2.5 & $(0,1)$ & $(0,0)$ & $(0,0)$ & $(0,0)$ & $(0,0)$ & $0 \rightarrow 1$ \\
\hline Student 2.6 & $(0,2)$ & $(0,2)$ & $(0,2)$ & $(0,2)$ & $(0,2)$ & $0 \rightarrow 10^{++}$ \\
\hline Student 2.7 & $(0,2)$ & $(0,2)$ & $(0,2)$ & $(0,2)$ & $(0,2)$ & $0 \rightarrow 10^{++}$ \\
\hline Student 2.8 & $(0,2)$ & $(0,2)$ & $(0,2)$ & $(0,2)$ & $(0,2)$ & $0 \rightarrow 10^{++}$ \\
\hline Student 2.9 & $(0,2)$ & $(0,2)$ & $(0,2)$ & $(0,2)$ & $(0,2)$ & $0 \rightarrow 10^{++}$ \\
\hline Student 2.10 & $(0,0)$ & $(0,0)$ & $(0,0)$ & $(0,0)$ & $(0,0)$ & $0 \rightarrow 0$ \\
\hline Student 2.11 & $(0,1)$ & $(0,1)$ & $(0,1)$ & $(0,1)$ & $(0,1)$ & $0 \rightarrow 5^{+}$ \\
\hline Student 2.12 & $(0,1)$ & $(0,1)$ & $(0,1)$ & $(0,1)$ & $(0,1)$ & $0 \rightarrow 5^{+}$ \\
\hline Student 2.13 & $(0,1)$ & $(0,0)$ & $(0,0)$ & $(0,0)$ & $(0,0)$ & $0 \rightarrow 1$ \\
\hline Student 2.14 & $(0,1)$ & $(0,1)$ & $(0,1)$ & $(0,1)$ & $(0,1)$ & $0 \rightarrow 5^{+}$ \\
\hline Student 2.15 & $(0,2)$ & $(0,2)$ & $(0,2)$ & $(0,2)$ & $(0,2)$ & $0 \rightarrow 10^{++}$ \\
\hline
\end{tabular}

Eighteen of the 28 interviewees experienced significant growth, and three (Students 2.11, 2.12, and 2.14)) experienced modest growth. For seven students (Students 1.1, 1.12. 1.15, 2.4, 2.5, 2.10 and 2.13), however, there was no noticeable growth. 


\section{SUBSCRIPT NOTATION and VARIABLE, COGNITIVE STRUCTURE GROWTH, 28 INTERVIEWEES}

Table H4

Summary of Pre-Teaching to Post-Teaching "Growth" for the Five Basic Cognitive Structure Components, with Respect to Subscript Notation and Variable (for Linear Sequences), of the 13 Group 1 and the 15 Group 2 Interviewees

\begin{tabular}{|c|c|c|c|c|c|c|}
\hline & Verbal & Skills & Imagery & Episodes & Attitudes & "Growth" \\
\hline Student 1.1 & $(0,2)$ & $(0,2)$ & $(0,2)$ & $(0,2)$ & $(0,2)$ & $0 \rightarrow 10^{++}$ \\
\hline Student 1.2 & $(0,2)$ & $(0,2)$ & $(0,2)$ & $(0,2)$ & $(0,2)$ & $0 \rightarrow 10^{++}$ \\
\hline Student 1.3 & $(0,2)$ & $(0,2)$ & $(0,2)$ & $(0,2)$ & $(0,2)$ & $0 \rightarrow 10^{++}$ \\
\hline Student 1.4 & $(0,2)$ & $(1,2)$ & $(0,2)$ & $(1,2)$ & $(1,2)$ & $3 \rightarrow 10^{++}$ \\
\hline Student 1.5 & $(0,2)$ & $(1,2)$ & $(1,2)$ & $(0,2)$ & $(1,2)$ & $3 \rightarrow 10^{++}$ \\
\hline Student 1.6 & $(0,2)$ & $(1,2)$ & $(0,2)$ & $(1,2)$ & $(1,2)$ & $3 \rightarrow 10^{++}$ \\
\hline Student 1.7 & $(0,2)$ & $(1,2)$ & $(1,2)$ & $(0,2)$ & $(1,2)$ & $3 \rightarrow 10^{++}$ \\
\hline Student 1.8 & $(0,2)$ & $(0,2)$ & $(0,2)$ & $(0,2)$ & $(0,2)$ & $0 \rightarrow 10^{++}$ \\
\hline Student 1.11 & $(0,2)$ & $(0,2)$ & $(0,2)$ & $(0,2)$ & $(0,2)$ & $0 \rightarrow 10^{++}$ \\
\hline Student 1.12 & $(0,0)$ & $(1,1)$ & $(1,1)$ & $(0,0)$ & $(1,1)$ & $3 \rightarrow 3$ \\
\hline Student 1.13 & $(0,2)$ & $(0,2)$ & $(0,2)$ & $(0,2)$ & $(0,2)$ & $0 \rightarrow 10^{++}$ \\
\hline Student 1.15 & $(0,0)$ & $(0,0)$ & $(0,0)$ & $(0,0)$ & $(0,0)$ & $0 \rightarrow 0$ \\
\hline Student 1.16 & $(0,2)$ & $(0,2)$ & $(0,2)$ & $(0,2)$ & $(0,2)$ & $0 \rightarrow 10^{++}$ \\
\hline & Verbal & Skills & Imagery & Episodes & Attitudes & "Growth" \\
\hline Student 2.1 & $(0,2)$ & $(1,2)$ & $(1,2)$ & $(0,2)$ & $(1,2)$ & $3 \rightarrow 10^{++}$ \\
\hline Student 2.2 & $(0,1)$ & $(0,2)$ & $(0,2)$ & $(0,2)$ & $(0,2)$ & $10 \rightarrow 10^{++}$ \\
\hline Student 2.3 & $(0,2)$ & $(1,2)$ & $(1,2)$ & $(0,2)$ & $(1,2)$ & $3 \rightarrow 10^{++}$ \\
\hline Student 2.4 & $(0,0)$ & $(0,0)$ & $(0,0)$ & $(0,0)$ & $(0,0)$ & $0 \rightarrow 0$ \\
\hline Student 2.5 & $(2,2)$ & $(2,2)$ & $(2,2)$ & $(2,2)$ & $(2,2)$ & $10 \rightarrow 10$ \\
\hline Student 2.6 & $(0,2)$ & $(1,2)$ & $(1,2)$ & $(0,2)$ & $(1,2)$ & $3 \rightarrow 10^{++}$ \\
\hline Student 2.7 & $(0,2)$ & $(1,2)$ & $(1,2)$ & $(0,2)$ & $(1,2)$ & $3 \rightarrow 10^{++}$ \\
\hline Student 2.8 & $(0,2)$ & $(1,2)$ & $(1,2)$ & $(0,2)$ & $(1,2)$ & $3 \rightarrow 10^{++}$ \\
\hline Student 2.9 & $(0,2)$ & $(1,2)$ & $(1,2)$ & $(0,2)$ & $(1,2)$ & $3 \rightarrow 10^{++}$ \\
\hline Student 2.10 & $(0,0)$ & $(0,0)$ & $(0,0)$ & $(0,0)$ & $(0,0)$ & $0 \rightarrow 0$ \\
\hline Student 2.11 & $(0,0)$ & $(0,0)$ & $(0,0)$ & $(0,0)$ & $(0,0)$ & $0 \rightarrow 0$ \\
\hline Student 2.12 & $(0,2)$ & $(0,2)$ & $(0,2)$ & $(0,2)$ & $(0,2)$ & $0 \rightarrow 10^{++}$ \\
\hline Student 2.13 & $(0,0)$ & $(0,1)$ & $(0,1)$ & $(0,0)$ & $(0,1)$ & $0 \rightarrow 3$ \\
\hline Student 2.14 & $(0,0)$ & $(1,1)$ & $(1,1)$ & $(0,0)$ & $(1,1)$ & $3 \rightarrow 3$ \\
\hline Student 2.15 & $(2,2)$ & $(2,2)$ & $(2,2)$ & $(2,2)$ & $(2,2)$ & $10 \rightarrow 10$ \\
\hline
\end{tabular}

Nineteen of the 28 interviewees experienced significant growth. For nine students (Students 1.12. 1.15, 2.4, 2.5, 2.10, 2.11, 2.13, 2.14, and 2.15), however, there was no noticeable growth. 


\section{RECURSIVE AND EXPLICIT RULES, 3 DOTS (...), COGNITIVE STRUCTURE GROWTH, 28 INTERVIEWEES}

Table H5

Summary of Pre-Teaching to Post-Teaching "Growth" for the Five Basic Cognitive Structure Components, with Respect to Recursive and Explicit Rules, and 3 Dots (...) for a Linear Sequence of the 13 Group 1 and the 15 Group 2 Interviewees

\begin{tabular}{|c|c|c|c|c|c|c|}
\hline & Verbal & Skills & Imagery & Episodes & Attitudes & "Growth" \\
\hline Student 1.1 & $(0,1)$ & $(0,1)$ & $(0,2)$ & $(0,2)$ & $(0,2)$ & $0 \rightarrow 8^{++}$ \\
\hline Student 1.2 & $(0,2)$ & $(0,2)$ & $(0,2)$ & $(0,2)$ & $(0,2)$ & $0 \rightarrow 10^{++}$ \\
\hline Student 1.3 & $(0,2)$ & $(0,2)$ & $(0,2)$ & $(0,2)$ & $(0,2)$ & $0 \rightarrow 10^{++}$ \\
\hline Student 1.4 & $(0,2)$ & $(0,2)$ & $(0,2)$ & $(0,2)$ & $(0,2)$ & $0 \rightarrow 10^{++}$ \\
\hline Student 1.5 & $(0,2)$ & $(0,2)$ & $(0,2)$ & $(0,2)$ & $(0,2)$ & $0 \rightarrow 10^{++}$ \\
\hline Student 1.6 & $(0,2)$ & $(0,2)$ & $(0,2)$ & $(0,2)$ & $(0,2)$ & $0 \rightarrow 10^{++}$ \\
\hline Student 1.7 & $(0,2)$ & $(0,2)$ & $(0,2)$ & $(0,2)$ & $(0,2)$ & $0 \rightarrow 10^{++}$ \\
\hline Student 1.8 & $(0,0)$ & $(0,0)$ & $(0,0)$ & $(0,0)$ & $(0,0)$ & $0 \rightarrow 0$ \\
\hline Student 1.11 & $(0,2)$ & $(0,2)$ & $(0,2)$ & $(0,2)$ & $(0,2)$ & $0 \rightarrow 10^{++}$ \\
\hline Student 1.12 & $(0,0)$ & $(0,0)$ & $(0,0)$ & $(0,0)$ & $(0,0)$ & $0 \rightarrow 0$ \\
\hline Student 1.13 & $(0,2)$ & $(0,2)$ & $(0,2)$ & $(0,2)$ & $(0,2)$ & $0 \rightarrow 10^{++}$ \\
\hline Student 1.15 & $(0,0)$ & $(0,0)$ & $(0,0)$ & $(0,0)$ & $(0,0)$ & $0 \rightarrow 0$ \\
\hline Student 1.16 & $(0,2)$ & $(0,2)$ & $(0,2)$ & $(0,2)$ & $(0,2)$ & $0 \rightarrow 10^{++}$ \\
\hline & Verbal & Skills & Imagery & Episodes & Attitudes & "Growth" \\
\hline Student 2.1 & $(0,1)$ & $(0,1)$ & $(0,1)$ & $(0,1)$ & $(0,1)$ & $0 \rightarrow 5^{++}$ \\
\hline Student 2.2 & $(0,1)$ & $(0,2)$ & $(0,2)$ & $(0,2)$ & $(0,2)$ & $0 \rightarrow 10^{++}$ \\
\hline Student 2.3 & $(1,2)$ & $(1,2)$ & $(1,2)$ & $(1,2)$ & $(1,2)$ & $5 \rightarrow 10^{+}$ \\
\hline Student 2.4 & $(0,2)$ & $(0,2)$ & $(0,2)$ & $(0,2)$ & $(0,2)$ & $0 \rightarrow 10^{++}$ \\
\hline Student 2.5 & $(0,2)$ & $(0,2)$ & $(0,2)$ & $(0,2)$ & $(0,2)$ & $0 \rightarrow 10^{++}$ \\
\hline Student 2.6 & $(0,1)$ & $(0,1)$ & $(0,1)$ & $(0,1)$ & $(1,1)$ & $0 \rightarrow 5^{+}$ \\
\hline Student 2.7 & $(1,2)$ & $(1,2)$ & $(1,2)$ & $(1,2)$ & $(1,2)$ & $5 \rightarrow 10^{++}$ \\
\hline Student 2.8 & $(0,2)$ & $(0,2)$ & $(0,2)$ & $(0,2)$ & $(0,2)$ & $0 \rightarrow 10^{++}$ \\
\hline Student 2.9 & $(0,2)$ & $(0,2)$ & $(0,2)$ & $(0,2)$ & $(0,2)$ & $0 \rightarrow 10^{++}$ \\
\hline Student 2.10 & $(0,0)$ & $(0,0)$ & $(0,0)$ & $(0,0)$ & $(0,0)$ & $0 \rightarrow 10^{++}$ \\
\hline Student 2.11 & $(0,1)$ & $(0,1)$ & $(0,1)$ & $(0,1)$ & $(0,1)$ & $0 \rightarrow 5^{+}$ \\
\hline Student 2.12 & $(0,0)$ & $(0,0)$ & $(0,0)$ & $(0,0)$ & $(0,0)$ & $0 \rightarrow 0$ \\
\hline Student 2.13 & $(0,1)$ & $(0,1)$ & $(0,1)$ & $(0,1)$ & $(0,1)$ & $0 \rightarrow 5^{+}$ \\
\hline Student 2.14 & $(0,1)$ & $(0,1)$ & $(0,1)$ & $(0,0)$ & $(0,1)$ & $0 \rightarrow 5^{+}$ \\
\hline Student 2.15 & $(0,2)$ & $(0,2)$ & $(0,2)$ & $(0,2)$ & $(0,2)$ & $0 \rightarrow 10^{++}$ \\
\hline
\end{tabular}

Seventeen of the 28 interviewees experienced significant growth, and seven (Students 2.1, 2.3 2.6, 2.10, 2.11, 2.13, and 2.14)) experienced modest growth. For four students (Students 1.8, 1.12. 1.15, and 2.12), however, there was no noticeable growth. 


\section{APPENDIX I}

\section{GENERALIZATION CATEGORIES (AFTER RADFORD, 2006)}

In Chapter 5 of this dissertation the levels of generalization for elementary algebra put forward by Luis Radford in 2006 were described. Radford described three levels of generalization — which he termed "Factual Generalization," "Contextual Generalization," and "Symbolic Generalization" (these are defined in Table 5.8 of Chapter 5). I added a fourth level, which I termed "Post-Symbolic Generalization," because I thought that that was needed for the purposes of the current study.

Although Radford (2006) called his first, and lowest, level of generalization, "Factual Generalization," he also included a "Counting/Arithmetic" category which preceded Factual Generalization. As the name "Counting/Arithmetic" implies, it was to be applied to learners who insisted on remaining in the realm of arithmetic, and did not try to generalize. In the current study, almost all of the seventh-grade students at the preteaching stage, would have been in that category. When tackling questions which could be modeled by linear sequences, the idea of generalizing did not occur to them.

With Question 7 in the interview protocol (see Appendix A), interviewees were given a sheet of paper with the following table of values on it, and were then asked what should replace the question marks beneath the 5 , and beneath the $n$. 


\begin{tabular}{|l|l|l|l|l|l|l|l|}
\hline $\begin{array}{l}\text { First } \\
\text { Value }\end{array}$ & 1 & 2 & 3 & 4 & 5 & $\ldots$ & $n$ \\
\hline $\begin{array}{l}\text { Second } \\
\text { Value }\end{array}$ & 3 & 5 & 7 & 9 & $?$ & $\ldots$ & $?$ \\
\hline
\end{tabular}

At the pre-teaching stage all of the interviewees saw this task as purely something concerning arithmetic. No interviewee showed any inclination to want to give an algebraic expression like $2 n+1$ for the answer to the second question. For them, the top row of the table of values was increasing by 1 's, and therefore $n$ had to be 7; and the bottom row was increasing by 2's, and therefore 15 should be below the $n$. The students did not know the meaning of the convention of the three dots (...). But, at the postteaching stage, most of these same students saw the table of values in a different lightalmost certainly because they had been generalizing from tables of values and real-life contexts during the intervention modeling workshops.

The second interview question to be discussed here was Question 8. It provided an image of a possible real situation (students sitting around tables joined together in the school cafeteria). However, at the pre-teaching stage, most of the students did not seem to recognize that the question was inviting them to generalize. Most of their responses were of the Counting/Arithmetic variety. That had changed by the post-teaching stage, with most students then being capable of offering contextual, symbolic, and even postsymbolic generalizations.

The following table, which I developed from analysis of the interview data, should enable the reader to "see" the extent of the effects of the modeling workshops on students' generalizations. 
Table I

Summary of Pre-Teaching to Post-Teaching Responses to Two Interview Tasks (Questions 7 and 8 on the Interview Protocol) Inviting Generalizations for Linear Sequence Modeling Tasks

\begin{tabular}{|c|c|c|c|c|}
\hline \multirow{2}{*}{$\begin{array}{l}\text { Interviewee } \\
(n=28)\end{array}$} & \multicolumn{2}{|c|}{$\frac{n \text {th term and three dots (...) with a }}{\text { Horizontal Table of Values }}$} & \multicolumn{2}{|c|}{$\begin{array}{c}10^{\text {th }} \text { table Pushed Together? } \\
\text { Explicit Rule for } \mathrm{n} \text { Tables Pushed Together? }\end{array}$} \\
\hline & Pre-Teaching & Post-Teaching & Pre-Teaching & Post-Teaching \\
\hline Student 1.1 & Counting/Arithmetic & $\begin{array}{l}\text { Counting/Arith } \\
\text { metic }\end{array}$ & Counting/Arithmetic & Counting/Arithmetic \\
\hline Student 1.2 & Counting/Arithmetic & Contextual & Counting/Arithmetic & Contextual \\
\hline Student 1.3 & Counting/Arithmetic & Symbolic & Counting/Arithmetic & Symbolic \\
\hline Student 1.4 & Counting/Arithmetic & Post-Symbolic & Counting/Arithmetic & Post-Symbolic \\
\hline Student 1.5 & Counting/Arithmetic & $\begin{array}{l}\text { Counting/Arith } \\
\text { metic }\end{array}$ & Counting/Arithmetic & Factual \\
\hline Student 1.6 & Counting/Arithmetic & Post-Symbolic & Counting/Arithmetic & Symbolic \\
\hline Student 1.7 & Counting/Arithmetic & Post-Symbolic & Counting/Arithmetic & Post-Symbolic \\
\hline Student 1.8 & Counting/Arithmetic & $\begin{array}{l}\text { Counting/Arith } \\
\text { metic }\end{array}$ & Counting/Arithmetic & Counting/Arithmetic \\
\hline Student 1.11 & Counting/Arithmetic & Post-Symbolic & Counting/Arithmetic & Post-Symbolic \\
\hline Student 1.12 & Counting/Arithmetic & $\begin{array}{l}\text { Counting/Arith } \\
\text { metic }\end{array}$ & Counting/Arithmetic & Counting/Arithmetic \\
\hline Student 1.13 & Counting/Arithmetic & Post-Symbolic & Counting/Arithmetic & Post-Symbolic \\
\hline Student 1.15 & g/Arith & $\begin{array}{l}\text { Counting/Arith } \\
\text { metic }\end{array}$ & ic & rithmetic \\
\hline Student 1.16 & Counting/Arithmetic & Post-Symbolic & Counting/Arithmetic & Post-Symbolic \\
\hline Student 2.1 & Counting/Arithmetic & Contextual & Counting/Arithmetic & Contextual \\
\hline Student 2.2 & Counting/Arithmetic & Post-Symbolic & Counting/Arithmetic & Post-Symbolic \\
\hline Student 2.3 & Counting/Arithmetic & Post-Symbolic & Factual & Post-Symbolic \\
\hline Student 2.4 & Counting/Arithmetic & $\begin{array}{l}\text { Counting/Arith } \\
\text { metic }\end{array}$ & Counting/Arithmetic & Contextual \\
\hline Student 2.5 & Counting/Arithmetic & Symbolic & Counting/Arithmetic & Symbolic \\
\hline Student 2.6 & Counting/Arithmetic & $\begin{array}{l}\text { Counting/Arith } \\
\text { metic }\end{array}$ & Counting/Arithmetic & Counting/Arithmetic \\
\hline Student 2.7 & Counting/Arithmetic & Post-Symbolic & Contextual & Post-Symbolic \\
\hline Student 2.8 & Counting/Arithmetic & Symbolic & Counting/Arithmetic & Post-Symbolic \\
\hline Student 2.9 & Counting/Arithmetic & Post-Symbolic & Counting/Arithmetic & Symbolic \\
\hline Student 2.10 & Counting/Arithmetic & Factual & Counting/Arithmetic & Factual \\
\hline Student 2.11 & Counting/Arithmetic & Contextual & Counting/Arithmetic & Symbolic \\
\hline Student 2.12 & Counting/Arithmetic & Factual & Counting/Arithmetic & Factual \\
\hline Student 2.13 & Counting/Arithmetic & $\begin{array}{l}\text { Counting/Arith } \\
\text { metic }\end{array}$ & Counting/Arithmetic & Symbolic \\
\hline Student 2.14 & Counting/Arithmetic & $\begin{array}{l}\text { Counting/Arith } \\
\text { metic }\end{array}$ & Counting/Arithmetic & Factual \\
\hline Student 2.15 & Counting/Arithmetic & Post-Symbolic & Counting/Arithmetic & Post-Symbolic \\
\hline
\end{tabular}

